\title{
Third wave behaviour therapy
}

Citation for published version (APA):

Batink, T. (2017). Third wave behaviour therapy: process measures and contextual interventions. [, Maastricht University]. Proefschriftmaken.nl II Uitgeverij Boxpress.

https://doi.org/10.26481/dis.20171020tb

Document status and date:

Published: 01/01/2017

DOI:

10.26481/dis.20171020tb

Document Version:

Publisher's PDF, also known as Version of record

\section{Please check the document version of this publication:}

- A submitted manuscript is the version of the article upon submission and before peer-review. There can be important differences between the submitted version and the official published version of record.

People interested in the research are advised to contact the author for the final version of the publication, or visit the DOI to the publisher's website.

- The final author version and the galley proof are versions of the publication after peer review.

- The final published version features the final layout of the paper including the volume, issue and page numbers.

Link to publication

\footnotetext{
General rights rights.

- You may freely distribute the URL identifying the publication in the public portal. please follow below link for the End User Agreement:

www.umlib.nl/taverne-license

Take down policy

If you believe that this document breaches copyright please contact us at:

repository@maastrichtuniversity.nl

providing details and we will investigate your claim.
}

Copyright and moral rights for the publications made accessible in the public portal are retained by the authors and/or other copyright owners and it is a condition of accessing publications that users recognise and abide by the legal requirements associated with these

- Users may download and print one copy of any publication from the public portal for the purpose of private study or research.

- You may not further distribute the material or use it for any profit-making activity or commercial gain

If the publication is distributed under the terms of Article $25 \mathrm{fa}$ of the Dutch Copyright Act, indicated by the "Taverne" license above, 


\section{THIRD WAVE BEHAVIOUR THERAPY \\ Process Measures and Contextual Interventions}

Tim Batink 



\title{
THIRD WAVE BEHAVIOUR THERAPY \\ Process Measures and Contextual Interventions
}

\author{
Tim Batink
}


ISBN: 978-94-6295-739-8

Cover and lay-out by: wenz iD \|| Wendy Schoneveld

Printed by: Proefschriftmaken || Proefschriftmaken.nl

Copyright (c) 2017 door Tim Batink, Maastricht 2017. Alle rechten zijn voorbehouden. Niets van deze thesis mag worden verveelvoudigd, opgeslagen in een geautomatiseerd gegevensbestand en/of openbaar worden gemaakt, in enige vorm of op enige wijze, hetzij elektronisch, mechanisch, door fotokopieën, opnamen of enige andere manier, zonder uitdrukkelijke voorafgaande schriftelijke toestemming van de auteur. 


\section{THIRD WAVE BEHAVIOUR THERAPY \\ Process Measures and Contextual Interventions}

\section{PROEFSCHRIFT}

Ter verkrijging van de graad van doctor aan de Universiteit Maastricht, op gezag van de Rector Magnificus, Prof. dr. Rianne M. Letchert, volgens besluit van het College van Decanen,

in het openbaar te verdedigen

op vrijdag 20 oktober 2017 om 14:00

Door:

\section{Tim Batink}

Geboren op 2 januari 1987 te Sittard 


\section{Promotores}

Prof. dr. F.P.M.L. Peeters

Prof. dr. J.J. van Os (UMC Utrecht)

Prof. dr. M.C. Wichers (UMC Groningen)

\section{Beoordelingscommissie}

Prof. dr. R.W.H.M. Ponds (voorzitter)

Prof. dr. N.E. Jacobs (Open Universiteit)

Prof. dr. M.L. Peters

Prof. dr. K.R.J. Schruers

Prof. dr. K.M.G. Schreurs (Universiteit Twente)

The research presented in this thesis was conducted at the School for Mental Health and Neuroscience (MHeNS), Department of Psychiatry \& Psychology, Maastricht University Medical Center, Maastricht, the Netherlands.

Publication of this thesis was financially supported by:

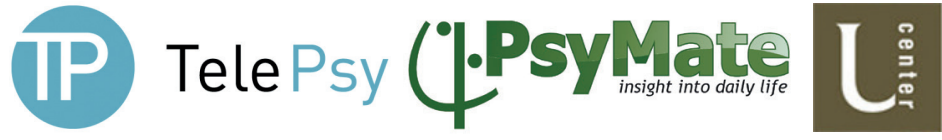


Paranimfen

Rufa Diederen

Truda Driesen 

Juli 2013, Sydney - Bondi Beach

Hoewel het winter is in Sydney, is het aangenaam warm vandaag.

Ik loop vanaf Bondi Beach richting de zee.

Eenmaal door de branding gelopen, duik ik de zee in en begin te zwemmen.

Ik heb de zee helemaal voor mezelf, alleen een paar surfers in de verte. Ik geniet van het uitzicht. Als ik mij omdraai, zie ik dat ik het strand al een behoorlijk eind van mij vandaan is.

Er zijn flinke golven. Ik besluit weer terug te gaan zwemmen.

Na een minuut kijk ik even op, en zie dat het strand nog verder weg lijkt te zijn.

$H \mathrm{~mm}$, toch even nog wat extra aanzetten dus.

Na een minuut crawelen kijk ik weer omhoog. Shit, nog verder van het strand; ik kom niet meer terug! Ik word langzaam de zee ingetrokken door de onderstroom! Ohw nee, daarom is er niemand anders in de zee...

Mijn hart begint nog sneller te kloppen, en ik krijg het benauwd. Dit is gewoon echt gevaarlijk, zo verdrinken mensen dus...

Ik besluit even te stoppen met zwemmen en even op adem te komen. In de verte zie ik de surfers nog, die zich laten meedragen door de golven.

Dat is het natuurlijk! Ik moet niet door de golven heen proberen te zwemmen, maar mij erdoor laten dragen; zoals de surfers zich ook laten dragen door de golven.

En inderdaad, zodra ik mij op de kop van de golven laat meevoeren kom ik weer dichter bij het strand.

Uiteindelijk voel ik weer vaste grond onder mijn voeten. Ik besluit nog even uit te puffen in de branding, ik voel de schrik nog door mijn lijf gieren.

Ik ben in Sydney, vanwege het jaarlijke internationale congres over Acceptance and Commitment Therapy. 
HOOFDSTUK 2 Nieuwe generatie gedragstherapie, nieuwe generatie meetinstrumenten. Een overzicht van beschikbare ACT-meetinstrumenten

HOOFDSTUK 3 De Flexibiliteits Index Test (FIT-60):

Een beknopte beschrijving

HOOFDSTUK Meten van psychologische flexibiliteit

De Flexibiliteits Index Test (FIT-60)

HOOFDSTUK 5 The ACT in Daily Life Training; a feasibility study of an add-on 75 mHealth intervention in a general out-patient population

HOOFDSTUK $\bigcirc$ ACT in Daily Life - A Momentary Intervention Approach

HOOFDSTUK 7 How Does MBCT for Depression Work? Studying Cognitive and Affective Mediation Pathways

HOOFDSTUK 
HоOFdstuk Epiloog

- Valorisatie

- Samenvatting

- Summary

- Dankwoord

- Curriculum Vitae

- Publicaties

APPENDIX 1 FIT-60 


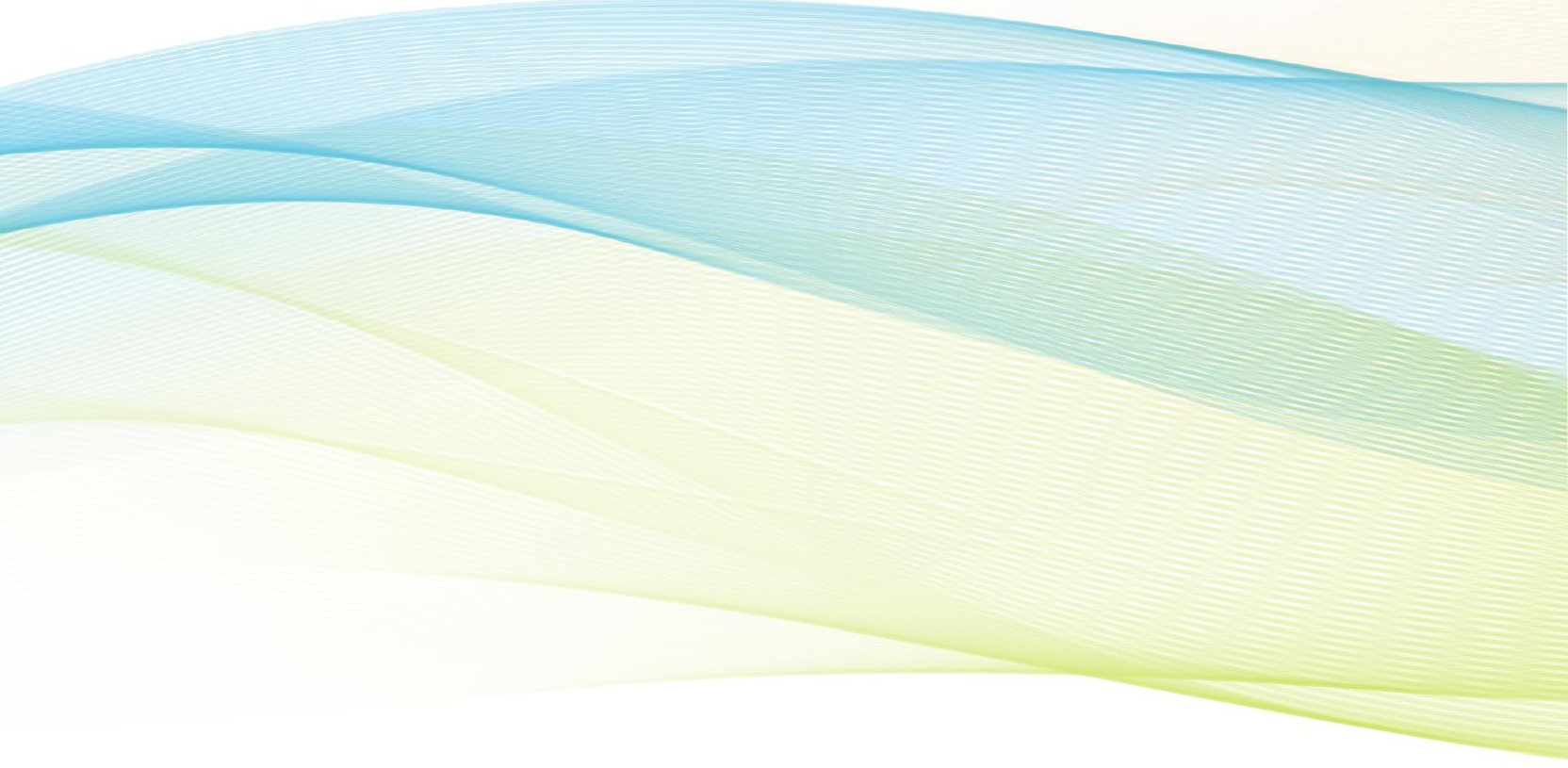


hoofdstuk

Introductie 


\section{Derde Generatie Gedragstherapie}

Het vakgebied van de klinische psychologie, het aandachtsgebied binnen de psychologie die zich bezig houdt met de bevordering van de geestelijke gezondheid middels psychologische behandeling, is continue in ontwikkeling. Een van de recente ontwikkelingen op het gebied van psychotherapie, is de opkomst van de zogenaamde third wave behaviour therapy; oftewel de derde generatie gedragstherapie. De derde generatie gedragstherapie is een nieuwe stroming binnen de gedragstherapie [1, 2, 3], waarbij gedragsverandering minder in het teken van klachtreductie, maar meer in het teken staat van het op een andere manier verhouden tot deze negatieve interne ervaringen (cognities, affect \& sensaties). Om deze ontwikkeling goed te kunnen positioneren, zal er eerst worden stilgestaan bij de historische context; de eerste en tweede generatie gedragstherapie die hieraan vooraf gingen.

De basis van de gedragstherapie, de eerste generatie gedragstherapie bestaat uit de klassieke conditionering en de operante conditionering. De klassieke conditionering vindt zijn oorsprong in het fysiologische onderzoek van Pavlov [4]. Het was vervolgens Watson die deze principes in de psychologie heeft toegepast (Little Albert, [5]). Bij klassieke conditionering wordt via associatieleren een neutrale prikkel geassocieerd met een prikkel waar een automatische reactie op volgt. Op een gegeven moment zal bij de neutrale prikkel ook deze automatische reactie optreden. Op basis van deze processen heeft Wolpe vervolgens systematische desensitisatie ontwikkeld: hiërarchische blootstelling aan de prikkels die de problematische reactie (angst) teweeg brengen, voorafgegaan door een relaxatieoefening om deze angstreactie te beperken [6]. De operante conditionering vond zijn oorsprong in de puzzelbox ${ }^{1}$ van Thorndike [7], maar is vooral bekend door de uitwerking van Skinner en zijn Skinnerbox ${ }^{2}$ [8]. De operante conditionering is een leerproces waarbij een respons in een bepaalde context wordt gevolgd door een consequentie, die zowel positief (bekrachtiger) als negatief kan zijn (bestraffen). Bij een beloning zal de frequentie van het gedrag toenemen, bij een bestraffing zal de frequentie afnemen. Dit principe is heden ten dagen nog in veel gedragstherapeutische behandelprotocollen terug te vinden [9, 10]. De eerste generatie gedragstherapie richt dus uitsluitend op direct observeerbaar gedrag.

\footnotetext{
${ }^{1}$ De puzzelbox is een kooi waarin zich een hongerig dier bevindt. Buiten de kooi ligt voedsel. De kooi is gesloten, maar kan worden geopend door in de kooi aan een koord te trekken.

${ }^{2}$ De Skinnerbox is een gesloten kist waarin zich een dier bevindt. Het dier wordt beloond zodra hij op een hendeltje in deze kist drukt; er valt dan voedsel in het bakje

Noot: Een bewerkte versie van de Introductie en Algemene Discussie van dit proefschrift zal als artikel worden gepubliceerd in het tijdschrift De Psycholoog (Acceptance and Commitment Therapy: Achtergrond, Assessment \& Applicatie; T. Batink \& F. Peeters).
} 
De tweede generatie gedragstherapie is midden jaren '50 ontstaan door het werk van Ellis [11] en Beck [12], met de ontwikkeling van de cognitieve therapie. Het einddoel is nog steeds gedragsverandering, echter de insteek is veranderd; de focus ligt nu meer op de binnenwereld. De cognitieve therapie gaat ervanuit dat negatieve gedachten bepaalde negatieve gevoelens veroorzaken, die op hun beurt ons aanzetten tot gedrag. Middels verschillende uitdaagtechnieken alsook de socratische dialoog, kunnen disfunctionele cognities worden geherstructureerd tot meer adaptieve cognities die via het emotionele systeem leiden tot functioneel gedrag. De cognitieve therapie is vervolgens samengesmolten met de eerste generatie gedragstherapie tot cognitieve gedragstherapie (CGT); de tweede generatie gedragstherapie. Er is zeer veel onderzoek gedaan naar CGT $[13,14]$ en deze is dan ook te kenmerken als de meest prominente therapievorm van dit moment.

De derde generatie gedragstherapie gaat in bepaalde opzichten weer terug naar de uitgangspunten van de eerste generatie gedragstherapie, met name wat betreft de operante conditioneringsprincipes [15]. Uit recent onderzoek bleek dat effectieve onderdelen van CGT-behandelingen vaak vooral bestonden uit de gedragstherapeutische onderdelen en dat de cognitief therapeutische toevoeging de effectiviteit niet veel verhoogde $[16,17,18$, $19,20]$. Toch werd de introductie van het werken met cognitieve processen in het veld van de gedragstherapie wel degelijk als een stap vooruit gezien (aandacht voor de binnenwereld; intern gedrag). De kernopvatting van CGT, dat directe verandering van cognities noodzakelijk is voor klinische verbetering, was echter niet solide ondersteund [21]. Dit heeft gezorgd voor ruimte voor de ontwikkeling van nieuwe benaderingen van omgaan met psychische klachten. De derde generatie gedragstherapie richt zich meer op het veranderen van de context en de functie van deze negatieve interne gewaarwordingen, in plaats van het inhoudelijk veranderen van deze ervaringen zelf. Dus in plaats van het veranderen van ongewenste gedachten en gevoelens, leert men er zich op een andere manier mee te verhouden (mindful \& acceptance-based [2]). Met name uit de hoek van de aanhangers van de tweede generatie gedragstherapie is er soms weerstand tegen de term derde generatie, omdat dit gemakkelijk kan worden opgevat als een betere versie [22]. De term derdegeneratie duidt echter niet op een superieure versie ten opzichte van de tweede generatie, maar op een verschuiving van focus.

Onder de noemer derde generatie gedragstherapie kunnen vele uiteenlopende therapievormen worden geschaard: Acceptance and Commitment Therapy (ACT), Gedragsactivatie, Functional Analytic Psychotherapy (FAP), Integrative Behavioral Couple Therapy (IBCT), Compassion Focused Therapy (CFT), Dialectical Behavior Therapy (DBT), Mindfulness Based Stress Reduction (MBSR), Mindfulness Based Cognitive Therapy (MBCT), Metacognitive Therapy (MCT), Cognitive Behavioral Analysis System of Psychotherapy (CBASP) \& Schema Focused Therapy (SFT) $[2,23]$. Dit is overigens nog geen uitgemaakte zaak, het debat hierover is nog in volle gang [24, 25]. Binnen de derde generatie gedragstherapie kan ACT worden gepositioneerd als één van de meest prominente vertegenwoordigers. In dit proefschrift zal het accent liggen op onderzoek naar deze specifieke therapievorm. 


\section{Acceptance and Commitment Therapy}

\section{Achtergrond}

ACT is geworteld in de wetenschapsfilosofische stroming van het contextualisme; die stelt dat gedrag alleen begrepen kan worden vanuit de huidige en historische context waarin het plaatsvindt [26]. Meer specifiek is ACT gestoeld op het functioneel contextualisme dat niet alleen tot doel heeft om gedrag te kunnen voorspellen vanuit deze context, maar ook te beïnvloeden met precisie, focus, en diepgang [27]. Hierop is tenslotte de wetenschapsfilosofische stroming "contextual behavioral science" gebaseerd, waar naast dit filosofische uitgangspunt ook strategieën voor kennisontwikkeling en -toepassing zijn toegevoegd [28].

Het theoretisch fundament van ACT is het radicaal behaviourisme en de hieruit voortvloeiende gedragsanalyse van Skinner [29]. Radicaal behaviourisme ziet zowel de overte processen observeerbaar in de buitenwereld, als coverte processen in de binnenwereld van het individu als gedrag en daarmee onderwerp voor de gedragsanalyse. De Relational Frame Theory (RFT, [30, 31]) bouwt hierop voort als een behavioristische theorie over taal en cognitie. RFT is een theorie die tracht te verklaren waarom mensen niet alleen kunnen leren middels directe ervaringen, maar ook stimuli met elkaar kunnen associëren zonder ze direct te hoeven ervaren door gebruik van taal als externe en interne symbolisering (uniek voor mensen). Deze indirecte manier van leren wordt ook wel relational framing genoemd. Mensen kunnen namelijk via afgeleid leren koppelingen maken. Er zijn twee varianten van dit afgeleide leren: leren via wederzijdse verbondenheid en gecombineerde verbondenheid. Via deze wederzijdse verbondenheid kan men leren dat wanneer $A<B, B>A$. Tevens kan men via gecombineerde verbondenheid leren dat als $A>B$ en $B>C$, dat A > C. Wanneer twee stimuli aan elkaar gekoppeld worden middels relational framing treedt er ook een overdracht van de psychische functies (betekenis) van de ene naar de andere stimulus op; ook wel transformatie van stimulusfuncties genoemd. Deze vaardigheid tot relational framing zorgt ervoor dat wij veel sneller en veel meer kunnen leren dan dieren. Echter het maakt ons ook kwetsbaar. Hierdoor ontstaat namelijk ook de neiging om gedachten (interne taal) heel serieus te nemen, ook wel cognitieve fusie genoemd (en hieruit de neiging tot rigide regelgeleid gedrag). Tevens ontstaat er door ons vermogen om alles met elkaar in verband te brengen de neiging om negatieve interne ervaringen te proberen te controleren of vermijden; ook wel experiëntiële vermijding genoemd. Bijvoorbeeld: Een persoon met een sociale angststoornis neemt de gedachte 'anderen vinden mij raar' heel serieus. Hierdoor voelt hij zich angstig in het bijzijn van anderen en heeft hij de neiging sociaal contact zoveel mogelijk uit de weg te gaan. ACT is ontwikkeld als therapeutische interventie voor vanuit het relational framen voortkomende pathologische processen, waarvan de meest prominente cognitieve fusie en experiëntiële vermijding zijn [32]. 


\section{Wat is ACT?}

Acceptance and Commitment Therapy (ACT, uitgesproken als "ekt") werd in de jaren '90 ontwikkeld door de Amerikaanse psychologen Steven Hayes, Kelly Wilson en Kirk Strosahl [33]. ACT richt zich op het veranderen van de context en de functie van negatieve interne gewaarwordingen, in plaats van het inhoudelijk veranderen van deze gedachten, gevoelens en sensaties zelf. ACT heeft niet tot primair doel om de klachten te verminderen [32, 34], maar richt zich op gezonde coping en bevordering van welzijn en kwaliteit van leven. Het doel van ACT is het ontwikkelen van psychologische flexibiliteit (veerkracht); het vermogen om op een flexibele en werkbare manier om te gaan met de problemen die men tegenkomt (acceptance) terwijl men blijft investeren in de dingen die er echt toe doen voor iemand (commitment). Het acroniem van ACT: Accept, Choose, and Take action geeft ook treffend de werkwijze weer. ACT bestaat uit zes kernprocessen; acceptatie, cognitieve defusie, zelf als context, aandacht voor het hier en nu, waarden en toegewijd handelen. Elk proces zal nu beknopt worden beschreven.

Acceptatie: Het staken van worstelen met vervelende emoties, gedachten en gewaarwordingen en ruimte maken voor deze vervelende innerlijke ervaringen, in plaats van proberen ze te controleren of te vermijden. Het betreft hier een actief en bewust omarmen van deze negative ervaringen zonder poging deze te veranderen.

Defusie: Gedachten leren zien voor wat ze zijn, namelijk geen waarheden waarnaar gehandeld moet worden maar producten van je verstand. Het betreft hier de vaardigheid te leren observeren wat je verstand ingeeft, in plaats van hier automatisch op te reageren.

Zelf als Context: Je bent meer dan alleen je gedachten, gevoelens en zelfbeeld. Er is ook nog het observerende zelf, een constant stuk in jou, dat deze ervaringen allemaal waarneemt. Je bent niet je ervaringen, je hebt ervaringen. Daarnaast besta je.

Aandacht voor het Hier en Nu: Aandacht hebben voor wat er op dit moment te ervaren is (zowel binnenwereld als buitenwereld), in plaats van een preoccupatie met het verleden of de toekomst.

Waarden: Stilstaan bij de dingen die jij als persoon écht belangrijk vindt, je waarden. Deze waarden geven richting en betekenis aan je leven.

Toegewijd Handelen: Handelen op basis van je waarden, door middel van het stellen van concrete doelen die zijn verankerd in deze waarden, en deze doelen vervolgens realiseren middels verschillende acties. In deze fase ga je weer investeren in je leven.

De beschreven processen kunnen op drie niveaus spelen: het niveau van de cliënt, dat van de therapeut en in de interactie tussen beiden. De processen acceptatie, defusie, zelf als context en aandacht voor het hier en nu zijn te scharen onder het acceptanceonderdeel, de processen waarden en toegewijd handelen zijn te scharen onder het commitment-onderdeel van ACT. Deze zes processen zijn onderling verbonden en stimuleren elkaar op een synergetische wijze. Samen vormen deze ACT-processen psychologische flexibiliteit. Het ACT-model wordt visueel weergegeven in het ACT-hexaflex (Figuur 1). Op basis van het hexaflex is ook een aantal versimpelde modellen ontwikkeld; zoals de weergave in drie pijlers (Open, Centered, Engaged [32]), via de Triflex (Open up, 
Be present, Do what matters [35]), of in het Matrix-model (Away vs Toward, Mental experiencing vs 5-senses experiencing [36]). De zes ACT-processen zijn, in gecomprimeerde vorm, echter nog steeds aanwezig in elk van deze modellen.

Er wordt binnen ACT veel gebruik gemaakt van experiëntiële oefeningen om de cliënt ook op ervaringsniveau leerervaringen op te laten doen (en niet alleen op cognitief niveau). Tevens gaat het bij ACT om het aanleren van vaardigheden (versterken van de ACTprocessen), die men alleen ontwikkelt door er actief mee te oefenen. Daarnaast wordt er binnen ACT veel gebruik gemaakt van metaforen. De kracht van metaforen is dat ze alternatieven kunnen aanbieden in een situatie waarin het voor een cliënt moeilijk is deze te zien [37]. Een metafoor kan vaak ook als kapstok fungeren voor het ACT-proces; het beeldende karakter van de metafoor kan bijdragen aan de retentie en retrieval van het ACT-concept. Hoewel er binnen ACT een veelheid aan kant-en-klare ACT-oefeningen en -metaforen beschikbaar zijn, is het niet noodzakelijk deze te gebruiken. Men kan ook eigen oefeningen / metaforen bedenken, zolang ze maar in dienst staan van het faciliteren van de ACT-processen (en theoretisch consistent zijn). In Tabel 1 zijn ter illustratie een ACToefening en ACT-metafoor uitgewerkt.

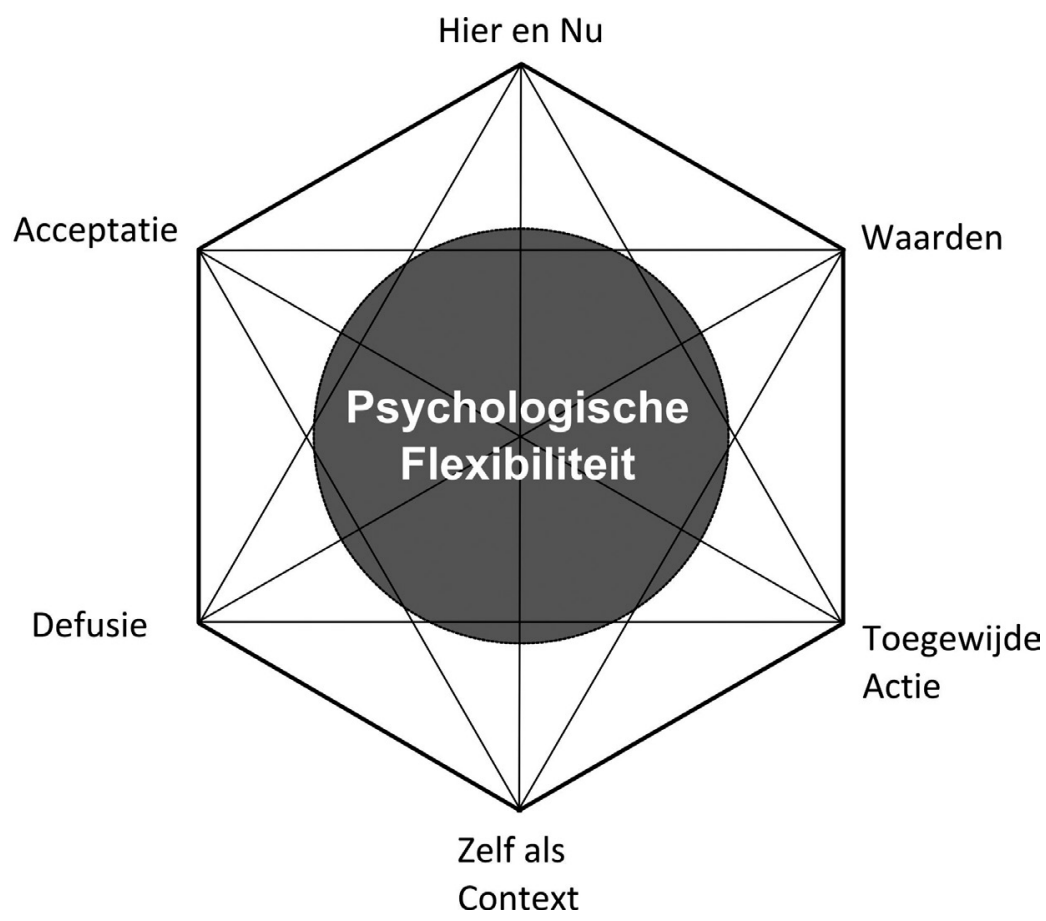

Figuur 1. ACT-hexaflex. 
Tenslotte behoeft de therapeutische relatie nog even kort de aandacht. Omdat de uitdagingen waar de cliënt mee worstelt niet fundamenteel anders zijn dan de uitdagingen die de therapeut ervaart (we hebben immers hetzelfde systeem), is de therapeut oprecht gelijkwaardig. Je bent als therapeut model voor de cliënt; dat houdt in dat jijzelf ook de ACT-processen moet kunnen hanteren met je eigen interne ervaringen.

Tabel 1. ACT-oefening \& ACT-metafoor.

\begin{tabular}{ll}
\hline ACT-oefening: Bladeren op Rivier (Defusie) & ACT-metafoor: Drijfzand (Acceptatie) \\
\hline Stel je een rustig kabbelende rivier voor. Het water & Het effect van worstelen met je vervelende \\
stroomt over stenen, langs bomen, en stroomt de & gedachten, gevoelens en sensaties kun je vergelijken \\
valei door. Af en toe valt er een groot blad in het & met het worstelen als je vast zit in drijfzand. Hoe \\
water, en deze drijft de rivier af. Schrijf nu één voor & harder je je verzet, hoe dieper je erin wegzakt. Kun je \\
één je gedachten op een voorbijdrijvend blad en laat & $\begin{array}{l}\text { deze worsteling staken, en deze vervelende gevoelens } \\
\text { deze rivier afdrijven. Blijf dit even doen. }\end{array}$
\end{tabular}

\section{Wetenschappelijke Evidentie}

Vanaf het verschijnen van het ACT-basisboek [33], is er zowel vanuit de klinische als vanuit de academische wereld meer interesse gekomen in ACT. Op het moment van dit schrijven zijn er reeds meer dan 175 Randomized Controlled Trials (RCT's) verschenen met in totaal meer dan 10.000 deelnemers [38]. In navolging van deze RCT's zijn er ook verschillende reviews en meta-analyses verschenen. In 2006 verscheen de eerste review van Hayes [39] waar werd geconcludeerd dat er nog niet voldoende gecontroleerde studies waren uitgevoerd om te kunnen concluderen dat ACT effectiever was dan andere actieve behandelingen maar dat de resultaten wel veelbelovend waren. Uit de volgende review van Öst [40] kwam naar voren dat ACT nog niet kon worden aangeduid als research supported treatment, mede vanwege de lage methodologische kwaliteit van de studies. De daarna volgende meta-analyse van Powers [41] was positiever; ACT bleek effectiever dan controle condities maar niet effectiever dan reeds bestaande behandelingen. De review van Ruiz [42] concludeerde dat ACT een effectieve interventie bleek voor verschillende problematieken, met grote effectsizes die bij de follow-up nog hoger werden. Smout [43] heeft vervolgens gekeken naar de ACT RCT's die na de review van Öst [40] waren verschenen en concludeerde dat de methodologie sindsdien sterk verbeterd was. Tevens concludeerde hij dat er voldoende bewijs was om ACT op te nemen in de Australische richtlijnen voor de behandeling van chronische pijn, angststoornissen en OCD. In een meta-analyse vergeleek Ruiz [44] ACT met CGT, waarbij ACT over het algemeen effectiever was maar geen significante verschillen liet zien bij de behandeling van subgroepen (angststoornis \& depressie). In zijn bijgewerkte review gaf Öst [45] aan dat ACT niet effectiever was dan CGT, dat ACT voor geen enkele stoornis al goed gefundeerd was, maar waarschijnlijk wel bruikbaar was voor chronische pijn en mogelijk bruikbaar was voor depressie, gemengde angst, OCD, psychose, afhankelijkheid en werkstress. Uit de meta-analyse van A-tjak [46] bleek ook dat ACT niet effectiever was dan CGT, maar dat het wel degelijk een effectieve behandelinterventie was voor angststoornissen, depressie, verslaving, en somatische problemen waarbij vergelijkbare 
effecten werden gemeten ten opzichte van de bestaande therapievormen. In de laatste cumulatieve meta-analyse van Hacker [47] komt eveneens naar voren dat ACT een effectieve therapievorm is voor veelvoorkomende psychische klachten (angst en depressie), met de kanttekening dat ACT niet effectiever is dan de traditionele benaderingen ${ }^{3}$.

Vanwege bovenstaande bevindingen is ACT sinds 2011 opgenomen in het Nationale Register voor Evidence Based Practices van het Amerikaanse ministerie voor de geestelijke gezondheidszorg (SAMSHA, [48]) voor de Obsessief Compulsieve Stoornis, Depressie, Rehospitalisatie en Algemeen Welzijn. Tevens is ACT opgenomen in het register van Research Supported Treatments van de APA (Division 12; Society of Clinical Psychology, [49]); voor Chronische Pijn (strong support), Depressieve Stoornis (modest support), Angststoornissen (modest support), Obsessief Compulsieve Stoornis (modest support) en Psychose (modest support). In Nederland heeft ACT zijn weg nog niet gevonden naar de multidisciplinaire richtlijn zoals die ontwikkeld worden door Landelijke Stuurgroep Multidisciplinaire Richtlijnontwikkeling in de GGZ en het Trimbos-instituut.

Uit bovenstaande evidentie blijkt ook het transdiagnostische karakter van ACT; het is geen stoornisspecifieke interventie maar is breed inzetbaar voor verschillende problematieken. Naast het effectonderzoek begint procesonderzoek nu ook langzaam op gang te komen (mediatie \& moderatie). Begrip van de onderliggende processen, kan helpen om de behandeling te optimaliseren en daarmee de behandeleffecten te vergroten. Tenslotte kan ACT naast therapeutische interventie, ook worden ingezet in de trainingscontext. De ACTvaardigheden zijn namelijk ook bruikbaar in het dagelijks leven, zonder de aanwezigheid van psychopathologie.

\section{Assessment en Optimalisatie van derde generatie therapeutische processen}

Acceptance and Commitment Therapy begint zijn positie te verwerven binnen de GGZ. De huidige GGZ in Nederland is echter voornamelijk gericht op klachtreductie [50] mede door de classificerende diagnostiek middels de DSM-IV (en vanaf 2017 de DSM-5). Omdat de focus van ACT niet zozeer gericht is op klachtreductie, is deze classificerende diagnostiek ook minder relevant. De reguliere instrumenten die deze klachten in kaart brengen (o.a. SCL-90, BSI, OQ-45), zijn dan ook minder informatief. Er is behoefte aan meer functionele diagnostiek en daarbij aan meetinstrumenten die de functionele processen in kaart brengen. Uit een review van Jacobs van beschikbare procesmaten [51], bleek dat de beschikbare ACT-instrumenten vaak beperkt waren onderzocht en er in veel gevallen geen gevalideerde Nederlandse vertaling beschikbaar was. Ook bleek dat nog niet voor elk ACT-proces een geschikte vragenlijst was ontwikkeld om deze in kaart te kunnen brengen (zelf als context, waarden \& toegewijd handelen). Er is dus behoefte aan een Nederlands meetinstrument met goede psychometrische kwaliteiten die alle ACT-processen in kaart kan brengen en

\footnotetext{
${ }^{3}$ Reviews en Meta-analyses die zich uitsluitend op één specifieke pathologie hebben gefocust zijn hier buiten beschouwing gelaten.
} 
daarmee ook uitspraken kan doen over het overkoepelend construct: de psychologische flexibiliteit van een persoon.

De ACT-processen kunnen ook gezien worden als (een gebrek aan) vaardigheden [52]. Vaardigheden die de cliënt niet alleen in de gecontroleerde therapieruimte wil kunnen toepassen, maar ook in het dagelijks leven. De generalisatie van deze vaardigheden van de therapeutische context naar de natuurlijke context is niet vanzelfsprekend is en er dient dan door de cliënt ook actief mee te worden geoefend in zijn dagelijks leven. Nieuwe technologie maakt het mogelijk interventies in het dagelijks leven aan te bieden via mobiele hulpmiddelen: eHealth - Electronic Health: Gebruik van technologie om gezondheid te bevorderen - \& mHealth - Mobile Health: Gebruik van mobiele technologie om gezondheid te bevorderen - $[53,54,55]$. Hierdoor kunnen mensen in hun thuisomgeving verder worden begeleid in het ontwikkelen en toepassen van de verschillende ACT-vaardigheden. Door de integratie in het dagelijks leven kan de effectiviteit van de ACT-interventie worden vergroot. Een dergelijke mHealth interventie zal tevens een gevoel van empowerment geven aan de cliënten. Ze hebben namelijk zelf regie over hun eigen behandeling waarmee ook het gevoel van regie over hun eigen leven kan worden gefaciliteerd.

Tevens maakt deze mobiele technologie het mogelijk in de thuisomgeving metingen te doen in plaats van afhankelijk te zijn van retrospectieve zelfrapportage. Deze monitoring in het dagelijks leven geeft niet alleen waardevolle informatie maar kan ook worden gezien als een therapeutische interventie op zichzelf: mensen worden hierdoor bewuster van hun eigen processen $[56,57]$. Een bijkomend voordeel van het inzetten van eHealth en mHealth interventies (eventueel in combinatie met face to face gesprekken; blended-care) is dat dit kan bijdragen aan de reductie van zorgkosten. De zorgverzekeraars sturen ook actief aan op deze integratie, door als richtlijn vast te stellen dat $20 \%$ van de trajecten in de basis-GGZ gebruik van eHealth dienen te maken [58].

Naast de integratie van een interventie in het dagelijks leven, kan er ook worden ingezoomd op de interventie zelf en worden gekeken naar de onderliggende veranderingsprocessen om zo de effectiviteit van de interventie verder te verhogen. Het identificeren van variabelen die deze therapeutische effecten mediëren kan worden gezien als een eerste stap in dit proces [59]. Aangezien de behandeltrajecten in de GGZ steeds korter worden [60], is het belangrijk te weten welke elementen verantwoordelijk zijn voor het behandeleffect.

\section{Doelen van het proefschrift}

Op basis van boven beschreven uitdagingen en ontwikkelingen zijn de onderzoeksdoelen van dit proefschrift gebaseerd. Het eerste deel van het proefschrift richt zich op de beschikbare ACT-meetinstrumenten. Omdat het ACT-onderzoeksveld volop in beweging is, zeker ook op het gebied van de ontwikkeling van vragenlijsten, is er middels een systematisch literatuuronderzoek een overzicht gegeven van de op dit moment beschikbare ACTvragenlijsten, alsook welke geschikt zijn voor het Nederlands taalgebied. Vervolgens zal er 
worden ingezoomd op de ontwikkeling alsook het in kaart brengen van de psychometrische kwaliteiten van een Nederlandstalige ACT-vragenlijst die de zes verschillende ACT-processen alsook de Psychologische Flexibiliteit van een persoon in kaart kan brengen.

Het tweede gedeelte van dit proefschrift richt zich op het vraagstuk van de integratie van ACT in het dagelijks leven van de cliënt. Er zal een specifiek voor dit doel ontwikkelde add-on mHealth interventie worden beschreven waarbij ACT-training en monitoring in het dagelijks leven plaatsvindt. Zowel de haalbaarheid, aanvaardbaarheid als de effectiviteit van deze interventie zal worden onderzocht. Tevens zal een herziene versie van deze mHealth interventie, ontwikkeld voor individuele begeleiding, worden beschreven in een conceptueel artikel. In dit artikel zal zowel de opzet van de face to face ACT-training uitvoerig worden beschreven, alsook het design van de aanvullende mHealth interventie worden geschetst.

Tenslotte zal er binnen het derde generatie gedragstherapeutisch kader een uitstap worden gemaakt van ACT naar MBCT. Hoewel MBCT een effectieve interventie voor residuele depressie-klachten is [61], zijn de werkzame mechanismen niet duidelijk. De werkzame mechanismen zijn ook informatief voor de mechanismen van andere loten aan de boom van de derde generatie gedragstherapie, en meer specifiek ACT, gezien één van de ACTprocessen (aandacht voor het hier en nu) duidelijke parallellen heeft met MBCT. MBCT wordt ook wel onder de acceptance-based therapieën geschaard.

Deze thema's zullen verder worden uitgewerkt in onderstaande hoofdstukken.

In hoofdstuk 2 zal middels een systematische literatuurstudie een overzicht worden gegeven van de ACT-specifieke meetinstrumenten die tot op heden beschikbaar zijn, zowel voor de zes specifieke ACT-processen alsook voor specifieke doelgroepen. Tevens zal er per ACT-proces advies worden gegeven over de meest geschikte ACT-vragenlijst voor het Nederlandse taalgebied. Van deze geselecteerde ACT-vragenlijsten zullen ook de psychometrische kwaliteiten worden beschreven.

In hoofdstuk 3 zal de ontwikkeling van een nieuwe ACT-vragenlijst worden beschreven: de Flexibiliteits Index Test (FIT-60). Tevens zal de interne betrouwbaarheid van dit instrument worden onderzocht e zal de construct validiteit in kaart worden gebracht. Ook zal worden onderzocht in hoeverre de FIT-60 in staat is verandering in de verschillende ACT-processen te meten. Tenslotte zal er voor een algemene populatie en een studentpopulatie de normering worden bepaald. Ten tijde van de ontwikkeling van de FIT-60 (2010) waren de beschikbare ACT-meetinstrumenten relatief schaars of zelfs niet voorhanden voor een aantal ACT-processen.

Hoofdstuk $\mathbf{4}$ beschrijft vervolgonderzoek naar de psychometrische kwaliteiten van de FIT60 . Dit vervolgonderzoek is opgedeeld in drie deelonderzoeken waarbij er in een therapeutpopulatie, een klinische patiënten-populatie en een ambulante patiënten-populatie onderzoek wordt gedaan naar de interne betrouwbaarheid, de test-hertest betrouwbaarheid 
en naar de invloed van demografische variabelen op de uitslag van de FIT-60. Tevens zal er convergent en divergent validatieonderzoek plaatsvinden, zowel met ACT-specifieke als non-specifieke vragenlijsten. Ook zal worden onderzocht in hoeverre de FIT-60 in staat is om verandering in de verschillende ACT-processen te meten en zal worden bepaald wanneer deze veranderingen klinisch significant zijn. Tenslotte zal voor elk sample de normering worden bepaald.

Hoofdstuk 5 zal een mHealth interventie beschrijven die cliënten ondersteunt bij de integratie van ACT in hun dagelijks leven: de ACT in Daily Life Training (ACT-DL). Naast de beschrijving van de opzet van deze add-on interventie (monitoring \& training), zal ook onderzoek naar de haalbaarheid (feasibility), aanvaardbaarheid (acceptability) en effectiviteit van de ACT-DL worden gedaan. Het betreft een observationeel onderzoek bij een groep cliënten met diverse psychische problematieken die in klinische behandeling zijn en zich vrijwillig hebben opgegeven om na de zes weken durende ACT-groepstraining in het klinische traject, tijdens hun ambulante traject in hun thuisomgeving, vier weken aan de slag te gaan met de ACT-DL als aanvulling.

In hoofdstuk $\mathbf{6}$ zal er middels een conceptueel artikel een herziene versie (op basis van de aandachtspunten die naar voren kwamen in de feasibility-studie) van de ACT in Daily Life Training (ACT-DL) uitgebreid worden beschreven. Er zal worden begonnen met een schets van de achtergrond en de ontwikkelingen die hebben geleidt tot het ontwikkelen van de ACT-DL. Hierna zal zowel de opzet van de acht bijeenkomsten van de ACT-training, alsook de aanvullende training in het dagelijks leven middels de mHealth interventie (combinatie van monitoring en training) worden beschreven.

Hoofdstuk 7 zal inzoomen op de werkzame mechanismen die het symptoom reducerend effect van MBCT op residuele depressie klachten kunnen verklaren. Middels exploratieve systematische mediatie-analyses zal de bijdrage van mindfulness-vaardigheden, positief affect, negatief affect, piekeren en rumineren als potentiele mediatoren worden onderzocht. Tevens zal er worden onderzocht of dit werkzame mechanisme verschilt bij cliënten die maximaal twee episodes hebben gehad, in vergelijking met cliënten die drie of meer episodes hebben gehad, gezien de interventie effectief bleek te zijn bij de laatstgenoemde groep maar niet bij de eerste groep.

Tenslotte zal hoofdstuk $\mathbf{8}$ de discussie beslaan van dit proefschrift. De belangrijkste resultaten aangaande het monitoren van de ACT-processen, alsook de actieve stimulatie van deze processen in de dagelijkse praktijk zullen worden beschreven en de uitkomsten zullen worden besproken in het licht van recente wetenschappelijk literatuur. Tenslotte zullen de implicaties van deze resultaten worden besproken voor de huidige GGZ en zal een suggestie worden gedaan voor een herziening van de focus van de GGZ en de integratie van nieuwe technologieën binnen deze GGZ. 


\section{Literatuur}

1. Kohlenberg, R. J., Bolling, M. Y., Kanter, J. W., \& Parker, C. R. (2002). Clinical behavior analysis: Where it went wrong, how it was made good again, and why its future is so bright. The Behavior Analyst Today 3, 248-253.

2. Hayes, S. C. (2004). Acceptance and Commitment Therapy, Relational Frame Theory, and the third wave of behavior therapy. Behavior Therapy, 35, 639-665.

3. Hayes, S. C. (2004). Acceptance and Commitment Therapy and the new behavior therapies: Mindfulness, acceptance and relationship. In S. C. Hayes, V. M. Follette, \& M. Linehan (Eds.), Mindfulness and acceptance: Expanding the cognitive behavioral tradition (pp. 1-29). New York: Guilford.

4. Pavlov, I. P. (1897/1902). The work of the digestive glands. London: Griffin.

5. Watson, J. B., \& Rayner, R. (1920). Conditioned emotional reactions. Journal of Experimental Psychology, 3, 1-14.

6. Wolpe, J. (1958). Psychotherapy by reciprocal inhibition. Palo Alto: Stanford University.

7. Thorndike, E. L. (1898). Animal intelligence: An experimental study of the associative processes in animals. Psychological Monographs: General and Applied, 2, i-109.

8. Skinner, B. F. (1948). Superstition' in the pigeon. Journal of Experimental Psychology, 38, 168-172.

9. Ten Broeke, E., Korrelboom., K., \& Verbraak (Eds.). (2009). Praktijkboek Geïntegreerde Cognitieve Gedragstherapie. Protocollaire behandelingen op maat. Bussum: Uitgeverij Coutinho.

10. Keijsers, G.P.J., van Minnen, A., \& Hoogduin., K. (Reds.). (2011). Protocollaire behandelingen voor volwassenen met psychische klachten (1 \& 2). Amsterdam: Boom Uitgevers.

11. Ellis, A. (1957). Rational psychotherapy and individual psychology. Journal of Individual Psychology, 13, 38-44.

12. Beck, A. T. (1967). Depression: Causes and Treatment. Philidelphia: University of Pennsylvania Press.

13. Butler, A. C., Chapman, J. E., Forman, E. M., \& Beck, A. T. (2006). The empirical status of cognitive-behavioral therapy: a review of meta-analyses. Clinical psychology review, 26, 17-31.

14. Hofmann, S. G., Asnaani, A., Vonk, I. J., Sawyer, A. T., \& Fang, A. (2012). The Efficacy of Cognitive Behavioral Therapy: A Review of Meta-analyses. Cognitive Therapy and Research, 36, 427-440.

15. Kahl, K. G., Winter, L., Schweiger, U., \& Sipos, V. (2011). The third wave of cognitive-behavioural psychotherapies: concepts and efficacy [in German]. Fortschritte der Neurologie-Psychiatrie, 79, 330-339.

16. Jacobson, N. S., Dobson, K. S., Truax, P. A., Addis, M. E., Koerner, K., Gollan, J. K., Gortner, E. \& Prince, S. E. (1996). A component analysis of cognitive-behavioral treatment for depression. Journal of Consulting and Clinical Psychology, 64, 295-304.

17. Dobson, K. S., \& Khatri, N. (2000). Cognitive therapy: Looking backward, looking forward. Journal of Clinical Psychology, 56, 907-923.

18. Borkovec, T. D., Newman, M. G., Pincus, A. L., \& Lytle, R. (2002). A component analysis of cognitivebehavioral therapy for generalized anxiety disorder and the role of interpersonal problems. Journal of Consulting and Clinical Psychology, 70, 288-298.

19. Longmore, R. J., \& Worrell, M. (2007). Do we need to challenge thoughts in cognitive behavior therapy? Clinical Psychology Review, 27, 173-187.

20. Foa, E. B. (2010). Cognitive behavioral therapy of obsessive-compulsive disorder. Dialogues in Clinical Neuroscience, 12, 199-207.

21. Hayes, S. C., Luoma, J., Bond, F., Masuda, A., \& Lillis, J. (2006). Acceptance and Commitment Therapy: Model, processes, and outcomes. Behaviour Research and Therapy, 44, 1-25.

22. Raes, F. (2015). De derde generatie CGT: een vloek of een zegen? Tijdschrift voor gedragstherapie, 1, 61-69.

23. Kahl, K. G., Winter, L., \& Schweiger, U. (2012). The third wave of cognitive behavioural therapies: what is new and what is effective? Current Opinion in Psychiatry, 6, 522-528.

24. David, D., \& Hofmann, S. G. (2013). Another error of Descartes? Implications for the "third wave" cognitivebehavioural therapy. Journal of Cognitive and Behavioural Psychotherapies, 13, 111-121.

25. Hooper, N., \& Larsson, A. (2015). The Research Journey of Acceptance and Commitment Therapy (ACT). London: Palgrave Macmillan.

26. Pepper, S. C. (1942). World hypotheses: A study in evidence. Berkeley: University of California Press.

27. Hayes, S. C. (1993). Analytic goals and the varieties of scientific contextualism. In S.C. Hayes, L.J. Hayes, H.W. Reese \& T.R. Sarbin (Eds.), Varieties of scientific contextualism (pp. 11-27). Reno: Context Press.

28. Hayes, S. C., Barnes-Holmes, D., \& Wilson, K. G. (2012). Contextual Behavioral Science: Creating a science more adequate to the challenge of the human condition. Journal of Contextual Behavioral Science, 1, 1-16.

29. Skinner, B . F (1945). The operational analysis of psychological terms. Psychological Review, 52, $270-277$.

30. Hayes, S. C., Barnes-Holmes, D. \& Roche, B. (Eds.) (2001). Relational Frame Theory: a post-Skinnerian account of human language and cognition. New York: Plenum Press.

31. Blackledge, J. T. (2003). An introduction to Relational Frame Theory: Basics and applications. The Behavior Analyst Today, 3, 421-433.

32. Hayes, S. C, Strosahl, K. D., \& Wilson, K. G. (2012). Acceptance and commitment therapy: The process and practice of mindful change (2nd edition). New York: The Guilford Press. 
33. Hayes, S. C., Strosahl, K. D., \& Wilson, K. G. (1999). Acceptance and Commitment Therapy: An experiential approach to behavior change. New York: Guilford Press.

34. Jansen, G., \& Batink, T. (2014). Time to ACT! Het basisboek voor professionals. Zaltbommel: Uitgeverij Thema.

35. Harris, R. (2009). ACT Made Simple: An Easy-To-Read Primer on Acceptance and Commitment Therapy. Oakland: New Harbinger.

36. Polk, K. L., \& Schoendorff, B. (Eds.). (2014). The ACT Matrix: A New Approach to Building Psychological Flexibility Across Settings and Populations. Oakland: New Harbinger Publications.

37. Foody, M., Barnes-Holmes, Y., Barnes-Holmes, D., Torneke, N., Luciano, C., Stewart, I., \& McEnteggart, C. (2014). RFT for clinical use: The example of metaphor. Journal of Contextual Behavioral Science, 3, 305-313.

38. Hayes, S.C. (March 2017). ACT Randomized Controlled Trails. Retrieved from https://contextualscience. org/ACT_Randomized_Controlled_Trials.

39. Hayes, S. C., Luoma, J., Bond, F., Masuda, A., \& Lillis, J. (2006). Acceptance and Commitment Therapy: Model, processes, and outcomes. Behaviour Research and Therapy, 44, 1-25.

40. Öst, L. (2008). Efficacy of the third wave of behavioral therapies: A systematic review and meta-analysis. Behaviour Research and Therapy, 46, 296-321.

41. Powers, M. B., Vörding, M. \& Emmelkamp, P. M. G. (2009). Acceptance and commitment therapy: A metaanalytic review. Psychotherapy and Psychosomatics, 8, 73-80.

42. Ruiz, F. J. (2010). A review of Acceptance and Commitment Therapy (ACT) empirical evidence: Correlational, experimental psychopathology, component and outcome studies. International Journal of Psychology and Psychological Therapy, 10, 125-162.

43. Smout, M. F., Hayes, L., Atkins, P. W. B., Klausen, J., \& Duguid, J. E. (2012). The empirically supported status of acceptance and commitment therapy: An update. Clinical Psychologist, 16, 97-109.

44. Ruiz, F. J. (2012). Acceptance and commitment therapy versus traditional cognitive behavioral therapy: A systematic review and meta-analysis of current empirical evidence. International Journal of Psychology and Psychological Therapy, 12, 333-358.

45. Öst, L. G. (2014). The efficacy of Acceptance and Commitment Therapy: an updated systematic review and meta-analysis. Behaviour Research and Therapy, 61, 105-121.

46. A-Tjak, J. G., Davis, M. L., Morina, N., Powers, M. B., Smits, J. A., \& Emmelkamp P. M. (2015). A meta-analysis of the efficacy of acceptance and commitment therapy for clinically relevant mental and physical health problems. Psychotherapy and Psychosomatics, 84, 30-36.

47. Hacker, T., Stone, P., \& MacBeth, A. (2016). Acceptance and commitment therapy - Do we know enough? Cumulative and sequential meta-analyses of randomized controlled trials. Journal of Affective Disorders, 190, 551-565

48. SAMSHA's National Registry of Evidence-based Programs and Practices. http://www.samhsa.gov/nrepp

49. Research-Supported Treatments - Society of Clinical Psychology, APA Division 12. https://www.div12.org/ psychological-treatments/

50. Van Os, J. (2014). De DSM-5 voorbij! Persoonlijke diagnostiek in een nieuwe GGZ. Leusden: Diagnosis Uitgevers.

51. Jacobs, N., Beckers, J., \& Raes, F. (2009). Evaluatie van ACT in de praktijk: geschikte procesmaten. Psychopraxis, 1, 152-156.

52. A-Tjak, J. (Ed.). (2015). Acceptance \& Commitment Therapy: Theorie en praktijk (Tweede, herziene druk). Houten: Bohn Stafleu van Loghum.

53. Heron, K. E., \& Smyth, J. M. (2010). Ecological Momentary Interventions: Incorporating mobile technology into psychosocial and health behavior treatments. British Journal of Health Psychology, 15, 1-39.

54. Runyan, J. D., \& Steinke, E. G. (2015). Virtues, ecological momentary assessment/intervention and smartphone technology. Frontiers in Psychology, 6, 481.

55. Loo Gee, B., Griffiths K. M., \& Gulliver, A. (2016). Effectiveness of mobile technologies delivering Ecological Momentary Interventions for stress and anxiety: a systematic review. Journal of the American Medical Informatics Association, 23, 221-229.

56. Barta, W. D., Tennen, H., \& Litt, M. D. (2012). Measurement reactivity in diary research. In M.R. Mehl \& T.S. Conner (Eds). Handbook of research methods for studying daily life (pp. 108-123). New York: The Guilford Press.

57. Telford, C., McCarthy-Jones, S., Corcoran, R., \& Rowse, G. (2012). Experience sampling methodology studies of depression: the state of the art. Psychological medicine, 42, 1119-1129.

58. Bureau HHM (2013). Generalistische Basis GGZ: Verwijsmodel en Productbeschrijvingen. Retrieved from GGZ Nederland: http://www.ggznederland.nl/uploads/assets/asset_955656.pdf

59. Kazdin, A.E. (2007). Mediators and mechanisms of change in psychotherapy research. Annual Review of Clinical Psychology, 3, 1-27.

60. Keijsers, G.P.J. (2015). Het grote psychotherapiedebat. Tijdschrift voor Psychotherapie, 41, 157-173.

61. Kingston, T., Dooley, B., Bates, A., Lawlor, E., \& Malone, K. (2007). Mindfulness-based cognitive therapy for residual depressive symptoms. Psychology and Psychotherapy: Theory, Research and Practice, 80, 193-203. 
Tim Batink $k^{1,2,3}$, Gijs Jansen ${ }^{4}$, Frenk Peeters ${ }^{5,6,7}$

${ }^{1}$ U-center, Epen (L), The Netherlands.

${ }^{2}$ School for Mental Health and Neuroscience, Division 2, Mental Health, Maastricht University, Maastricht, The Netherlands.

${ }^{3}$ ACT in Actie, Valkenburg aan de Geul, The Netherlands.

${ }_{4}$ SeeTrue, Maastricht, The Netherlands.

${ }_{5}^{5}$ Maastricht University Medical Center, Department of Psychiatry and Psychology, Maastricht, The Netherlands.

${ }^{6}$ RIAGG Maastricht, Maastricht, The Netherlands.

7 Faculty of Health Medicine and Life Sciences, Maastricht University, Maastricht, The Netherlands. 


\section{New generation behaviour therapy; new generation assessment}

\section{measures; A review of currently available assessment measures}

Nieuwe generatie gedragstherapie, nieuwe generatie meetinstrumenten:

Een overzicht van beschikbare ACT-meetinstrumenten

Gepubliceerd: Tijdschrift voor Psychiatrie (2015), 10, 739-748

Noot: Dit artikel is een bewerking van een eerder verschenen boekhoofdstuk:

Batink T, Jansen G. Functionele testdiagnostiek. In: Jansen G, Batink T, red. Time to ACT!

Het basisboek voor professionals. Zaltbommel: Thema; 2014. p. 397-411. 


\section{Abstract}

\section{Background}

Acceptance and commitment therapy (ACT) is a relatively new form of behaviour therapy, which has relational frame theory as its theoretical foundation. Since ACT is not aimed primarily at reducing psychopathological symptoms, changes are likely to be needed in the nature and purpose of the assessment measures used.

Aim

To provide an up-to-date overview of ACT-measures that are suitable for use with adults and that will assist Dutch-speaking clinicians and researchers.

\section{Method}

We performed a systematic review of the literature.

\section{Results}

More than 50 ACT-related questionnaires were identified; of these, the AAQ-II was the most suitable for acceptance as an ACT component, the CFQ was the most appropriate for defusion and the SACS was the best for self as context; the FFMQ-SF was regarded as the best for contact with the present moment, the VLQ for values, the ELS for committed action and the FIT-60 for psychological flexibility.

\section{Conclusion}

Clinicians and researchers with an interest in ACT have many measures at their disposal. Most of these are available free of charge and can also be used without payment. 


\section{Samenvatting}

Achtergrond

Acceptance and commitment therapy (ACT) is een relatief nieuwe vorm van gedragstherapie met als theoretisch fundament de relational frame theory. Het feit dat ACT niet primair gericht is op reductie van psychopathologische symptomen, brengt veranderingen in aard en doel van bijpassende meetinstrumenten met zich mee.

Doel

Een actueel overzicht bieden van bij ACT passende meetinstrumenten voor volwassenen, ten behoeve van Nederlandstalige clinici en onderzoekers.

\section{Methode}

Een systematische literatuurstudie.

\section{Resultaten}

Meer dan 50 ACT-gerelateerde vragenlijsten werden geïdentificeerd, waarbij de AAQ-II de geschiktste maat bleek voor de ACT-component acceptatie, de CFQ voor defusie, de SACS voor het zelf als context, de FFMQ-SF voor contact met het hier en nu, de VLQ voor waarden, de ELS voor toegewijd handelen en de FIT-60 voor psychologische flexibiliteit.

\section{Conclusie}

Er zijn voor clinici en onderzoekers met interesse in ACT vele meetinstrumenten voorhanden die merendeels vrij te verkrijgen en te gebruiken zijn. 


\section{Introductie}

Acceptance and commitment therapy (ACT), is een relatief nieuwe vorm van gedragstherapie met als theoretisch fundament de relational frame theory [1]. RFT is een gedragsanalytische theorie over taal en cognitie en verklaart hoe wij mensen niet alleen via directe ervaring kunnen leren, maar ook indirect nieuwe verbanden kunnen leggen tussen stimuli en hoe stimuli afgeleide betekenissen of functies kunnen verwerven. ACT wordt toegepast bij uiteenlopende stoornissen zoals depressie, chronische pijnklachten, gemengde angst, obsessieve-compulsieve stoornis en psychose. ACT is sinds juli 2010 opgenomen in het National Registry of Evidence-based Programs and Practices [2], en staat tevens voor verschillende stoornissen vermeld op de website van de American Psychological Association [3], als psychologische behandeling die door onderzoek ondersteund wordt. Het onderzoek naar ACT heeft een sterke groei doorgemaakt; op het moment van schrijven zijn er reeds meer dan 100 gerandomiseerde onderzoeken naar de effectiviteit van ACT gepubliceerd. Uit een meta-analyse [4] blijkt ACT effectief bij angstklachten, depressie, verslaving en somatische klachten. Recent werd in dit tijdschrift aandacht besteed aan onderzoek naar de effectiviteit van ACT bij verslaving [5].

ACT richt zich niet op symptoomreductie, maar op coping met symptomen zodat er ruimte ontstaat om weer te gaan investeren in een waardevol leven [6]. ACT bestaat uit zes kernprocessen die nauw samenhangen met elkaar (zie Figuur 1). Acceptatie gaat om ruimte maken voor vervelende emoties, in plaats van deze te vermijden. Bij defusie leert de patiënt gedachten te herkennen als gedachten, niet als waarheden waarnaar gehandeld moet worden (fusie). Tevens leert de patiënt op een andere manier naar zichzelf kijken: je bent meer dan alleen je gedachten, gevoelens en zelfbeeld, er is ook nog het observerende zelf dat dit allemaal waarneemt (zelf als context). Contact met het hier en nu gaat om het leren de aandacht te richten op het hier en nu. Bij waarden wordt er stilgestaan bij de dingen die er echt toe doen voor de betrokkenen, waarna middels toegewijd handelen actie wordt ondernomen op basis van deze waarden. Tezamen vormen deze elementen psychologische flexibiliteit: het vermogen om flexibel om te gaan met problemen die je tegenkomt in je leven (acceptance), terwijl je actie onderneemt op basis van je waarden (commitment). Het feit dat ACT niet primair gericht is op reductie van psychopathologische symptomen, brengt veranderingen in aard en doel van bijpassende meetinstrumenten met zich mee. Ze beogen in kaart te brengen hoe mensen omgaan met hun klachten en in hoeverre ze vaardig zijn om te blijven investeren in hun eigen leven; dit wordt wel functionele testdiagnostiek genoemd [7].

\section{Methode}

Wij verrichtten een systematische literatuurstudie naar de beschikbare ACTmeetinstrumenten. Daarbij startten we met zoekopdrachten binnen ACT-georiënteerde bronnen: de website van de Association for Contextual Behavioural Science (ACBS; http:// 


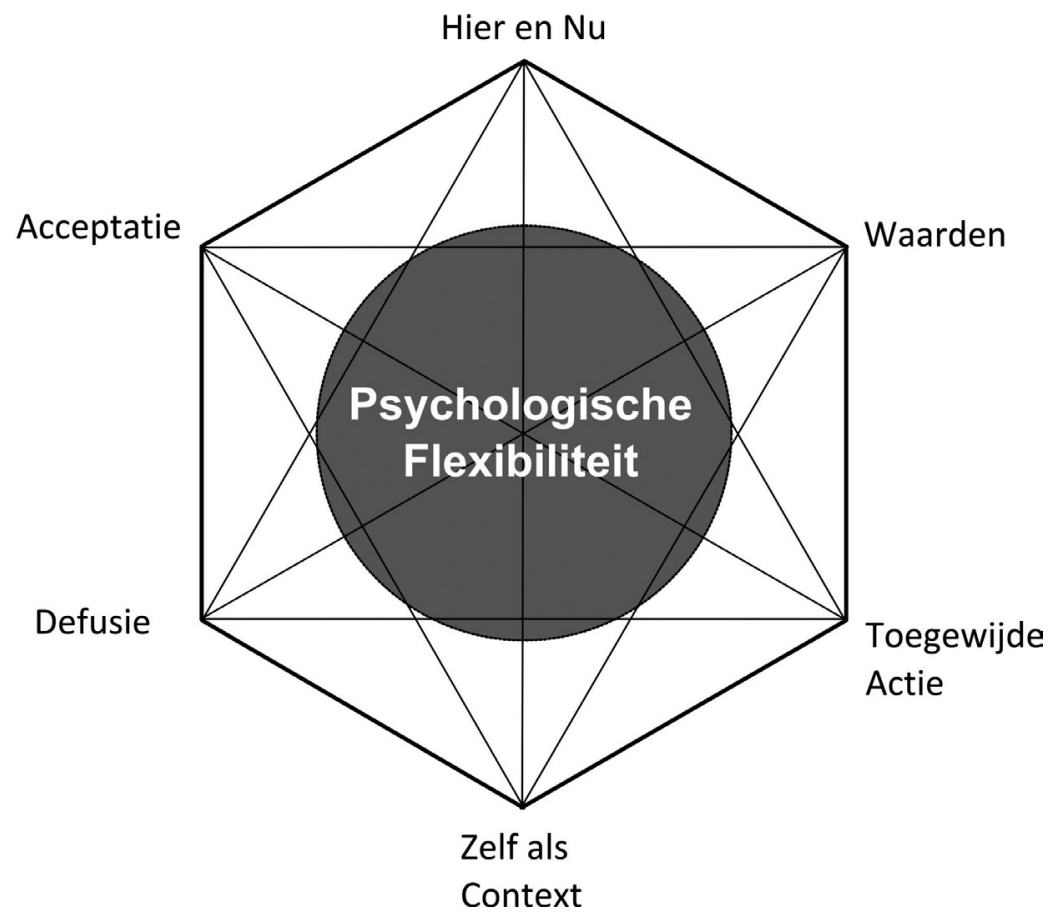

Figuur 1. ACT-hexaflex met de zes kernprocessen.

contextualscience.org), de mailinglijst van de ACBS en Journal of Contextual Behavioural Science. Als zoektermen werden 'questionnaire', 'scale' en 'test' gebruikt. Vervolgens pasten we deze zelfde aanpak toe bij PubMed, met 'acceptance' en 'commitment' als aanvullende zoektermen. Dit resulteerde uiteindelijk in 59 vragenlijsten (in februari 2015). In dit artikel zullen we eerst voor elk ACT-proces het geschiktste meetinstrument beschrijven, op basis van beschikbare vertaling, psychometrische kwaliteit en populariteit. Vervolgens geven we een overzicht van alternatieve meetinstrumenten voor de kernprocessen en meetinstrumenten die zijn ontwikkeld voor specifieke doelgroepen (zie Tabel 1). Alle besproken instrumenten zijn vrij beschikbaar. In de bijlage vindt u een alfabetisch overzicht van de meetinstrumenten met bijbehorende referentie.

\section{Resultaten}

\section{Acceptance and Action Questionnaire - Acceptatie}

De Acceptance and Action Questionnaire (AAQ-II, [8]) is een zelfrapportagevragenlijst die de mate van acceptatie en experiëntiële vermijding in kaart brengt. De AAQ-II bestaat uit 7 stellingen, waarbij men op een 7-puntslikertschaal kan aangeven in hoeverre deze van toepassing zijn. Hoe hoger de totaalscore, hoe lager de acceptatie en hoe hoger de 
experiëntiële vermijding. De AAQ-II heeft geen officiële normgroepen, er zijn echter wel voor 6 steekproeven normatieve data bekend (gemiddelde en sd [8]). De vragenlijst is vertaald naar het Nederlands en gevalideerd door Jacobs e.a. [9]. De psychometrische kwaliteiten van de Nederlandse vertaling van de AAQ-II zijn goed met een interne betrouwbaarheid van 0,87 en een constructvaliditeit van $-0,67$ tot $-0,79$ op onderdrukking en psychische klachten $[9,10,11]$.

\section{Cognitive Fusion Questionnaire - Defusie}

De Cognitive Fusion Questionnaire (CFQ, [12]) is een zelfrapportagevragenlijst die de mate van fusie met gedachten in kaart brengt. De CFQ bestaat uit 13 stellingen, waarbij men op een 7-puntslikertschaal kan aangeven in hoeverre deze van toepassing zijn. Hoe hoger de totaalscore, hoe meer gefuseerd iemand is met zijn gedachten. De CFQ heeft geen officiële normgroepen, er zijn echter wel voor 5 steekproeven normatieve data bekend [12]. De psychometrische kwaliteiten van de CFQ zijn uitstekend; een zeer goede interne betrouwbaarheid en een goede test-hertestbetrouwbaarheid en validiteit is geïllustreerd via voorspelde relaties met andere relevante constructen [12]. De CFQ is door Batink en De Mey vertaald naar het Nederlands [13]. De in kaart gebrachte initiële psychometrische kwaliteiten van de Nederlandse vertaling van de CFQ zijn voldoende: de interne betrouwbaarheid $(0,80)$ en de convergente validiteit met piekeren $(0,65)$ zijn goed. De recentste versie van de CFQ bestaat niet meer uit 13, maar uit 7 items [12], maar deze is nog niet beschikbaar in het Nederlands.

Tabel 1. Overzicht beschikbare ACT-meetinstrumenten per ACT-proces en per specifieke doelgroep.

\begin{tabular}{ll}
\hline Aandachtsgebied & Geschikte ACT-meetinstrumenten \\
\hline ACT-processen & \\
Acceptatie & AAQ-II, MEAQ, BEAQ, FIT-60. \\
Defusie & CFQ, ATQ-F\&B, BAFT, DDS, FIT-60. \\
Zelf als Context & SACS, EQ, SCS, FIT-60. \\
Hier en Nu & FFMQ-SF, FFMQ, MAAS, KIMS, FMI, TMS, CAMS-R, PHLMS, SMQ, \\
& SMS, FIT-60. \\
Waarden & VLQ, PVQ-2, BEVS, VQ, ELS, FIT-60. \\
Toegewijde Actie & ELS, FIT-60. \\
Psychologische Flexibiliteit & FIT-60, AAQ-II. \\
Specifieke doelgroepen & \\
Varianten van de AAQ & FAAQ (Eten), AAQ-W (Gewicht), CVD-AAQ (Hart en Vaatziekten), \\
& BI-AAQ (Body Image), AADQ (Diabetes), IBSAAQ (Prikkelbare Darm \\
& Syndroom), MSAQ (MS), TAQ (Tinnitus), AAQ-ABI (Hersenletsel), \\
& AAQEpQ (Epilepsie), AAQ-SA (Verslaving), AIS (Roken), SA-AAQ \\
& (Sociale Angst), SAB \& AAQ-S (Stigma), VAAS (Stemmen Horen), \\
& WAAQ (Werk), AAQ-TTM (Trichotillomanie). \\
CPAQ, CPVI, PIPS, BPRI, CAQ, AAQ-II-P, PAAQ. & AFQ-Y, PAAQ, CAMM, PPF, EACQ, PPAQ, PPFQ. \\
Cinderen, Adolescenten \& Ouders & BIBS (Body Image). \\
\hline
\end{tabular}




\section{Self as Context Scale - Zelf als context}

De Self as Context Scale (SACS, [14]) is een zelfrapportagevragenlijst die in kaart brengt in hoeverre iemand een basisgevoel van het zelf (transcendente zelf) heeft dat verder gaat dan zijn zelfbeeld. De SACS bestaat uit 11 stellingen, waarbij men op een 7-puntslikertschaal kan aangeven in hoeverre deze van toepassing zijn. Hoe hoger de totaalscore, hoe minder iemand zijn identiteit baseert op zijn zelfbeeld, en hoe stabieler het basisgevoel van het zelf aanwezig is. De SACS heeft geen officiële normering, maar heeft wel beschrijvende data voor een steekproef studenten [14]. Er is nog maar beperkte informatie beschikbaar over de psychometrische kwaliteiten van de SACS; de initiële resultaten lijken goede interne betrouwbaarheid en redelijke convergente validiteit met spiritualiteit aan te tonen. De vragenlijst is nog in ontwikkeling en is op dit moment alleen verkrijgbaar door deze op te vragen bij de auteurs. Er is een Nederlandse vertaling van de SACS beschikbaar [15].

\section{Five-Facet Mindfulness Questionnaire Short-Form - Contact met het hier en nu}

De Five-Facet Mindfulness Questionnaire Short-Form (FFMQ-SF, [16]) is een Nederlandse zelfrapportagevragenlijst die mindfulness meet: het vermogen om de aandacht te kunnen richten op het huidige moment. De FFMQ-SF bestaat uit 24 items, die vijf facetten van mindfulness meten, namelijk: observeren, beschrijven, bewust handelen, niet-oordelen en non-reactief zijn. Men kan op een 5-puntslikertschaal aangeven in hoeverre deze items van toepassing zijn. Hoe hoger de totaalscore, hoe meer mindful iemand in het leven staat. De FFMQ-SF heeft geen officiële normering, er zijn echter wel beschrijvende data beschikbaar voor een groep patiënten met chronische pijn. De psychometrische kwaliteiten van de FFMQ-SF zijn voldoende; het is een betrouwbaar $(a, 0,75-0,87)$ en valide instrument om mindfulness te beoordelen. De FFMQ is overigens niet specifiek ontwikkeld voor het gebruik bij ACT; deze komt uit het mindfulness-onderzoek. Dit instrument lijkt echter wel geschikt voor het in kaart brengen van het ACT-component contact met het hier en nu.

\section{Valued Living Questionnaire - Waarden}

De Valued Living Questionnaire (VLQ, [17]) is een zelfrapportagevragenlijst die in kaart brengt welke levensgebieden belangrijk zijn voor iemand en in hoeverre deze persoon daadwerkelijk investeert in deze gebieden. De VLQ bestaat uit 10 levensgebieden, waarbij iemand eerst voor elk levensgebied met een cijfer van 0-10 dient aan te geven hoe belangrijk dat waardegebied voor hem of haar is. Vervolgens moet men voor deze zelfde waardegebieden met een cijfer aangeven hoe consistent men hier afgelopen week daadwerkelijk naar heeft gehandeld. De VLQ heeft geen totaalscore: het doel van de vragenlijst is dat de patiënt de balans opmaakt voor zichzelf en ziet waar de grootste discrepanties zijn; het is een kwalitatief instrument voor de klinische praktijk. De psychometrische eigenschappen van de VLQ zijn onderzocht en uit initiële resultaten is er steun gevonden voor de elementaire psychometrische kwaliteiten [18]. De interne betrouwbaarheid was goed $(0,77)$, de constructvaliditeit met kwaliteit van leven was matig. Een Nederlandse versie van de VLQ is beschikbaar [19]. 


\section{Engaged Living Scale - Waarden en toegewijd handelen}

De Engaged Living Scale (ELS, [20]) is een Nederlandse zelfrapportagevragenlijst die waarden en toegewijd handelen in kaart brengt, gebundeld als: betrokken actie. De ELS bestaat uit 16 stellingen waar men op een 5-puntslikertschaal kan aangeven in hoeverre deze van toepassing zijn. Naast een totaalscore (betrokken leven) geeft de ELS ook nog twee subschaalscores: waardevol leven (waarden) en levensvervulling (toegewijd handelen). Hoe hoger de totaalscore, hoe meer iemand zijn of haar leven invult op basis van zijn of haar waarden. De ELS heeft twee officiële normgroepen beschikbaar (niet-klinische groep en patiënten met chronische pijn) om de totaalscore te kunnen interpreteren. De psychometrische kwaliteiten van de ELS zijn ook onderzocht: zowel de totaalschaal als de twee subschalen toonden goede interne betrouwbaarheid (tussen 0,87 en 0,91). Ook de constructvaliditeit blijkt te voldoen: de convergente validiteit met psychologisch welzijn was rond de 0,50. De ELS blijkt dus een valide en betrouwbare maat te zijn [20].

\section{Flexibiliteits Index Test (FIT-60) - Psychologische flexibiliteit}

De Flexibiliteits Index Test (FIT-60, [21]) is een Nederlandse zelfrapportagevragenlijst die psychologische flexibiliteit, en de 6 verschillende ACT-processen (acceptatie, defusie, zelf als context, hier en nu, waarden, toegewijd handelen) in kaart brengt. De FIT-60 bestaat uit

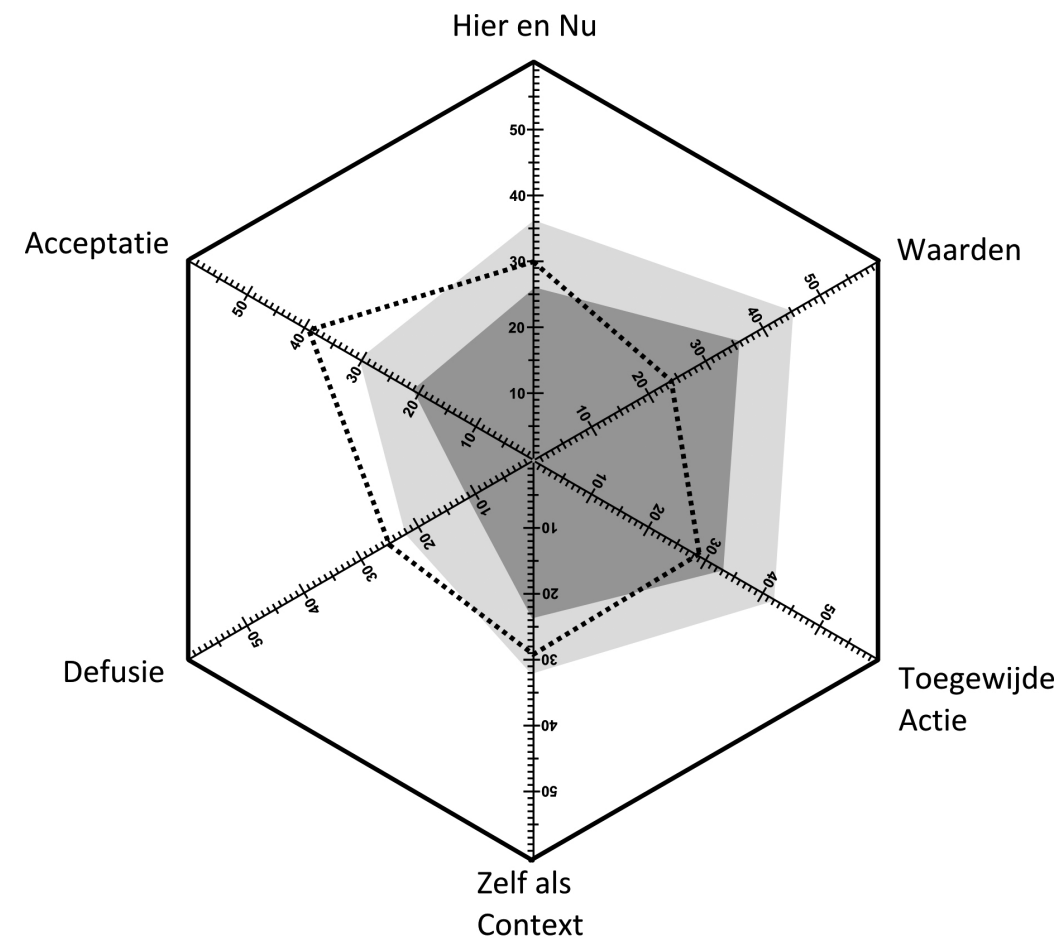

Figuur 2. Persoonlijk flexibiliteitsprofiel (stippellijn), vergeleken met algemene normgroep. 
60 items, met elk een 7-puntslikertschaal. De uitslag van de FIT bestaat dan ook zowel uit een totaalscore voor psychologische flexibiliteit alsook een score voor elk van de 6 ACTsubschalen. De scoring van de FIT-60 kan zowel met de hand, alsook met een geautomatiseerd Excel-formulier worden gedaan. De scores kunnen vervolgens grafisch worden weergegeven in een persoonlijk flexibiliteitsprofiel (zie Figuur 2). Hogere scores wijzen op grote flexibiliteit en grotere ACT-vaardigheden bij de proefpersoon. Voor de FIT-60 zijn gegevens over vier verschillende normgroepen beschikbaar: een studentenpopulatie, een algemene populatie, ambulante patiënten en klinische patiënten. De psychometrische kwaliteiten van de FIT-60 zijn goed. De interne betrouwbaarheid van de subschaalscores en totaalscore varieerde tussen 0,69 en 0,95 , de test-hertestbetrouwbaarheid van deze schalen varieerde van 0,75 tot 0,89 . De resultaten wat betreft de validiteit zijn eveneens bemoedigend; er is sprake van redelijk tot zeer goede convergente constructvaliditeit (tussen 0,39 en 0,91). Ten slotte kan men met de FIT-60 de toename van ACT-vaardigheden over de tijd meten [21]. De vragenlijst is gratis te downloaden op de website www.hoeflexibelbenjij.nl.

\section{Alternatieve ACT-meetinstrumenten}

Naast de in het voorgaande beschreven lijsten zijn er ook andere ACT-meetinstrumenten voorhanden die bruikbaar kunnen zijn voor de inventarisatie van de verschillende ACTcomponenten. De Multidimensional Experiential Avoidance Questionnaire (MEAQ) is een alternatieve vragenlijst om experiëntiële vermijding, de tegenpool van acceptatie, in kaart te brengen [22]. Hier is tevens een verkorte versie van beschikbaar: de Brief Experiential Avoidance Questionnaire (BEAQ, [23]). De Automatic Thought Questionnaire (ATQ-F\&B) is een vragenlijst die de frequentie en geloofwaardigheid van gedachten in kaart kan brengen [24]. De Believability of Anxious Feelings and Thoughts Questionnaire (BAFT, [25]) en de Drexel Defusion Scale (DDS, [26]) zijn beide meetinstrumenten die cognitieve fusie in kaart brengen. De Experiences Questionnaire (EQ, [27]) is een instrument waarmee men 'het observerende zelf' in kaart kan brengen. Een andere gerelateerde maat is de Self Compassion Scale van Kirsten Neff (SCS, [28]). De Mindful Attention Awareness Scale (MAAS, [29]), de Kentucky Inventory of Mindfulness Skills (KIMS, [30]), de Freiburg Mindfulness Inventory (FMI, [31]), de Toronto Mindfulness Scale (TMS, [32]), de Cognitive and Affective Mindfulness Scale (CAMS-R, [33]), de Philadelphia Mindfulness Scale (PHLMS, [34]), de Southampton Mindfulness Questionnaire (SMQ, [35]) en de State Mindfulness Scale (SMS, [36]) zijn alternatieve meetinstrumenten voor het in kaart brengen van contact met het hier en nu. De Personal Values Questionnaire (PVQ-2, [37]), de Bull's-Eye Values Survey (BEVS, [38]), en de Valuing Questionnaire (VQ, [39]) zijn ten slotte nog drie alternatieve maten voor het in kaart brengen van de waarden van een patiënt. Helaas is het merendeel van deze alternatieve lijsten nog niet vertaald naar het Nederlands. Er zijn ten slotte ook ACTmeetinstrumenten voor specifieke doelgroepen, waaronder meer dan 15 stoornisspecifieke varianten van de AAQ. Opvallend is dat er op het gebied van somatische aandoeningen en voor kinderen en adolescenten veel specifieke vragenlijsten zijn ontwikkeld. Bespreking van deze instrumenten valt buiten het bereik van dit artikel, maar ze zijn voor de volledigheid van het overzicht wel opgenomen in Tabel 1. 


\section{Conclusie}

Er zijn voor clinici en onderzoekers met interesse in ACT vele meetinstrumenten voorhanden; echter, er zijn maar enkele instrumenten naar het Nederlands vertaald en onderzocht op psychometrische kwaliteiten. De AAQ-II (acceptatie), CFQ (defusie), FFMQ-SF (hier en nu), VLQ (waarden), ELS (handelen) en de FIT-60 (psychologische flexibiliteit) beschikken over adequate psychometrische kwaliteiten. Hoewel blijkt dat de initiële psychometrische kwaliteiten van de SACS (zelf als context) voldoende zijn, is aanvullend onderzoek nodig. Het is dan ook raadzaam deze gevalideerde lijsten te gebruiken in praktijk en onderzoek. 


\section{Literatuur}

1. Hayes, S. C., Strosahl, K. D., \& Wilson, K. G. (1999). Acceptance and Commitment Therapy: An Experiental Approach to Behavioural Change. New York: The Guilford Press.

2. SAMHSA's National Registry of Evidencebased Programs and Practices (2014, Oktober). Acceptance and Commitment Therapy. http://www.nrepp.samhsa.gov/ ViewIntervention.aspx?id=191

3. Society of Clinical Psychology, American Psychological Association, Division 12 (2014, Oktober). Psychological Treatments. http://www.div12.org/ PsychologicalTreatments/

4. A-Tjak, J. G. L., Davis, M. L., Morina, N., Powers, M. B., Smits, J. A. J., \& Emmelkamp, P. M. G. (2015). A metaanalysis of the efficacy of acceptance and commitment therapy for clinically relevant mental and physical health problems. Psychotherapy and Psychosomatics, 84, 30-36.

5. Groot, F. de, Morrens, M., \& Dom, G. (2014). Acceptance and commitment therapy (ACT) en verslaving: een literatuuroverzicht. Tijdschrift voor Psychiatrie, 56, 577-585.

6. Hayes, S. C., Strosahl, K. D., \& Wilson, K. G. (2012). Acceptance and commitment therapy: The process and practice of mindful change (2de druk). New York: The Guilford Press.

7. Jansen, G., \& Batink, T. (2014). Time to ACT!: Het basisboek voor professionals. Zaltbommel: Uitgeverij Thema.

8. Bond, F. W., Hayes, S. C., Baer, R. A., Carpenter, K. C., Guenole, N., \& Orcutt, H. K., Waltz, T., \& Zettle, R. D. (2011). Preliminary psychometric properties of the Acceptance and Action Questionnaire - II: A revised measure of psychological flexibility and acceptance. Behavior Therapy, 42, 676-688.

9. Jacobs, N., Kleen, M., De Groot, F., \&A-Tjak, J. (2008). Het meten van experiëntiële vermijding: De Nederlandstalige versie van de Acceptance and Action Questionnaire-II (AAQ-II). Gedragstherapie, 41, 349-361.

10. Bernaerts, I., De Groot, F., \& Kleen, M. (2014). De AAQ-II (Acceptance and Action Questionnaire-II), een maat voor experiëntiële vermijding: normering bij jongeren. Gedragstherapie, 45, 389-399.

11. Fledderus, M., Oude Voshaar, M. A., ten Klooster, P. M., \& Bohlmeijer, E. T. (2012). Further evaluation of the psychometric properties of the Acceptance and Action Questionnaire-II. Psychological Assessment, 24, 925-936.

12. Gillanders, D. T., Bolderston, H., Bond, F. W., Dempster, M., Flaxman, P.E., Campbell, L., Kerr, S., Tansey, L., Noel, P., Ferenbach, C., Masley, S., Roach, L., Lloyd, J., May, L., Clarke, S., \& Remington, B. (2014). The development and initial validation of The Cognitive Fusion Questionnaire. Behavior Therapy, 45, 83-101.

13. Batink, T., \& De Mey, H. R. A. (2011). Cognitive Fusion Questionnaire (CFQ13): Dutch Translation and adaptation. Unpublished Manuscript.

14. Gird, S. R., Zettle, R. D., Webster, B. K., \& HardageBundy, A. (2012, July). Developing a Quantitative Measure of Self-as-Context: Preliminary Findings. In R. D. Zettle (Chair), Sizing up Selfing: Efforts to Assess Self-asContext. Symposium conducted at the ACBS World Conference X, Washington.

15. Damme S, Van., Prins, B., \& Leroy, H. (2012). Dutch translation of the Self-As-Context Scale (SACS-DV). Unpublished Manuscript.

16. Bohlmeijer, E. T., Ten Klooster, P. M., Fledderus, M., Veehof, M. M., \& Baer, R. (2011). Psychometric properties of the Five Facet Mindfulness Questionnaire in depressed adults and development of a short form. Assessment, 18, 308-320.

17. Wilson, K. G., \& Murrell, A. R. (2004). Values work in acceptance and commitment therapy: Setting a course for behavioral treatment. In S. C. Hayes, V. M. Follette, M. M. Linehan (Eds). Mindfulness and acceptance: Expanding the cognitive behavioral tradition (pp. 120-151). New York: Guilford Press.

18. Wilson, K. G., Sandoz, E. K., Kitchens, J., \& Roberts, M. E. (2010). The Valued Living Questionnaire: Defining and measuring valued action within a behavioral framework. Psychological Record, 60, 249-272.

19. Hayes, S. C., Strosahl, K. D., \& Wilson, K. G. (2006). ACT, een experientiele weg naar gedragsverandering. Amsterdam: Harcourt Book Publishers.

20. Trompetter, H. R., ten Klooster, P. M., Schreurs, K. M. G., Fledderus, M., Westerhof, G. J., \& Bohlmeijer, E. T. (2013). Measuring values and committed action with the Engaged Living Scale (ELS): Psychometric evaluation in a nonclinical and chronic pain sample. Psychological Assessment, 25, 1235-1246.

21. Batink, T., Jansen, G., \& De Mey, H. R. A. (2012). De Flexibiliteits Index Test (FIT-60): Een beknopte beschrijving. GZ-Psychologie, 5, 18-21.

22. Gámez, W., Chmielewski, M., Kotov, R., Ruggero, C., \& Watson, D. (2011). Development of a measure of experiential avoidance: the Multidimensional Experiential Avoidance Questionnaire. Psychological Assessment, 23, 692-713.

23. Gámez, W., Chmielewski, M., Kotov, R., Ruggero, C., Suzuki, N., \& Watson, D. (2014). The Brief Experiential Avoidance Questionnaire: development and initial validation. Psychological Assessment, 26, 35-45.

24. Zettle, R. D., \& Hayes, S. C. (1986). Dysfunctional control by client verbal behavior: The context of reason giving. The Analysis of Verbal Behavior, 4, 30-38.

25. Herzberg, K. N., Sheppard, S. C., Forsyth, J. P., Credé, M., Earleywine, M., \& Eifert, G.H. (2012). The Believability of Anxious Feelings and Thoughts Questionnaire (BAFT): a psychometric evaluation of cognitive fusion in a nonclinical and highly anxious community sample. Psychological Assessment, 24, 877 891. 
26. Forman, E. M., Herbert, J. D., Juarascio, A. S., Yeomans, P. D., Zebell, J. A., Goetter, E. M., \& Moitra, E. (2012). The Drexel defusion scale: A new measure of experiential distancing. Journal of Contextual Behavioral Science, 1, 55-65.

27. Fresco, D. M., Moore, M. T., van Dulmen, M. H., Segal, Z. V., Ma, S. H., Teasdale, J. D., \& Williams, J. M. (2007). Initial psychometric properties of the experiences questionnaire: validation of a self-report measure of decentering. Behavior Therapy, 38, 234-46.

28. Neff, K. D. (2003). The development and validation of a scale to measure self-compassion. Self and Identity, 2, 223-250.

29. Brown, K. W., \& Ryan, R. M. (2003). The benefits of being present: Mindfulness and its role in psychological well-being. Journal of Personality and Social Psychology, 84, 822-848.

30. Baer, R. A., Smith, G. T., \& Allen, K. B. (2004). Assessment of mindfulness by self-report: The Kentucky Inventory of Mindfulness Skills. Assessment, 11, 191-206.

31. Walach, H., Buchheld, N., Buttenmüller, V., Kleinknecht, N., \& Schmidt, S. (2006). Measuring mindfulness the Freiburg Mindfulness Inventory (FMI). Personality and Individual Differences, 40, 1543-1555.

32. Lau, M. A., Bishop, S. R., Segal, Z. V., Buis, T., Anderson, N. D., Carlson, L., Shapiro, S., Carmody, J., Abbey, S., \& Devins, G. (2006). The Toronto Mindfulness Scale: development and validation. Journal of Clinical Psychology, 62, 1445-1467.

33. Feldman, G., Hayes, A., Kumar, S., Greeson, J., \& Laurenceau, J. (2007). Mindfulness and emotion regulation: The development and initial validation of the Cognitive and Affective Mindfulness Scale-revised (CAMS-R). Journal of Psychopathology and Behavioral Assessment, 29, 177-190.

34. Cardaciotto, L., Herbert, J. D., Forman, E. M., Moitra, E., \& Farrow, V. (2008). The assessment of presentmoment awareness and acceptance: the Philadelphia Mindfulness Scale. Assessment, 15, 204-223.

35. Chadwick, P., Hember, M., Symes, J., Peters, E., Kuipers, E., \& Dagnan, D. (2008). Responding mindfully to unpleasant thoughts and images: reliability and validity of the Southampton Mindfulness Questionnaire (SMQ). British Journal of Clinical Psychology, 47, 451-455.

36. Tanay, G., \& Bernstein, A. (2013). State mindfulness scale (SMS): Development and initial validation. Psychological Assessment, 25, 1286-1299.

37. Blackledge, T., Ciarrochi, J., \& Bailey, A. (2010). Personal Values Questionnaire II. Unpublished Manuscript.

38. Lundgren, T., Luoma, J.B., Dahl, J., Strosahl, K., \& Melin, L. (2012). The Bull's-Eye Values Survey: A Psychometric Evaluation. Cognitive and Behavioral Practice, 19, 518-526.

39. Smout, M., Davies, M., Burns, N., \& Christie, A. (2014). Development of the Valuing Questionnaire (VQ). Journal of Contextual Behavioral Science, 3, 164-172.

40. Gregg, J. A., Callaghan, G. M., Hayes, S. C., \& Glenn-Lawson, J. L. (2007). Improving diabetes self-management through acceptance, mindfulness, and values: a randomized controlled trial. Journal of Consulting and Clinical Psychology, 75, 336-343.

41. Sylvester, M. (2011). Acceptance and commitment therapy for improving adaptive functioning in persons with a history of pediatric acquired brain injury. (Doctoral Dissertation, University of Nevada). Retrieved from http://gradworks.umi.com/34/72/3472789.html

42. Lundgren, T., Dahl, J., \& Hayes, S. C. (2008). Evaluation of mediators of change in the treatment of epilepsy with acceptance and commitment therapy. Journal of Behavioral Medicine, 31, 225-235.

43. Reneman, M. F., Kleen, M., Trompetter, H. R., Schiphorst, H. R., Köke, A., van Baalen, B., \& Schreurs, K. M. (2014). Measuring avoidance of pain: validation of the Acceptance and Action Questionnaire II-pain version. International Journal of Rehabilitation Research, 37, 125-129.

44. Levin, M. E., Luoma, J. B., Lillis, J., Hayes, S. C., \& Vilardaga, R. (2014). The Acceptance and Action Questionnaire - Stigma (AAQ-S): Developing a measure of psychological flexibility with stigmatizing thoughts. Journal of Contextual Behavioral Science, 3, 21-26.

45. Luoma, J. B., Drake, C., Hayes, S. C., \& Kohlenberg, B. (2011). Substance Abuse and Psychological Flexibility: The Development of a New Measure. Addiction Research and Theory, 19, 3-13.

46. Houghton, D. C., Compton, S. N., Twohig, M. P., Saunders, S. M., Franklin, M. E., Neal-Barnett, A. M., Ely, L., Capriotti, M. R., \& Woods, D. W. (2014). Measuring the role of psychological inflexibility in Trichotillomania. Psychiatry Research, 220, 356-361.

47. Lillis, J., \& Hayes, S. C. (2008). Measuring avoidance and inflexibility in weight related problems. International Journal of Behavioral Consultation and Therapy, 4, 348-354.

48. Greco, L. A., Lambert, W., \& Baer, R. A. (2008). Psychological inflexibility in childhood and adolescence: Development and evaluation of the Avoidance and Fusion Questionnaire for Youth. Psychological Assessment, 20, 93-102.

49. Gifford, E. V., Kohlenberg, B. S., Hayes, S. C., Antonuccio, D. O., Piasecki, M. M., Rasmussen-Hall, M. L., \& Palm, K. M. (2004). Acceptance-based treatment for smoking cessation. Behavior Therapy, 35, 689-705.

50. Sandoz, E. K., Wilson, K. G., Merwin, R. M., \& Kellum, K. K. (2013). Assessment of body image flexibility: The Body Image-Acceptance and Action Questionnaire. Journal of Contextual Behavioral Science, 2, 39-48. 
51. Callaghan, G. M., Sandoz, E. K., Darrow, S. M., \& Feeney, T. K. (2015). The Body Image Psychological Inflexibility Scale: Development and psychometric properties. Psychiatry Research, 226, 45-52.

52. McCracken, L. M., Vowles, K. E., \& Zhao-O'Brien, J. (2010). Further development of an instrument to assess psychological flexibility in people with chronic pain. Journal of Behavioral Medicine, 33, 346-354.

53. Greco, L. A., Baer, R. A., \& Smith, G. T. (2011). Assessing mindfulness in children and adolescents: development and validation of the Child and Adolescent Mindfulness Measure (CAMM). Psychological Assessment, 23, 606-614.

54. McCracken, L.M. (2013). Committed action: An application of the Psychological Flexibility Model to activity patterns in chronic pain. The Journal of Pain, 14, 828-835.

55. Spatola, C. A., Cappella, E. A., Goodwin, C. L., Baruffi, M., Malfatto, G., Facchini, M., Castelnuovo, G., Manzoni, G. M., \& Molinari, E. (2014). Development and initial validation of the Cardiovascular Disease Acceptance and Action Questionnaire (CVD-AAQ) in an Italian sample of cardiac patients. Frontiers in Psychology, 5, 1284.

56. McCracken, L. M., Vowles, K. E., \& Eccleston, C. (2004). Acceptance of chronic pain: Component analysis and a revised assessment method. Pain, 107, 159-166.

57. McCracken, L. M., \& Yang, S. Y. (2006). The role of values in a contextual cognitive-behavioral approach to chronic pain. Pain, 123, 137-145.

58. Losada, A., Márquez-González, M., Romero-Moreno, R., \& López, J. (2014). Development and validation of the Experiential Avoidance in Caregiving Questionnaire (EACQ). Aging \& Mental Health, 18, 897-904.

59. Juarascio, A., Forman, E., Timko, C. A., Butryn, M., \& Goodwin, C. (2011). The development and validation of the food craving acceptance and action questionnaire (FAAQ). Eating Behaviors, 12, 182-187.

60. Wallace, D. P., McCracken, L. M., Weiss, K. E., Harbeck-Weber, C.,T. (2015). The role of parent psychological flexibility in relation to adolescent chronic pain: further instrument development. The Journal of Pain,16, 235-246.

61. Ferreira, N. B., Eugenicos, M. P., Morris, P. G., \& Gillanders, D. T. (2013). Measuring acceptance in irritable bowel syndrome: preliminary validation of an adapted scale and construct utility. Quality of Life Research, 22, 1761-1766.

62. Pakenham, K.I., \& Fleming, M. (2011). Relations between acceptance of multiple sclerosis and positive and negative adjustments. Psychology \& Health, 26, 1292-1309.

63. Cheron, D. M., Ehrenreich, J. T., \& Pincus, D. B. (2009). Assessment of parental experiential avoidance in a clinical sample of children with anxiety disorders. Child Psychiatry \& Human Development, 40, 383-403.

64. Butryn, M. L., Arigo, D., Raggio, G. A., Kaufman, A. I., Kerrigan, S. G., \& Forman, E. M. (2015). Measuring the ability to tolerate activityrelated discomfort: initial validation of the Physical Activity Acceptance Questionnaire (PAAQ). Journal of Physical Activity and Health, 12, 717-716.

65. Burke, K., \& Moore, S. (2015). Development of the Parental Psychological Flexibility Questionnaire. Child Psychiatry \& Human Development, 46, 548-557.

66. Wallace, D. P., McCracken, L. M., Weiss, K. E., \& Harbeck-Weber, C. (2015). The role of parent psychological flexibility in relation to adolescent chronic pain: further instrument development. The Journal of Pain, 16, 235-246.

67. Wicksell, R. K., Renöfält, J., Olsson, G. L., Bond, F. W., \& Melin, L. (2008). Avoidance and cognitive fusion central components in pain related disability? Development and preliminary validation of the Psychological Inflexibility in Pain Scale (PIPS). European Journal of Pain, 12, 491-500.

68. Smith, A. M., Sieberg, C. B., Odell, S., Randall, E., \& Simons, L. E. (2015). Living Life with My Child's Pain: The Parent Pain Acceptance Questionnaire (PPAQ). The Clinical Journal of Pain, 31, 633-641.

69. Hayes, S. C., Bissett, R., Roget, N., Padilla, M., Kohlenberg, B. S., Fisher, G., Masuda, A., Pistorello, J., Rye, A. K., Berry, K., \& Niccolls, R. (2004). The impact of acceptance and commitment training and multicultural training on the stigmatizing attitudes and professional burnout of substance abuse counselors. Behavior Therapy, 35, 821-835.

70. MacKenzie, M. B., \& Kocovski, N. L. (2010). Self-reported acceptance of social anxiety symptoms: Development and validation of the Social Anxiety - Acceptance and Action Questionnaire. International Journal of Behavioral Consultation and Therapy, 6, 214-232.

71. Weise, C., Kleinstäuber, M., Hesser, H., Westin, V. Z., \& Andersson, G. (2013). Acceptance of Tinnitus: Validation of the Tinnitus Acceptance Questionnaire. Cognitive Behaviour Therapy, 42, 100-115.

72. Shawyer, F., Ratcliff, K., Mackinnon, A., Farhall, J., Hayes, S. C., \& Copolov, D. (2007). The voices acceptance and action scale (VAAS): Pilot data. Journal of Clinical Psychology, 63, 593-606.

73. Bond, F. W., Lloyd, J., \& Guenole, N. (2014). The work-related acceptance and action questionnaire (WAAQ): Initial psychometric findings and their implications for measuring psychological flexibility in specific contexts. Journal of Occupational and Organizational Psychology, 86, 331-347. 
Bijlage. Overzicht ACT- meetinstrumenten met referenties.

\begin{tabular}{|c|c|c|c|}
\hline Vragenlijst & Referentie & Vragenlijst & Referentie \\
\hline AADQ & Gregg e.a. [40] & FFMQ & Bohlmeijer e.a. [16] \\
\hline AAQ-ABI & Sylvester [41] & FFMQ-SF & Bohlmeijer e.a. [16] \\
\hline AAQEpQ & Lundgren e.a. [42] & FIT-60 & Batink e.a. [21] \\
\hline AAQ-II & Bond e.a. [8] & FMI & Wallace e.a. [60] \\
\hline AAQ-II-P & Reneman e.a. [43] & IBSAAQ & Ferreira e.a. [61] \\
\hline AAQ-S & Levin e.a. [44] & KIMS & Baer e.a. [30] \\
\hline AAQ-SA & Luoma e.a. [45] & MAAS & Brown e.a. [29] \\
\hline AAQ-TTM & Houghton e.a. [46] & MEAQ & Gámez e.a. [22] \\
\hline AAQ-W & Lillis en Hayes [47] & MSAQ & Pakenham en Fleming [62] \\
\hline AFQ-Y & Greco e.a. [48] & PAAQ & Cheron e.a. [63] \\
\hline AIS & Gifford e.a. [49] & PAAQ & Butryn e.a. [64] \\
\hline ATQ-F\&B & Zettle e.a. [24] & PPF & Burke en Moore [65] \\
\hline BAFT & Herzberg e.a. [25] & PPFQ & Wallace e.a. [66] \\
\hline BEAQ & Gámez e.a. [23] & PHLMS & Cardaciotto e.a. [34] \\
\hline BEVS & Lundgren e.a. [38] & PIPS & Wicksel e.a. [67] \\
\hline BI-AAQ & Sandoz e.a. [50] & PPAQ & Smith e.a. [68] \\
\hline BIBS & Callaghan e.a [51] & PVQ-2 & Blackledge e.a. [37] \\
\hline BPRI & McCracken e.a. 2010 [52] & $\mathrm{SAB}$ & Hayes e.a. [69] \\
\hline CAMM & Greco e.a. 2011 [53] & SA-AAQ & MacKenzie e.a. [70] \\
\hline CAMS-R & Feldman e.a. [33] & SACS & Gird e.a. [14] \\
\hline CAQ & McCracken [54] & SCS & Neff [28] \\
\hline CDV-AAQ & Spatola e.a. [55] & SMS & Tanay en Bernstein [36] \\
\hline CFQ & Gillanders e.a. [12] & SMQ & Chadwick e.a. [35] \\
\hline CPAQ & McCracken e.a. [56] & TAQ & Weise e.a [71] \\
\hline CPVI & McCracken en Yang [57] & TMS & Lau e.a. [32] \\
\hline DDS & Forman e.a. [26] & VAAS & Shawyer e.a. [72] \\
\hline EACQ & Losada e.a. [58] & VLQ & Wilson e.a. [17] \\
\hline ELS & Trompetter e.a. [20] & VQ & Smout e.a. [39] \\
\hline EQ & Fresco e.a. [27] & WAAQ & Bond e.a. [73] \\
\hline FAAQ & Juarascio e.a. [59] & & \\
\hline
\end{tabular}


Nieuwe Generatie Gedragstherapie, Nieuwe Generatie Meetinstrumenten 
Tim Batink ${ }^{1,2}$, Gijs Jansen³, Hubert de Mey ${ }^{4}$

${ }^{1}$ U-center, Epen (L), The Netherlands.

${ }^{2}$ School for Mental Health and Neuroscience, Division 2, Mental Health, Maastricht University, Maastricht, The Netherlands.

3 SeeTrue, Maastricht, The Netherlands.

${ }^{4}$ Klinische psychologie, Radboud Universiteit Nijmegen, Nijmegen, The Netherlands. 


\section{The Flexibility Index Test (FIT-60): A brief description.}

De Flexibiliteits Index Test (FIT-60): Een beknopte beschrijving.

Gepubliceerd: GZ-Psychologie (2012), 5, 18-21. 


\begin{abstract}
Acceptance and Commitment Therapy (ACT) is on the rise in the Netherlands [1]. This form of behavioural therapy concerns itself not directly with the reduction of psychological symptoms but with learning to deal with them more functionally. Since most of the assessment measures are concerned with measuring these symptoms, there is also a need for other psychodiagnostic instruments which chart the functioning of the client. Though a number of specific ACT-questionnaires have already been developed there is no questionnaire available to date for bringing all the components of ACT together in a single test. This is one of the main reasons for developing the Flexibility Index Test (FIT-60). The results of this study show that the FIT-60 features encouraging psychometric properties. The questionnaire is ready-to-use for the clinical practise and is freely available. The FIT-60 can contribute to the choice of therapy focus, as well as to the monitoring of the development of the client during the ACT-therapy.
\end{abstract}




\section{Samenvatting}

Acceptance and Commitment Therapy (ACT) is in opmars in Nederland [1]. Deze vorm van gedragstherapie richt zich niet rechtstreeks op het reduceren van psychische klachten, maar op het functioneel leren omgaan ermee. Omdat de meeste instrumenten gericht zijn op het meten van deze klachten, zijn er ook andere psychodiagnostische instrumenten nodig om het functioneren van de cliënt in kaart te brengen. Hoewel er reeds een aantal specifieke ACT-vragenlijsten zijn ontwikkeld, is er tot op heden nog geen vragenlijst beschikbaar die alle componenten van ACT in één test bij elkaar brengt. Dit is een van de redenen waarom de Flexibiliteits Index Test (FIT-60) is ontwikkeld. Uit de resultaten van deze studie blijkt dat de FIT-60 over bemoedigende psychometrische eigenschappen beschikt. De vragenlijst is gebruiksklaar voor de klinische praktijk en is gratis beschikbaar. De FIT-60 kan bijdragen aan het kiezen van therapiefocus, alsook aan de monitoring van de ontwikkeling van een cliënt gedurende de ACT-therapie. 


\section{Achtergrond}

Acceptance and Commitment Therapy (ACT) is een relatief nieuwe vorm van gedragstherapie die snel terrein wint in Nederland. ACT maakt onderdeel uit van de zogenoemde derde generatie cognitieve gedragstherapieën. Anders dan veel bestaande therapievormen richt ACT zich niet primair op het reduceren van psychische klachten. Veel eerder probeert ACT mensen te leren hoe ze functioneler met die klachten om kunnen gaan. ACT bestaat uit zes kerncomponenten, acceptatie, defusie (afstand nemen van het denken), het zelf, hier en nu, waarden en handelen, die gezamenlijk zorgen voor meer psychologische flexibiliteit. Dit laatste zou je kunnen definiëren als de vaardigheid om op een flexibele manier met de pijn van het leven om te gaan [2].

In 2010 is ACT in de V.S. erkend als evidence based-therapie voor o.a. depressie en chronische pijn (NREPP \& APA). Parallel aan de ontwikkeling van de therapievorm zelf, is er ook een ontwikkeling gaande op het vlak van ACT-diagnostiek. Deze ontwikkelingen gaan echter beduidend trager. Op het moment van schrijven zijn er voor vier van de zes ACTcomponenten vragenlijsten ontwikkeld. Voor acceptatie is de Acceptance and Action Questionnaire (AAQ-2) beschikbaar van Bond et al. [3]; voor defusie de Cognitive Fusion Questionnaire (CFQ-13) van Gillanders et al. [4]; voor hier en nu / mindfulness de Five Facet Mindfulnes Questionnaire (FFMQ) van Baer et al. [5]'; en voor waarden de Valued Living Questionnaire (VLQ-2) van Wilson et al. [6]. Dat betekent dat twee componenten nog niet in kaart kunnen worden gebracht, anders dan via klinische inschatting. Ook is er nog geen algemene ACT-vragenlijst beschikbaar die de zes ACT-componenten als geheel in kaart brengt.

\section{Doel}

Het doel van dit onderzoeksproject is om een klinisch bruikbare ACT-vragenlijst te ontwikkelen, die de zes kerncomponenten goed in beeld brengt en daarmee ook uitspraken kan doen over de psychologische flexibiliteit van cliënten. De focus ligt dus niet op het meten van klachten, maar het registeren van de aanwezigheid van functioneel gedrag binnen de zes verschillende ACT-competenties. Een dergelijk instrument zou kunnen worden ingezet in de klinische praktijk voor het (mede-)bepalen van behandelfoci voor de ACT-therapie, alsook in het bijhouden van de ontwikkelingen op de verschillende ACT-gebieden (voor/ na meting). Tevens zou het instrument een bijdrage kunnen leveren aan toekomstig ACTonderzoek.

\footnotetext{
${ }^{1}$ Niet specifiek voor ACT maar voor MBCT ontwikkeld.
} 


\section{Procedure}

$\mathrm{Na}$ het samenstellen van een itempool van ruim 150 vragen op basis van de ACT-literatuur en reeds beschikbare ACT-vragenlijsten (AAQ-2, de CFQ-13, FFMQ en de VLQ-2) is uit deze pool door de auteurs een eerste selectie gemaakt van 15 items per kerncomponent, die het beste de kernaspecten van elk van deze componenten weergeven. Dit was de basis van de ruwe versie van de Flexibiliteits Index Test met 90 vragen (FIT-90). Vervolgens is deze versie gebruikt in onderzoek met als doel de vragenlijst in te korten tot een 60-items versie, ten behoeve van de afnameduur, om deze vervolgens te onderzoeken op betrouwbaarheid. Ten slotte is deze 60-item versie middels correlationeel onderzoek verder onderzocht op validiteit. De vragenlijst is online afgenomen via de website www.hoeflexibelbenjij.nl. Het onderzoek heeft bij twee onderzoeksgroepen plaatsgevonden; een studentgroep van de Radboud Universiteit Nijmegen (21,8 jaar, 86\% vrouw) en een groep deelnemers van het online traject Leer Loslaten van Psychologie Magazine (42,7 jaar, 90\% vrouw).

\section{Resultaten en Conclusie}

\section{Ontwikkeling Flexibiliteits Index Test (FIT-6o)}

529 studenten van de Radboud Universiteit Nijmegen hebben online de FIT-90 ingevuld. Per ACT-component is een selectie gemaakt van de 10 meest betrouwbare items door de vijf items te verwijderen waarbij de betrouwbaarheid van de schaal substantieel toenam als het item werd verwijderd; zo ontstond de FIT-60. De interne consistentie van de totaalschaal en de subschalen van de FIT-60 werden bepaald op basis van Cronbach's alpha, alsook op basis van de gemiddelde interitem correlatie gezien deze laatste maat minder gevoelig is voor het aantal items. Voor de totaalschaal van psychologische flexibiliteit was Cronbach's alpha .95. Voor de zes subschalen waren deze als volgt: Acceptatie: .84, Defusie: .87, Zelf: .69, Hier en $\mathrm{Nu}$.78, Waarden: .78, Toegewijd Handelen: .84. Deze resultaten vallen in de marge van acceptabele (.70) tot goede ( $>.80$ ) betrouwbaarheid [7]. De gemiddelde inter-item correlatie voor de totaalschaal psychologische flexibiliteit was .22. Voor Acceptatie: .33, Defusie: .42, Zelf: .19, Hier en Nu: .26, Waarden: .28, en Toegewijd Handelen: .34. Ook deze waarden vallen binnen de gewenste marges van $.15-.50$, wat aangeeft dat de items per schaal hetzelfde construct meten [8]. Men kan uit bovenstaande resultaten concluderen dat de interne consistentie van de FIT-60 en haar subschalen acceptabel (met name de subschaal Zelf) tot goed is te noemen. Een exploratieve principale componentenanalyse (PCA) geeft op basis van eigenwaarden 12 factoren (58,5\% verklaarde variantie). Deze hoeveelheid van factoren is mogelijk te verklaren vanuit het feit dat elk ACT-component zelf ook weer bestaat uit verschillende aspecten. Echter deze factoren bleken inhoudelijk moeilijk te relateren aan het 6-factorenmodel van ACT. Uit de visuele inspectie van het screeplot kwam een oplossing van vier factoren naar voren, die wederom moeilijk te relateren was aan het ACT-model. Er is daarom besloten de subschalen apart te onderzoeken op constructvaliditeit. $\mathrm{Er}$ is tevens gekeken naar de onderlinge correlaties van de zes subschalen van de FIT-60. Acceptatie correleert hoog met defusie (.78), het zelf (.65), en hier en nu (.68). Defusie correleert hoog 
met het zelf (.69), en hier en nu (.69). Het cluster van componenten die het acceptatie gedeelte van ACT vormen, blijken onderling sterk samen te hangen. Het commitmentcluster vertoont deze onderlinge samenhang echter niet. Voor deze groep (studenten) zijn tevens de voorlopige normgegevens bepaald, zie Tabel 1 voor meer informatie. De drie scorecategorieën zijn bepaald op basis van de volgende percentielverdeling: 0-29 (lager dan gemiddeld), 30-69 (gemiddeld) en 70-100 (hoger dan gemiddeld).

Tabel 1. Overzicht voorlopige normen voor de twee referentiegroepen; gemiddelde en standaarddeviatie voor de totaalscore en voor de subschaalscores van de FIT-60.

\begin{tabular}{|c|c|c|c|c|c|c|c|}
\hline & Totaal & Acceptatie & Defusie & Zelf & Hier en $\mathrm{Nu}$ & Waarden & Handelen \\
\hline $\begin{array}{l}\text { Referentiegroep } \\
\text { I: Studenten } \\
(N=529)\end{array}$ & $222,6(43,1)$ & $36,3(9,6)$ & $30,4(11,4)$ & $32,0(8,2)$ & $35,8(9,2)$ & $46,7(6,9)$ & $41,3(8,0)$ \\
\hline $\begin{array}{l}\text { Referentiegroep } \\
\text { II: Algemeen } \\
(N=1087)\end{array}$ & $182,8(41,9)$ & $26,3(10,4)$ & $18,2(9,6)$ & $28,0(7,9)$ & $31,3(9,7)$ & $41,3(7,8)$ & $37,8(9,5)$ \\
\hline
\end{tabular}

\section{Vervolgonderzoek psychometrische eigenschappen FIT-6o}

1087 deelnemers aan het online traject 'Leer Loslaten' hebben de FIT-60 ingevuld, samen met de AAQ-2, de CFQ-13 en de MAAS (vragenlijst met als thema hier en nu), als onderdeel van de construct validering. Zie Tabel 2 voor een overzicht van de correlaties van de FITsubschalen met de ACT-vragenlijsten. In het overzicht staan zowel de correlaties van de FIT-subschalen met de corresponderende vragenlijsten vermeld (convergent), als de correlaties van de FIT-subschalen met niet-corresponderende vragenlijsten (divergent). Het bepalen of een lijst correspondeert of juist niet, is gedaan op basis van de scheiding tussen acceptatieprocessen (acceptatie, defusie, zelf, hier en nu) en commitmentprocessen (waarden \& handelen). Uit de correlatiematrix blijkt dat de convergente vragenlijsten matig tot sterk correleren met de corresponderende FIT-subschalen (.39-.91). Tevens blijkt dat de divergente vragenlijsten wel samenhang vertonen met de lijsten, maar wel een beduidend zwakkere $(z=6.99, p=0.000)$; zwak tot matig (.25-.52). Dit komt echter ook overeen met het theoretische paradigma van ACT, namelijk dat alle componenten in verbinding staan met elkaar. Er is dus sprake van redelijk tot goede convergente constructvaliditeit en matig tot redelijke divergente constructvaliditeit. Van de 1.087 participanten hebben 135 deelnemers de volledige online ACT-training doorlopen en daarbij de FIT-60 bij voor- en nameting ingevuld. De gemiddelde scores verschilden van elkaar in de verwachte richting; bij de voormeting scoorde men gemiddeld 184,5 en bij de nameting scoorde men gemiddeld 217,5; men werd dus psychologisch flexibeler. Uit de variantieanalyse bleek dit een significant verschil te zijn $(F(1,268)=36.56, p=0.000)$. Hieruit kan men concluderen dat de FIT gevoelig is voor het in kaart brengen van veranderingen in ACT-vaardigheden in de loop van de tijd. Tevens biedt dit resultaat extra ondersteuning voor de constructvaliditeit van deze test. Tenslotte zijn ook voor deze groep (algemeen) de voorlopige normgegevens bepaald, zie Tabel 1 voor meer informatie. 
Tabel 2. Correlaties van de FIT-schalen met drie verschillende ACT-vragenlijsten $(N=1087)$.

\begin{tabular}{llll}
\hline & & \multicolumn{2}{c}{ ACT-Vragenlijsten } \\
\hline FIT-60 Schalen & AAQ-2 & CFQ-13 & MAAS \\
-Acceptatie & $r=.91 *$ & $r=-.65 *$ & $r=-.42 *$ \\
-Defusie & $r=.74 *$ & $r=-.61 *$ & $r=-.41 *$ \\
-Zelf & $r=.59 *$ & $r=-.60 *$ & $r=-.39 *$ \\
-Hier en Nu & $r=.60 *$ & $r=-.59 *$ & $r=-.52 *$ \\
-Waarden & $r=.52 * *$ & $r=-.41 * *$ & $r=-.25 * *$ \\
-Handelen & $r=.47 * *$ & $r=-.39 * *$ & $r=-.25 * *$ \\
-Totaal & $r=.85 *$ & $r=-.71 *$ & $r=-.50 *$ \\
\hline
\end{tabular}

Noot. Alle correlaties zijn significant $(p<.001)$

* = Corresponderende vragenlijsten.

** = Niet-corresponderende vragenlijsten.

De vetgedrukte cellen geven aan welke vragenlijsten in enge zin corresponderen met de subschalen.

\section{Discussie}

De doelstelling van dit onderzoek was de ontwikkeling van een algemene ACT-vragenlijst die alle zes ACT-componenten in kaart zou kunnen brengen. Het resultaat van dit project is de totstandkoming van de Flexibiliteits Index Test (FIT-60). De FIT-60 is een zelfrapportage vragenlijst die bestaat uit 60 stellingen (10 per subschaal), met elk een 7-punts Likertantwoordschaal $(0=$ helemaal oneens, tot $6=$ helemaal eens). Als uitslag krijgt men zowel een totaalscore van psychologische flexibiliteit (de Flexibiliteits Index Score) alsook een score voor elk van de zes subschalen. Gezien de complexe scoring (randomisering \& omkering van items) wordt bij de FIT-vragenlijst standaard een scoreblad geleverd. Er zijn twee referentiegroepen beschikbaar waarmee men de scores kan interpreteren. De scores kunnen ook grafisch worden ingevuld in een flexibiliteitsprofiel, zie Figuur 1 ter illustratie. Dit profiel geeft in één oogopslag weer waar de sterke en zwakke punten van een cliënt zich bevinden binnen het ACT-hexaflex. Het invullen van de FIT-60 neemt ongeveer 15 minuten in beslag.

De initiële psychometrische kwaliteiten van de FIT-60 zijn bemoedigend; de interne betrouwbaarheid is acceptabel tot goed, en de eerste resultaten met betrekking tot de validiteit zijn eveneens bemoedigend te noemen. Tevens is de FIT-60 in staat tot het meten van de ontwikkeling van ACT-vaardigheden over de tijd heen. Hiermee lijkt de FIT op het eerste gezicht een bruikbaar instrument te zijn voor de klinische praktijk. Verder onderzoek naar de psychometrische kwaliteiten van de FIT-60 is hier echter noodzakelijk. Ook dient de validering verder te worden uitgebreid en moet de test-hertest betrouwbaarheid van de lijst nog worden bepaald. Ten slotte kunnen er ook nog patiënt-normgroepen worden toegevoegd. Een ander punt van aandacht is het feit dat uit de factoranalyse niet de veronderstelde 6 ACT-facetten naar voren kwamen. Dit is mogelijk te verklaren vanuit het feit dat elke ACT-component zelf ook weer bestaat uit verschillende facetten, welke los 
moeilijk te interpreteren zijn. Hoewel de FIT-60 nog verder onderzoek behoeft, is deze wel klaar voor gebruik (met beleid) in de klinische praktijk. De vragenlijst blijft natuurlijk een hulpmiddel. Diagnostiek zou moeten bestaan uit meer dan alleen de afname van een vragenlijst.

De ACT-gemeenschap is een 'open community' die tezamen werkt aan de verdere ontwikkelingen in het veld. Vanuit deze filosofie is er dan ook voor gekozen de FIT-60 gratis beschikbaar te stellen (geen restricties, anders dan dat er geen geld aan mag worden verdiend en dat bovengenoemde auteurs worden vermeld). De vragenlijst is vrij te downloaden op www. hoeflexibelbenjij.nl, of kan per mail worden opgevraagd bij de eerstgenoemde auteur. Tenslotte is het belangrijk dank uit te spreken richting de pioniers van de eerste ACT-vragenlijsten (AAQ-2,CFQ-13 \& VLQ-2), die de ontwikkeling van de FIT-60 mogelijk hebben gemaakt.
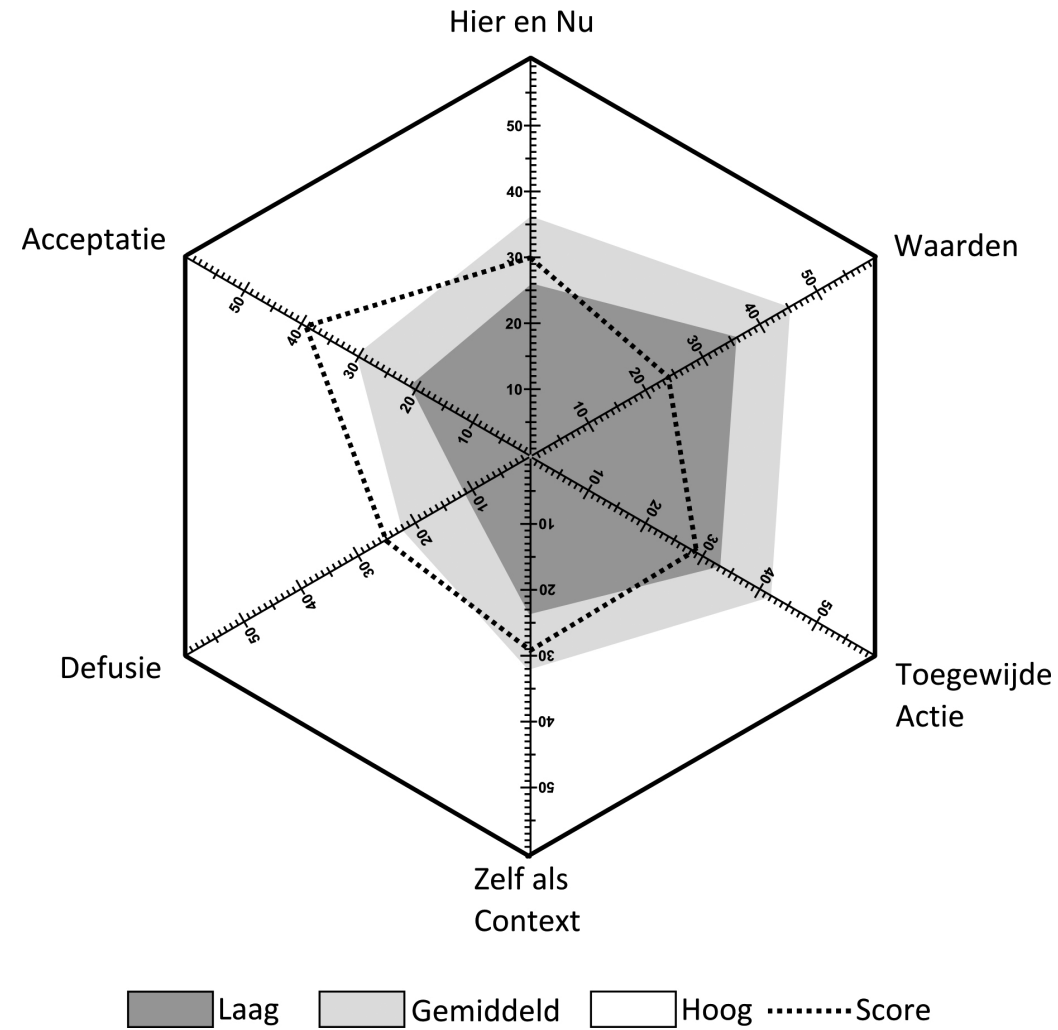

Figuur 1. Grafische weergave van de score op de FIT-60: het Flexibiliteitsprofiel. De gestippelde lijn binnen het hexaflex geeft de score aan van de cliënt op de assen van elk van de zes subschalen. In dit profiel is te zien dat de cliënt hoog scoort op acceptatie en defusie (wit), gemiddeld scoort op het zelf en hier en nu (lichtgrijs), en lager dan gemiddeld scoort op waarden en toegewijd handelen (donkergrijs). De cliëntscore is hier vergeleken met de normgegevens van algemene referentiegroep. 


\section{Literatuur}

1. De Mey, H. R. A. (2007). Acceptance and Commitment Therapy (ACT) in opmars. In A. H. Schene, F. Boer, J. P. C. Jaspers, B. Sabbe \& J. van Weeghel (Eds.), Jaarboek voor Psychiatrie en Psychotherapie 2007-2008 (Vol. 10, pp. 177- 187). Houten: Bohn Stafleu van Loghum.

2. Hayes, S. C., Strosahl, K. D., \& Wilson, K. G. (2011). Acceptance and Commitment Therapy. The Process and Practice of Mindful Change (Second Edition). New York : Guilford Press.

3. Bond, F. W., Hayes, S. C., Baer, R. A., Carpenter, K. M., Guenole, N., Orcutt, H. K., Waltz, T., \& Zettle, R. D. (2011). Preliminary psychometric properties of the Acceptance and Action Questionniare - II: A revised measure of psychological flexibility and experiential avoidance. Behavior Therapy, 42, 676-688.

4. Gillanders, D. T., Bolderston, H., Bond, F. W, Dempster, M., Campbell, L., Kerr, S., Tansey, L., Clarke, S., Remington, B., Flaxman, P. \& Deans, G. (2010). The Cognitive Fusion Questionnaire: Further developments in measuring cognitive fusion. Conference presentation at the Association for Contextual Behavioral Science, World Congress VIII, Reno, NV, Juni 2010. Available to download at: http://contextualpsychology. org/node/4249

5. Baer, R. A., Smith, G. T., Hopkins, J., Krietemeyer, J., \& Toney, L. (2006). Using self-report assessment methods to explore facets of mindfulness. Assessment, 13, 27-45.

6. Wilson, K. G., Sandoz, E. K., Kitchens, J., \& Roberts, M. E. (2010). The Valued Living Questionnaire: Defining and measuring valued action within a behavioral framework. The Psychological Record, 60, 249-272.

7. Cronbach, L. J. (1951). Coefficient alpha and the internal structure of tests. Psychometrika, 16, $297-334$.

8. Clark, L. A., \& Watson, D. (1995). Constructing Validity: Basic Issues in Objective Scale Development. Psychological Assessment, 7, 309-319. 
Tim Batink $k^{1,2}$, Philippe Delespaul1,3

${ }^{1} \mathrm{U}$-center, Epen (L), The Netherlands.

2 School for Mental Health and Neuroscience, Division 2, Mental Health, Maastricht University, Maastricht, The Netherlands.

${ }^{3}$ Integrale Zorg en Psychotische Stoornissen, Mondriaan, Maastricht, The Netherlands. 
hoofdstuk

\section{Measuring Psychological Flexibility: The Flexibility Index Test} (FIT-60)

Meten van psychologische flexibiliteit: De Flexibiliteits Index Test (FIT-60)

Gepubliceerd: Tijdschrift voor Gedragstherapie en Cognitieve Therapie (2014), 4, 310-332 


\section{Abstract}

\section{Background}

The Flexibility Index Test (FIT-60) is developed to measure the application of the theoretical concepts in Acceptance and Commitment Therapy. The current study provides a better understanding of the psychometric properties of the FIT-60 and also aims to develop two additional patient-standard groups.

\section{Method}

Via three substudies test stability, reliability and construct validity of the FIT-60 total scale and its six subscales were investigated.

\section{Results}

The test stability of the FIT-60 was .89 , the subscales ranged from .75 to .85 . The internal consistency of the total scale was .90 , the subscales varied between .51 and .92 . The validation study showed that the FIT-60 and its subscales correlated the highest with the corresponding ACT-measures.

\section{Conclusion}

FIT-60 appears to be a stable, reliable and valid questionnaire that is able to measure change over time. The FIT-60 is able to measure psychological flexibility, as well as charting the six underlying ACT processes. 


\section{Samenvatting}

\section{Achtergrond}

De Flexibiliteits Index Test (FIT-60) is ontwikkeld om de modelgetrouwe toepassing van concepten uit de Acceptance and Commitment Therapy te meten. Het huidige onderzoek biedt meer inzicht in de psychometrische kwaliteiten van de FIT-60 en heeft tevens tot doel twee aanvullende patiëntnormgroepen te ontwikkelen.

\section{Methode}

Middels drie deelonderzoeken zijn de teststabiliteit, betrouwbaarheid en constructvaliditeit van de FIT-60 totaalschaal en zijn zes subschalen onderzocht.

\section{Resultaten}

De teststabiliteit van de FIT-60 was .89, terwijl de subschalen varieerden tussen .75 en .85 . De interne consistentie van de totaalschaal was .90 , terwijl die van de subschalen fluctueerde tussen .51 en .92. Uit validatieonderzoek bleek dat de FIT-60 en zijn subschalen het hoogste correleerden met de corresponderende ACT-maten.

\section{Conclusie}

De FIT-60 blijkt een stabiele, betrouwbare en valide vragenlijst, die in staat is verandering over tijd te meten. De FIT-60 is in staat zowel psychologische flexibiliteit als de zes onderliggende ACT-processen in kaart brengen. 


\section{Inleiding}

De curatieve GGZ richt zich op klachtreductie. Klachten worden gezien als abnormaal, en zorg en behandeling moeten bestaan uit interventies om klachten te reduceren [1]. Toch heeft 38\% van de Europese bevolking op jaarbasis last van deze psychische klachten [2]. Ze kunnen daarom moeilijk als 'abnormaal' gezien worden. Moderne interventies als ACT richten zich op het functioneel leren omgaan met klachten. De derde generatie gedragstherapie verschuift de aandacht van symptomen naar functioneren. Acceptance and Commitment Therapy (ACT) is een van de therapievormen binnen deze stroming. Ze gaat ervan uit dat menselijk leed ontstaat uit normale psychologische processen die horen bij het leven [3]. Bij ACT staat de psychologische flexibiliteit om functioneel te leren omgaan met klachten (functionele vaardigheden, c.q. coping) centraal. Deze psychologische flexibiliteit zorgt ervoor dat iemand zich bewust is van zijn ervaringen op het moment zonder ermee in worsteling te raken. Dit biedt ruimte om te blijven investeren in de dingen die echt belangrijk voor hem zijn. ACT richt zich op zes processen die een rol spelen bij psychologische flexibiliteit en vaak in een hexagoon voorgesteld worden (figuur 1). De zes kernprocessen zijn:

Acceptatie: Ruimte maken voor vervelende emoties, gedachten en gewaarwordingen, in plaats van deze proberen te controleren.

Defusie: Gedachten leren zien voor wat ze zijn, niet als waarheden waarnaar gehandeld moet worden (fusie) maar als producten van het verstand.

Zelf als Context: lemand is meer dan alleen zijn gedachten, gevoelens en zelfbeeld; er is ook nog het observerende zelf dat dit waarneemt.

Hier en Nu: Aandacht hebben voor wat er op dit moment te ervaren is, in plaats van een preoccupatie met het verleden of de toekomst.

Waarden: Stilstaan bij de dingen die iemand als persoon echt belangrijk vindt: zijn waarden. Toegewijd Handelen: Het eigen gedrag in de gewenste richting aanpassen: handelen naar eigen waarden.

De verschuiving in de behandelfocus van ACT vraagt een andere vorm van diagnostiek. In plaats van klachtinventarisatie en classificatie, dient er functionele diagnostiek ontwikkeld te worden die de strategieën die iemand gebruikt om met de problemen die hij tegenkomt om te gaan in kaart brengt [4]. Vanuit dit kader is de Flexibiliteits Index Test (FIT- 60) ontwikkeld. De FIT-60 is een zelfrapportagevragenlijst die de functionele kernprocessen van ACT in kaart brengt [5]. De FIT-60 bestaat uit 60 items, die op een zevenpunts Likertschaal worden gescoord ( 0 = helemaal oneens, $6=$ helemaal eens). De FIT-60 totaalscore weerspiegelt de psychologische flexibiliteit van een individu. Zes subschalen (Acceptatie, Defusie, Zelf als Context, Hier en Nu, Waarden, en Toegewijd Handelen) brengen specifieke processen uit de ACT-theorie in kaart. ledere subschaal bevat 10 items. De minimale score op een subschaal is 0 , de maximale score is 60 . Voor de totaalschaal is het minimum eveneens 0 , en het maximum 360. Hoe hoger iemand scoort, hoe meer men de ACTvaardigheid beheerst. Gezien de complexe scoring (randomisering en omkering van items) 


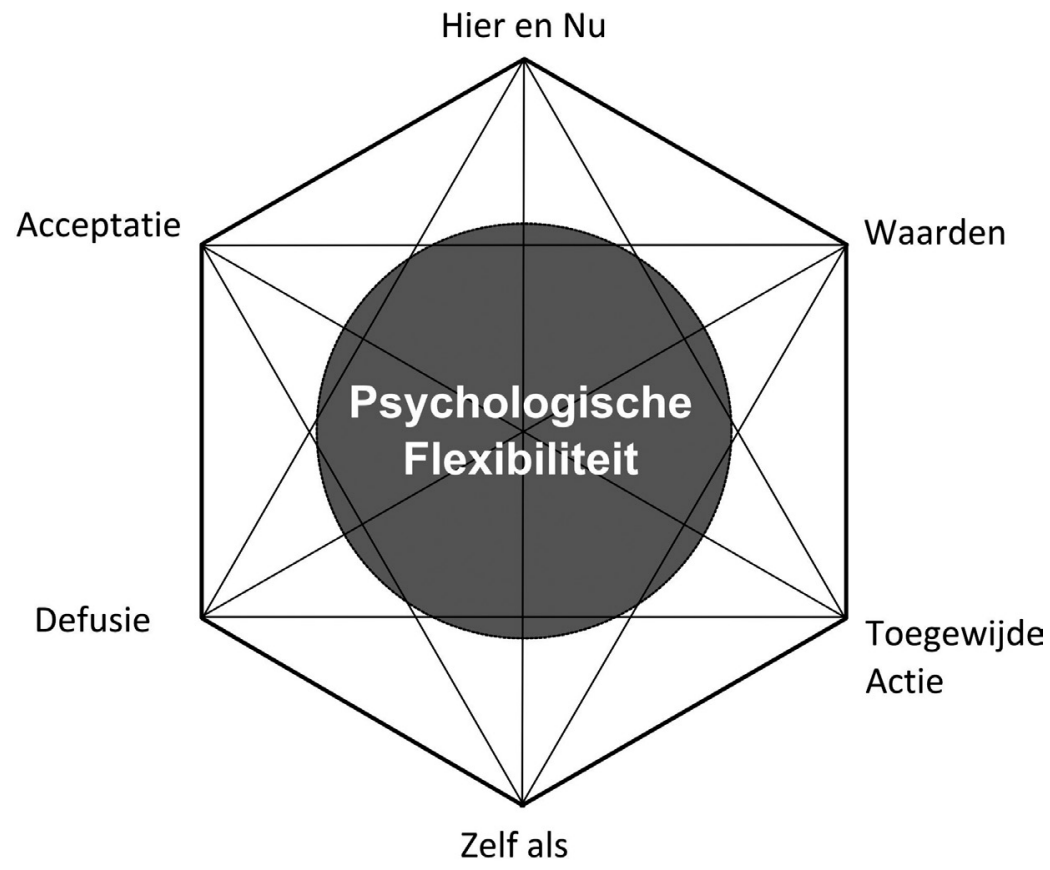

Context

Figuur 1. ACT-hexaflex: zes processen die een rol spelen bij psychologische flexibiliteit.

wordt bij de FIT-vragenlijst standaard een scoreblad geleverd. Tevens is er een zelfscorend Excelformulier beschikbaar. De scores van de FIT-60 kunnen vervolgens worden vergeleken met twee normgroepen (algemene populatie en studenten) en zijn tevens visueel weer te geven in het flexibiliteitsprofiel (zie figuur 2).

Het flexibiliteitsprofiel maakt in één oogopslag duidelijk waar de sterke punten en de aandachtspunten van de patiënt liggen, mede door de visuele normering die in het profiel is opgenomen. Tevens is een ipsatieve of profielvergelijking mogelijk. De FIT-60 is gratis beschikbaar op de website www.hoeflexibelbenjij.nl, zowel als download (pdf) als in een online versie (geschikt voor pc en tablet). De FIT-60 is ontwikkeld voor volwassenen (18-75 jaar) en vraagt 15 minuten afnametijd. Een vertaling naar het Engels is in ontwikkeling. De ontwikkeling en de initiële psychometrische kwaliteiten van de FIT- 60 zijn elders beschreven [5]. De psychometrische kenmerken zijn bemoedigend. De interne consistentie is acceptabel tot uitstekend ( $a=.69-.95)$, en dat geldt ook voor de eerste resultaten met betrekking tot de validiteit $(r=.42-.91)$. De FIT-60 lijkt in staat de ontwikkeling van ACT-vaardigheden over de tijd heen te meten. Vervolgonderzoek is echter noodzakelijk, aangezien de totaalschaal Psychologische Flexibiliteit, alsook drie van de zes subschalen (Zelf als Context, Waarden, en Toegewijd Handelen) nog niet zijn gevalideerd. Ook is er nog geen informatie bekend over de test-hertestbetrouwbaarheid van de FIT-60. Er zijn ijkingsgegevens van twee 


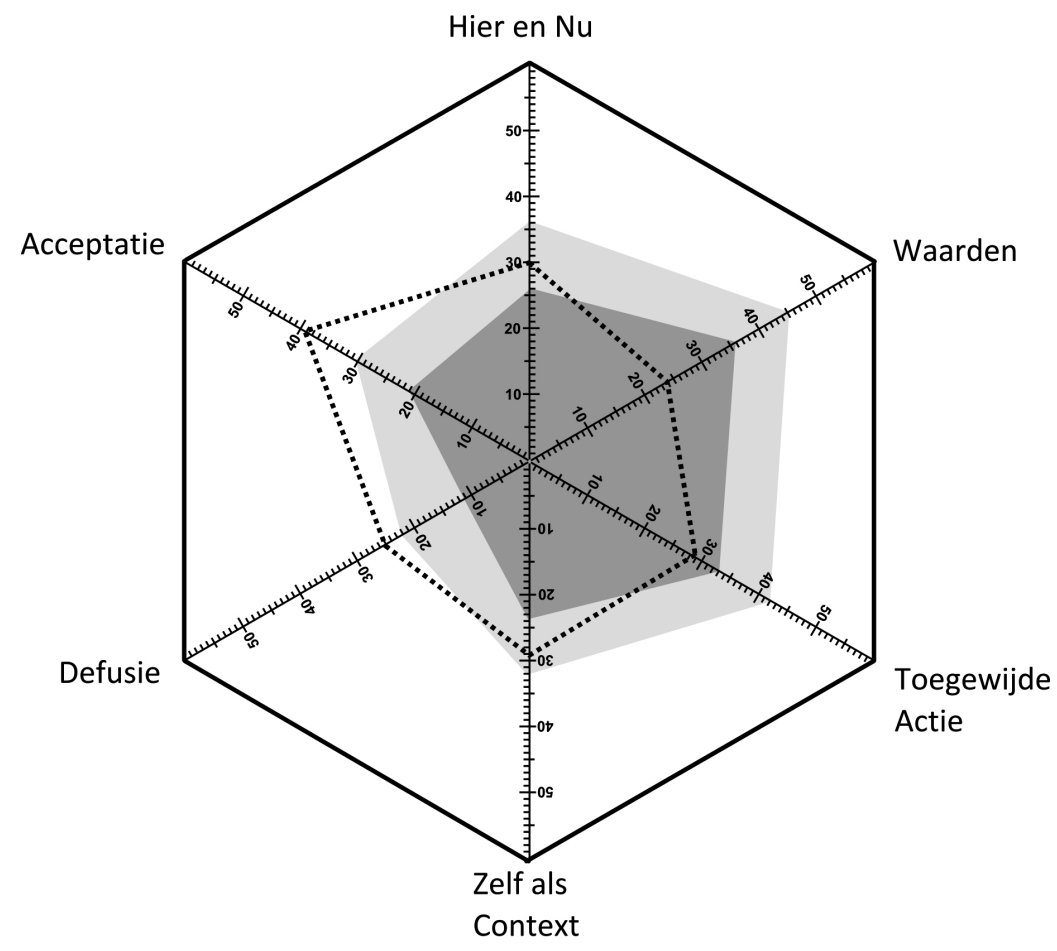

Figuur 2. Flexibiliteitsprofiel.

referentiegroepen beschikbaar (algemene populatie en studenten), maar nog niet voor patiënten. Ten slotte is er nog niets bekend over het effect van verschillende demografische variabelen op de test. Hier rapporteren we bijkomende evidentie van de validiteit en betrouwbaarheid van de FIT-60 en patiëntreferentiegegevens (ambulant en klinisch). De FIT-60 meet zes verschillende ACT-processen, met psychologische flexibiliteit als overkoepelende noemer. De zes ACT-processen zijn theoretisch te onderscheiden, maar wel met elkaar vervlochten. Elke ACT-component bestaat uit onderliggende thema's, die eveneens in kaart worden gebracht. Om de itemset beknopt te houden zijn er geen dubbele items in de lijst opgenomen. Dit resulteert in een instrument dat middels factoranalyse moeilijk te valideren is. Daarom wordt voor de strategie van de externe validatie gekozen. Middels convergente vragenlijsten worden de constructen post hoc gevalideerd. Deze strategie lag aan de basis van de ontwikkeling van de vragenlijst. Het huidige onderzoek bouwt hier op voort. Dit artikel bevat drie deelonderzoeken: (1) test-hertestbetrouwbaarheid en constructvaliditeit bij een groep van ACT-therapeuten ( $n=73)$; (2) interne consistentie, constructvaliditeit en vaststelling van een klinische normgroep $(n=414)$; en ten slotte (3) interne consistentie en ontwikkeling van een ambulante normgroep ( $n=674)$. De studieprocedure is goedgekeurd door de Ethische Commissie Psychologie (ECP) van Maastricht University (werd niet WMO-plichtig bevonden), en alle proefpersonen hebben 
een toestemmingsformulier ondertekend. De verwachting is dat de FIT-60 en zijn subschalen convergeert met de ACT-lijsten die vergelijkbare constructen meten. Tevens is de verwachting dat de FIT-60 een negatieve samenhang laat zien met de vermijdende en passieve copingsstijlen, aangezien de ACT-vaardigheden juist het doorbreken van deze coping beogen. Ten slotte wordt verwacht dat de FIT-60 negatief zal samenhangen met klachten, en positief zal samenhangen met kwaliteit van leven. Uit eerder onderzoek bleek dat de FIT-60 in staat was verandering te meten; de verwachting is dat de FIT-60 dezelfde resultaten in deze populatie zal laten zien.

ONDERZOEK 1

\section{Teststabiliteit en validiteit}

\section{Deelnemers}

De deelnemers aan deze studie $(n=73)$ zijn geworven onder een groep professionals (coaches, counselors, psychologen en psychiaters) die een zesdaagse geaccrediteerde ACTopleiding hebben gevolgd en met succes hebben afgerond (inclusiecriterium). De gemiddelde leeftijd was 47,4 jaar $(S D=9,5)$, en van hen was $82,2 \%$ vrouw en $17,8 \%$ man. Het opleidingsniveau varieerde tussen hoger beroepsonderwijs $(57,5 \%)$ en wetenschappelijk onderwijs (42,5\%).

\section{Meetinstrumenten Demografische vragenlijst}

Bij aanvang van de testafname werd er gevraagd naar leeftijd, geslacht en opleidingsniveau van de deelnemers. Tevens werd genoteerd of de ACT-opleiding succesvol was afgerond.

\section{Flexibiliteits Index Test (FIT-60)}

De FIT-60 is een zelfrapportagevragenlijst met 60 zevenpunts Likert-items. De FIT-60 meet psychologische flexibiliteit: het vermogen om flexibel om te kunnen gaan met psychische problemen. Tevens bepaalt de FIT-60 ook de positie van een individu op zes onderliggende ACT-componenten: acceptatie, defusie, zelf als context, hier en nu, waarden, en toegewijd handelen [5]. Penn State Worry Questionnaire (PSWQ) - De PSWQ [6] brengt piekeren in kaart op basis van 16 stellingen, welke op een vijfpunts Likertschaal worden beoordeeld. We gebruikten de Nederlandse vertaling [7]. Deze heeft een hoge interne betrouwbaarheid en goede test-hertestbetrouwbaarheid [8].

Drexel Defusion Scale (DDS)

De DDS [9] meet de mate van fusie (samenvallen) met het denken (ACT-component Defusie). De DDS bestaat uit 10 zespunts Likert-items. Het instrument werd voor de gelegenheid in het Nederlands vertaald. De DDS heeft een hoge interne betrouwbaarheid en een goede constructvaliditeit [9]. 


\section{Self as Context Scale (SACS)}

De Nederlandse vertaling van de SACS is gebruikt [10] om de gehechtheid aan het zelfconcept en de vaardigheid om zichzelf te kunnen observeren te meten (ACT-component Zelf als Context). De SACS bestaat uit 11 zevenpunts Likert-items. De SACS is nog in ontwikkeling, maar de eerste resultaten tonen aan dat de SACS goede betrouwbaarheid en discriminatieve validiteit heeft [11].

Kentucky Inventory of Mindfulness Skills (KIMS)

De KIMS [12] is een 39 items tellende zelfrapportage die gebruikt is om mindfulnessvaardigheden te meten (ACT-component Hier en Nu). Deze vragenlijst heeft de volgende vier subschalen: Observeren, Beschrijven, Aandachtig handelen en Toelaten zonder oordelen. De Nederlandse versie van de KIMS heeft goede psychometrische eigenschappen [13].

\section{Engaged Living Scale (ELS)}

De ELS bestaat uit 16 items die in kaart brengen hoe iemand zijn leven invult op basis van waarden (ACT-componenten Waarden en Toegewijde actie). De vragenlijst heeft twee subschalen: Waardengericht Leven en Vervuld leven. De ELS is een valide en betrouwbaar instrument om waardegericht gedrag te meten [14].

\section{Valued Living Questionnaire (VLQ)}

De Nederlandse vertaling van een aangepaste versie van de VLQ is gebruikt [15], om waardegericht leven te meten (ACT-component Waarden). Voor elk van de 12 levensgebieden wordt gevraagd om op een tienpunts schaal ( 1 = helemaal niet in balans, $10=$ helemaal in balans) aan te geven in hoeverre dit gebied in balans is qua belang en tijdsinvestering. De VLQ [16] heeft een goede interne betrouwbaarheid en een matige contructvaliditeit [17].

\section{World Health Organization Quality of Life (WHOQOL-BREF)}

De Nederlandse, verkorte versie van de WHOQOL [18] is afgenomen om de kwaliteit van leven te bepalen. De WHOQOL is een zelfrapportagevragenlijst die bestaat uit 26 items waarop via een vijfpunts Likertschaal kan worden geantwoord [19]. De WHOQOL geeft tevens op vier subschalen een uitslag over subdomeinen van de kwaliteit van leven: fysiologisch, psychologisch, sociaal en omgeving. De betrouwbaarheid van de WHOQOL is goed tot uitstekend en de validiteit is voldoende [20].

\section{Procedure}

De werving is medio januari 2014 gestart en duurde tot medio februari 2014. Ouddeelnemers aan een geaccrediteerde ACT-opleiding (+/- 250) hebben via e-mail een uitnodiging gekregen vrijblijvend deel te nemen aan een online vragenlijstonderzoek ter ondersteuning van de verdere ontwikkeling van de FIT-60. In deze mail was een link opgenomen naar de eerste meting, die online werd aangeboden via het open source vragenlijstenplatform LimeSurvey (gehost op een eigen server). Deze link bleef een week geldig om de vragenlijsten in te kunnen vullen. Een week na het verlopen van de eerste meting werd een tweede link gestuurd naar de deelnemers die de eerste meting hadden 
ingevuld. Ook deze link bleef een week geldig. Bij meting 1 werd demografische informatie verzameld en de FIT-60 afgenomen. Bij meting 2 werd wederom de FIT-60, alsook de PSWQ, DDS, SACS, KIMS, ELS, VLQ en de WHOQOL-BREF afgenomen. Hiermee werd de (test-hertest) betrouwbaarheid en de validiteit van de FIT-60 bepaald. Als incentive werd bij het volledig invullen van het eerste meetmoment toegang tot 50 ACT-illustraties verschaft en kregen de deelnemers bij het volledig invullen van het tweede meetmoment een mp3-cd met twaalf geleide ACT-oefeningen.

\section{Statistische analyse}

Voor beide meetmomenten werd gekeken naar de interne consistentie van de FIT-60. Tevens is de test-hertestbetrouwbaarheid berekend, om zo de stabiliteit van de FIT-60 te bepalen. Daarnaast werd de constructvaliditeit van de FIT-60 beschreven aan de hand van verschillende convergente ACTvragenlijsten. De sterkte van de Pearson-correlatiecoëfficiënt werd bepaald op basis van de uitgebreide classificatie van Evans [21]: .80 is een zeer sterke correlatie. De verwachting was dat de FIT-60 convergeert met de ACT-lijsten die vergelijkbare constructen meten (DDS, SACS, KIMS, ELS, VLQ en WHOQOL-BREF) en divergeert met de lijst (PSWQ) die een ander construct meet. De analyses werden gedaan met SPSS 22.0.

\section{Resultaten}

Teststabiliteit

Meetmoment 1 is door 73 deelnemers ingevuld. De interne consistentie (Cronbachs $\alpha$ ) van de FIT-60 voor deze meting was .936 (Acceptatie .809, Defusie .861, Zelf als Context .662, Hier en Nu .827, Waarden .721, en Toegewijd Handelen .812). Van die 73 deelnemers hebben 71 meetmoment 2 ingevuld (97,3\%). De interne consistentie (Cronbachs $\alpha$ ) van de FIT-60 voor dit tweede meetmoment was .954 (Acceptatie .834, Defusie .921, Zelf als Context .750, Hier en Nu .841, Waarden .738, en Toegewijd Handelen .849). Het gemiddelde tijdsinterval tussen T1 en T2 was 13,7 dagen (SD 3,93). Vervolgens is middels een bivariate Pearson-correlatie de test-hertestbetrouwbaarheid van de FIT-60 bepaald, zowel voor de gehele vragenlijst als voor de zes subschalen. Voor de totaalschaal Psychologische Flexibiliteit was de test-hertestbetrouwbaarheid $r=.894(p<.001)$. Voor de subschalen waren deze als volgt: Acceptatie $r=.838(p<.001)$; Defusie $r=.793(p<.001)$; Zelf als Context $r=.821(p<.001)$; Hier en Nu $r=.856(p<.001)$; Waarden $r=.753(p<.001)$; en Toegewijd Handelen $r=.842(p<.001)$.

\section{Validiteit}

Meetmoment 2 is door 71 deelnemers ingevuld. Naast de FIT- 60 is hier een aantal convergente vragenlijsten afgenomen (en één divergente) om de constructvaliditeit van de FIT-60 nader te bepalen (zie tabel 1 voor een overzicht van de Pearson-correlaties). Aangezien er 77 correlaties zijn bepaald ( 7 schalen $\times 11$ maten), is het significantieniveau aangepast middels de Bonferroni-correctie $(p=.05 / 77=.0006494)$. De subschaal Acceptatie heeft een sterke correlatie met KIMS-accept $(r=.717, p<.0005)$. De subschaal Defusie heeft een sterke correlatie op de PSWQ $(r=-.759, p<.0005)$ en een matige correlatie op de DDS $(r=.520, p$ $<.0005)$. De subschaal Zelf als Context heeft een matige correlatie op de SACS $(r=.432, p$ 
$<$.0005). De subschaal betreffende het Hier en Nu heeft een zeer sterke correlatie op de KIMS-totaal $(r=.811, p<.0005)$, een sterke correlatie met KIMS-describe $(r=.689, p<.0005)$, en een zwakke, niet significante correlatie met KIMS-observe $(r=.377, p=.001)$. De subschaal Waarden heeft een sterke correlatie op de ELS $(r=.733, p<.0005)$ en een sterke correlatie met de VLQ $(r=.606, p<.0005)$. De subschaal Toegewijd Handelen heeft een sterke correlatie op de ELS ( $r=.751, p<.0005)$. Ten slotte heeft de totaalschaal Psychologische Flexibiliteit een sterke correlatie met de WHOQOL $(r=.690, p<.0005)$. Omdat een aantal FIT-60 subschalen hoog correleren met verschillende vragenlijsten, zijn tevens de partiële Pearsoncorrelaties van de FIT-60 subschalen met deze verschillende maten bepaald (en eenzijdig getoetst) om zo de unieke relatie per subschaal te kunnen bepalen. Vervolgens is onderzocht hoeveel vragenlijsten het hoogst correleerden met de verwachte subschaal. Voor de PSWQ, KIMS-totaal, KIMS-Observe, KIMS-describe, KIMS-aware, ELS, VLQ en de WHOQOL was dit het geval (8 van de 11 maten). Uit de Fisher Z-transformatie bleek dat dit een significante afwijking van de verhouding was op basis van kansniveau $(Z=-3.04, p<.002)$.

\section{Discussie}

Uit de resultaten blijkt dat de interne betrouwbaarheid van de totaalschaal psychologische flexibiliteit van de FIT-60 zeer hoog is en stabiel blijft voor de verschillende testmomenten. Voor de zes subschalen is eenzelfde trend te zien. Tevens blijkt de FIT-60 over een hoge testhertestbetrouwbaarheid te beschikken voor zowel de subschalen als de totaalschaal. Ook is er aanvullende steun gevonden voor de constructvaliditeit van vijf van de zes subschalen (Acceptatie, Defusie, Hier en Nu, Waarden, en Toegewijd Handelen), alsook de totaalschaal Psychologische Flexibiliteit. De subschaal Zelf als Context liet een matige samenhang zien met het gerelateerde construct (hoewel de vragenlijst waarmee dit construct zelf in kaart wordt gebracht, de SACS, nog niet goed onderzocht is op betrouwbaarheid en validiteit). Ten slotte is er op modelniveau aangetoond dat deze gedemonstreerde samenhang met gerelateerde constructen niet verklaard kan worden als kansbevinding. Een beperking van dit deelonderzoek is dat bij deze sample met ACT-therapeuten protoprofessionalisering een rol kan hebben gespeeld bij het beantwoorden van de vragen (niet vanuit ervaring en vaardigheid, maar vanuit theoretische kennis over ACT). 
Tabel 1. Correlaties van de FIT-60-totaal en haar subschalen met verschillenden ACT-vragenlijsten (de vet weergeven getallen zijn de cellen waar volgens de theorie een fit (hoge correlatie) verwacht werd) $(n=71)$.

\begin{tabular}{lccccccc}
\hline & Acceptatie & Defusie & $\begin{array}{c}\text { Zelf als } \\
\text { Context }\end{array}$ & Hier en Nu & Waarden & \multicolumn{2}{c}{$\begin{array}{c}\text { Toegewijd Flexibiliteit } \\
\text { Handelen }\end{array}$} \\
\hline PSWQ & -.649 &. .759 & -.635 & -.491 & -.418 & $-.354^{*}$ & -.695 \\
DDS & .502 & .520 & .475 & .542 & .422 & .434 & .592 \\
SACS & .502 & .408 & .432 & .485 & .502 & $.351^{*}$ & .536 \\
KIMS-Totaal & .710 & .620 & .597 & .811 & .471 & .607 & .780 \\
KIMS-Observe & $.202^{*}$ & $.079^{*}$ & $.246^{*}$ & $.377^{*}$ & $.180^{*}$ & $.259^{*}$ & $.263^{*}$ \\
KIMS-Describe & .436 & $.295^{*}$ & $.306^{*}$ & .689 & $.301^{*}$ & .439 & .496 \\
KIMS-Aware & .524 & .405 & $.367^{*}$ & .517 & $.378^{*}$ & .608 & .562 \\
KIMS-Accept & .717 & .836 & .657 & .610 & .401 & $.326^{*}$ & .752 \\
ELS & .729 & .542 & .573 & .606 & .733 & .751 & .777 \\
VLQ & .442 & .438 & $.303^{*}$ & $.388^{*}$ & .606 & .463 & .521 \\
WHOQOL & .637 & .593 & .486 & .478 & .671 & .583 & .690 \\
\hline
\end{tabular}

PSWQ, Penn State Worry Questionnaire; DDS, Drexel Defusion Scale; SACS, Self as Context Scale; KIMS, Kentucky Inventory of Mindfulness Skills; ELS, Engaged Living Scale; VLQ, Valued Living Questionnaire; WHOQOL-BREF, World Health Organization Quality of Life.

Noot. Alle correlaties zijn significant op $p=.0005495$ niveau.

* Niet significant.

\section{ONDERZOEK 2}

\section{Betrouwbaarheid, validiteit en klinische normering}

\section{Deelnemers}

De deelnemers aan deze studie $(n=414)$ zijn geworven in het U-center, een breedspectrumkliniek voor mensen met psychische problemen in Epen (Zuid-Limburg). De behandeling is vrijwillig en klinisch, en duurt zeven weken. De verdeling van de hoofddiagnose voor opname was als volgt: stemming $(40,1 \%)$, angst $(12,5 \%)$, somatoform $(10,5 \%)$, middelen $(32,3 \%)$ en overig (4,6\%). De gemiddelde leeftijd van de patiënten was 45,43 jaar (SD 12,55), $51,0 \%$ was man en $49,0 \%$ was vrouw. Het opleidingsniveau varieerde tussen lager beroepsonderwijs (12,3\%), middelbaar beroepsonderwijs (31,6\%), hoger beroepsonderwijs $(29,5 \%)$ en wetenschappelijk onderwijs $(26,6 \%)$.

\section{Meetinstrumenten}

Demografische vragenlijst

Bij aanvang van de testafname werd er gevraagd naar leeftijd, geslacht en opleidingsniveau van deelnemers. Tevens werd per patiënt de DSM-classificatie geregistreerd.

\section{Flexibiliteits Index Test (FIT-60)}

De FIT-60 is een zelfrapportagevragenlijst die psychologische flexibiliteit meet: in hoeverre iemand flexibel om kan gaan met zijn psychische problemen [5]. Zie onderzoek 1 hierboven voor een uitgebreidere beschrijving van de FIT-60. 


\section{Brief Symptom Inventory (BSI)}

De BSI is de verkorte versie van de SCL-90-R bestaande uit 53 items, die op een vijfpunts Likertschaal worden gescoord [22]. De BSI is een zelfrapportagevragenlijst waarmee bij volwassenen een overzicht verkregen wordt van symptomen van psychopathologie. De BSI inventariseert de aard en de ernst van de klachten op negen dimensies: somatische klachten, cognitieve problemen, interpersoonlijke gevoeligheid, depressieve stemming, angst, hostiliteit, fobische angst, paranoïde gedachten en psychoticisme. De psychometrische kwaliteit van de Nederlandse vertaling van de BSI is goed, net als de interne betrouwbaarheid en de test-hertestbetrouwbaarheid. De begripsvaliditeit en voorspellende power zijn voldoende. Ten slotte is de test gevoelig voor therapie-invloeden [23, 24].

\section{Utrechtse Coping Lijst (UCL)}

De UCL meet copingsgedrag: de manier waarop iemand omgaat met problemen of stressvolle situaties. De UCL bestaat uit 47 items die worden beoordeeld op een vierpuntsschaal: zelden of niet, soms, vaak, en zeer vaak. De UCL geeft een uitslag op zeven schalen: Actief aanpakken, Palliatieve reactie, Vermijden, Sociale steun zoeken, Passief reactiepatroon, Expressie van emoties en Geruststellende gedachten [25]. De interne consistentie van de schalen is matig tot goed. De constructvaliditeit en predictieve validiteit zijn voldoende [26]. Er zijn Nederlandse normgroepen beschikbaar, maar COTAN beschouwt ze als verouderd [27].

\section{Neuroticism-Extroversion-Openness Five-Factor Inventory (NEO-FFI)}

De NEO-FFI is een zelfrapportagevragenlijst naar persoonlijkheid op basis van de big five domeinen: Neuroticisme, Extraversie, Openheid, Altruïsme en Consciëntieusheid [28].De vragenlijst bestaat uit 60 uitspraken waarvan de respondent wordt gevraagd aan te geven in hoeverre de uitspraak voor hem van toepassing is in vijf antwoordmogelijkheden. De NEO-FFI is een verkorte versie van de NEO Personality Inventory (NEO-PIR). De betrouwbaarheid van de NEO-FFI is voldoende. De interne betrouwbaarheid van de domeinschalen varieert van acceptabel tot goed en de stabiliteit van de vragenlijst is hoog. De constructvaliditeit van de Nederlandse vertaling van de NEO-FFI werd bevestigd met factoranalyse, en ook de convergente en divergente validiteit werden aangetoond [29].

\section{Quality of Life - Visual Analog Scale (QOL-VAS)}

De mate van geluk werd gemeten met het Qol-VAS-item: 'Hoe gelukkig voelt u zich op dit moment?', waarbij iemand op een tienpunts VAS-schaal kon aangeven hoe gelukkig hij zich op dat moment voelde. Deze Nederlandse Qol-VAS beschikt over een goede constructvaliditeit [30].

\section{Procedure}

Subjecten werden geïncludeerd tussen november 2012 en april 2014. De patiënten vullen in het kader van Routine Outcome Monitoring (ROM) een vragenlijstenbatterij in via een webbased platform. Middels een informedconsent-formulier werd bij aanvang van opname aan de patiënten gevraagd of deze ROM-gegevens geanonimiseerd gebruikt mochten 
worden voor wetenschappelijk onderzoek. De ROM-batterij bestaat uit een aantal vragenlijsten. Slechts de bovengenoemde lijsten worden in het huidige onderzoek behandeld (demografische vragenlijst, BSI, UCL, NEO-FFI en QoI-VAS). Voor dit onderzoek werd de FIT60 bij de ROM-batterij gevoegd. Alleen de voor- en na-ROM-meting zijn gebruikt voor het huidige onderzoek.

\section{Statistische analyse}

Voor beide meetmomenten werd gekeken naar de interne consistentie van de FIT-60 en naar de relatie met demografische kenmerken. Tevens werd onderzocht in hoeverre de FIT-60 in staat is verandering te meten na een (klinische) interventie. Verder werd de constructvaliditeit van de FIT-60 vastgesteld aan de hand van een aantal veelgebruikte vragenlijsten. De verwachting was dat de FIT-60 een negatieve samenhang laat zien met de vermijdende en passieve copingsstijlen (UCL) en met klachten (BSI) en positief zal samenhangen met kwaliteit van leven (Qol-VAS). Ten slotte werd met deze data een klinische normgroep bepaald. De scorecategorieën werden bepaald op basis van percentielen (0-30 laag, 31-70 midden, 71-100 hoog). De analyses werden gedaan met SPSS 22.0.

\section{Resultaten \\ Beschrijvende informatie}

De FIT-60 is door 414 deelnemers op T1 (voor aanvang van de behandeling) ingevuld en door 333 deelnemers op T2 (na afronding van de klinische interventie). Tabel 2 geeft een overzicht van de gemiddelde scores. Verder worden de verschillen tussen T1 en T2 getoetst op significantie. Hieruit is op te maken dat de FIT-60 gevoelig is voor verandering over de tijd, uitgezonderd de subschaal Waarden, waar mogelijk sprake is van een plafondeffect. In tabel 3 is een overzicht gegeven van de scorecategorieën zoals deze werden bepaald voor deze klinische normgroep.

\section{Demografische variabelen}

$\mathrm{Er}$ is tevens gekeken naar het effect van verschillende demografische variabelen op de scores van de FIT-60 (T1). Leeftijd had een zeer zwakke, significante correlatie met de scores van de FIT-60 ( $r=.182, p<.001)$. Geslacht bleek eveneens een zeer zwakke, significante negatieve correlatie te hebben met de resultaten van de FIT $(r=-.127, p=.01)$. Op basis van de non-parametrische correlatie (Kendalls tau) bleek opleidingsniveau geen correlatie te hebben met de FIT-60 ( $r \tau=.046, p=.217)$.

\section{Betrouwbaarheid}

Ook is er gekeken naar de interne consistentie van de FIT-60 (T1). De Cronbachs alfa was .910 op de totaalschaal Psychologische Flexibiliteit en .617 voor Acceptatie, .828 voor Defusie, .561 voor het Zelf, .755 voor het Hier en Nu, .506 voor Waarden, en .686 voor Toegewijd Handelen. 


\section{Validiteit}

Naast de FIT-60 werden op T1 een aantal conventionele vragenlijsten afgenomen op het gebied van klachten (BSI), kwaliteit van leven (Qol-VAS), coping (UCL) en persoonlijkheid (NEO-FFI). Zij illustreren de convergente en divergente validiteit van de FIT-60 alsook de bruikbaarheid in het klinische veld. Tabel 4 geeft een overzicht van de Pearson-correlaties. Aangezien er 28 confirmatieve correlaties zijn bepaald (7 schalen $\times 4$ maten), is het significantieniveau aangepast middels de Bonferroni-correctie ( $p=.05 / 28=.001786)$. Bij de overige exploratieve correlaties is het niveau op $p=.05$ aangehouden. Uit de confirmatieve correlaties komt naar voren dat de subschaal Acceptatie een matige negatieve correlatie heeft met UCL-passief reageren $(r=-.557, p<.001)$ en een zwakke negatieve correlatie heeft met UCL-vermijden $(r=-.325, p<.001)$. De subschaal Defusie heeft tevens een sterke negatieve correlatie met UCL-passief reageren $(r=-.613, p<.001)$. De subschaal Hier en Nu heeft een zwakke negatieve correlatie met UCL-vermijden $(r=$ -.341, $p<.001)$. Ten slotte heeft de totaalschaal Psychologische Flexibiliteit een sterke negatieve correlatie met de BSI-totaal $(r=-.602, p<.001)$, en een matige positieve relatie met de Qol-VAS $(r=.416, p<.001)$.

Tabel 2. Beschrijvende informatie van de FIT-60 totaal en haar subschalen: Gemiddelde en SD van T1 \& T2, en $\Delta T(n=414)$.

\begin{tabular}{lllllllll}
\hline & T1 (M) & T1 (SD) & T1 (N) & T2 (M) & T2 (SD) & T2 (N) & \multicolumn{1}{c}{ T } & P \\
\hline FIT-60 Acceptatie & 26,34 & 8,921 & 414 & 33,05 & 11,197 & 333 & 6,71 & $<.001$ \\
FIT-60 Defusie & 27,62 & 10,184 & 414 & 34,53 & 11,700 & 333 & 6,91 & $<.001$ \\
FIT-60 Zelf als Context & 27,69 & 7,984 & 414 & 33,05 & 9,949 & 333 & 5,36 & $<.001$ \\
FIT-60 Hier en Nu & 31,58 & 10,261 & 414 & 36,71 & 10,700 & 333 & 5,13 & $<.001$ \\
FIT-60 Waarden & 43,06 & 7,053 & 414 & 43,64 & 7,769 & 333 & 0,58 & .291 \\
FIT-60 Handelen & 37,55 & 8,816 & 414 & 40,80 & 9,305 & 333 & 3,25 & $<.001$ \\
FIT-60 Totaal & 186,16 & 40,792 & 414 & 215,05 & 52,866 & 333 & 28,89 & $<.001$ \\
\hline
\end{tabular}

Noot. De scores op alle subschalen en de totaalschaal zijn normaal verdeeld.

Tabel 3. Indeling scorecategorieën klinische normgroep ( $n=414)$.

\begin{tabular}{llllllll}
\hline & Acceptatie & Defusie & Zelf & $\begin{array}{l}\text { Hier en } \\
\text { Nu }\end{array}$ & Waarden & Handelen & Totaal \\
\hline $\begin{array}{l}\text { Laag } \\
(0-30 \%)\end{array}$ & $0-21$ & $0-21$ & $0-23$ & $0-25$ & $0-39$ & $0-32$ & $0-161$ \\
$\begin{array}{l}\text { Gemiddeld } \\
(30-70 \%)\end{array}$ & $22-30$ & $22-31$ & $23-31$ & $26-37$ & $40-47$ & $33-42$ & $162-200$ \\
$\begin{array}{l}\text { Hoog } \\
(70-100 \%)\end{array}$ & $31-60$ & $32-60$ & $32-60$ & $38-60$ & $48-60$ & $43-60$ & $201-360$ \\
\hline
\end{tabular}


Tabel 4. Correlaties van de FIT-60 totaal en haar subschalen met verschillenden vragenlijsten (de vet weergegeven getallen zijn de cellen waar volgens de theorie een fit (hoge correlatie) verwacht werd) $(n=414)$.

\begin{tabular}{|c|c|c|c|c|c|c|c|}
\hline & Acceptatie & Defusie & $\begin{array}{l}\text { Zelf als } \\
\text { Context }\end{array}$ & $\begin{array}{l}\text { Hier en } \\
\mathrm{Nu}\end{array}$ & Waarden & $\begin{array}{l}\text { Toegewijd } \\
\text { Handelen }\end{array}$ & Flexibiliteit \\
\hline BSI-TOT & -.514 & -.625 & -.503 & -.558 & $-.152^{\star}$ & -.225 & -.602 \\
\hline QOL-VAS & .363 & .396 & .321 & .357 & $.080 *$ & .261 & .416 \\
\hline UCL-VER & -.325 & -.267 & -.303 & -.341 & $-.147 \star$ & -.255 & -.373 \\
\hline UCL-PAS & -.557 & -.613 & -.524 & -.501 & $-.112^{*}$ & -.275 & -.604 \\
\hline UCL-ACT & .285 & .349 & .318 & .466 & .157 & .380 & .449 \\
\hline UCL-PAL & -.130 & -.158 & $-.085^{*}$ & $-.070 *$ & $.064^{\star}$ & $.057^{\star}$ & $-.083^{\star}$ \\
\hline UCL-STE & .122 & $-.003 *$ & .141 & .223 & .222 & $.074^{*}$ & .164 \\
\hline UCL-EXP & $.019 *$ & $-.034 *$ & $.049 *$ & $-.020 *$ & $.035^{\star}$ & $.009 *$ & $.009 *$ \\
\hline UCL-GER & $.084 *$ & .112 & .219 & .177 & .156 & .322 & .235 \\
\hline NEO-NEU & -.555 & -.666 & -.601 & -.543 & -.141 * & -.316 & -.665 \\
\hline NEO-EXT & .288 & .277 & .345 & .292 & .222 & .398 & .420 \\
\hline NEO-OP & $.085^{\star}$ & $.007 *$ & $-.043 *$ & .186 & $.020 *$ & $.070 *$ & $.081 *$ \\
\hline NEO-ALT & .180 & $.113^{*}$ & .168 & .276 & .190 & $.143^{*}$ & .243 \\
\hline NEO-CON & .152 & .211 & .271 & .319 & .254 & .359 & .361 \\
\hline
\end{tabular}

BSI-TOT, Brief Symptom Invenstory Totaal; Qol-VAS, Quality of Life - Visual Analog Scale || UCL, Utrechtse Coping Lijst; ACT, Actief aanpakken; PAL, Palliatieve reactie; VER, Vermijden; STE, Sociale steun zoeken; PAS, Passief reactiepatroon; EXP, Expressie van emoties; GER, Geruststellende gedachten || NEO, NeuroticismExtroversion-Openness Five-Factor Inventory; NEU, Neuroticisme; EXT, Extraversie; OP, Openheid; ALT, Altruïsme; CON, Consciëntieusheid ||

Noot. De correlaties van de eerste vier variabelen (BSI-TOT t/m UCL-PAS) zijn significant op $p=.001786$ niveau, de overige 10 variabelen zijn significant op $p<.05$.

* Niet significant.

Omdat een aantal FIT-60 subschalen hoog correleren met verschillende vragenlijsten, zijn ook hier de partiële Pearson-correlaties van de FIT-60 subschalen met de vier confirmatieve maten bepaald (eenzijdig getoetst), om zo de unieke relatie per subschaal te kunnen vaststellen. Vervolgens is bepaald hoeveel vragenlijsten het hoogst correleerde met de verwachte subschaal. Voor de Qol-VAS en de subschalen UCL-acceptatie en UCL-vermijding was dit het geval (3 van de 4 maten). Uit de Fisher Z-transformatie bleek dat dit geen significante afwijking van de verhouding was op basis van kansniveau $(Z=-1.41, p=.159)$.

Dit is echter verklaarbaar vanwege het kleine aantal tests.

\section{Discussie}

De interne consistentie voor de verschillende subschalen van de FIT-60 voor deze heterogene, klinische populatie varieerde van redelijk tot goed. De subschalen Zelf als Context en Waarden vormen hierop een uitzondering. De interne betrouwbaarheid van de totaalschaal Psychologische Flexibiliteit was zeer hoog. Tevens lijkt de FIT-60 gevoelig voor het meten van veranderingen in ACT-vaardigheden over de tijd, met als enig aandachtspunt 
de subschaal Waarden, waarbij er sprake lijkt te zijn van een plafondeffect. De gebruikte vragenlijsten in dit onderzoek zijn geen ACT-specifieke maten en meten dus niet exact hetzelfde construct als de FIT-subschalen. Uit de resultaten blijkt echter wel dat de richtingen van de correlaties allemaal naar verwachting zijn, en dat er sprake is van significante, zwakke tot sterke samenhang met de psychologische klachten, de copingsstijlen vermijden en passief reageren (veelal middels piekeren), en kwaliteit van leven. Dit is wederom een ondersteuning van de constructvaliditeit van de FIT-60 met niet-ACT-specifieke, doch convergerende constructen. Vanwege het kleine aantal toetsen (4) kon niet worden aangetoond dat dit verband een significant resultaat was. Uit de beschrijvende correlaties kan worden opgemaakt dat de ACT-vaardigheden beperkte verbanden hebben met algemene copingsstijlen zoals beschreven met de UCL en dat er sprake lijkt van ACTspecifieke copingsvaardigheden. Ook zijn er geen subschaalspecifieke banden gevonden met de NEO-FFI. Dat wijst dus op de afwezigheid van een samenhang van de ACTcomponenten met de big five persoonlijkheidskenmerken en is daarmee een indicatie dat deze vaardigheden niet persoonlijkheidsgebonden zijn. Ten slotte bleek opleidingsniveau geen significante correlatie te hebben met de uitkomst van de FIT-60. Leeftijd en geslacht bleken wel een significante, maar zeer zwakke correlatie te vertonen. Vanwege deze zwakke samenhang zijn hier geen aparte normgroepen voor bepaald. Een beperking van bovenstaand onderzoek is dat het om een vrij specifieke sample gaat: relatief hoog opgeleide patiënten, met gemiddeld behoorlijk wat maatschappelijke steun (financieel, woning, werk, sociaal netwerk), die vrijwillig zijn opgenomen voor behandeling.

\section{ONDERZOEK 3}

\section{Betrouwbaarheid en ambulante normering}

\section{Deelnemers}

De deelnemers aan deze studie $(n=674)$ zijn geworven in vier verschillende ambulante GGZ-instellingen in Nederland. De gemiddelde leeftijd van de patiënten was 35,0 jaar (SD $11,4), 56,5 \%$ was vrouw en $43,5 \%$ was man. Het opleidingsniveau varieerde tussen lager beroepsonderwijs (32,0\%), middelbaar beroepsonderwijs (35,5\%), hoger beroepsonderwijs $(26,7 \%)$ en wetenschappelijk onderwijs $(5,8 \%)$.

\section{Meetinstrumenten}

Demografische vragenlijst

Bij aanvang van de testafname werd er gevraagd naar leeftijd, geslacht en opleidingsniveau van deelnemers.

\section{Flexibiliteits Index Test (FIT-60)}

De FIT-60 is een zelfrapportagevragenlijst die psychologische flexibiliteit meet: in hoeverre iemand flexibel om kan gaan met zijn psychische problemen [5]. Zie onderzoek 1 hierboven voor een uitgebreidere beschrijving van de FIT-60. 


\section{Procedure}

De werving is in januari 2013 begonnen en liep tot en met december 2013. Er werd geworven bij vier vestigingen van ambulante GGZ-instelling PsyQ (Maastricht, Heerlen, Eindhoven en Tilburg). Twee van de vier vestigingen waren gericht op de behandeling van angststoornissen, de andere twee waren generalistisch van aard. Bij de intakeprocedure werd naast de reguliere vragenlijstbatterij ook de papieren versie van FIT-60 afgenomen ter screening voor een ACT-interventie, alsook ten behoeve van dit onderzoek. Ten slotte was er tevens een informed-consent-formulier opgenomen.

\section{Statistische analyse}

Middels descriptieve statistiek werd er gekeken naar het effect van verschillende demografische eigenschappen op de uitslag op de FIT. Ook werd er aan de hand van deze data een ambulante normgroep bepaald. De scorecategorieën werden bepaald op basis van percentielen (0-30 laag, 31-70 midden, 71-100 hoog). Tevens werd de interne consistentie van de FIT-60 bepaald. Ten slotte werd de Reliable Change Index voor de verschillende schalen van de FIT-60 bepaald. De analyses werden gedaan met SPSS 22.0.

\section{Resultaten}

\section{Beschrijvende informatie}

De FIT-60 is door 674 deelnemers ingevuld voor aanvang van een ambulante behandeling. Tabel 5 geeft een overzicht van de gemiddelde scores en een overzicht van de scorecategorieën zoals deze werden bepaald voor de ambulante normgroep.

Tabel 5. Indeling scorecategorieën ambulante normgroep $(n=674)$.

\begin{tabular}{llllllll}
\hline & Acceptatie & Defusie & Zelf & Hier en Nu & Waarden & Handelen & Totaal \\
\hline Gemiddeld & 23,44 & 18,89 & 25,03 & 27,10 & 37,04 & 31,65 & 163,17 \\
SD & 10,381 & 10,486 & 7,340 & 9,567 & 9,100 & 11,142 & 43,775 \\
Laag & $0-18$ & $0-13$ & $0-21$ & $0-22$ & $0-32$ & $0-26$ & $0-141$ \\
$\begin{array}{l}(0-30 \%) \\
\begin{array}{l}\text { Gemiddeld } \\
(30-70 \%)\end{array}\end{array}$ & $19-28$ & $14-23$ & $22-29$ & $23-31$ & $33-43$ & $27-38$ & $142-183$ \\
$\begin{array}{l}\text { Hoog } \\
(70-100 \%)\end{array}$ & $29-60$ & $24-60$ & $30-60$ & $32-60$ & $44-60$ & $39-60$ & $184-360$
\end{tabular}

Noot. De scores op alle subschalen en de totaalschaal zijn normaal verdeeld.

\section{Demografische variabelen}

Er is tevens gekeken naar het effect van verschillende demografische variabelen op de scores van de FIT-60. Leeftijd had geen correlatie met de scores van de FIT-60 ( $r=-.011, p$ $=.779$ ). Geslacht bleek een zeer zwakke, significante negatieve correlatie te hebben met de resultaten van de FIT $(r=-.103, p=.007)$. Op basis van de non-parametrische correlatie 
(Kendalls tau) bleek ook opleidingsniveau een zeer zwakke, significante correlatie te hebben met de FIT-60 $(r \tau=.135, p<.001)$.

\section{Betrouwbaarheid}

Ten slotte is er ook voor deze sample gekeken naar de interne consistentie van de FIT-60. Cronbachs alfa was .923 op de totaalschaal, .807 voor Acceptatie, .835 voor Defusie, .550 voor het Zelf als Context, .744 voor het Hier en Nu, .748 voor Waarden, en .838 voor Toegewijd Handelen.

\section{Klinische verandering}

Omdat de FIT-60 waarschijnlijk het meest zal worden gebruikt binnen de ambulante patiëntenzorg, werd voor deze populatie berekend wanneer er sprake is van een significante klinische verandering met de Reliable Change Index [31]. De RCI kan worden berekend op basis van de betrouwbaarheid en de standaarddeviatie van een vragenlijst. De $\mathrm{RCI}$ voor de totaalschaal Psychologische Flexibiliteit is 34 punten (op een maximale score van 360). De RCI's voor de FIT-60 subschalen zijn 13 punten voor Acceptatie, 12 punten voor Defusie, 14 punten voor Zelf als Context, 13 punten voor Hier en Nu, 13 punten voor Waarden, en 12 punten voor Toegewijd Handelen (op een maximale score van 60).

\section{Discussie}

De interne betrouwbaarheid voor de subschalen van de FIT-60 voor deze heterogene, ambulante populatie varieerde van redelijk tot goed. De subschaal Zelf als Context vormt een uitzondering. De interne betrouwbaarheid voor de totaalschaal met betrekking tot de Psychologische Flexibiliteit was wederom zeer hoog. In deze sample bleek dat leeftijd geen significante correlatie had met de uitkomst van de FIT-60. Geslacht en opleidingsniveau hadden wel een significante correlatie met de uitkomst, doch de samenhang was zeer beperkt. Ten slotte zijn de normscores voor deze ambulante groep bepaald. Het is belangrijk op te merken dat angstproblematiek oververtegenwoordigd is in deze sample en dat dit mogelijk een vertekening geeft.

\section{Algemene discussie}

De Flexibiliteits Index Test (FIT-60) is de enige vragenlijst die zowel Psychologische Flexibiliteit als de zes componenten Acceptatie, Defusie, Zelf als Context, Hier en Nu, Waarden, en Toegewijd Handelen in kaart brengt. De FIT-60 is daarmee bruikbaar als outcome-instrument voor derde generatie gedragstherapie, in het bijzonder voor Acceptance and Commitment Therapy. De FIT-60 wordt reeds gebruikt in onderzoek en in de klinische praktijk (al vierduizend keer ingevuld via de website). Aangezien de FIT-60 is ontwikkeld op basis van de theoretische constructen van ACT, geeft deze een goede indruk van de verschillende ACT-processen. De FIT-60 werd onderzocht op de psychometrische kwaliteiten bij drie verschillende populaties: ACT-therapeuten, ambulante patiënten en klinische patiënten in de GGZ. De FIT-60 bleek bij alle drie de samples over 
een goede betrouwbaarheid te beschikken: de interne betrouwbaarheid voor de schalen was redelijk tot goed, met uitzondering van de subschaal Zelf als Context. De testhertestbetrouwbaarheid voor de verschillende schalen was zeer goed. Daarnaast bleek de FIT-60 ook in staat te zijn om verandering over tijd te meten. Tevens is er ondersteuning gevonden voor een goede constructvaliditeit van de verschillende schalen, met ook hier als uitzondering de schaal Zelf als Context. Hoewel de schaal Zelf als Context onderpresteert, blijft deze nog acceptabel en dus bruikbaar. Ten slotte is er gekeken naar het effect van de demografische variabelen op de score van de FIT. Het bleek dat leeftijd, geslacht en opleidingsniveau een zeer zwakke correlatie hadden met de resultaten van de FIT. Behalve de beschrijving van de psychometrische kwaliteiten van de FIT-60, heeft dit onderzoek tevens twee aanvullende normgroepen opgeleverd: een ambulante en klinische populatie. Dit maakt de FIT-60 beter bruikbaar in de klinische praktijk. Naast ondersteuning voor de interne validiteit van de FIT-60 geeft het huidige onderzoek tevens een indicatie van goede externe validiteit van deze vragenlijst in de verschillende samples. Er dienen een aantal kanttekeningen te worden geplaatst bij bovenstaande analyses. Zoals reeds in de inleiding is aangegeven, bleek het niet mogelijk om middels een factoranalyse de constructvaliditeit van de FIT-60 aan te tonen. Dit geeft een indicatie dat de verschillende theoretische ACT-componenten empirisch minder te onderscheiden zijn. Daarom is de schaal verder geëxploreerd middels correlationeel onderzoek, met vragenlijsten die conceptueel gerelateerd zijn om de constructvaliditeit van de FIT-60 aan te tonen. De matige betrouwbaarheid en validiteit van de subschaal Zelf als Context vraagt aandacht. In de literatuur is voor dit onderdeel slechts één andere ACT-vragenlijst beschikbaar (de SACS). Deze is tot op heden nog niet goed onderzocht op psychometrische kwaliteiten. Dit zou kunnen betekenen dat het domein niet goed is uitgekristalliseerd. Deze component werd in 2012 opnieuw gedefinieerd, en voorlopig lijkt het veld terughoudend om meetinstrumenten voor dit domein te ontwikkelen. Bij de FIT-60 is ervoor gekozen dit lastig te definiëren gebied toch op te nemen. Hierdoor wordt een bijdrage geleverd aan de meetbaarheid van het gebied. Maar we staan nog ver van een gouden standaard. Ten slotte, er is in deze publicatie gebruikgemaakt van conveniënt samples, met een redelijke breedte maar toch met een specifiek profiel (selectiebias). De ACT-therapeut-sample is bijzonder omdat de betreffende proefpersonen getraind zijn in het ACT-begrippenkader. Ze zijn geschoold in de onderliggende theorie, en daarom heeft protoprofessionalisering van de therapeut-respondenten zeker een rol gespeeld bij het beantwoorden van de vragen. Toch kan geconcludeerd worden dat de FIT-60 beschikt over goede psychometrische kwaliteiten. Het is een betrouwbaar en valide meetinstrument dat goed kan worden gebruikt om psychologische flexibiliteit en de zes onderliggende kernprocessen in kaart te brengen binnen het domein van de Acceptance and Commitment Therapy.

\section{Dankbetuiging}

Dit onderzoek heeft alleen kunnen plaatsvinden dankzij de onbaatzuchtige medewerking van PsyQ Eindhoven, Tilburg, Maastricht en Heerlen, en van breedspectrumkliniek U-center. 
Zij hebben de FIT-60 opgenomen in de standaardtestbatterij voor hun patiënten. Tevens wil ik Gijs Jansen, coauteur van de FIT-60, bedanken voor het beschikbaar stellen van zijn intervisiegroep met ACT-therapeuten. Ten slotte wil ik Truda Driesen en Ger Driessen bedanken voor hun ondersteuning bij de verwerking van de lijsten en het toegankelijk maken van de datasets. 


\section{Literatuur}

1. van Os, J. (2014). De DSM-5 voorbij! Persoonlijke diagnostiek in een nieuwe GGZ. Leusden: Diagnosis Uitgevers.

2. Wittchen, H. U., Jacobi, F., Rehm, J., Gustavsson, A., Svensson, M., Jönsson, B., ... Steinhausen, H. C. (2011). The size and burden of mental disorders and other disorders of the brain in Europe 2010. European Neuropsychopharmacology, 21, 655-679.

3. Hayes, S. C., Strosahl, K. D., \& Wilson, K. G. (1999). Acceptance and Commitment Therapy: An experiental approach to behavioural change. New York: The Guilford Press.

4. Jansen, G., \& Batink, T. (2014). Time to ACT! Het basisboek voor professionals. Zaltbommel: Uitgeverij Thema.

5. Batink, T., Jansen, G., \& de Mey, H. R. A. (2012). De Flexibiliteits Index Test (FIT-60): Een beknopte beschrijving. GZ-Psychologie, 5, 18-21.

6. Meyer, T. J., Miller, M. L., Metzger, R. L. \& Borkovec, T. D. (1990). Development and validation of the Penn State Worry Questionnaire. Behaviour Research and Therapy, 28, 487-495.

7. van Rijsoort, S., Vervaeke, G., \& Emmelkamp, P. (1997). The Penn State Worry Questionnaire en de Worry Domains Questionnaire: Eerste resultaten bij een normale Nederlandse populatie. Gedragstherapie, 30, 121- 128.

8. Joos, E., \& Hermans, D. (2012). Penn State Worry Questionnaire (PSWQ). Tijdschrift voor Gedragstherapie, 1, 93-96.

9. Forman, E. M., Herbert, J. D., Juarascio, A. S., Yeomans, P. D., Zebell, J. A., Goetter, E. M., \& Moitra, E. (2012). The Drexel defusion scale: A new measure of experiential distancing. Journal of Contextual Behavioral Science, 1, 55-65.

10. van Damme, S., Prins, B., \& Leroy, H. (2012). Dutch trans/ation of the SelfAs-Context Scale (SACS-DV). Unpublished Manuscript.

11. Gird, S. R., Zettle, R. D., Webster, B. K., \& Hardage-Bundy, A. (2012, July). Developing a quantitative measure of self-as-context: Preliminary findings. In R. D. Zettle (Chair), Sizing up selfing: Efforts to assess self-ascontext. Symposium conducted at the ACBS World Conference X, Washington.

12. Baer, R. A., Smith, G. T., \& Allen, K. B. (2004). Assessment of mindfulness by self-report: The Kentucky inventory of mindfulness skills. Assessment, 11, 191-206.

13. Dekeyser, M., Raes, F., Leijssen, M., Leysen, S., \& Dewulf, D. (2008). Mindfulness skills and interpersonal behaviour. Personality and Individual Differences, 44, 1235-1245.

14. Trompetter, H. R, ten Klooster, P. M., Schreurs, K. M. G., Fledderus, M., Westerhof, G. J., \& Bohlmeijer, E. T. (2013). Measuring values and committed action with the Engaged Living Scale (ELS): Psychometric evaluation in a nonclinical and chronic pain sample. Psychological Assessment, 25, 1235-1246.

15. Hayes, S. C., Strosahl, K. D., \& Wilson, K. G. (2012). Acceptance en Commitment Therapie: Veranderingen door mindfulness, het proces en de praktijk. Amsterdam: Pearson Assessment and Information.

16. Wilson, K. G. \& Murrell, A. R. (2004). Values work in acceptance and commitment therapy: Setting a course for behavioral treatment. In S.C. Hayes, V.M. Follette, \& M.M. Linehan (Eds.), Mindfulness and acceptance: Expanding the cognitive behavioral tradition (pp. 120-151). New York, NY: Guilford.

17. Wilson, K. G., Sandoz, E. K., Kitchens, J., \& Roberts, M. E. (2010). The Valued Living Questionnaire: Defining and measuring valued action within a behavioral framework. The Psychological Record, 60, 249-272.

18. de Vries, J., \& van Heck, G. L. (1995). The Dutch Version of the WHOQOL-100 (In Dutch: De Nederlandse Versie van de WHOQOL-100). Tilburg: Tilburg University.

19. WHOQOL Group (1998). Development of the World Health Organization WHOQOL-BREF quality of life assessment. Psychological Medicine, 28, 551-558.

20. WHOQOL Group (2004). The World Health Organization's WHOQOL-BREF quality of life assessment: Psychometric properties and results of the international field trial. A report from the WHOQOL group. Quality of Life Research, 13, 299-310.

21. Evans, J. D. (1996). Straightforward statistics for the behavioral sciences. Pacific Grove, CA: Brooks/Cole Publishing.

22. Derogatis, L., \& Melisaratos, N. (1983). The Brief Symptom Inventory: An introductory report. Psychological Medicine, 13, 595-605.

23. de Beurs, E. (2004). Handleiding bij de Brief Symptom Inventory (BSI). Leiden: Pits Publishers.

24. de Beurs, E., \& Zitman, F. G. (2006). De Brief Symptom Inventory (BSI): De betrouwbaarheid en validiteit van een handzaam alternatief voor de SCL-90. Maandblad Geestelijke Volksgezondheid, 61, 120-141.

25. Schreurs, P. J. G., \& van de Willige, G. (1988). Omgaan met problemen en gebeurtenissen: De Utrechtse Copinglijst (UCL). Lisse: Swets \& Zeitlinger.

26. Schreurs, P. J. G., van de Willige, G., Brosschot, J. F., Tellegen, B., \& Graus, G. M. H. (1993). Handleiding Utrechtse Coping Lijst UCL (herziene versie). Lisse: Swets \& Zeitlinger.

27. COTAN (2014). Utrechtse Coping Lijst, UCL, 1988-1993. Beschikbaar op: http://www.cotandocumentatie. $\mathrm{nl} /$ test_details.php?id=494 [Geraadpleegd 1 oktober 2014] 
28. Costa, P. T., Jr., \& McCrae, R. R. (1992). Revised NEO Personality Inventory (NEO-PI-R) and the Five Factor Inventory (NEO-FFI): Professional Manual. Odessa, Florida: Psychological Assessment Resources Inc.

29. Hoekstra, H. A., de Fruyt, F., \& Ormel, J. (2007). NEO-PI-R en NEO-FFI persoonlijkheidsvragenlijsten: Handleiding Amsterdam: Hogrefe Uitgevers B.V.

30. Hoefman, R. J., van Exel, J., \& Brouwer, W. B. (2013). Measuring the impact of caregiving on informal carers: A construct validation study of the CarerQol instrument. Health and Quality of Life Outcomes, 11, 173. doi: 10.1186/1477-7525-11-173

31. Jacobson, N. S., Follette, W C., \& Revenstorf, D. (1986). Toward a standard definition of clinically significant change. Behavior Therapy, 17, 308-311. 
Flexibiliteits Index Test - Psychometrische Kwaliteiten 
Tim Batink ${ }^{1,2}$, Jindra Bakker ${ }^{1}$, Thomas Vaessen ${ }^{1,3}$, Zuzana Kasanova ${ }^{1,3}$, Dina Collip ${ }^{1}$, Jim van Os ${ }^{1,4}$, Marieke Wichers ${ }^{5}$, Inez Germeys ${ }^{1,3}$, Frenk Peeters ${ }^{1,6}$

${ }^{1}$ Department of Psychiatry and Psychology, Maastricht University Medical Centre, Maastricht University, Maastricht, Netherlands

${ }^{2}$ U-Center, Epen, Netherlands

${ }^{3}$ Center for Contextual Psychiatry, Department of Neuroscience, KU Leuven, Leuven, Belgium

${ }^{4}$ Institute of Psychiatry, Department of Psychosis Studies, King’s College London, London, United Kingdom

${ }_{5}^{5}$ University Medical Center Groningen, Interdisciplinary Center Psychopathology and Emotion Regulation, Department of Psychiatry, University of Groningen, Groningen, Netherlands

${ }^{6}$ Virenze RIAGG, Maastricht, Netherlands 
Acceptance and Commitment Therapy in Daily Life Training:

A Feasibility Study of an mHealth Intervention

Published: Journal of Medical Internet Research - Mhealth / Uhealth (2016), 4(3):e103 


\section{Abstract}

\section{Background}

With the development of mHealth, it is possible to treat patients in their natural environment. Mobile technology helps to bridge the gap between the therapist's office and the "real world." The ACT in Daily Life training (ACT-DL) was designed as an add-on intervention to help patients practice with acceptance and commitment therapy in their daily lives. The ACT-DL consists of two main components: daily monitoring using experience sampling and ACT training in daily life. Objectives: To assess the acceptability and feasibility of the ACT-DL in a general outpatient population. A secondary objective was to conduct a preliminary examination of the effectiveness of the ACT-DL.

\section{Objective}

To assess the acceptability and feasibility of the ACT-DL in a general outpatient population. A secondary objective was to conduct a preliminary examination of the effectiveness of the ACT-DL.

\section{Method}

An observational comparative study was conducted. The experimental group consisted of 49 patients who volunteered for ACT-DL, and the control group consisted of 112 patients who did not volunteer. As part of an inpatient treatment program, both groups received a 6-week ACT training. Participants went home to continue their treatment on an outpatient basis, during which time the experimental group received the 4-week add-on ACT-DL. Acceptability and feasibility of the ACT-DL was assessed weekly by telephone survey. Effectiveness of the ACT-DL was evaluated with several self-report questionnaires (Flexibility Index Test (FIT-60): psychological flexibility, Brief Symptom Inventory: symptoms, Utrechtse Coping List: coping, and Quality of life visual analog scale (QoL-VAS): quality of life).

\section{Results}

More than three-quarters of the participants (76\%) completed the full 4-week training. User evaluations showed that ACT-DL stimulated the use of ACT in daily life: participants practiced over an hour a week (mean 78.8 minutes, standard deviation 54.4), doing 10.4 exercises (standard deviation 6.0) on average. Both ACT exercises and metaphors were experienced as useful components of the training (rated 5 out of 7). Repeated measures ANCOVA did not show significant effects of the ACT-DL on psychological flexibility $(P=.88)$, symptoms $(P=.39)$, avoidant coping $(P=.28)$, or quality of life $(P=.15)$.

\section{Conclusion}

This is the first study that uses experience sampling to foster awareness in daily life in combination with acceptance and commitment therapy to foster skill building. Adherence to the ACT-DL was high for an intensive mHealth intervention. ACT-DL appears to be an acceptable and feasible mHealth intervention, suitable for a broad range of mental health problems. However, short-term effectiveness could not be demonstrated. Additional clinical trials are needed to examine both short-term and long-term effects. 


\section{Introduction}

\section{Background}

Over the last decade, the field of psychological treatment has seen the emergence of third generation behavioral therapies [1]. These third wave therapies focus on how to relate in a more workable way to difficult thoughts and feelings rather than trying to change them. One of these therapies is acceptance and commitment therapy (ACT). Instead of focusing on the content, the person focuses on the function of difficult experiences and the context in which they occur [2]. Here, we examine a novel strategy designed to implement ACT interventions in the daily lives of patients, thereby enhancing the usefulness and effect of the treatment.

\section{Acceptance and Commitment Therapy}

ACT is a form of psychotherapy positioned within the third wave behavioral therapies. ACT does not primarily focus on symptom reduction but teaches patients to deal with their challenging experiences in such a way that they can behave according to their values [2]. The ACT model consists of six core processes that are closely interlinked (Figure 1). Acceptance teaches patients to pay attention to unpleasant feelings instead of trying to get rid of them. Defusion helps patients to recognize thoughts for what they are: cognitions they can distance themselves from rather than truths they have to react on. The self as context helps patients realize they are more than their thoughts, emotions, and self-image; there is also an observer who is having these experiences. Patients also learn to focus their attention to the present moment-to be aware of their internal and external environment. Values helps patients refocus on the things that really matter to them, and committed action encourages them to start investing in their personal values again. Together, these core processes form psychological flexibility, the ability to deal with challenging experiences in a flexible way while continuing to act based on one's values [3, 4]. Since ACT is an experiential form of therapy, many exercises are used (learning by experiencing). The exercises also support skill-building by patients. Metaphors are also frequently applied in this form of therapy to validate the patient's experience, create awareness of the situation, and introduce new approaches to handle the situation [5].

The American Psychological Association has included ACT in its register of researchsupported psychological treatments for depression, mixed anxiety, obsessive-compulsive disorder, psychoses, and chronic pain. A recent meta-analysis from A-Tjak and colleagues [6] showed that ACT is an effective intervention for treating depression, anxiety disorders, addiction, and somatic health problems. The evidence thus suggests transdiagnostic effectiveness of ACT.

Although it is most valuable to acquire ACT skills during therapy sessions, it is equally important to get ACT out of the therapist office and into the daily life of the patient. This helps the patient to generalize ACT skills to different situations and different challenges, changing behavioral patterns at home. Put shortly: learning to apply ACT in their daily lives. 


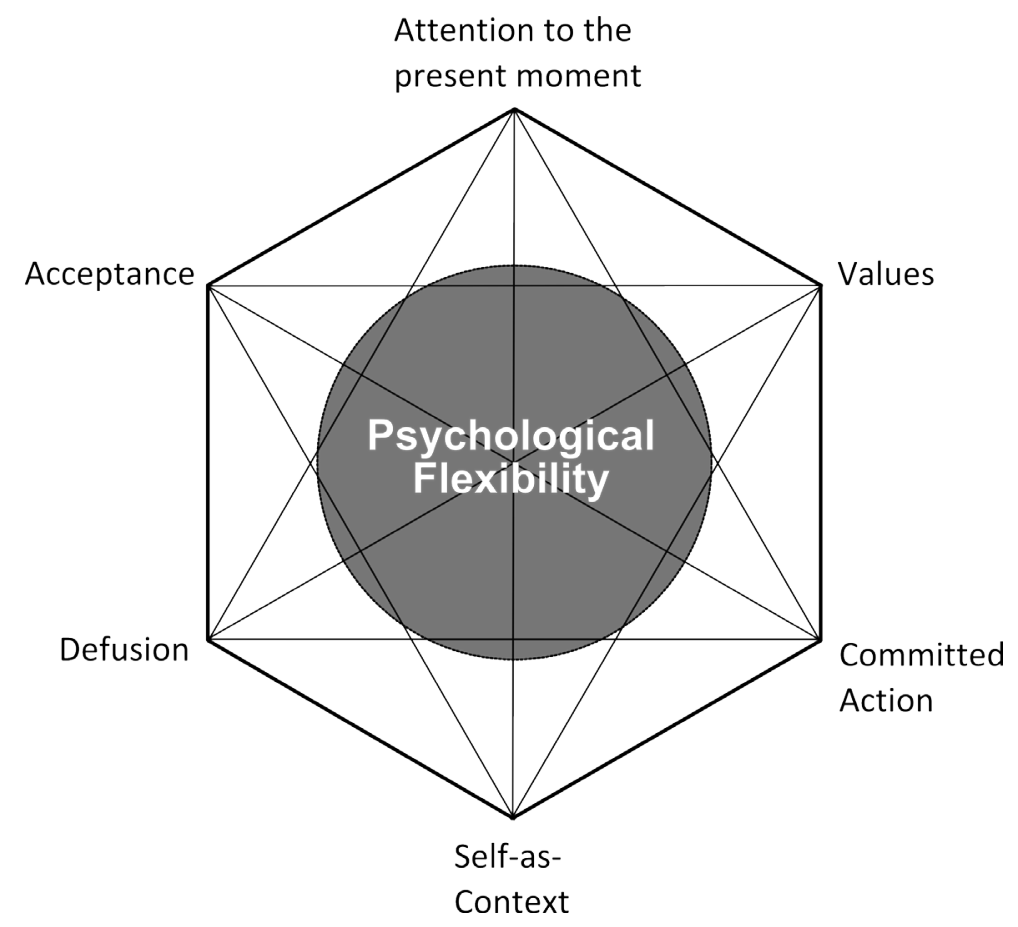

Figure 1. The ACT hexaflex with the six core processes

\section{Experience Sampling Method}

The experience sampling method (ESM) is an ambulatory assessment method that consists of multiple assessments per day, at random times, asking patients to complete a brief questionnaire about experiences, environments, and activities in-the-moment (ecological validity) [7]. By measuring in daily life, ESM takes into account the importance of the context in which experiences and behavior occur and also provides information regarding this context [8]. From an ACT perspective, ESM not only represents a suitable ecologically valid assessment method but also facilitates the ACT processes attention to the present moment and self as context, which together represent the core pillar "being aware." Completing multiple assessments at random moments throughout the day promotes awareness of both internal and external experiences, as well as insight into the relationship between experiences and context [9].

\section{mHealth}

Mobile Health (mHealth) is a relatively recent technological development and can be defined as the use of mobile devices such as personal digital assistants (PDAs), mobile phones, and tablets to promote health $[10,11]$. In February $2016,72 \%$ of adults in the United States and $60 \%$ to $71 \%$ of adults in Western Europe owned a mobile phone [12]. Mobile devices can assess and intervene at any time or place in the personal context of the user (online and 
offline). Therefore, they are an ideal medium for personal ecological assessment and intervention. ESM has already successfully found its way in mHealth $[13,14,15,16,17,18]$, showing its potential in the treatment of depression [19] and anxiety [20]. Similarly, the first mHealth ACT interventions are showing promising results for chronic medical conditions $[21]$, stress [22, 23], and smoking cessation [24].

\section{Objectives}

The ACT in Daily Life training (ACT-DL) focuses on daily life monitoring and ACT training in context, combining ACT techniques, ESM, and mobile technology (see Multimedia Appendix 1 for example). The goal of the intervention is to stimulate patients to practice ACT skills in their daily life after completing a regular ACT training. The primary objective was to assess the ACT-DL with respect to feasibility and acceptability in a heterogeneous population of patients with a mental health disorder. The secondary objective was to conduct a preliminary examination of the effectiveness of ACT-DL.

\section{Methods}

\section{Participants}

Participants were recruited in an inpatient mental health care facility in Epen, the Netherlands, between June and November 2013. The center provides treatment for common mental problems like major depression, anxiety, and substance use disorder. All patients received a flyer about the study with information about the aim and set-up of ACT-DL, duration of the training, and estimated time investment. Inclusion criteria were intentionally kept broad; all consecutive referrals in the study period could participate in the study. There were two exclusion criteria: deviation from the length of inpatient stay (standard 7-week program) and participation in another study within the treatment facility. The control group consisted of all other patients who participated in the full treatment program (7-week inpatient and 7-week outpatient treatment) between 2013 and 2014 and completed all the required measures. Due to the clinical setting, it was impossible to randomize participants into two conditions and therefore an observational design was chosen.

The initial aim for the feasibility study was to include a minimum of 20 participants (suggested by sample size calculation, Cohen $\mathrm{d}=1.8$, alpha error probability $=.05$, power $=.95$, allocation ratio N2/N1=1). Given the enthusiasm for participation, 49 participants were included in the experimental intervention (mean age 45.7 years, standard deviation [SD] 10.0 years) and 112 participants composed the control group (mean age 47.5 [SD 12.4] years).

\section{Sample Characteristics}

Both the ACT-DL and the control group were heterogeneous with regard to age, level of education, and diagnosis on Diagnostic and Statistical Manual of Mental Disorders(Fourth Edition) (DSM-IV-TR), Axis I and Axis 2 (Table 1). There were no significant differences in demographics between the ACT-DL and the control group with the exception of gender $(P=.02)$. A total of 8 participants dropped out after the first week, 3 after the second week, 
and 1 after the third week. Of the 49 participants, 37 (76\%) completed the full 4-week ACT$\mathrm{DL}$. The completers did not deviate significantly on demographics or baseline measures from the noncompleters. Additionally, because of the qualitative nature of the evaluation by telephone (participants did not always give a clear answer on every question), missing data points were present in the dataset (20\%) and assumed to be missing at random. An intention-to-treat analysis was used.

\section{Procedures}

The Medical Ethics Committee of Maastricht University Medical Centre approved the study procedures, and all participants provided written informed consent. All participants underwent a 7-week inpatient treatment program that started with a 1-week diagnostic phase including structured interviews in which DSM-IV-TR axis I (Mini-International Neuropsychiatric Interview, or MINI, [25]) and axis II disorders (Structured Interview for

Table 1. Demographic characteristics of participants in the intervention $(n=49)$ and control $(n=112)$ groups.

\begin{tabular}{|c|c|c|c|}
\hline & ACT-DL ${ }^{a}$ & Control & $P$-value \\
\hline \multirow[t]{2}{*}{ Age, years, mean (SD) } & $45.7(10.0)$ & $47.5(12.4)$ & $(p=.378)$ \\
\hline & Min $23-$ Max 65 & Min 22 - Max 68 & \\
\hline Gender, n(\%) & & & $(p=.016)$ \\
\hline - Male & $17(35)$ & $62(55)$ & \\
\hline - Female & $32(65)$ & $50(45)$ & \\
\hline Education Level, n (\%) & & & $(p=.145)$ \\
\hline - Primary & - & $1(1)$ & \\
\hline - Secondary & $21(43)$ & $51(46)$ & \\
\hline - Undergraduate & $17(35)$ & $21(19)$ & \\
\hline - Graduate & $11(22)$ & $35(31)$ & \\
\hline - Other & - & $4(4)$ & \\
\hline Main diagnosis on Axis I (DSM-IV-TR'), n(\%) & & & $(p=.633)$ \\
\hline - Anxiety & $6(12)$ & $20(18)$ & \\
\hline - Mood & $26(53)$ & $44(39)$ & \\
\hline - Somatoform & $4(8)$ & $9(8)$ & \\
\hline - Substance & $11(22)$ & $31(28)$ & \\
\hline - Other & $2(4)$ & $8(7)$ & \\
\hline Additional diagnosis on Axis II (DSM-IV-TR), n (\%) & & & $(p=.094)$ \\
\hline - None & $36(74)$ & $90(80)$ & \\
\hline - Cluster A & - & - & \\
\hline - Cluster B & $6(12)$ & $4(4)$ & \\
\hline - Cluster C & $5(10)$ & $8(7)$ & \\
\hline - Other & $2(4)$ & $10(9)$ & \\
\hline
\end{tabular}

aCT-DL: ACT in Daily Life.

${ }^{b}$ DSM-IV-TR-TR: Diagnostic and Statistical Manual of Mental Disorders (Fourth Edition, Text Revision) 
DSM-IV-TR Personality Disorders, [26]) were assessed. Participants also completed a range of pretreatment questionnaires (T1). After the diagnostic week, participants followed an intensive 6-week treatment program (psychoeduction, cognitive-behavior therapy, ACT, mindfulness, group psychotherapy, creative therapy, relapse prevention, and vitality management). One of the main components of the program was an ACT group. This was a weekly, 90-minute group therapy session (10-12 members) guided by a structured treatment manual, during which one of the 6 ACT core components was targeted each week (handouts were provided). Throughout the 6 sessions, the metaphors and exercises that were going be used in the ACT-DL during the outpatient phase were discussed. An experienced ACT therapist conducted the weekly sessions.

After the 6-week inpatient program, participants completed the posttreatment questionnaire battery (T2). During the last week of inpatient treatment, participants who volunteered for the ACT-DL received a 60-minute briefing on how the training would be implemented in their daily lives. At this point, the participants of the ACT-DL training received the PsyMate digital devices with the ACT-DL program. Participants were asked to keep the PsyMate with them at all times during the training days but not let this interfere with their daily lives. Treatment was then continued for a 7-week outpatient phase to which a 4-week ACT-DL was added in the experimental group. ACT-DL participants started with the 4-week training as soon as they arrived home. At the end of each week of training, participants were contacted by a member of the research staff for a semistructured interview (approximately 15 minutes) on their experiences of that week. The evaluation of the last training week was more elaborate and was also used for debriefing (approximately 30 minutes). The answers to the Likert-scale questions were noted, and the answers to the open-ended questions were transcribed. At the end of the outpatient treatment phase, participants completed the postoutpatient questionnaire battery (T3, Figure 2 ) and returned the PsyMates with the ACT-DL program.

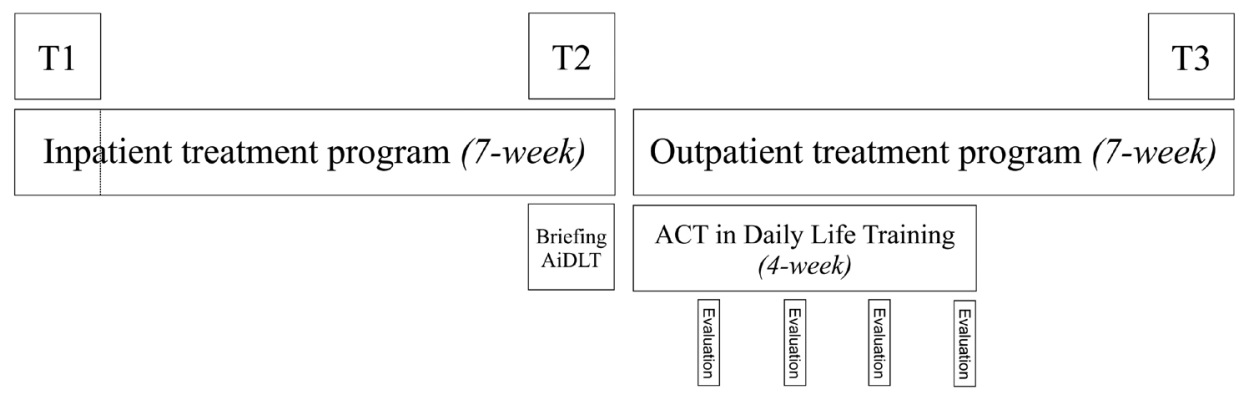

Figure 2. Timeline of the procedure for the experimental group. 


\section{Intervention: ACT in Daily Life Training}

\section{Design of ACT in Daily Life}

The ACT-DL is a fully automated mobile ACT intervention delivered by a PDA-like device, the PsyMate (see Myin-Germeys et al [27] for a global description). This mHealth intervention assists participants to practice with ACT skills in their daily lives. The goal of the training is to help participants integrate ACT skills in their daily life, thus improving psychological flexibility and, ultimately, quality of life. The ACT-DL has a duration of 4 weeks during which participants receive training for 3 consecutive days each week-Thursday, Friday, and Saturday-to get a cross-section of the week (approximately 1 hour per day). The ACT-DL is not a stand-alone intervention. Participants need to be familiar with ACT (prior therapy/ training) to be able to benefit from this add-on intervention. The ACT-DL consists of two main components: daily monitoring via experience sampling and ACT training in the personal environment. The ACT-DL uses persuasive techniques such as tunnelling (leading users through a predetermined sequence of actions), self-monitoring, and reminders.

\section{PsyMate}

The PsyMate is a PDA-like device that provides the ACT-DL. It facilitates both the monitoring in daily life as a pocket diary and the ACT training by providing 18 different ACT exercises and 6 ACT metaphors as described above. The mode of delivery of the exercises is textbased; metaphors are offered as an illustration. Since it is a mobile device, it allows participants to practice with ACT in their daily lives. Figure 3 provides a schematic overview of the ACT-DL.

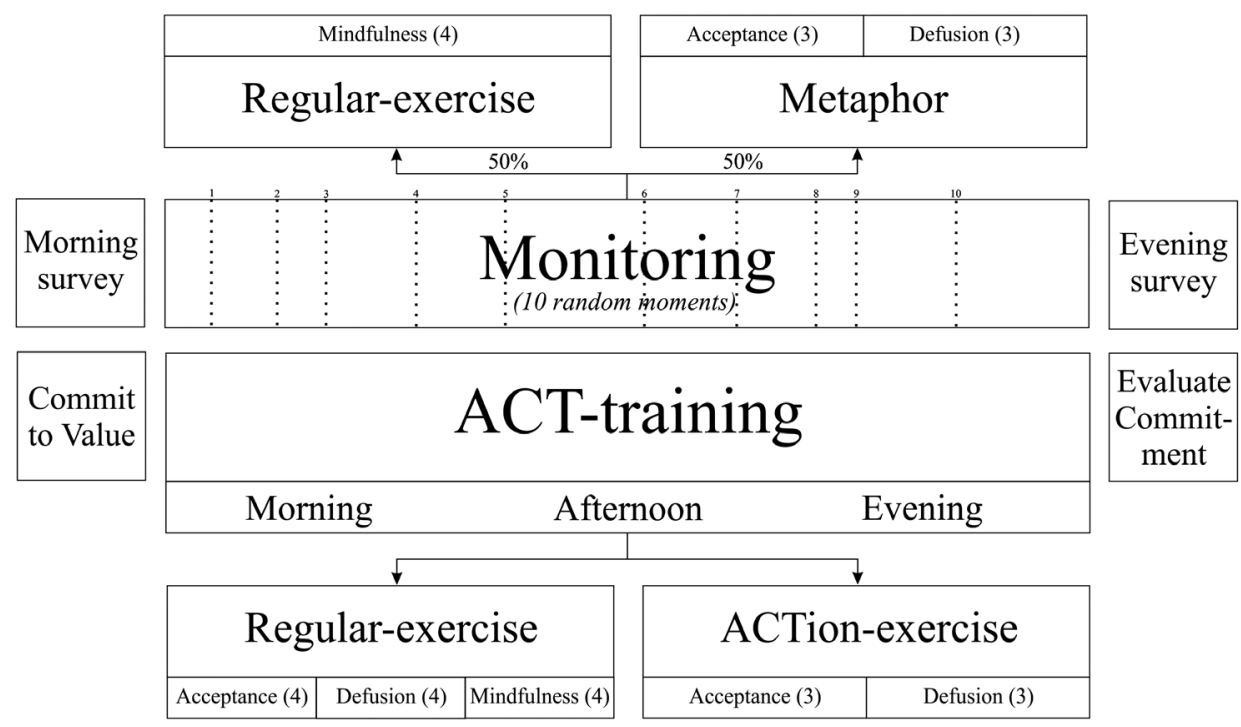

Figure 3. Schematic overview of the ACT in Daily Life Training (ACT-DL). The ACT-DL consists of two main components; Monitoring and ACT training. 


\section{Monitoring}

The ACT-DL uses daily life monitoring to foster awareness of one's mental state, as well as the impact of the context on that state. Between 7:30 AM and 10:30 PM, the PsyMate beeps randomly 10 times, prompting the participant to complete a brief self-report questionnaire about current symptoms (affect and cognition), activity, company, and whereabouts. Furthermore, participants are asked to complete a brief morning questionnaire and evening questionnaire, appraising their day and quality of sleep. Monitoring was also restricted to the three ACT-DL training days.

\section{ACT Training}

The ACT-DL focuses on four core components of ACT: acceptance, defusion, mindfulness, and committed action. Two types of ACT exercises are available via the PsyMate during the ACT-DL: regular exercises and ACTion exercises. The regular exercises are always applicable because they focus on general ACT skill training independent of current thought, feelings, or situations. The exercises on acceptance, defusion, and mindfulness are made available on demand (4 exercises per component). Participants are required to carry out at least 3 exercises of their choice per training day (morning, afternoon, evening). Also, mindfulnessrelated exercises are offered after 5 out of 10 self-assessments (signal-contingent). The ACTion exercises are specifically designed to be applicable in distressing situations. Whenever a participant has an unpleasant thought or feeling, they can activate one of the ACTion exercises (event-contingent) to deal with those distressing experiences in an ACT-consistent manner. Both acceptance and defusion ACTion exercises are available (3 exercises per component, see Textbox 1). In order to integrate committed action in the ACT-DL, at the end of each morning questionnaire, participants have to choose a personal value they want to invest in that day. Following the evening questionnaire, participants have to evaluate whether they had invested in their chosen value of the day (interval-contingent). In addition to the ACT exercises, illustrated ACT metaphors are used in the training (Figure 4). These illustrated metaphors serve as a reminder/cue to reactivate important ACT concepts learned during previous ACT training sessions (without needing to explain the concept in detail again). Both metaphors for acceptance and defusion can be accessed on demand (3 metaphors per component). The ACT metaphors are also offered after $50 \%$ of the selfassessment moments during the day, alternating with the mindfulness exercises (after 5 out of 10 self-assessments [signal-contingent]).

\section{Measures}

\section{Usage and User Experiences}

During the 4-week intervention period of the ACT-DL training, participants were contacted once a week by phone by a member of the research team to evaluate the previous week's training. This evaluation was conducted via a semistructured interview during which participants were asked to evaluate the usability of the PsyMate, the ACT metaphors, and the ACT exercises of that week. Open-ended questions (eg, "How did your practice go last 
week?") and questions using a 7-point Likert scale (eg, "The ACT exercises were useful; 1 = not at all, 7 = very much") were used. Also usage of the exercises and metaphors was evaluated (eg, "How many ACT exercises did you on average perform per day?"). After the last week, a more elaborate evaluation was conducted.

Textbox 1. Example of an ACTion-exercise.

\section{Acceptance exercise: Opening up}

Unpleasant feelings are showing up for you right now.

See if you can open up to them, allowing these feelings to be there.

Explore what there is to experience - what goes through your mind?

Can you stay present with these difficult feelings, keep in touch with them?

Do these feelings remain the same, or do they change?

Are they getting heavier, lighter, do they remain the same, or do they fluctuate?

See if you can continue giving some space to these unpleasant feelings for a while, instead of trying to control them or trying to get rid of them.

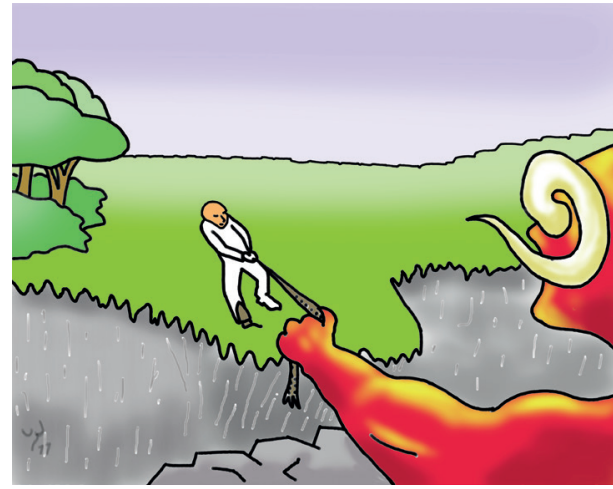

Acceptance Metaphor: Tug of War

Try to stop your attempts of solving your pain by winning the war with it; try to let go of the rope.

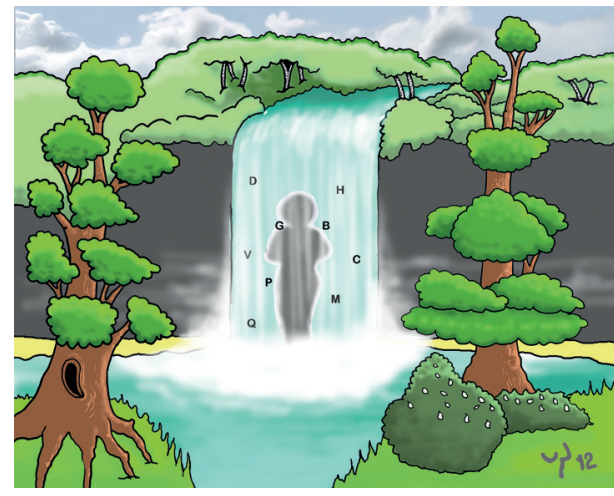

Defusion Metaphor: Waterfall

Instead of getting carried away by your stream of thoughts, take a step back and observe them.

Figure 4. Examples of illustrated ACT metaphors.

\section{Psychological Flexibility}

The Flexibility Index Test (FIT-60) is a self-report questionnaire that measures psychological flexibility and its six underlying ACT components: acceptance, defusion, self as context, present moment, values, and committed action [28]. The FIT-60 consists of 60 items that are scored on a 7-point Likert Scale. The FIT-60 has good psychometric properties [28, 29].

\section{Coping Skills}

The Utrechtse Coping List (UCL) is a 47-item self-report questionnaire that measures seven coping styles: actively addressing, palliative reacting, avoiding, seeking social support, passive reacting, expression of emotions, and reassuring thoughts [30]. Only the subscale avoiding 
was used for this study. The internal consistency of the UCL is moderate to good. Construct validity and predictive validity are sufficient [31].

\section{Psychological Symptoms}

The Brief Symptom Inventory (BSI) provides an overview of symptoms and their intensity at a specific point in time [32]. The BSI consists of 53 items which are scored on a 5-point Likert scale. Besides a total symptom rating, the BSI indexes symptoms on 9 specific dimensions: somatization, obsessive-compulsive, interpersonal sensitivity, depression, anxiety, hostility, phobic anxiety, paranoid ideation, and psychoticism. The internal reliability and test-retest are sufficient. Furthermore, the inventory is sensitive to treatment effects $[33,34]$.

\section{Quality of Life}

Quality of life was assessed with the question "How happy do you feel at this moment?" and scored on a 10-point visual analog scale (QoL-VAS). This question is used as a proxy for living a valued, committed life. The Dutch QoL-VAS has good construct validity [35]. Participants completed the self-report questionnaires before starting the inpatient treatment (T1: preinpatient), after the inpatient treatment (T2: postinpatient), and after the outpatient treatment, during which the experimental group also received the ACT-DL (T3: postoutpatient).

\section{Statistical Analyses}

Feasibility and acceptability of the ACT-DL were assessed with descriptive statistics. The open-ended answers of the user evaluation were analyzed via a conventional qualitative content analysis method (codes were derived from the verbatim transcripts and merged into a coding scheme). The effectiveness of the ACT-DL on ACT skills, coping, quality of life, and clinical symptoms were analyzed using SPSS version 22.0 statistical software (IBM Corp) with several analyses of covariance (ANCOVAs, level of significance was adjusted for the number of hypotheses with a Bonferroni correction; $P=.05 / 4: P=.01)$. Interaction effects were tested with a repeated measures ANCOVA.

\section{Results}

\section{Acceptability and Feasibility of ACT in Daily Life}

The semistructured evaluation via telephone of the ACT-DL focused on user experience. These evaluations revealed that the training was rated positively, it stimulated the use of ACT, and the ACT exercises and metaphors were rated as useful (Figure 5). The ratings did not significantly change over the four assessment periods, assessed with a repeated measures analysis of variance regarding use of ACT $\left(F_{3,42}=0.063, P=.98\right)$, usefulness of the exercises $\left(F_{3,39}=0.856, P=.47\right)$, and usefulness of the metaphors $\left(F_{3,42}=0.788, P=.51\right)$. The ACT exercises and ACT metaphors were rated equally useful $\left(t_{129}=-1.453, P=.15\right)$. Participants were asked to keep track of the number of exercises they activated and how much time they spent on the training. Participants activated on average 8 to 13 exercises per week 
(mean 10.4, SD 6.0) in addition to the 15 exercises that were prompted that week and spent between 69 and 85 minutes (mean 78.8, SD 54.4) on the ACT training each week. The use of the ACT-DL was consistent over time, with a minor decline in use of exercises during week 3 (mean -2.5). Participants responded with an average of 5.8 (SD 1.2) out of 7 on the question whether they would recommend the ACT-DL to others. Remarks from the participants during the debriefing about the training were, for example: "It helped me practice more with ACT than I would normally do," "It kept me aware of myself," and "I want to continue with this training."

\section{User experience ACT-DL}

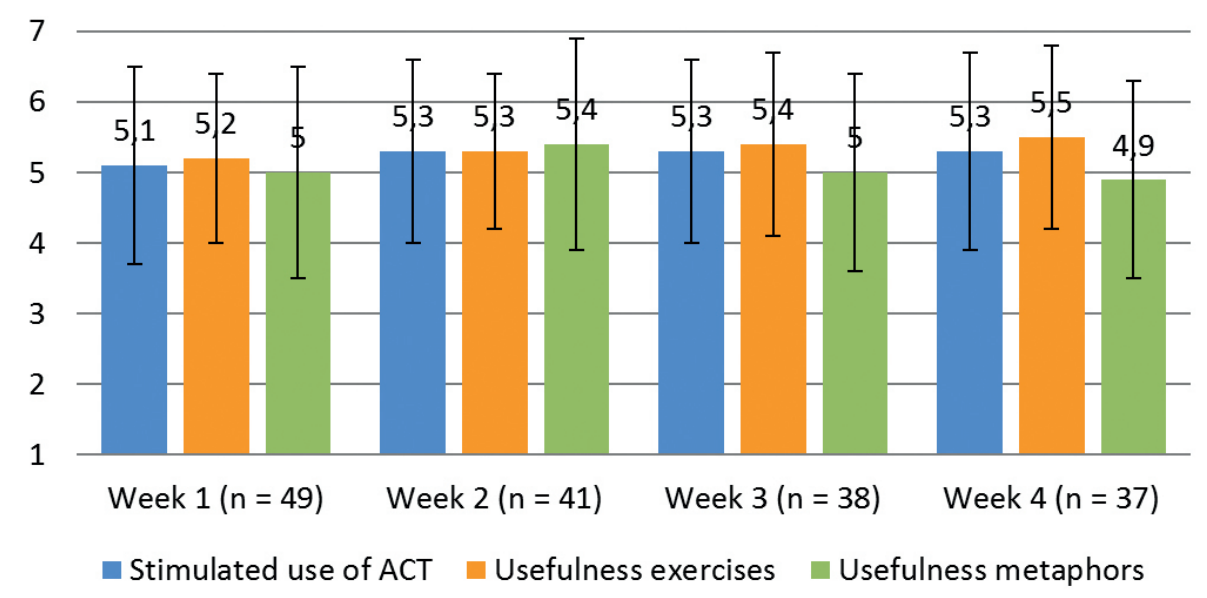

Figure 5. User experience of the ACT in Daily Life Training (ACT-DL).

When asked for suggestions for improvement of the ACT-DL, the following three considerations were proposed most commonly by the participants. The first one was the desire for more ACT exercises and more variations within these exercises (more topics, 7x). In addition, it was suggested to reduce the number of ACT metaphors that were offered each day (7x). A final suggestion was the preference for having auditory rather than visual awareness exercises (4x). The same question was also presented to the two research assistants who conducted the close to 200 semistructured interviews by phone. An important observation both interviewers made was that some participants seemed to have had difficulty discerning between the regular ACT exercises and the ACTion exercises (which were specifically designed to help participants deal with momentary negative thoughts and feelings).

\section{Effectiveness of ACT in Daily Life}

The effectiveness of the ACT-DL was assessed with self-report questionnaires. Three assessment moments were used (Table 2): preinpatient (T1), postinpatient (T2), and 
postoutpatient (T3). The effectiveness of the ACT-DL was assessed by comparing results between T2 and T3. Gender was taken into account as a possible confounder. As can been seen in Table 2, generally, the direction of the effects between T1 and T2 shows improvement (decline of symptoms, increase in skills), whereas the direction of the effects between T2 and T3 shows a slight deterioration (rise of symptoms, decline in skills).

Results show that the ACT-DL group and the control group did not differ significantly from each other at the preinpatient (T1) and the postinpatient assessment (T2). Also at the post outpatient assessment (T3), the groups did not differ significantly on psychological flexibility $\left(F_{1,152}=1.346, P=.25\right)$, symptoms $\left(F_{1,153}=1.094, P=.30\right)$, avoidant coping $\left(F_{1,148}=.153, P=.70\right)$ and quality of life $\left(F_{1,147}=0.569, P=.11\right)$. Furthermore, time (T2-T3) did not have a significant effect on these four outcomes for the ACT-DL-group ( $P=.03$ to $P=1.00)$. The repeated measures ANCOVA also showed no significant interactions between treatment group and time (T2-T3) on psychological flexibility $\left(F_{1,152}=0.023, P=.88\right)$, symptoms $\left(F_{1,153}=0.748, P=.39\right)$, avoidant coping $\left(F_{1,147}=1.184, P=.28\right)$, or quality of life $\left(F_{1,146}=2.053, P=.15\right)$. Treatment dose effect of the ACT-DL has been examined with Pearson correlations, showing a weak ( $r=.040$ to .210) and nonsignificant ( $P=.26$ to .86 ) association between dosage, defined as self-reported information on number of executed exercises during the ACT-DL and minutes of time spent on those exercises, and treatment effect. Finally there were no significant differences between diagnoses (determined with the MINI) on treatment effect regarding psychological flexibility of the ACT-DL $\left(F_{1,44}=0.005, P=.95\right)$.

Table 2. Results of self-report questionnaires at different assessment time points for participants in the intervention ( $n=49)$ and control $(n=112)$ groups in ACT in Daily Life Training (ACT-DL).

\begin{tabular}{|c|c|c|c|c|c|c|}
\hline & \multicolumn{3}{|l|}{$\begin{array}{l}\text { ACT-DL } \\
\text { Mean }(S D)\end{array}$} & \multicolumn{3}{|l|}{$\begin{array}{l}\text { Control } \\
\text { Mean (SD) }\end{array}$} \\
\hline & $(\mathrm{T} 1)^{\mathrm{a}}$ & $(\mathrm{T} 2)^{\mathrm{b}}$ & $(\mathrm{T} 3)^{\mathrm{c}}$ & $(\mathrm{T} 1)^{\mathrm{a}}$ & $(\mathrm{T} 2)^{\mathrm{b}}$ & $(\mathrm{T} 3)^{\mathrm{c}}$ \\
\hline FIT-60 ${ }^{d}$ & $177.4(33.8)$ & 206.2 (50.3) & $197.7(53.0)$ & $181.0(39.4)$ & $215.4(52.6)$ & $208.8(58.0)$ \\
\hline$\left.B S\right|^{e}$ & $1.40(.65)$ & $.70(.52)$ & $1.00(.72)$ & $1.31(.62)$ & $.67(.57)$ & $.85(.72)$ \\
\hline UCL (Avoiding) ${ }^{f}$ & $18.2(3.5)$ & $17.7(3.5)$ & $17.8(3.3)$ & $17.8(3.5)$ & $17.0(3.0)$ & $17.3(3.4)$ \\
\hline QoLg & $2.3(2.3)$ & $5.8(2.5)$ & $4.4(3.0)$ & $2.8(2.2)$ & $5.8(2.4)$ & $5.3(2.9)$ \\
\hline
\end{tabular}

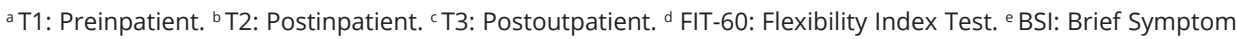
Inventory. ${ }^{\mathrm{f} U C L}$ : Utrechtse Coping List. ${ }^{\mathrm{g}} \mathrm{Q}$ oL: Quality of Life - Visual Analog Scale. 


\section{Discussion}

\section{Principal Findings}

The primary objective of this study was to assess the feasibility and acceptability of the ACT-DL in a heterogeneous mental health population. Due to enthusiasm for participation, the recruitment aim was more than doubled (20 to 49). Adherence to treatment was adequate given the intensity of the mHealth intervention with $76 \%$ of participants completing the full 4-week training. Other mHealth studies reported dropout rates as high as 50\% [36], and even higher attrition rates were reported with Web-based interventions [37]. A systematic review from Kelders et al [38] has identified important variables that could explain why the adherence to the ACT-DL was relatively high: the intervention used persuasive techniques (tunnelling, self-monitoring, and reminders); participants had frequent contact with the researchers; and the duration of the training was relatively short (4 weeks), which has been shown to produce higher adherence than interventions with a longer duration [39]. Taken together, the ACT-DL seems to be a feasible mHealth treatment. User evaluations showed that the program stimulated the use of ACT in daily life; participants practiced over an hour a week, doing 10 exercises on average. Both ACT exercises and metaphors were experienced as useful components of the training. Also participants would highly recommend the training to others. These results also suggest high acceptability of the ACT-DL. These findings are in line with previous studies [21, 22, 23, 24], showing that it is feasible to deliver ACT via mHealth.

User evaluations showed that the acceptability of ACT-DL could be enhanced by extending the number of available ACT exercises. Auditory awareness exercises could also increase treatment adherence. Although ACT metaphors were generally appreciated, the frequency should be limited (once or twice a day). A further recommendation was that the tool should be simple in its design and functions (distinguishing between regular ACT exercises and ACTion exercises seemed to be unclear for some participants). These results correspond with and add to recommendations of a similar nature by Ahtinen and colleagues [40], who stressed easy-to-do daily life exercises and guiding participants gently through but not restricting choice in exercises.

A revised version of the ACT-DL, based on lessons learned from this study, will be used in future research $(\mathrm{H}$, Steinhart, MSc, unpublished data, 25-2-2016). In this revised version an additional 16 ACT exercises and 8 metaphors are added, divided over all 6 instead of 3 ACT components (in line with the feedback for more exercises and variation). Also the number of beeps are lowered from 10 to 8 per day (thereby lowering the amount of metaphors offered and restricting to two different metaphors per day). Furthermore, the differences between the regular ACT exercises and ACTion exercises are more articulated. When participants activate the training menu, a question is added that helps to guide them to the exercise that is most appropriate for that particular moment. For example, when participants answer yes to the question "Do you experience unpleasant thoughts, feelings, or sensations at this moment?" they are guided to the ACTion exercises that are specifically designed to deal with negative experiences in the present moment. If answering no, participants are guided to general ACT exercises. Finally, the setup of the intervention is changed from 
sequential (first ACT training, than mHealth training) to synchronized (ACT training and mHealth training combined), and the training is extended from a 4-week to a 7-week training. Finally, a preliminary examination of the effectiveness of the ACT-DL was performed. These results showed no short-term effect immediately after termination of the ambulatory ACTDL on top of the effect of the inpatient ACT group intervention. We cannot rule out that subtle add-on effects of the ACT-DL were obscured by the impact of the transition from an intensive inpatient treatment to an ambulatory treatment. This effect was apparent in both ACT-DL and control participants. It is also possible that a ceiling effect, due to the intensive inpatient treatment, hampered measurement of additional improvement. Additionally, only short-term effects were investigated since there were no follow-up data available to assess the effectiveness of the ACT-DL in the long term. Differences may emerge at a later stage as it has been shown that effects of acceptance-based interventions can increase over time [41]. A recent RCT(randomized controlled trial) from Lappalainen [42] showed significant differences at 18-month follow-up.

\section{Limitations}

Our study had some limitations. User evaluation is sensitive to recall bias. Therefore, ESM data could a valuable source of information on user experience, but a structured log was not available to provide this data. Hence, objectifying ACT practice was not possible. Also, there was no information available on the dropout rate in the control group making it impossible to compare rates. The proportion of females was higher in the ACT-DL group than the control group; female participants were apparently more willing to participate in the study or more willing to take ACT-DL into use. Overall, this study has a high proportion of females, and this could limit generalizability of results to males. A final limitation is the observational nature of the study. It is possible that the groups differed from each other on unmeasured confounders.

\section{Conclusions}

This is the first study that uses experience sampling, fostering awareness in daily life, in combination with acceptance and commitment therapy, fostering skill-building in daily life. The study suggests that the combination not only fits theoretically but also seems to function well in practice. Another strength of this study is the use of a heterogeneous clinical sample. Therefore, the generalizability of the results may be high, suggesting that ACT-DL is suitable for a broad range of mental health problems. Effectiveness will have to be examined further in experimental settings that also address long-term effects. 


\section{Acknowledgments}

We thank our study participants, as well as the treatment facility, U-Center, for the collaboration in this research project. We also want to thank Ron Mengelers for the IT support, Truda Driesen for the PsyMate support, Rufa Diederen for the briefing, Tom Schiphof for Routine Outcome Monitoring support, and Ger Driessen for help with cleaning and restructuring the dataset. This study was supported by a European Research Council consolidator grant to IMG (ERC-2012-StG, project 309767-INTERACT) and by the Weijerhorst Foundation.

\section{Conflicts of Interest}

None declared 


\section{Multimedia Appendix 1}

Photos of ACT in Daily Life training with the PsyMate.

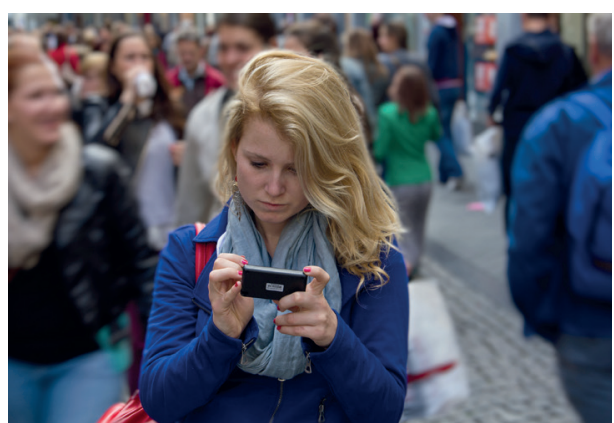

Using the ACT-DL with PsyMate in daily life

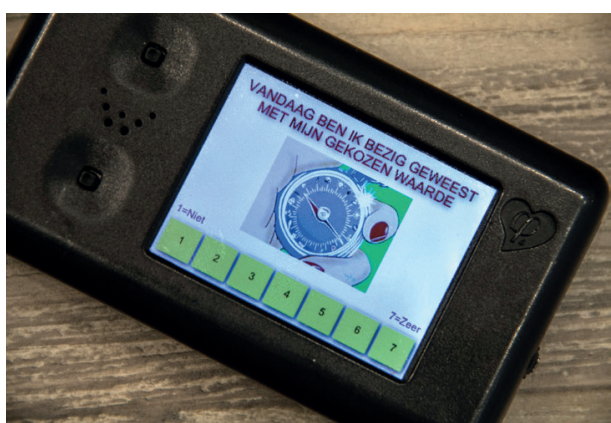

PsyMate showing exercise of the ACT-DL-program

\section{Abbreviations}

ACT: acceptance and commitment therapy

ACT-DL: ACT in Daily Life

ANCOVA: analysis of covariance

BSI: Brief Symptom Inventory

ESM: experience sampling method

FIT-60: Flexibility Index Test

MINI: Mini-International Neuropsychiatric Interview

PDA: personal digital assistant

QoL-VAS: Quality of life visual analog scale

SIDP-IV: Structured Interview for DSM Personality Disorders

DSM-IV-TR: Diagnostic and Statistical Manual of Mental Disorders(Fourth Edition)

UCL: Utrechtse Coping List 


\section{References}

1. Kohlenberg, R. J., Bolling, M. Y., Kanter, J. W., \& Parker, C. R. (2002). Clinical behavior analysis: Where it went wrong, how it was made good again, and why its future is so bright. The Behavior Analyst Today 3: 248-253. doi:10.1037/h0099988

2. Hayes, S. C. (2004). Acceptance and commitment therapy, relational frame theory, and the third wave of behavioral and cognitive therapies. Behavior therapy, 35(4), 639-665. doi:10.1016/S0005-7894(04)80013-3

3. Hayes, S. C., Strosahl, K., \& Wilson, K. G. (1999). Acceptance and Commitment Therapy: An experiential approach to behavior change. New York: Guilford Press. ISBN:978-1572304819

4. Hayes, S. C, Strosahl, K. D., \& Wilson, K. G. (2012). Acceptance and commitment therapy: The process and practice of mindful change (2nd edition). New York, NY: The Guilford Press. ISBN:858-1000003816

5. Foody, M., Barnes-Holmes, Y., Barnes-Holmes, D., Torneke, N., Luciano, C., Stewart, I., \& McEnteggart, C. (2014). RFT for clinical use: The example of metaphor. Journal of Contextual Behavioral Science, 3, 305313. doi:10.1016/j.jcbs.2014.08.001

6. A-Tjak, J. G. L., Davis, M. L., Morina, N., Powers, M. B., Smits, J. A. J. \& Emmelkamp P. M. G. (2015). A Meta-Analysis of the Efficacy of Acceptance and Commitment Therapy for Clinically Relevant Mental and Physical Health Problems. Psychotherapy and Psychosomatics, 84, 30-36. PMID:25547522

7. Larson, R., \& Csikszentmihalyi, M. (1983). "The experience sampling method". New Directions for Methodology of Social and Behavioral Science, 15, 41-56.

8. Myin-Germeys, I., Oorschot, M., Collip, D., Lataster, T., Delespaul, P., \& van Os, J. (2009). Experience sampling research in psychopathology: opening the black box of daily life. Psychological Medicine, 39, 15331547. PMID:19215626

9. Barta, W. D., Tennen, H., \& Litt, M. D. (2012). Measurement reactivity in diary research. In: Mehl MR, Conner TS, editors. Handbook of research methods for studying daily life. The Guilford Press; New York: pp. 108-123. ISBN:9781609187477

10. Istepanian, R., Laxminarayan, S., \& Pattichis, C. S., eds. (2006). M-Health: Emerging Mobile Health Systems. Springer. ISBN:9780387265599

11. Torgan, C. (November, 2009). "The mHealth Summit: Local \& Global Converge". caroltorgan.com. http:// caroltorgan.com/mhealth-summit/ . Archived at: http://www.webcitation.org/6cMAlgvNs

12. Pew Research Center (February, 2016). "Smartphone Ownership and Internet Usage Continues to Climb in Emerging Economies". http://www.pewglobal.org/2016/02/22/smartphone-ownership-and-internetusage-continues-to-climb-in-emerging-economies/. Archived at: http://www.webcitation.org/6gUeKe386

13. Delespaul, P. (1995). Assessing schizophrenia in daily life. Maastricht (The Netherlands): ISPER. ISBN: 978 9052781815

14. Kimhy, D., Delespaul, P., Corcoran, C., Ahn, H., Yale, S. \& Malaspina, D. (2006). Computerized experience sampling method (ESMc): Assessing feasibility and validity among individuals with schizophrenia. Journal of Psychiatric Research, 40, 221-230. PMID:16300791

15. Morris, M. E., Kathawala, Q., Leen, T. K., Gorenstein, E. E., Guilak, F., Labhard, M., \& Deleeuw, W. (2010). Mobile therapy: case study evaluations of a cell phone application for emotional self-awareness. Journal of Medical Internet Research, 12(2):e10. PMID:20439251

16. Heron, K. E., \& Smyth, J. M. (2010). Ecological Momentary Interventions: Incorporating mobile technology into psychosocial and health behavior treatments. British Journal of Health Psychology, 15, 1-39. PMID:19646331

17. Kramer, I., Simons, C. J., Hartmann, J. A., Menne-Lothmann, C., Viechtbauer, W., Peeters, F., Schreurs, K., Bemmel, A. L., Myin-Germeys, I., Delespaul, P., van Os, J., \& Wichers, M. (2014). A therapeutic application of the experience sampling method in the treatment of depression: a randomized controlled trial. World Psychiatry, 13, 68-77. PMID:24497255

18. Runyan, J. D., \& Steinke, E. G. (2015). Virtues, ecological momentary assessment/intervention and smartphone technology. Frontiers in Psychology, 6, 481. PMID:25999869

19. Van Os, J., Delespaul, P., Barge, D., \& Bakker, R. P. (2014). Testing an mHealth momentary assessment Routine Outcome Monitoring application: a focus on restoration of daily life positive mood states. PLoS One, 9(12). doi:10.1371/journal.pone.0115254

20. Loo Gee, B., Griffiths K. M., \& Gulliver, A (2015). Effectiveness of mobile technologies delivering Ecological Momentary Interventions for stress and anxiety: a systematic review. Journal of the American Medical Informatics Association. doi:10.1093/jamia/ocv043 [Epub ahead of print]

21. Cheng, C., Brown, R. C., Cohen, L .L., Venugopalan, J., Stokes, T. H., \& Wang, M. D. (2013). IACT - An interactive $\mathrm{mHealth}$ monitoring system to enhance psychotherapy for adolescents with sickle cell disease. Conference proceedings: ... Annual International Conference of the IEEE, Engineering in Medicine and Biology Society (EMBC), Annual Conference, 07/2013; 2279-2282. PMID:24110179

22. Ly, K. H., Dahl, J., Carlbring, P., \& Andersson, G. (2012). Development and initial evaluation of a smartphone application based on acceptance and commitment therapy. Springerplus, 1(1), 11. PMID:23961342 
23. Ly, K. H., Asplund, K., \& Andersson, G. (2014). Stress management for middle managers via an acceptance and commitment-based smartphone application: A randomized controlled trial. Internet Interventions, 1, 95-101. doi:10.1016/j.invent.2014.06.003

24. Bricker, J. B., Mull, K., Vilardaga, R., Kientz, J. A., Mercer, L. D., Akioka, K., \& Heffner, J. L. (2014). Randomized, controlled trial of a smartphone app for smoking cessation using Acceptance and Commitment Therapy. Drug and Alcohol Dependence, 143, 87-94. PMID:25085225

25. Vliet, I. M. van, Leroy, H., \& Megen, H. J. G. M. van (2000). MINI International Neuropsychiatric Interview (M.I.N.I.), Nederlandse versie 5.0.0.

26. Jong, C. A. J. de, Derks, F. C. H., Oel, C. J. van \& Rinne, Th. (1996). SIDP-IV: Gestructureerd interview voor de DSM-IV persoonlijkheidsstoornissen. Sint Oedenrode: StichtingVerslavingszorg Oost Brabant.

27. Myin-Germeys, I., Birchwood, M., \& Kwapil, T. (2011). From environment to therapy in psychosis: a realworld momentary assessment approach. Schizophrenia Bulletin, 37(2), 244-247. PMID:21224492

28. Batink, T., Jansen, G., \& De Mey, H. R. A. (2012). De Flexibiliteits Index Test (FIT-60): Een beknopte beschrijving. GZ-Psychologie, 5, 18-21.

29. Batink, T., \& Delespaul, P. (2015). Meten van psychologische flexibiliteit - De Flexibiliteits Index Test (FIT60). Tijdschrift voor Gedragstherapie en Cognitieve Therapie, 4, 310-332.

30. Schreurs, P. J. G., \& Willige, G. van de (1988). Omgaan met problemen en gebeurtenissen: De Utrechtse Copinglijst (UCL). Lisse: Swets \& Zeitlinger.

31. Schreurs, P. J. G., Willige, G. van de., Brosschot, J. F., Tellegen, B., \& Graus, G. M. H. (1993). Handleiding Utrechtse Coping Lijst UCL (herziene versie). Lisse: Swets \& Zeitlinger.

32. Derogatis, L. \& Melisaratos, N. (1983). The Brief Symptom Inventory: An introductory report. Psychological Medicine, 13, 595-605. PMID:6622612

33. De Beurs, E. (2004). Handleiding bij de Brief Symptom Inventory (BSI). Leiden: Pits Publishers.

34. De Beurs, E. \& Zitman, F.G. (2006). De Brief Symptom Inventory (BSI): De betrouwbaarheid en validiteit van een handzaam alternatief voor de SCL-90. Maandblad Geestelijke Volksgezondheid, 61, 120-141.

35. Hoefman, R. J., van Exel, J., \& Brouwer, W. B. (2013). Measuring the impact of caregiving on informal carers: a construct validation study of the CarerQol instrument. Health and Quality of Life Outcomes,11, 173. doi: 10.1186/1477-7525-11-173. PMID:24139439

36. Stoner, S. A., Arenella, P. B., \& Hendershot, C. S. (2015). Randomized controlled trial of a mobile phone intervention for improving adherence to naltrexone for alcohol use disorders. PLoS One, 10 (4). PMID:25909320

37. Price, M., Gros, D. F., McCauley, J. L., Gros, K. S., \& Ruggiero, K. J. (2012). Nonuse and dropout attrition for a web-based mental health intervention delivered in a post-disaster context. Psychiatry, 75, 267-284. PMID:22913502

38. Kelders, S. M., Kok, R. N., Ossebaard, H. C., \& Van Gemert-Pijnen J. E. (2012). Persuasive system design does matter: a systematic review of adherence to web-based interventions. Journal of Medical Internet Research, 14(6):e152. PMID:23151820

39. Cugelman. B., Thelwall, M., \& Dawes, P. (2011). Online Interventions for Social Marketing Health Behavior Change Campaigns: A Meta-Analysis of Psychological Architectures and Adherence Factors. Journal of Medical Internet Research, 13(1):e17. PMID:21320854

40. Ahtinen, A., Mattila, E., Välkkynen, P., Kaipainen, K., Vanhala, T., Ermes, M., Sairanen, E., Myllymäki, T., Lappalainen, R. (2013). Mobile mental wellness training for stress management: feasibility and design implications based on a one-month field study. JMIR mHealth and uHealth, 10(2). PMID:25100683

41. Ruiz, F. J. (2010). A review of Acceptance and Commitment Therapy (ACT) empirical evidence: Correlational, experimental psychopathology, component and outcome studies. International Journal of Psychology and Psychological Therapy, 10, 125-162.

42. Lappalainen, P., Granlund, A., Siltanen, S., Ahonen, S., Vitikainen, M., Tolvanen., A., \& Lappalainen, R. (2014). ACT Internet-based vs face-to-face? A randomized controlled trial of two ways to deliver Acceptance and Commitment Therapy for depressive symptoms: An 18-month follow-up. Behaviour Research and Therapy, 61, 43-54. doi:10.1016/j.brat.2014.07.006. 
Henrietta Steinhart ${ }^{1,2 \star}$, Thomas Vaessen ${ }^{1,2 \star}$, Tim Batink ${ }^{2,3}$ Inez Myin-Germeys ${ }^{1}$

\section{* Shared 1st author}

${ }^{1}$ KU Leuven, Department of Neuroscience, Center for Contextual Psychiatry, Kapucijnenvoer 33 blok i - bus 7001, 3000 Leuven, Belgium.

${ }^{2}$ Maastricht University Medical Centre, South Limburg Mental Health Research and Teaching Network, Box 616, 6200 MD Maastricht, The Netherlands.

${ }^{3}$ U-center, Epen, The Netherlands. 
ACT in Daily Life: A Momentary Intervention Approach

Submitted 


\begin{abstract}
The current article describes the ACT in Daily Life (ACT-DL) training, a new mobile Health treatment protocol for Acceptance and Commitment Therapy (ACT). ACT-DL is an ecological momentary intervention. Between weekly ACT therapy sessions, patients are asked on several instances throughout the day to fill in brief questionnaires on the app about their mood, symptoms, activity, and current context, thus promoting awareness, a crucial component of ACT. The device also provides them with visual cues and exercises specifically related to the ACT sessions to help them implement the techniques previously learned in therapy into their daily lives. ACT-DL helps to apply ACT skills to diverse contexts of everyday life, thus extending practice beyond the therapist's office, thereby potentially enhancing effectiveness of ACT. ACT-DL is person-tailored as patients practice with their own experiences and complaints and it increases patient empowerment. Limitations and future directions are discussed.
\end{abstract}




\section{Introduction}

In the current article, we describe a new mobile Health (mHealth) treatment protocol -ACT in daily life (ACT-DL)- based on Acceptance and Commitment Therapy (ACT, [1]), helping patients build up more adaptive automatic responses to stressful situations and engage more in their personal values. ACT-DL uses a smartphone app to implement the therapeutic context into the patient's everyday life.

ACT focuses on acceptance of negative thoughts and emotions instead of trying to change or control them. It uses cognitive and behavioral techniques to teach patients cognitive flexibility (i.e. the ability to adapt one's cognitive strategies to changing conditions in the environment [2], which in turn decreases stress and improves mental health [3]. ACT is not symptom-specific, it can be applied to all experiences that people have. Similarly, ACT aims to teach patients skills that they can apply in every new situation. Furthermore, ACT does not only help patients to handle stressful situations, it also teaches them how to engage more in those values they deem important and yet are not enough reflected in their pattern of behavior - the commitment component [4]. Due to this broad mechanism of work, ACT has been demonstrated to be an effective treatment for many psychopathological disorders and symptoms $[5,6]$. ACT seems to be equally effective as traditional CBT in the treatment of anxiety disorders, depression, addiction and somatic disorders [5]. It thus seems to be a promising new approach to the treatment of psychiatric problems.

Most psychotherapies to date, including ACT, are entirely conducted in the therapist's office, which may contribute to the lack of success to produce consistently large effect sizes $[7,8$, 9]. A promising extension to this office-based approach is the mHealth approach, which employs the use of mobile devices for the delivery of health care services and public health communication in real life [10]. Although still in its infancy, mHealth has been proven useful in a wide range of areas, both for physical and mental health, its methods being deployed for treatment of diabetes, asthma, weight loss, smoking, depression, and anxiety [11, 12, $13,14,15,16]$. Using apps to introduce the therapeutic elements into the patients' everyday life, may aid 1) in focusing on the specific needs and complaints of that specific patient, thus making it person-tailored, and 2) in translating the techniques that patients have learned at their therapists' office into their everyday lives, thus increasing patient empowerment. Acquiring effective coping skills is an important step in the therapeutic process, but without the ability to apply these strategies in the appropriate circumstances, they may be of little use to the patient. Unfortunately, those situations that call for the implementation of therapeutic techniques (i.e. subjectively stressful situations) quickly lead individuals to switch from goal-directed to habitual behavior [17]. Hence, patients will often react by falling into old, dysfunctional patterns as these most easily come to mind. Reacting with newly acquired coping strategies needs to be practiced in real-life context in order to become an automatic response.

ACT may particularly benefit from an mHealth approach. ACT has its philosophical roots in functional contextualism, which particularly emphasizes the relevance of the context in which 
a behavior is taking place and the function the behavior is serving. In ACT, the central question is not "is what I am thinking valid?" but "is what I am thinking useful for me in this situation?". This philosophical basis makes ACT particularly suited to be expanded in real life using an mHealth approach, putting the therapeutic techniques - quite literally - into context.

In sum, the current article aims at introducing a protocol of ACT-DL, an ACT mHealth intervention that aims to increase ACT's therapeutic effectiveness through improved integration of its therapeutic techniques into the patient's everyday life.

\section{Overview of the ACT model}

In ACT, acceptance of unwanted experiences provides room for active investment in one's values. Acceptance is one of six components that, together with cognitive defusion, self-ascontext, contact with the present moment, values, and committed action, comprise ACT. Mastery of all six components provides an individual with the psychological flexibility to handle a broad range of challenging experiences. The ACT process typically starts with an exploration of the individual's unsuccessful attempts to cope with unwanted experiences (typically based on avoidance) in a process called creative hopelessness. The alternative is offered in the form of acceptance of these experiences, taking distance of unwanted cognitions and ideas about the self, being aware about the present moment (together referred to as the acceptance core component of ACT), and investment in personal values (the commitment core component). One of the strengths of new-generation contextual psychotherapies in general, and ACT in particular, is that it trains a broad and flexible behavioral repertoire that is not symptom-specific but can be applied in almost any situation.

\section{Overview of ACT-DL}

ACT in Daily Life (ACT-DL) is an ACT-based mHealth program aimed at transferring the skills and insights learned during weekly ACT sessions into the practice of daily life. In ACT-DL, patients engage in a mobile intervention that requires active exercise of ACT principles throughout the day in addition to standard ACT sessions where the ACT methods are introduced. The program's total duration can be modified flexibly to the patient's demands or therapist's professional appraisal (e.g. sessions can be repeated if needed). As noted earlier, in contrast to some other treatments ACT is not aimed at symptom reduction per se, but rather applies to the full range of an individual's experiences. This approach ideally lends itself to an mHealth format based on the experience sampling method (ESM, $[18,19])$, a structured diary technique assessing current experiences repeatedly throughout the day. Using mobile technology, ACT-DL guides individuals in the application of ACT in the realworld and in real-time, within the scope of their current experiences and situation. In ACT-DL, individual ACT sessions are provided under the guidance of an ACT therapist in 
every week of the program. An overview of the sessions' content, as well as a description of ACT-DL components and techniques, is provided below. During the sessions patients are introduced to the basic principles of ACT and provided with insights, exercises and metaphors that help implementing ACT in their lives. ACT-DL makes use of metaphors as a reminder of its basic ideas in an intuitive format. In ACT-DL, a metaphor is presented as a visual image of an abstract situation that cues the individual to apply ACT principles to any given situation. When trying to change old behavior patterns or making lasting change, frequent practice of new behaviors is needed. Hence, in addition to the metaphors, practical exercises comprise a crucial element of ACT-DL.

Following an ACT session, the patients engage on at least three consecutive days in a mobile ACT phase focusing on the components discussed in that week's session. The ACT-DL teaches patients to directly apply the newly discussed ACT-components to their daily lives in the form of exercises and metaphors. The mHealth modules of ACT-DL make use of a mobile application that can be installed on a smartphone, tablet or dedicated device. During the mobile intervention periods, on eight semi-random moments each day, patients receive prompts on their mobile aid. When prompted, they are provided with a short questionnaire assessing their current mood, symptoms and activity, guiding them in the process of becoming aware of their momentary psychological state and increase their contact with the present moment. At the end of the questionnaire, patients are either presented with a visual illustration of an ACT metaphor or with a written description of an ACT exercise. In case of acceptance or defusion exercises, patients have to indicate whether or not they currently suffer from unwanted experiences. Depending on their response they receive an exercise that taps into current negative experiences or an exercise to train general ACT principles. Throughout the entire ACT-DL therapy patients are given the opportunity to activate an ACT exercise at any time they need assistance in dealing with difficult thoughts or emotions. Furthermore, they are advised to do an extra exercise in the morning, afternoon and evening each day. The theme of the metaphors and exercises depends on the ACT components that are discussed during that week's session.

During the ACT session on personal values, the patients identify three values (e.g. family, career, health) which they feel are not enough reflected in their daily behavior. After the next ACT session, discussing the committed action component, patients are asked to take some time in the morning to consider one of these three personal values. They are instructed to choose a value with the intention of acting in ways consistent with it throughout the day. Patients are asked to set a practical, feasible goal for that day, to guide them in their commitment to the chosen value. After every questionnaire, and once more at the end of the day, patients are asked to evaluate the extent to which they were able to live in line with their chosen value and if they were able to reach their goal for the day.

After all components are trained separately, the mobile intervention expands to cover the full range of ACT processes and patients learn to flexibly adopt skills and mindsets depending on the context (see Table 1 for an example of how a full training program may look). Patients are instructed to employ learned techniques specifically in situations where they are needed (thus, at times of distress, bothersome symptoms or challenging situations). This renders 
the intervention person-tailored and interactive, considering current mental state as well as contextual situation.

The following paragraphs describe each of the eight modules of ACT-DL, including the ACT component central to the module and the structure of its daily-life part. During the first session, a brief introduction to ACT and its principles and cornerstones is provided where the therapist explicitly stresses that ACT is a behavioral therapy and explains the use and importance of metaphors and exercises. The therapist furthermore provides an overview of the ACT-DL program, including the ACT-DL mobile application and the concept of the questionnaires, metaphors and exercises within the mobile intervention. Although therapists can choose the order of the modules, some logical structure should be applied (e.g. Cognitive Defusion should precede the Self as Context module and the Values module logically precedes that Committed Action module). The last paragraph of this section describes how ACT-DL can be applied flexibly and tailored to each unique situation.

\section{Creative Hopelessness Module}

Creative hopelessness is the process of realization that despite all frantic efforts to avoid negative experiences, the suffering remains (note that the fact that the individuals sought help for their complaints indicates the ineffectiveness of these efforts). Importantly, no alternative to avoidance is offered during the session, typically leaving the individual with a sense of hopelessness. This ultimately creates room for change and hope, which is necessary before an alternative strategy can be offered.

During the week following this session, on three consecutive days patients engage in the daily-life part this session, using the ACT-DL mobile app module: creative hopelessness. This module contains two different ACT Metaphors and four ACT Exercises with the theme creative hopelessness (see Table 2 for examples of ACT-DL Metaphors and Exercises). The metaphors and exercises help the patients in their daily lives to recognize their avoidance behavior and to experience the costs (and relative lack of benefits) they come with.

In addition to every module in the mobile intervention, ACT-DL contains a questionnaire and four exercises of the contact with the present moment component. The questionnaires help the patients to become aware of the present moment by assessing their current experiences. Awareness of current thoughts and feelings is a necessity in the process of integrating the ACT skills and insights in daily life, and hence these skills are practiced from the first session onwards. In the creative hopelessness module, the questionnaires and exercises will help the patients gaining consciousness about their avoidant coping strategies in their process of creative hopelessness.

\section{Acceptance Module}

In this session, acceptance is offered as the alternative to control and avoidance. This session focuses on acceptance of unpleasant emotions or sensations and learning to "just notice" them, instead of trying to make them disappear. Patients practice acceptance through exposure to their pain. ACT assumes that pain is inevitably a part of life and that suffering is a result of ineffective coping with pain (i.e. avoidance). Pain, here, does not necessarily 


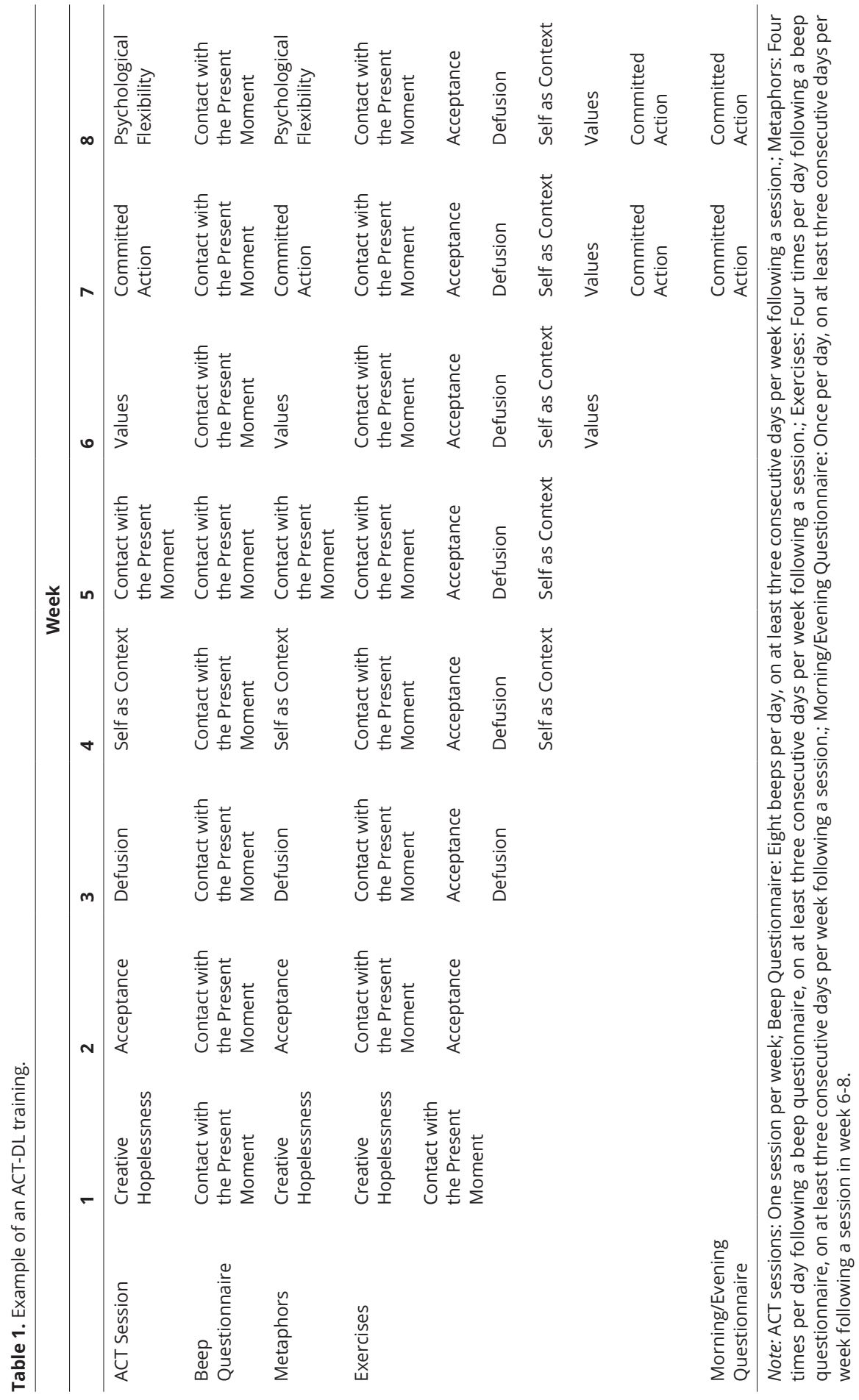


refer to nociception, but instead to any unwanted sensation or emotion. Suffering, then, refers to the negative consequences of avoidance behaviors, such as social isolation as a consequence of ceasing to engage in pleasant social activities out of social anxiety.

In the ACT-DL acceptance module, patients are provided with two ACT metaphors and seven ACT exercises centered on the acceptance component. Three of these exercises are aimed at current unwanted emotions and sensations; four are general acceptance exercises. During three days of the week following the session, they learn to face their own pain without attempting to control it in order to diminish the unnecessary suffering. Throughout the day, ACT metaphors remind them of the newly learned coping strategies to stop fighting pain. Practical exercises help them to put the theory into practice and experience their unwanted emotions and sensations without trying to change them. Again, this module is paralleled by ACT exercises and questionnaires of the contact with the present moment component. This helps the acceptance exercises, as they crucially rely on awareness about the pain.

\section{Cognitive Defusion Module}

With regard to unwanted thoughts, cognitive defusion is offered as a possibility to take some distance from thoughts, and forms the topic of this ACT module. ACT is built on the premise that people have a tendency to respond to their thoughts in a fused manner, treating them as if they were facts. If patients respond to their negative or judgmental thoughts as if they were facts, and base their behavioral choices on such thoughts, then they may end up engaging in behaviors that are self-limiting or self-destructive. To defuse from one's thoughts is a skill that can only be mastered through practice, and patients are guided in this process by exercises that focus on observation of, and distancing from their thoughts.

This week's mobile intervention module contains two metaphors of the cognitive defusion component. In addition, the module contains seven exercises focused on cognitive defusion, three of which are aimed at current unwanted thoughts and four of which are general defusion exercises. Cognitive defusion is a core ACT skill that requires substantial exercise. Once patients of the ACT-DL program are able to detach from their thoughts, they can transfer these techniques to thoughts about the self as well and let go of their self-image, which is the topic of the self as context module.

\section{Self as Context Module}

The ACT session of this module discusses the self as context component. Here, the distancing from unpleasant thoughts (as learned during the cognitive defusion session), is generalized to include believes about the self as well. ACT distinguishes between the "thinking self" and the "observing self." Whereas the first is the part of the self that produces thoughts, memories and convictions that form the self-image, the latter can be seen as the inner observer, the part of the self that observes the thinking self. This distinction is crucial for the realization that thoughts and feelings are something that we have- not that we are. From an ACT perspective, the fusion between self-image and thoughts or feelings is referred to as the "conceptualized self" and limits behavioral flexibility. As patients experience that their self-image takes different forms in different contexts they learn to realize that the self 
is not a rigid entity and that ultimately the observing self is the only characteristic of the self that persists over time. Like the ACT session, the daily life module of this week centers on the self as context component and contains two metaphors with this theme. The module further consists of four self as context exercises which guide the patients throughout the day in the process of understanding this relatively abstract component and living with a flexible self-image.

\section{Contact with the Present Moment Module}

As patients of the ACT-DL program practice with the contact with the present moment component throughout the other modules, they are familiar with the concept when they start this session (if this is not the first module of the treatment). As the name suggests, the contact with the present moment component teaches patients to focus less on the past and future, and more on the here and now. As people worry about the future or ruminate on the past, the present passes by unnoticed. As such, the contact with the present moment is also about awareness about the environment (both internal and external) instead of lingering in thoughts. Possibly even more than other components, contact with the present moment exercises need practice, which is why a considerable part of this session is dedicated to practical exercise.

Practicing continues during the daily life module in the week following this session, where two contact with the present moment metaphors remind patients to be aware of the current moment and the same four exercises that they have been practicing with thus far guide them in the process.

\section{Values Module}

In contrast with the previous modules, this module aims to help people live a life guided by values, rather than practicing making room for uncomfortable experiences. A first step in doing so is to become aware of what matters most to the individual. During this session, patients are invited to think about their personal values. Values are those principles that matter most to a person, which serve as a direction in life, as a guide for our behavior. Exploration of personal values is necessary to invest in them, which is the aim of the next ACT component: committed action.

The ACT-DL module of this session contains two metaphors of the values component. Furthermore, in addition to the four contact with the present moment exercises, during three days following this session, patients are provided with four exercises of the values component. These exercises aid them in further exploring which values are important to them.

\section{Committed Action Module}

Putting theory into practice, the committed action session is dedicated to the formulation of meaningful, realistic, concrete goals that are in accord with the personal values identified during the Values session. Setting concrete goals helps the patients to translate the abstract idea of a value into practical actions to carry out. Patients learn that knowing what is important to them is an important first step, but in itself does not influence their lives; committed action is necessary. 

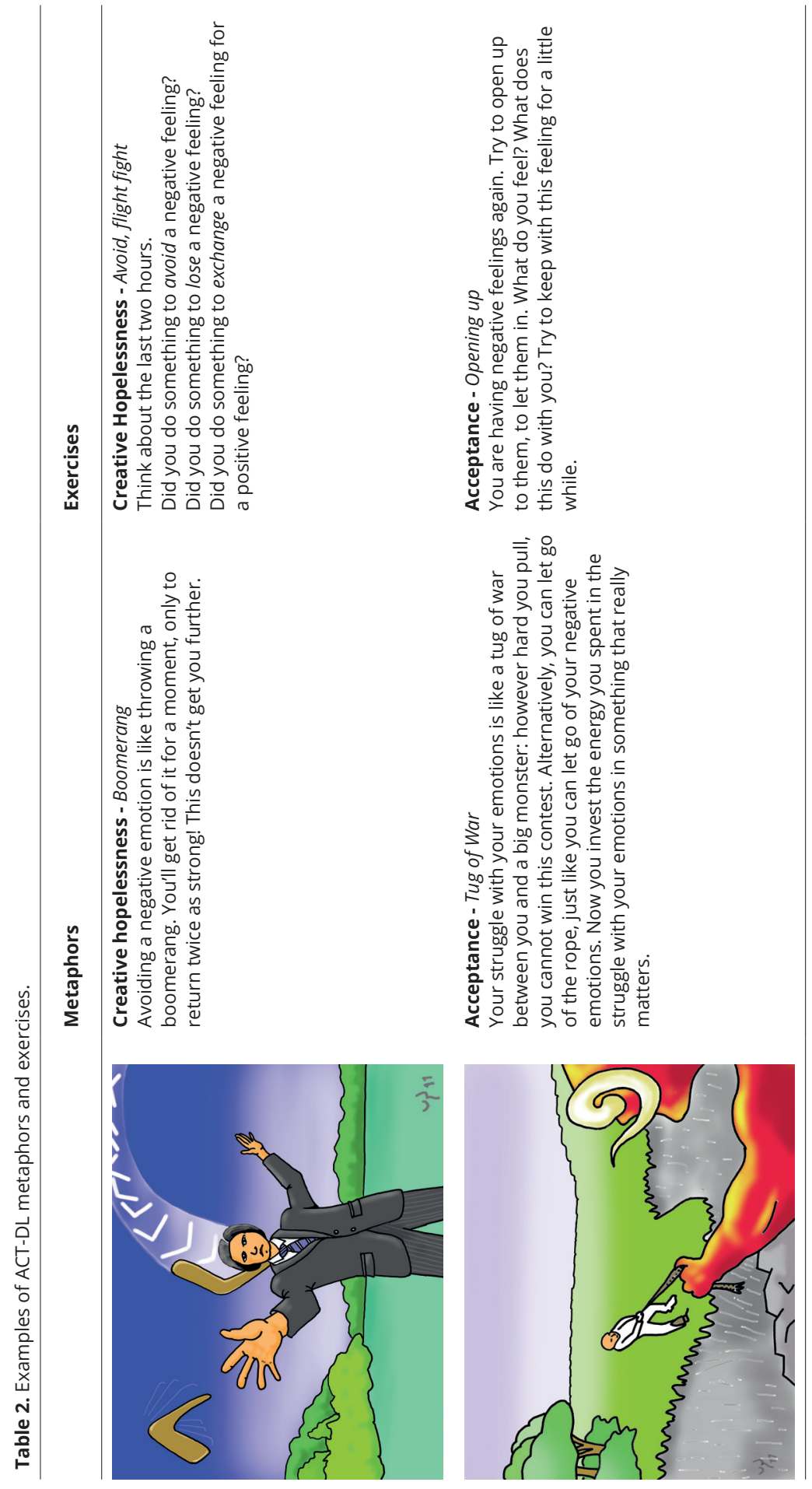

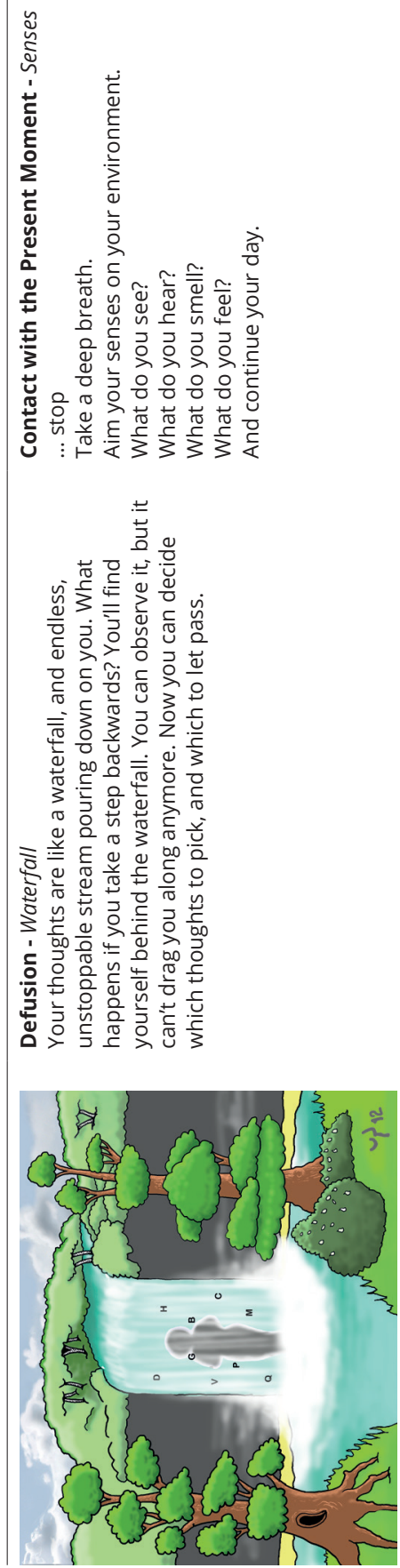
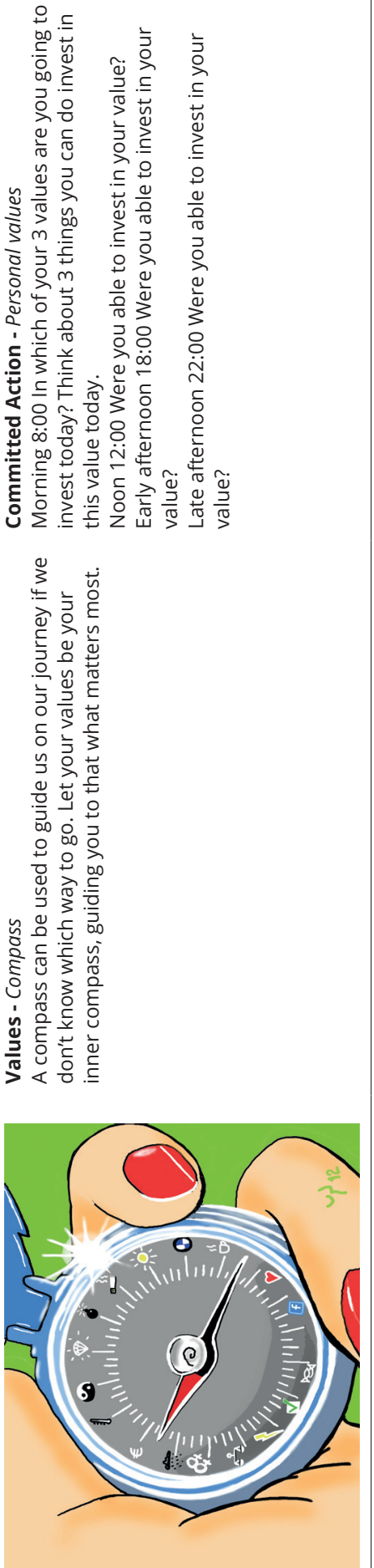
The committed action daily life module contains two new metaphors and four new exercises that aim to help patients to set goals and reach them taking one step at the time. In addition, patients will still be able to opt for contact with the present moment exercises whenever they wish and will be presented with contact with the present moment questionnaires throughout the day. The final additions to this module are the morning and evening questionnaires, which remind the patients of their chosen values and let them think about actions to invest in them.

\section{Psychological Flexibility Module}

The last step in ACT pertains to the integration of all components by means of psychological flexibility, providing the patients with a variety of skills to adapt to every situation. The central theme of the last ACT session is learning to apply ACT skills in a flexible manner to any given situation, depending on the demands of the present moment. This concept is compared to learning to dance, where separate elements, such as different movements, keeping balance and following the rhythm, represent ACT skills. Only after practicing all skills in isolation an individual is able to harmoniously combine them to a cohesive pattern. Exercises that require switching between different ACT skills during the session provide the patients with an opportunity to practice with psychological flexibility.

During this last week of the therapy patients are provided with a module that brings all previous components together. This module contains one metaphor for each of the components acceptance, cognitive defusion, values and committed action and all acceptance, cognitive defusion, values, committed action and contact with the present moment exercises, in addition to the morning and evening questionnaires (that remind them to commit to a valued action every day) and contact with the present moment questionnaires. Thus, during the final week of ACT-DL the patients are guided in the flexible application of all skills they learned throughout the therapy.

That the ACT-DL program ends after the psychological flexibility module does in no way imply that patients should stop using the daily life protocol. The period of the last daily life module may be prolonged for as long as patients wish. As stressed before, ACT skills need sufficient practice before they become intuitively integrated in everyday life. The daily life protocol aids this integration to the point where the patients feel that they adopted all skills and are able to apply them naturally in daily life.

\section{ACT-DL as a flexibly applicable treatment}

As presented here, ACT-DL adds an mHealth protocol to a standard ACT therapy. However, for various reasons (e.g. symptomatology, personality characteristics, practicalities, etc.) ACT-DL might be adjusted to match the diverse needs of the patients. First of all, ACT is a flexible treatment that can be fully adapted to the patient's needs and therapist's preferences. Not only can a therapist decide on the order of the modules, he also can opt to spend an extra week on the same module, or skip a module altogether. Another option is adding a psychoeducation session at the start of the therapy. Especially when patients experience 
excessive fear or confusion about their symptoms, starting off with a psychoeducation session aimed at normalization of the symptoms may create conditions where patients are more open for treatment in general. Also a possibility is shortening the therapy when this is desirable, or when one is limited to a preset number of sessions. For example, cognitive defusion and the self as context may be discussed in one session, as may values and committed action; the contact with the present moment module may be left out as this component runs through all daily life modules in the form of exercises. Finally, the ACT-DL protocol can also be applied in group sessions. In the ACT-DL group program, sessions last longer compared to an individual training.

\section{Discussion}

In the current article we describe the new mHealth approach ACT-DL, designed to facilitate the translation of therapeutic techniques learned during in-person ACT sessions into the patient's daily life. Following each ACT session, patients use a mobile phone application in order to train the newly acquired techniques in different contexts of their everyday lives. Through self-monitoring on the one hand, which helps to increase patients' awareness of their current experiences, and the provision of visual cues and brief exercises on the other hand, patients receive direct support at those moments and in those environments where they need help the most.

The approach described in the current protocol, i.e. the adoption of ESM or self-monitoring, sets itself apart from other mHealth approaches to ACT. While mHealth has been implemented in ACT trainings before [20, 21, 22, 23], no former mHealth ACT protocol has integrated ESM into a face-to-face ACT training program. Earlier approaches to the combination of ACT and mHealth used text-messaging and/or audio-files as a substitute for guided face-to-face therapy sessions $[20,21,23]$ and required the patients to self-initiate use of the provided electronic tools [20,22,23]. The combination of ESM on the one hand, which supports habit formation in different contexts, and guided, personal ACT training on the other hand, which builds on a framework that emphasizes the importance of context in our behavior and which has been proven to be effective for a wide array of psychological obstacles [5, 6, 8, 24, 25, 26], may particularly aid in developing healthy and consistent coping behavior in real life and an overall increased quality of life.

The current protocol provides patients with a certain number of 'reminders' in addition to the possibility to self-initiate coping- and other experiential exercises in order to counteract the potential difficulties patients may experience if required to self-initiate new coping strategies in their everyday lives. These reminders increase likelihood that exercises are carried out on different times of day and in different environments. Moreover, the use of ESM in itself governs the acquisition of self-insight and awareness of one's emotions, behavior, physical, and social environment [27, 28], hence a core-component of ACT. It is therefore suitable extension for this type of therapy.

An initial version of ACT-DL introduced in the current article has already been tested on its feasibility and acceptability among psychiatric patients in a feasibility study [29]. One 
hundred sixty-one in-patients with varying DSM-IV diagnoses (both on axis I and axis II, with the exception of psychotic disorder) participated in the trial. Overall, patients evaluated the training favorably and experienced the addition of the mHealth component as a useful training component, promoting the use of ACT in daily life. Moreover, patients indicated that they would recommend the use of ACT-DL to others. Based on findings of this first feasibility study the current protocol was developed further and is currently being implemented in a randomized clinical trial (trial number: NTR4252), testing its effectiveness in individuals in the prodromal and early stage of psychosis.

Next to the potential to improve effectiveness of ACT, the current protocol may have some limitations. First and foremost, patients might need to adjust to the amount of beeps and their potentially disruptive nature. ESM implies that patients are prompted with several beeps per day, requiring them to interrupt their daily routine on multiple occasions each day. This procedure might be experienced as challenging. However, patient reports from other ESM studies by our group have shown that many individuals grow fond of the apparatus and find it a valuable tool in their treatment process [30]. Another potential limitation is that execution of some of the ACT-DL exercises, such as mindfulness exercises, in the presence of others might lead to an unpleasant degree of self-awareness. However, since the ACT-DL exercises were designed to be carried out in varying life-situations, usually the presence of other would not hinder execution of those exercises. Moreover, only regular engagement in the exercises within varying environments will establish a routine in the application of the newly acquired ACT skills. If patients practice these skills in only one environment (i.e. an environment where it is easy to practice), generalization of these skills to different contexts will be much less likely to take place. Hence, it is assumed that this initial burden will eventually turn into a valuable procedure.

Advancements in technology imply advancements in mHealth, and also the current protocol holds potential that has not yet been exhausted. One possibility to further improve the current ACT-DL protocol is to build up on the answers patients provide via the ESM questionnaires, i.e. to use momentary indications of mood and symptoms to subsequently feed back exercises adjusted to these indications. For instance, whenever a patient indicates he or she is ruminating, a mindfulness exercise that specifically tackles rumination would be suggested at the end of the questionnaire. This adjusted feedback mechanism based on the patients' current needs, a feature that has already successfully been implemented into other mHealth protocols [31], would imply an even greater degree of treatment personalization.

The present paper introduces an innovative approach to improve translation of ACT techniques into the patients' daily life. Utilizing the inherent properties of ESM in an mHealth approach, the ACT-DL protocol aims at helping patients to a faster habit formation that is not context-dependent, substituting former, unhealthy coping strategies with adaptive ones and supporting patients in pursuing their personal values. 


\section{Acknowledgements}

We want to thank the programmers of ACT-DL, Truda Driesen and Wendy Beuken for their great support and Dina Collip, Jindra Bakker, and Klara de Kort for their help in the development of the training.

\section{Disclosure Statement}

This study was supported by an ERC consolidator grant to Inez Myin-Germeys (ERC-2012StG, project 309767 - INTERACT). Besides financial support, this funding source had no involvement in the production of the current manuscript. 


\section{References}

1. Hayes, S. C., Strosahl, K. D., \& Wilson, K. G. (1999). Acceptance and commitment therapy: An experiential approach to behavior change: Guilford Press.

2. Canas, J. J., Fajardo, I., \& Salmeron, L. (2006). Cognitive flexibility. In W. Karwowski (Ed), International Encyclopedia of Ergonomics and Human Factors, Second Edition - 3 Volume Set (pp. 297-300). Boca Raton: CRC Press.

3. Bond, F. W., \& Bunce, D. (2000). Mediators of change in emotion-focused and problem-focused worksite stress management interventions. Journal of occupational health psychology, 5(1), 156-163.

4. Kanter, J. W., Baruch, D. E., \& Gaynor, S. T. (2006). Acceptance and commitment therapy and behavioral activation for the treatment of depression: Description and comparison. Behavior Analyst, 29(2), 161-185.

5. A-Tjak, J., Davis, M., Morina, N., Powers, M., Smits, J., \& Emmelkamp, P. (2015). A meta-analysis of the efficacy of acceptance and commitment therapy for clinically relevant mental and physical health problems. Psychotherapy and Psychosomatics, 84(1), 30-36.

6. Ruiz, F. J. (2010). A review of Acceptance and Commitment Therapy (ACT) empirical evidence: Correlational, experimental psychopathology, component and outcome studies. International Journal of Psychology and Psychological Therapy, 10(1), 125-162.

7. Hoffman, B. M., Papas, R. K., Chatkoff, D. K., \& Kerns, R. D. (2007). Meta-analysis of psychological interventions for chronic low back pain. Health psychology, 26(1), 1-9.

8. Veehof, M. M., Oskam, M.-J., Schreurs, K. M., \& Bohlmeijer, E. T. (2011). Acceptance-based interventions for the treatment of chronic pain: a systematic review and meta-analysis. $P A I N \circledast, 152(3), 533-542$.

9. Zum, M. B. P. M. B., \& Emmelkamp, V. S. V. P. M. (2009). Acceptance and commitment therapy: A metaanalytic review. Psychotherapy and Psychosomatics, 78, 73-80.

10. Phillips, G., Felix, L., Galli, L., Patel, V., \& Edwards, P. (2010). The effectiveness of M-health technologies for improving health and health services: a systematic review protocol. BMC research notes, 3(1), 250-257.

11. Gerber, B. S., Stolley, M. R., Thompson, A. L., Sharp, L. K., \& Fitzgibbon, M. L. (2009). Mobile phone text messaging to promote healthy behaviors and weight loss maintenance: a feasibility study. Health informatics journal, 15(1), 17-25.

12. Kramer, I., Simons, C. J., Hartmann, J. A., MennelLothmann, C., Viechtbauer, W., Peeters, F., Schruers, K., van Bemmel, A. L., Myin-Germeys, I., Delespaul, P., \& van Os, J. (2014). A therapeutic application of the experience sampling method in the treatment of depression: a randomized controlled trial. World Psychiatry, 13(1), 68-77.

13. Pallavicini, F., Algeri, D., Repetto, C., Gorini, A., \& Riva, G. (2009). Biofeedback, virtual reality and mobile phones in the treatment of Generalized Anxiety Disorder (GAD): A phase-2 controlled clinical trial. Journal of CyberTherapy and Rehabilitation (Aprile), 315-327.

14. Quinn, C. C., Clough, S. S., Minor, J. M., Lender, D., Okafor, M. C., \& Gruber-Baldini, A. (2008). WellDoc ${ }^{\mathrm{TM}}$ mobile diabetes management randomized controlled trial: change in clinical and behavioral outcomes and patient and physician satisfaction. Diabetes technology \& therapeutics, 10(3), 160-168.

15. Rodgers, A., Corbett, T., Bramley, D., Riddell, T., Wills, M., Lin, R.-B., \& Jones, M. (2005). Do u smoke after txt? Results of a randomised trial of smoking cessation using mobile phone text messaging. Tobacco control, 14(4), 255-261.

16. Ryan, D., Cobern, W., Wheeler, J., Price, D., \& Tarassenko, L. (2005). Mobile phone technology in the management of asthma. Journal of telemedicine and telecare, 11(suppl 1), 43-46.

17. Schwabe, L., \& Wolf, O. T. (2009). Stress prompts habit behavior in humans. The Journal of Neuroscience, 29(22), 7191-7198.

18. Csikszentmihalyi, M., Larson, R., \& Prescott, S. (1977). The ecology of adolescent activity and experience. Journal of youth and adolescence, 6(3), 281-294.

19. Csikszentmihalyi, M., \& Larson, R. (2014). Validity and reliability of the experience-sampling method. In M. Csikszentmihalyi (Ed), Flow and the foundations of positive psychology (pp. 35-54). New Royk: Springer.

20. Bricker, J. B., Mull, K. E., Kientz, J. A., Vilardaga, R., Mercer, L. D., Akioka, K. J., \& Heffner, J. L. (2014). Randomized, controlled pilot trial of a smartphone app for smoking cessation using acceptance and commitment therapy. Drug and alcohol dependence, 143, 87-94.

21. Cheng, C., Brown, R. C., Cohen, L. L., Venugopalan, J., Stokes, T., \& Wang, M. D. (2013). iACT-An interactive $m$ Health monitoring system to enhance psychotherapy for adolescents with sickle cell disease. Paper presented at the Engineering in Medicine and Biology Society (EMBC), 2013, 35th Annual International Conference of the IEEE.

22. Lappalainen, P., Kaipainen, K., Lappalainen, R., Hoffrén, H., Myllymäki, T., Kinnunen, M. L., Mattila, E., Happonen, A. P., Rusko, H., \& Korhonen, I. (2013). Feasibility of a personal health technology-based psychological intervention for men with stress and mood problems: randomized controlled pilot trial. JMIR Research Protocols, 2(1):e1. 
23. Ly, K. H., Asplund, K., \& Andersson, G. (2014). Stress management for middle managers via an acceptance and commitment-based smartphone application: a randomized controlled trial. Internet Interventions, 1(3), 95-101.

24. Hayes, S. C., Luoma, J. B., Bond, F. W., Masuda, A., \& Lillis, J. (2006). Acceptance and commitment therapy: Model, processes and outcomes. Behaviour research and therapy, 44(1), 1-25.

25. Öst, L. G. (2014). The efficacy of Acceptance and Commitment Therapy: An updated systematic review and meta-analysis. Behaviour research and therapy, 61, 105-121.

26. Powers, M. B., Zum Vörde Sive Vörding, M. B., \& Emmelkamp, P. M. (2009). Acceptance and commitment therapy: A meta-analytic review. Psychotherapy and Psychosomatics, 78(2), 73-80.

27. Barta, W., Tennen, H., \& Litt, M. (2012). Measurement reactivity in diary research. In M. R. Mehl \& T. S. Conner (Eds), Handbook of research methods for studying daily life (pp. 108-123). New York: Guilford Press.

28. Telford, C., McCarthy-Jones, S., Corcoran, R., \& Rowse, G. (2012). Experience sampling methodology studies of depression: the state of the art. Psychological medicine, 42(06), 1119-1129.

29. Batink, T., Bakker, J., Vaessen, T., Kasanova, Z., Collip, D., van Os, J, Wichers, M., Germeys, I., \& Peeters, F. (2016). The ACT in Daily Life Training: A feasibility study of a mHealth intervention. JMIR Mhealth Uhealth;4(3):e103.

30. Wichers, M., Simons, C., Kramer, I., Hartmann, J., Lothmann, C., MyingGermeys, I., van Bemmel, A. L., Peeters, F., Delespaul, P., \& van Os, J. (2011). Momentary assessment technology as a tool to help patients with depression help themselves. Acta Psychiatrica Scandinavica, 124(4), 262-272.

31. Harrison, V., Proudfoot, J., Wee, P. P., Parker, G., Pavlovic, D. H., \& Manicavasagar, V. (2011). Mobile mental health: review of the emerging field and proof of concept study. Journal of mental health, 20(6), 509-524. 
Tim Batink ${ }^{1}$, Frenk Peeters ${ }^{1}$, Nicole Geschwind ${ }^{2}$, Jim van Os $^{1,3}$, Marieke Wichers

${ }^{1}$ Department of Psychiatry and Psychology, Maastricht University Medical Centre, South Limburg Mental Health Research and Teaching Network, EURON, Maastricht, The Netherlands.

${ }^{2}$ Department of Clinical Psychological Science, Maastricht University, Maastricht, The Netherlands.

3 Department of Psychosis Studies, Institute of Psychiatry, King's College London, King's Health Partners, London, England. 
How Does MBCT for Depression Work? Studying Cognitive and Affective Mediation Pathways

Published: PLoS ONE (2013), 8(8): e72778 


\begin{abstract}
Mindfulness based cognitive therapy (MBCT) is a non-pharmacological intervention to reduce current symptoms and to prevent recurrence of major depressive disorder. At present, it is not well understood which underlying mechanisms during MBCT are associated with its efficacy. The current study ( $n=130$ ) was designed to examine the roles of mindfulness skills, rumination, worry and affect, and the interplay between those factors, in the mechanisms of change in MBCT for residual depressive symptoms. An exploratory but systematic approach was chosen using Sobel-Goodman mediation analyses to identify mediators on the pathway from MBCT to reduction in depressive symptoms. We replicated earlier findings that therapeutic effects of MBCT are mediated by changes in mindfulness skills and worry. Second, results showed that changes in momentary positive and negative affect significantly mediated the efficacy of $\mathrm{MBCT}$, and also mediated the effect of worry on depressive symptoms. Third, within the group of patients with a prior history of $\leq 2$ episodes of MDD, predominantly changes in cognitive and to a lesser extent affective processes mediated the effect of MBCT. However, within the group of patients with a prior history of $\geq 3$ episodes of MDD, only changes in affect were significant mediators for the effect of MBCT.
\end{abstract}




\section{Introduction}

Major depressive disorder (MDD) is an invalidating condition, with high rates of residual symptoms and high probability of recurrence [1]. Segal, Williams \& Teasdale originally developed Mindfulness Based Cognitive Therapy (MBCT, [2]) as a nonpharmacological intervention to prevent recurrence of MDD. MBCT is a group-based, 8-week training, consisting of meditation exercises combined with cognitive behavioural techniques. The focus of MBCT is to teach individuals to become more aware of thoughts and feelings and to relate to them in a wider, decentered perspective as "mental events" rather than as aspects of the self or as necessarily accurate reflections of reality. Being mindful is a skill that can be learned by doing regular exercises, to train to focus one's attention on the present moment. It is assumed that the cultivation of a detached, decentered relationship to depression-related thoughts and feelings is central to the development of skills that prevent the escalation of negative thinking patterns at times of potential recurrence [3]. Although MBCT was originally developed as a preventive intervention, subsequent studies reported that $\mathrm{MBCT}$ also appeared effective as an intervention for the acute treatment phase in MDD, and for the reduction of residual symptomatology [4, 5, 6, 7, 8, 9].

At present, it is not well understood how MBCT leads to reduction and prevention of symptoms of depression [10,11,12]. Understanding the mechanisms underlying change arguably is the first step in further optimizing any treatment. Therefore, an important initial step in establishing mechanisms of change in MBCT is to identify variables that mediate its therapeutic effects [13].

MBCT was designed to reduce the contribution of depressed cognitions (reactivated by negative affect) to relapse and recurrence by training the patients in applying Mindfulnessskills [14]. One of the few studies that provided empirical evidence for putative mediating factors in the efficacy of MBCT as a preventive treatment was published recently [15]. Consistent with MBCT's theoretical premise, increases in mindfulness skills and self-compassion across treatment mediated the effect of MBCT on depressive relapse during follow-up. These initial results were confirmed in a subsequent study [16], that also reported that mindfulness skills and rumination mediated the effect of MBCT on reduction of depressive symptoms.

In an exploratory mediation analysis, van Aalderen and colleagues [9] found that the effectiveness of MBCT in reducing current levels of depression was mediated by a decrease in worry, rumination and an increase in the mindfulness skill 'accept without judgment'. These results are in line with previous findings $[15,16]$ but seem to be more specific in identifying which particular mindfulness skills mediate therapeutic effects. Another study in individuals with residual symptoms by Geschwind and colleagues [17] reported that the effect of MBCT was associated with increased experience of momentary positive emotions, greater appreciation of, and enhanced responsiveness to, pleasant daily-life activities. These changes appeared partially independent of more commonly observed decreases in worry and rumination. Together, this suggests that both changes in cognitive and affective processes contribute to reductions in depressive symptomatology. However, it is unknown how changes in mindfulness skills and cognition relate to these affective changes in bringing about clinical improvement during MBCT. 
Further knowledge is also needed regarding the role of previous episodes of depression in relation to the efficacy of $\mathrm{MBCT}$. Initial research on the efficacy of $\mathrm{MBCT}$ reported differential effects of $M B C T$ on relapse prevention contingent on number of previous episodes. The impact on prevention of future episodes seemed restricted to patients with three or more depressive episodes, whereas no effect was observed in patients with two or fewer episodes $[14,18]$. Based on these early findings, subsequent research in the field of MBCT did not include participants with two or fewer previous episodes. However, a recent study [5] reported equal effectiveness of $\mathrm{MBCT}$ in reducing depressive symptoms for participants with few $(\leq 2)$ or multiple $(\geq 3)$ previous depressive episodes. This divergent finding may be explained by the difference in therapeutic goal: prevention of recurrence of depression versus reduction of current depressive symptomatology. It cannot be ruled out that MBCT, when applied for reduction of residual symptoms, exerts therapeutic effects through different mechanisms of change in participants with $\leq 2$ previous depressive episodes compared to participants with $\geq 3$ previous depressive episodes. Thus it could be hypothesized that, although the efficacy of $M B C T$ in reducing residual symptoms may be independent from previous number of episodes, a difference in underlying mechanism of change may still result in differential risk for long-term course (recurrence) of MDD.

The current study was designed to examine the role of mindfulness skills, rumination/worry and affect in the mechanisms of change of $\mathrm{MBCT}$ in a sample with residual depressive symptoms. Participants meeting criteria for a full episode of major depressive disorder were excluded. Because affective states cannot be reliably measured retrospectively [19], the design of this study -of which data already have been reported previously [17]- used frequent and prospective in-themoment measurements of affect, thus minimizing recall bias. Whereas the previous report [17] focused on change in positive affect and reward experience following $M B C T$, the current manuscript tries to identify the cognitive and affective mediators of the effect of MBCT on reduction of depressive symptoms.

The current analysis is building on, and extending the study of van Aalderen and co-workers [9]. The first aim was to replicate the results reported by these authors with regard to the question to what degree worry, rumination and mindfulness skills mediate the reduction of depressive symptoms in MBCT. A second aim was to examine how changes in negative and positive affect relate to changes in worry, rumination and mindfulness skills and to what extent affective changes mediate the effects of MBCT. Combining both cognitive and affective variables in the mediation analyses may provide a better understanding of the processes that mediate the effects of MBCT on depressive symptomatology. A final aim was to examine to what degree different mechanisms of change may underlie the impact of MBCT on symptom reduction in participants with multiple major depressive episodes ( $\geq 3$ $\mathrm{MDE}$ ) compared to those with fewer episodes ( $\leq 2 \mathrm{MDE}$ ). 


\section{Methods}

\section{Participants}

Figure 1 shows the flow of participants through the study. Adults with current residual depressive symptoms after at least one episode of major depressive disorder (mean age 43.9 years, SD 9.6; 75\% female; all Caucasian) were randomized to MBCT ( $n=64)$ or treatment as usual (TAU; $n=66$ ) in a parallel, open-label, randomized controlled trial (MindMaastricht; trial number NTR1084, Netherlands Trial Register; http://www.trialregister.nl/trialreg/admin/rctview.asp?

$\mathrm{TC}=1084)$. Participants were recruited from outpatient mental health care facilities in Maastricht and through posters in public spaces. Residual symptomatology was defined as a score of seven or higher on the 17-item Hamilton Depression Rating Scale (HDRS, [20]) at the time of screening. Exclusion criteria were fulfilling criteria for a current major depressive episode, a lifetime diagnosis of schizophrenia, psychotic episodes in the past year, general conditions that made participation in a group intervention impossible, and recent (past four weeks) or upcoming changes in ongoing psychological or pharmacological treatment. Sample size $(n \geq 120)$ was determined on the basis of sufficient power for hypothesized geneenvironment interactions on momentary assessment outcomes (not analyzed here). For more details on the study design see 17. The protocol for this trial and supporting CONSORT checklist are available as supporting information; see Checklist S1 and Protocol S1.

\section{Measures}

Inventory of Depressive Symptoms (Self-Rating; IDSSR30).

The IDS-SR30 [21] is a self-rating scale, which includes 30 items rated 0 to 3 . Since rating of 'appetite' and 'weight' is duplicated (separate items for increases and decreases), only 28 items are taken into account for the final score. The scale is sensitive to change and has good psychometric properties [21].

\section{Hamilton Depression Rating Scale (HDRS).}

The 17-item HDRS was administered by trained research assistants with master degrees in psychology. The HDRS [20] is a semistructured interview designed to assess depressive symptoms over the past week. It is one of the most frequently used rating scales in depression research, and internal, inter-rater, and retest reliability estimates for the overall HDRS are good [22, 23].

\section{Kentucky Inventory of Mindfulness Skills (KIMS).}

The Dutch translation of the 39-item KIMS was used to measure mindfulness skills [24]. The KIMS was chosen as a measure of mindfulness skills because it is suitable for novices and its subscales are sensitive to change and have been validated in clinical samples [25, 26]. The KIMS consists of a total scale and four subscales: (i) The tendency to pay attention to all stimuli such as thoughts, feelings and sensations (observe); (ii) The tendency to briefly label experiences and redirect attention to present moment (describe); (iii) the tendency to fully engage in current activity with undivided attention (act with awareness) and (iv) the tendency to accept thoughts and feelings as they are while refraining from applying evaluative labels such as good or bad (accept). 


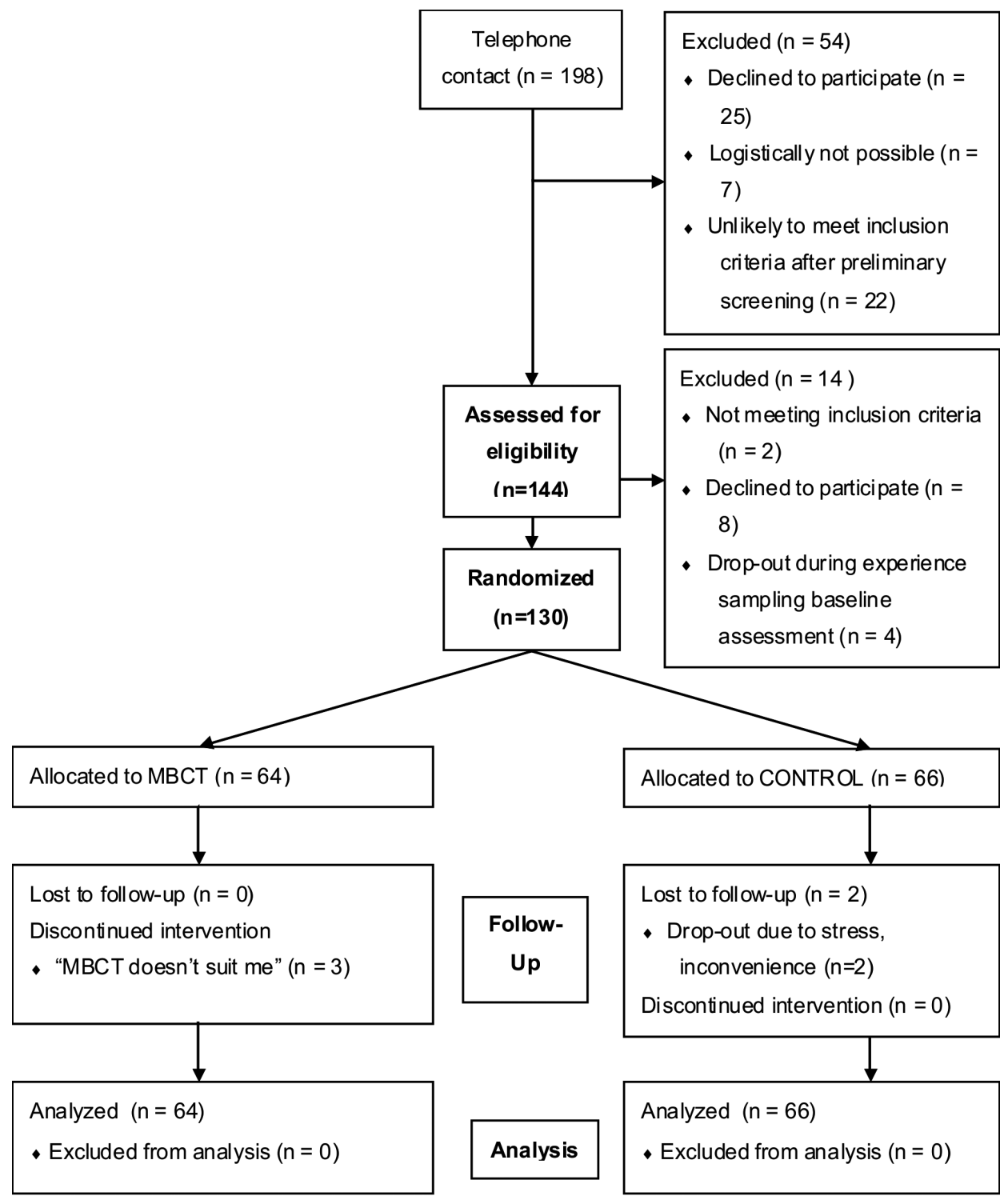

Figure 1. CONSORT participant flow diagram. MBCT = Mindfulness-based Cognitive Behavioral Therapy; CONTROL = waitlist control condition.

Penn State Worry Questionnaire (PSWQ).

The Dutch version of the 16-item PSWQ was used to assess worrying [27]. The PSWQ emerged from factor analysis of a large number of items and was found to possess high internal consistency and good test-retest reliability [28]. 


\section{Rumination on Sadness Scale (RSS).}

The Dutch translation of the RSS was used [29] to measure rumination. The RSS contains 13 items comprising one factor, has an adequate test-retest stability over a 2- to 3-week period, as well as good convergent and discriminant validity [30].

Positive affect (PA) and Negative affect (NA).

PA and NA were assessed repeatedly in daily life, using the experience sampling method (ESM; see 17). ESM is a research procedure asking individuals to provide systematic selfreports during the waking hours of a normal week. Participants rated current emotions 10 times a day at semi-random intervals on 7-point Likert scales ranging from 1 (not at all) to 7 (very). Consistent with previous work [31, 32], principal component factor analysis with oblique rotation was used to generate a factor representing positive affect (PA) and a factor representing negative affect (NA). The mood adjectives 'happy', 'satisfied', 'strong', 'enthusiastic', 'curious', 'animated' and 'inspired' loaded on the PA factor, while 'down', 'anxious', 'lonely', 'suspicious', 'disappointed', 'insecure' and 'guilty' loaded on the NA factor. Mean levels of PA and NA were then computed per participant and sampling moment.

\section{Childhood Trauma Questionnaire (CTQ-SF).}

The Dutch translation of the short form of the Childhood Trauma Questionnaire was used [33], a self-report inventory that provides brief, reliable, and valid screening for histories of abuse and neglect. It inquires about five types of maltreatment - emotional, physical, and sexual abuse, and emotional and physical neglect. The CTQ consists of 25 items rated on a 5- point Likert scale ( 1 = never true, 5 = very often true). The internal consistency of the CTQ is high, it has good test-retest reliability and the criterion validity was found to be acceptable [34].

Interview for Recent Life Events (IRLE).

The IRLE was used to assess the occurrence of negative life events in the last year. This self-report questionnaire covers a comprehensive range of recent life events, their timing and other important qualities. The instrument consists of 63 event-specific variables. Each event is rated for month of occurrence, independence and objective negative impact. The negative impact of recent life events are rated on a five point-scale [35].

\section{Procedure}

All study procedures were approved by the Medical Ethics Committee of Maastricht University Medical Center (MUMC+), and all participants signed an informed consent form. Recruitment started in January 2008 and ended in February 2009, and all post-intervention assessments were completed by August 2009, when the pre-determined number of participants was reached. An initial screening of potential participants was performed by phone to check for availability during the study period and likelihood of meeting in- and exclusion criteria. A second screening included administration of the Structured Clinical Interview for DSM IV axis I (SCID I [36]) and the 17-item HDRS. Eligible participants were invited for a detailed one-on-one explanation of the study procedures, and then took part 
in the baseline assessment. The baseline assessment consisted of six days of ESM in their own environment, and subsequent administration of a battery of questionnaires (see measures section) as well as the HDRS interview (in the laboratory). After the baseline assessment, participants were randomized to either MBCT+TAU or TAU (allocation ratio 1:1) if they were likely to have at least 20 valid ESM assessments [17, 37]. After either eight weeks of MBCT (see section "Intervention") or an equivalent waiting time (in the TAU condition), participants again took part in six days of experience sampling, followed by administration of the HDRS and questionnaires. All participants were compensated with gift vouchers worth fifty Euros. Participants in the TAU condition were offered the opportunity to take part in MBCT training after the post-intervention assessment.

Randomization was stratified according to number of depressive episodes ( $\leq 2 \mathrm{MDE}$ vs $\geq 3$ $\mathrm{MDE})$, given that, as discussed above, previous studies suggested a greater benefit for those with three or more previous episodes $[14,38]$. An independent researcher not involved in the project generated the randomization sequence in blocks of five (using the sequence generator on www.random.org), and wrote the randomization code into sealed numbered envelopes. After completion of all baseline assessments, the researcher allocated participants to their treatment condition based on the randomization code in the sealed envelope (opened in order of sequence).

\section{Intervention (MBCT)}

In accordance with the protocol of Segal, Williams and Teasdale [2], trainings took place in groups of 10-15 people and consisted of eight weekly meetings lasting 2,5 hours. MBCT groups started at different times throughout the year, and test periods for TAU participants were matched to MBCT participants. Sessions included guided meditation, experiential exercises, and discussions. In addition to the weekly group sessions, participants received CDs with guided exercises and were assigned daily homework exercises (30 to 60 minutes daily). Trainings were given by psychologists, general practitioners, and one psychodiagnostic worker who were all certified mindfulness trainers working in a center specialized in mindfulness trainings (SeeTrue; http://www.mindfulnessopleiding.nl). The majority of the trainers had multiple certifications from several mindfulness training institutes. All trainers also used mindfulness in personal practice. The trainers were supervised by an experienced health care professional who himself had trained with Williams and Teasdale, the developers of MBCT [2]. All mindfulness trainers were working under the guidelines of SeeTrue, which adheres to the guidelines of the Dutch Association for Mindfulness (http://www. verenigingvoormindfulness.nl//).

\section{Statistical analyses}

All analyses were carried out according to intention-to-treat. An exploratory but systematic approach was chosen using Sobel-Goodman mediation analyses [39, 40,41] to examine the potential effective components of MBCT. The Sobel-Goodman mediation analysis performs a statistical test to examine whether the indirect effect of the independent variable on the dependent variable, i.e. the effect exerted via the proposed mediator, is significantly different from zero. The sgmediation command [42] of Stata MP package 11.2 [43] was used. First, 
we examined which variables mediate the total effect of MBCT on depressive symptoms. We then subdivided this effect in smaller parts, hypothesizing that changes in mindfulness skills play an important role in explaining concomitant changes in other variables. Furthermore, we hypothesized that (i) resulting changes in cognitive processes and (ii) affective experiences mediate the impact of $\mathrm{MBCT}$ and mindfulness skills on depression outcome.

To answer the above questions we investigated to what extent the effects of MBCT on prepost intervention differences in depressive symptoms were mediated by changes in KIMS, PSWQ, RSS scores and momentary changes in PA and NA (level 1 in the graphical overview of the analyses in Figure 2). Next, in case of significant mediation effects of these top-level mediators, sub-effects were examined on the pathway from MBCT to depressive symptoms. First, it was examined whether, in case of significance of these top-level mediators, effects of MBCT on changes in scores of PSWQ, RSS and momentary PA and NA were mediated by changes in the KIMS scores (level 2 in Figure 2). Second, it was examined whether the effect of the KIMS scores (in case of significance) on depressive symptoms was mediated by changes in scores of the PSWQ, RSS or momentary PA and NA (level 3 in Figure 2). Finally, in case of significant mediation, we examined whether effects of the PSWQ and RSS scores on depressive symptoms were mediated by changes in momentary PA and NA (level 4 in Figure 2). This procedure was followed for the complete sample and for both subgroups ( $\leq 2 \mathrm{MDE}$ and $\geq 3 \mathrm{MDE}$ ) separately.

In order to examine the independence of effects a multiple regression analysis was performed including all of the variables above as additional independent variables in the association between condition (MBCT+TAU/TAU; predictor) and reduction in depressive symptoms (dependent variable) ${ }^{1}$.

\section{Results}

\section{Sample characteristics}

A total of 130 participants were included in the study (MBCT+TAU; $n=64$ and TAU; $n=66$ ). With regard to prior psychiatric history, 71 of the participants had experienced $\leq 2 \mathrm{MDE}$, and 59 had experienced $\geq 3$ MDE. Table 1 shows the demographic characteristics at baseline stratified by intervention group, and prior number of depressive episodes. There were no significant differences in baseline characteristics between the MBCT+TAU and the TAU groups. Second, there were no significant differences in baseline characteristics between the two subgroups ( $\leq 2 \mathrm{MDE}$ vs $\geq 3 \mathrm{MDE}$ ). However, stratification by MBCT+TAU and TAU revealed some group differences. Within the subgroup with patients who experienced $\leq 2$ $M D E$, more women than men entered the MBCT+TAU group compared to the TAU group. Also, for the $\leq 2$ MDE group baseline IDS-SR30 scores were lower in the MBCT+TAU group than the TAU group, while the opposite was the case for the $\geq 3$ MDE group. Childhood

\footnotetext{
1 Since Sobel mediation analysis does not allow for additional mediators within the same analysis, multiple regression analysis was used here to obtain an indication of the independence of the mediation effects.
} 
trauma was significantly greater in the $\geq 3 \mathrm{MDE}$ group than the group with $\leq 2 \mathrm{MDE}$. There was no difference in the presence of recent negative life events between the groups.

Table 2 describes the change scores (post-intervention - pre-intervention) of depressive symptoms, rumination, worrying, affective changes and mindfulness skills separately per treatment group and stratified per subgroup ( $\leq 2 \mathrm{MDE}$ vs $\geq 3 \mathrm{MDE})$.

\section{Mediation analyses}

The effect of the MBCT intervention on depressive symptoms in the total group was significantly mediated by changes in the total KIMS score (Proportional effect $=46.8, p=$ 0.01 ), and specifically by changes in the subscale "acceptance" (Prop. effect $=25.2, p=0.04$ ).
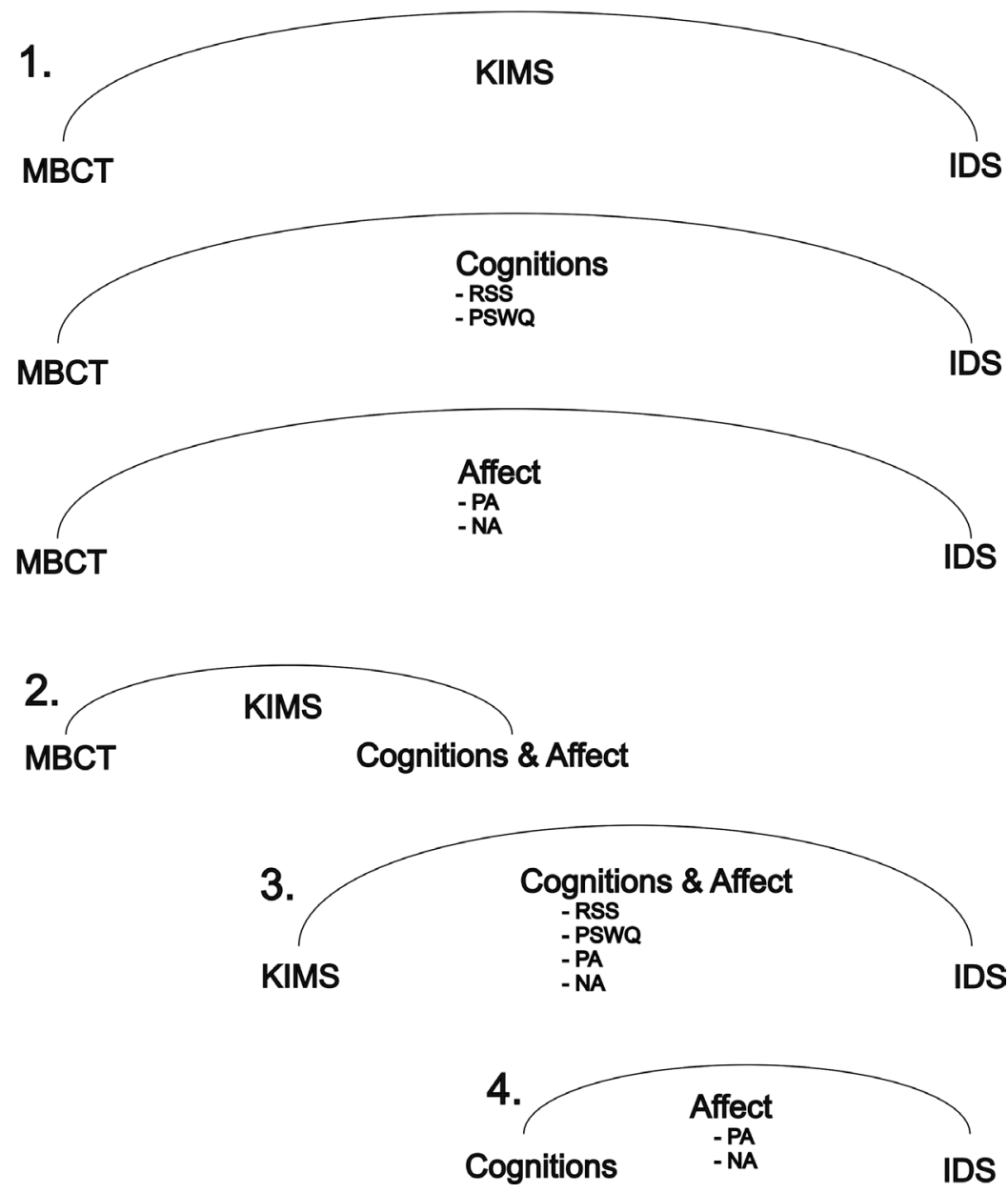

Figure 2. Mediation analysis pathway, for the effect of $M B C T$ on residual symptoms of depression. N.B. All variables are change scores over time. The numbers show the four different levels of analyses. 
The effect of the total KIMS score on depressive symptoms, in turn, was mediated by changes in the PSWQ score (Prop. effect $=44.5, p<0.001$ ) and changes in PA (Prop. effect $=48.3, p$ $<0.001$ ), but not NA. Finally, the effect of the PSWQ score on depressive symptoms, was mediated by changes in PA (Prop. effect $=43.5, p<0.001$ ) and NA (Prop. effect $=37.5, p<$ 0.001 ). The RSS score was not a significant mediator in this model. Table 3 shows in detail the proportional effect explained by the mediators and the significance of the effects of the tested mediation analyses. Figure $3 a$ displays a graphical representation of the significant findings. The numbers in Figure 3a show the percentage of mediation (indirect effect) of that particular mediator on its dependent variable. The reported mediations do not account for a unique effect, but overlap with each other, as they reflect separate regression analyses. Change in positive affect was the largest mediator (61\%) of the effect of MBCT on depressive symptoms.

\section{Subgroup analyses: Two or fewer episodes}

Results in Table 3 showed that the effect of MBCT on depressive symptoms in the subgroup with $\leq 2$ MDE was mediated by changes in the total KIMS score (Prop. effect $=76.7, p=0.01$ ) and specifically by the subscales acceptance (Prop. effect $=48.2, p=0.03$ ) and awareness (Prop. effect $=41.2, p=0.05$ ). The effect of the KIMS on depressive symptoms, in turn, was mediated by changes in the PSWQ score (Prop. effect $=48.7, p<0.001$ ). Finally, the effect of PSWQ on depressive symptoms was mediated by changes in PA (Prop. effect $=31.3, p=$ 0.03 ) and NA (Prop. effect $=33.4, p=0.01$ ). Figure $3 b$ shows a graphical representation of these findings. In contrast with the results for the total group, change in PSWQ was now the largest mediator (85\%) of the effect of MBCT on depressive symptoms.

\section{Subgroup analyses: Three or more episodes}

The effect of MBCT on depressive symptoms in the group with $\geq 3$ MDE was mediated only by changes in PA (Prop. effect $=80.1, p=0.01$ ) and NA (Prop. effect $=51.5, p=0.04$ ) (Table 3). In contrast with the subgroup with $\leq 2 \mathrm{MDE}$, the KIMS and the PSWQ did not contribute to the effect of MCBT on depressive symptoms in this model. A graphical representation of these findings is displayed in Figure 3c. Eighty percent of the effect of MBCT on depression was mediated by changes in $\mathrm{PA}^{2}$.

\section{Independence of effects}

A multiple regression analysis was performed to examine the independence of the mediators above. In the total group only the effects of NA and PA on reduction in depressive symptoms remained significant in the analysis. In both the group with $\leq 2$ depressive episodes and in the group with $\geq 3$ depressive episodes, only PA remained significant.

\footnotetext{
${ }^{2}$ Similar results were found for the total group and subsamples when the HDRS instead of the IDS SR30 was used as outcome measure (not described here).
} 


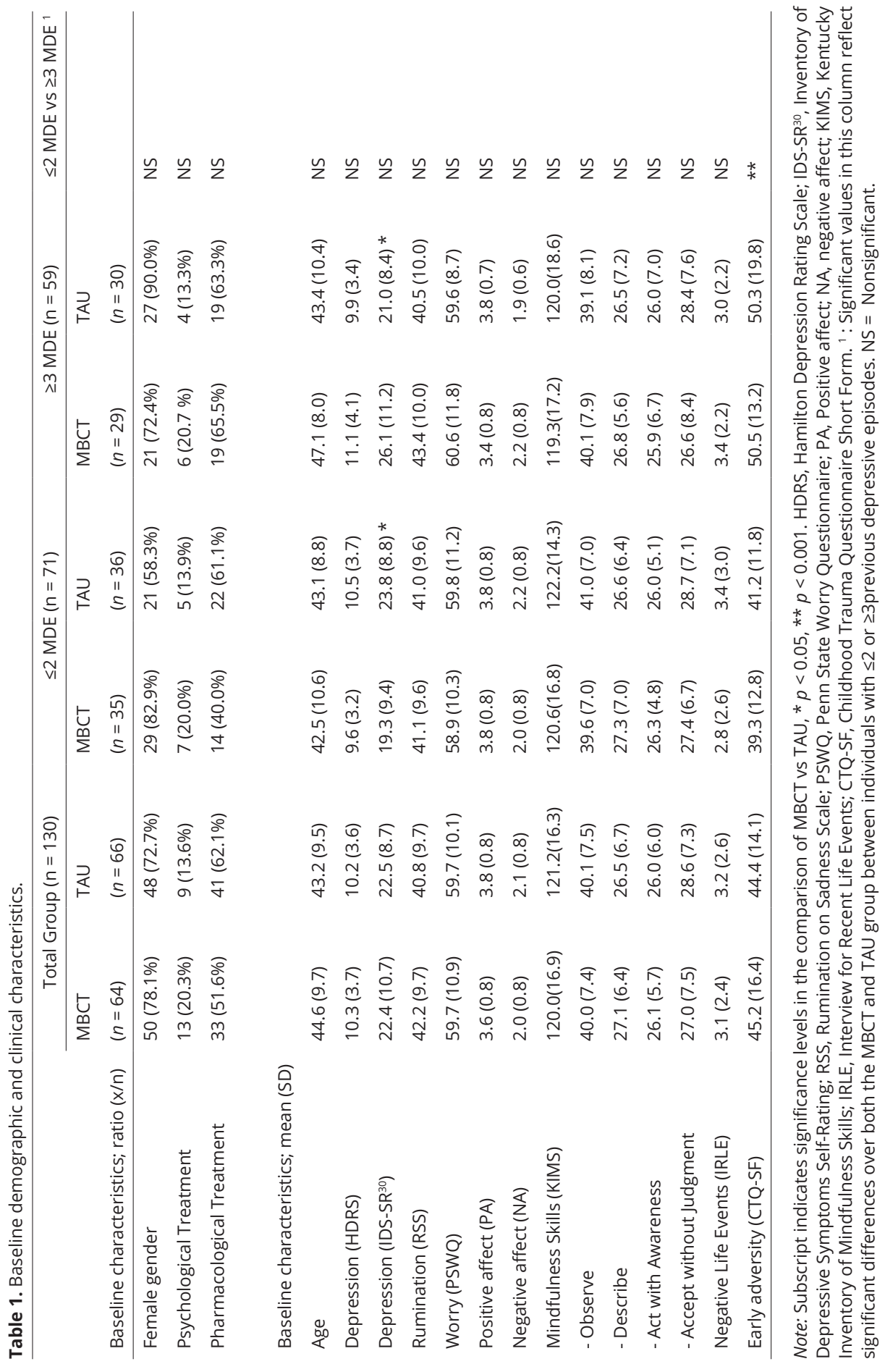


Table 2. Pre-post treatment change scores of residual depressive symptoms, rumination, worrying, positive $\&$ negative affect and mindfulness skills, separately per treatment group and stratified per subgroup ( $\leq 2$ or $\geq 3$ previous depressive episodes).

\begin{tabular}{|c|c|c|c|c|c|c|}
\hline \multirow[b]{2}{*}{$\begin{array}{l}\text { Pre-post } \\
\text { intervention } \\
\text { period change in } \\
\text { mean, }(S D)\end{array}$} & \multicolumn{2}{|c|}{ Total Group $(n=130)$} & \multicolumn{2}{|c|}{$\leq 2 \operatorname{MDE}(n=71)$} & \multicolumn{2}{|c|}{$\geq 3 \operatorname{MDE}(n=59)$} \\
\hline & MBCT & TAU & MBCT & TAU & MBCT & TAU \\
\hline HDRS & $-3.2(4.7)$ & $-0.5(4.3)$ ** & $-3.6(3.9)$ & $-0.6(4.2) * \star$ & $-2.6(5.5)$ & $-0.4(4.5)$ \\
\hline IDS-SR ${ }^{30}$ & $-7.7(8.8)$ & $-3.1(8.4) * *$ & $-7.9(8.2)$ & $-3.4(8.5)$ * & $-7.6(9.6)$ & $-2.7(8.4)$ * \\
\hline RSS & $-7.8(8.5)$ & $-2.7(7.7)$ ** & $-8.1(8.4)$ & $-1.9(6.9) * \star$ & $-7.5(8.8)$ & $-3.7(8.6)$ \\
\hline PSWQ & $-9.1(8.0)$ & $-3.2(8.0) * \star$ & $-9.3(7.3)$ & $-2.4(7.7) * \star$ & $-8.9(6.6)$ & $-4.2(8.2)$ * \\
\hline PA & $0.4(0.7)$ & $-0.1(0.6) * \star$ & $0.4(0.7)$ & $<-0.1(0.8)$ * & $0.4(0.7)$ & $-0.1(0.4) * \star$ \\
\hline NA & $-0.3(0.5)$ & $<-0.1(0.6) * \star$ & $-0.3(0.5)$ & $<0.1(0.8)$ & $-0.4(0.6)$ & $<-0.1(0.3)$ * \\
\hline KIMS & $14.8(16.8)$ & $3.1(9.0)$ ** & $14.8(16.8)$ & $2.6(7.8)$ ** & $14.8(17.1)$ & $3.7(10.4)$ ** \\
\hline - Observe & $4.5(7.3)$ & $<-0.1(4.5)$ ** & $4.4(7.2)$ & $-0.3(4.2) * \star$ & $4.6(7.6)$ & $0.2(4.9)$ * \\
\hline - Describe & $1.9(4.0)$ & $0.7(4.1)$ & $1.3(3.6)$ & $0.8(4.4)$ & $2.6(4.4)$ & $0.5(3.8)$ \\
\hline - Aware & $4.3(6.6)$ & $0.6(3.5)$ ** & $4.9(6.8)$ & $0.9(2.9)$ ** & $3.5(6.4)$ & $0.2(4.2)$ * \\
\hline - Accept & $4.2(5.5)$ & $2.0(4.4)$ * & $4.3(5.4)$ & $1.3(4.4)$ * & $4.1(5.7)$ & $2.8(4.4)$ \\
\hline
\end{tabular}

Note ${ }^{1}$ : Post-intervention measures were taken 8 weeks after the pre-intervention measures.

Note $^{2}$ : Subscript indicates significance levels in the comparison of MBCT vs TAU * $p<0.05, * * p<0.001$. HDRS, Hamilton Depression Rating Scale; IDS-SR ${ }^{30}$, Inventory of Depressive Symptoms Self-Rating; RSS, Rumination on Sadness Scale; PSWQ, Penn State Worry Questionnaire; PA, Positive affect; NA, negative affect; KIMS, Kentucky Inventory of Mindfulness Skills. 


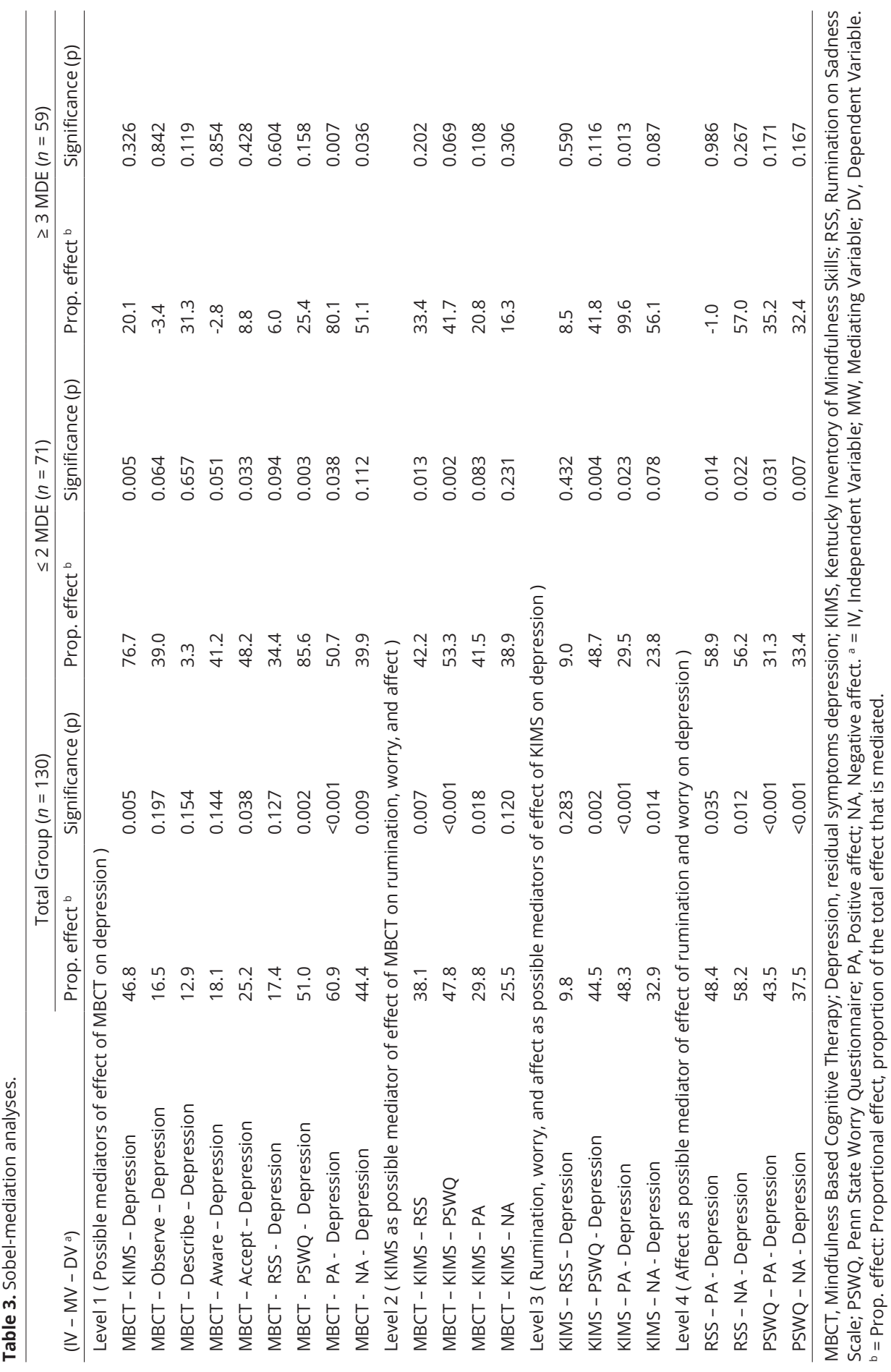



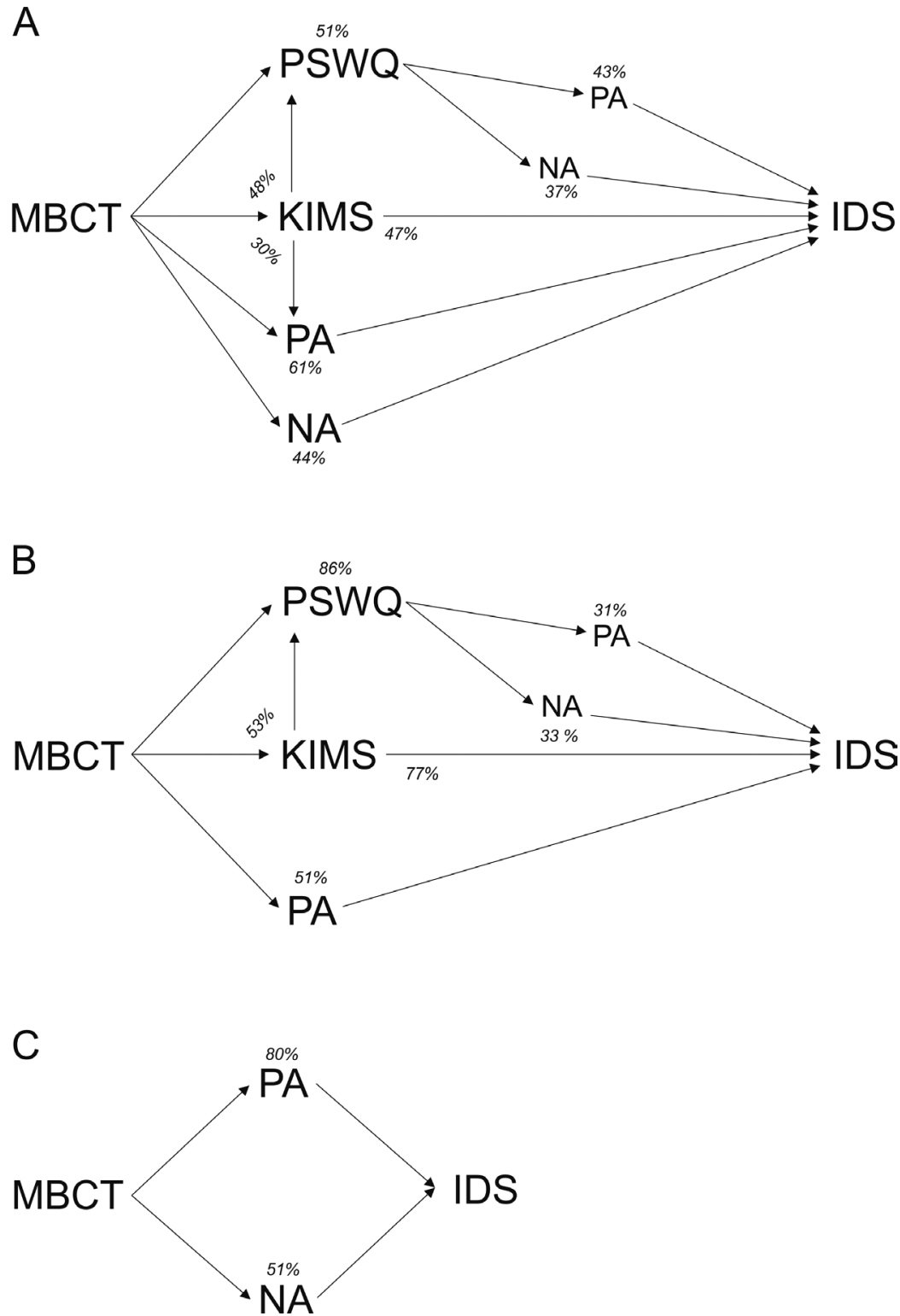

Figure 3. Graphical display of the resulting significant mediations for the total group and the two subgroups ( $\leq 2 \mathrm{MDE} \& \geq 3 \mathrm{MDE}$ ). A. Mediating mechanisms MBCT for total group. B. Mediating mechanisms MBCT for subgroup two or less depressions. C. Mediating mechanisms MBCT for subgroup three or more depressions. The numbers in the figure show the percentage of mediation (indirect effect) of that mediator on the next phenotype. The figure can be conceived as consisting of mediation-triangles, where on top of the triangle the percentage of mediation is shown. For example in Figure 3a, the effect of MBCT on IDS-SR30 is mediated for $51 \%$ by PSWQ (and the effect of PSWQ on IDS-SR30, is again mediated by PA \& NA). Also, the effect of MBCT on PSWQ is for $48 \%$ mediated by KIMS. The reported mediations do not account for a unique effect, but overlap with each other, reflecting a series of separate regressions (one for each triangle). 


\section{Discussion}

This study yields information about the pathway of change mediating the reduction of residual depressive symptoms during a course of $\mathrm{MBCT}$. First, we replicated the finding that therapeutic effects of MBCT are mediated by changes in mindfulness skills and worry [9]. Rumination, however, did not mediate a decrease in depressive symptoms. Second, changes in positive and negative affect appeared to be important mediators for the efficacy of MBCT, and also mediated the effect of worry on depressive symptoms. Third, differential mediators may be involved in the effect of MBCT depending on prior history of MDD.

\section{Comparison with previous studies}

In line with previous reports, changes in mindfulness skills and cognitive processes appeared important mediators in the effect of $\operatorname{MBCT}[9,15,16]$. In agreement with the results reported in these studies, increases in mindfulness skills were a significant mediator in the effect of MBCT. More specifically, using the same measurement instruments, this study replicated the mediating role of change in mindfulness skills (especially mindfulness skill 'accepting without judgment') and worrying in the depression-reducing effect of MBCT as reported by van Aalderen and colleagues [9]. However, other results of the current study contrasted with those reported by van Aalderen and colleagues. Although rumination decreased more strongly in the MBCT+TAU than the TAU group (Table 2), we did not find a significant mediating effect of rumination in the impact on depressive symptoms. Another difference was that within the group of participants with a prior history of $\geq 3 \mathrm{MDE}$, affect predominantly mediated the effect of MBCT, whereas van Aalderen [9] found that cognitive and mindfulness processes were significant mediators.

These differences may be traced to several factors. Whereas we assessed mediation using Sobel-Goodman mediation analyses, van Aalderen and colleagues [9] used a multiple mediation model. Nevertheless, a post-hoc analysis using the same multiple mediation model did not change the results of the current analysis, suggesting that this is not a sufficient explanation. Another difference relates to differences in the samples that were examined in both studies. The current study only included participants with residual symptoms, whereas Van Aalderen and colleagues [9] also included participants meeting full criteria for a current episode of MDD. Mediating factors may be different for different levels of depression severity. Future work needs to address this possibility.

\section{Affective and cognitive factors in the mechanism of MBCT}

The current study examined the role of both affective and cognitive variables in the mechanism of change of MBCT. The results suggest that PA and, to a lesser extent, NA play a substantial mediating role in the reduction of depressive symptoms during MBCT. Particularly the contribution of PA merits attention as changes in positive affect mediated $61 \%$ of the effect of MBCT on depressive symptoms. Its central role is in line with recent evidence showing that increased reward experience plays an important role in the process of remission of depressive symptomatology [17,44]. Apparently, changes in cognition and affect conjointly operate during a course of MBCT and can be hypothesized to bi-directionally impact each other. 
Our findings fit within a theoretical framework on dynamic elements of emotional systems as presented by Garland and co-workers [45], describing "self-perpetuating systems energized by reciprocal causal links between the cognitive, behavioral, and somatic mechanisms through which emotions are instantiated" (page 851). These dynamics can lead to downward spirals (self-perpetuating, damaging cycles that can be triggered by negative emotions), as well as upward spirals (self-perpetuating cycles that lead to optimal functioning, which can be triggered by positive emotions). The current results highlight the potential reciprocal relations between affective states, cognitive processes, and metacognitive skills as trained during MBCT. The complex role of affective changes with their direct and indirect contributions to the reduction of depressive symptomatology is illustrated in detail by the results displayed in Table 3. The generation of PA, either as direct result of practicing MBCT exercises or indirectly through reduction of worrying, appears to be a substantial ingredient of successful MBCT. It may be that reduction in worrying promotes an upward spiral of improved affect, which in turn reduces depression-related cognitions [44, 45, 46, 47]. This is also supported by the finding that only PA remained significant in the analyses stratified per episode group testing for the independence of the mediators. Changes in affect and especially in positive affect, which may partly result from changes in cognitive processes as worrying, thus seem to be particularly important in mediating the reduction in symptoms.

\section{Differential mechanisms depending on prior history of MDD}

Within the group of patients with a prior history of $\leq 2 \mathrm{MDE}$, predominantly changes in cognitive and to a lesser extent affective processes mediated the effect of MBCT. However, within the group of patients with a prior history of $\geq 3 \mathrm{MDE}$, only changes in affect were significant mediators for the effect of MBCT. MBCT thus reduces depressive symptoms in both groups but, contingent on prior history, possibly through different pathways. It should be noted that although changes in cognitive processes were no significant mediators in the group of patients with a prior history of $\geq 3 \mathrm{MDE}$, it cannot be concluded that they do not play a role in symptomatic improvement in this group. It merely illustrates that changes in cognition may be of importance, but that emotional changes are the most crucial element in MBCT-related improvement.

Several reasons may explain the possible difference in mediational pathways between these groups. First, it may be explained by differences in exposure rate to proximal risk factors of which the occurrence of recent severe life-events is a plausible candidate. This seems unlikely, however, as participants in both groups reported an equal exposure to severe life-events during the last year. Second, the difference may be a result of a more advanced sensitization or scarring process in the $\geq 3$ MDE group. A large body of evidence indicates that the experience of previous episodes increases the vulnerability for consecutive episodes and may result in more permanent undesirable changes in biological regulatory systems and negative patterns of information processing $[46,47,48,49]$. It can by speculated that depending on the level of sensitization, a more prominent role is reserved for affective changes to counteract more activated or more firmly embedded dysfunctional cognitions. Another but related aspect of prior history is age of onset of the first episode of MDD. From a developmental perspective, MDD earlier in life can have potentially more sensitization 
effects than a first episode of MDD at later stages in life when biological and psychological development has progressed towards adult stable levels. Regretfully, age of onset was not collected in our sample. Third, the $\geq 3$ MDE group reported a greater level of exposure to childhood adversity (Table 1). This was a meaningful difference with an effect size of one SD. High rates of childhood adversity are known to be a risk factor for the development of MDD, and in addition predict a more unfavorable course [50]. Childhood adversity is thought to be an environmental risk factor leading to enduring emotional, cognitive and biological vulnerabilities for psychopathology later in life. One of these enduring effects may be manifested in the finding that emotional rather than cognitive changes were a key feature of the reduction of depressive symptoms in particularly this group. Finally, higher familial loading for affective disorders and/or differences in genetic risk profile may contribute to different sensitivity between the groups to the therapeutic effects of MBCT.

Further research is necessary to confirm these hypotheses and examine underlying mechanisms for different populations and for individuals at different stages of the illness. Findings related to differences in prior history may stimulate further development of staging and profiling models that can be used for optimal planning of treatment of individuals suffering from affective disorders [51, 52].

\section{Strengths and limitations}

This study provides new insights in the cognitive and affective factors that mediate the reduction of depressive symptoms associated with $\mathrm{MBCT}$. We measured momentary affect in real-life while inclusion criteria for participants were intentionally kept broad in order to enhance generalizability. Attrition rate was low, and the analyses were intention-to treat, thus analyzing all participants who were randomized to treatment.

Some limitations should be considered. It is impossible to infer causal explanations based on our analyses because all variables were measured within the same time frame. Future studies may inform better by using prospective, multiple measurements over a complete course of $\mathrm{MBCT}$ to unravel in detail how affective and cognitive variables influence each other over time. Next, the current trial did not include an active control intervention. Therefore we cannot distinguish to what degree reported pathways are a direct result of MBCT or relate to nonspecific intervention effects. However, it is unlikely that these non-specific effects would result in changes in mindfulness skills as observed. Also, some participants received additional psychological or pharmacological treatment. This additional treatment was equally frequent in the MBCT group as in the control group and therefore does not confound our mediation results (see table 1). The only possibility we cannot exclude is that the observed mediation effects represent in part the synergistic effects of $\mathrm{MBCT}$ in combination with additional treatment. Furthermore, adherence to the MBCT protocol was not assessed formally, hence it cannot be ruled out that trainings may have differed slightly with regard to adherence. However, if this would be the case, then the currently observed mediation effects are likely conservative estimations of the true effects. Also, patients meeting criteria for depressive disorder were excluded in this study. Therefore, the current results may not generalize to patients with current depression. Lastly, the goal of the MBCT intervention was to reduce residual symptomatology and not to prevent relapse or recurrence of MDD. 


\section{Supporting Information}

\section{Checklist S1. CONSORT checklist.} (DOC)

Protocol S1. Trial protocol. (DOC)

\section{Acknowledgements}

We thank our study participants and also Rufa Diederen, Karlijn Gielen, Marga Schnitzeler, Greet Kellens and the RIAGG Maastricht for their help during data collection, SeeTrue Mindfulness trainings, and Truda Driesen, Philippe Delespaul, Frieda van Goethem and the 4D database team for their help with data entry. This manuscript partially uses data which has been used in a previous publication [17].

\section{Author Contributions}

Conceived and designed the experiments: TB FP NG JVO MW. Performed the experiments: TB FP NG JVO MW. Analyzed the data: TB FP NG JVO MW. Contributed reagents/materials/ analysis tools: TB FP NG JVO MW. Wrote the manuscript: TB FP NG JVO MW.

\section{Funding}

This research was supported in part by grants from the Dutch Organisation for Scientific Research (NWO) (VENI grant number: 916.76.147). Data collection was financially supported by Servier (unrestricted grant). The funders had no role in study design, data collection and analysis, decision to publish, or preparation of the manuscript.

\section{Competing interests}

Jim van Os is an editor for PLOS ONE. This also does not alter the authors' adherence to all the PLOS ONE policies on sharing data and materials. 


\section{References}

1. Rush, A. J., Trivedi, M. H., Wisniewski, S. R., Nierenberg, A. A., Stewart, J. W., Warden, D., Niederehe, G., Thase, M. E., Lavori, P. W., Lebowitz, B. D., McGrath, P. J., Rosenbaum, J. F., Sackeim, H. A., Kupfer, D. J., Luther, J., \& Fava, M. (2006). Acute and longer-term outcomes in depressed outpatients requiring one or several treatment steps: A STARD report. The American Journal of Psychiatry, 163, 1905-1917. doi:10.1176/ appi.ajp.163.11.1905. PubMed: 17074942.

2. Segal, Z. V., Williams, J. M. G., \& Teasdale, J. D. (2002). Mindfulness-Based Cognitive Therapy for Depression: A New Approach to Preventing Relapse. New York: The Guilford Press.

3. Teasdale, J. D. (1997). Psychological treatments for depression: How do they work? In S. J. Rachman. Best of behavior research and therapy (pp. 53-61). Amsterdam: Pergamon Publishing House/Elsevier Science Inc.

4. Barnhofer, T., Crane, C., Hargus, E., Amarasinghe, M., Winder, R., \& Williams, J. M. (2009). Mindfulnessbased cognitive therapy as a treatment for chronic depression: A preliminary study. Behaviour Research and Therapy, 47, 366-373. doi: 10.1016/j.brat.2009.01.019. PubMed: 19249017.

5. Geschwind, N., Peeters, F., Huibers, M., van Os, J., \& Wichers, M. (2012). Efficacy of mindfulness-based cognitive therapy in relation to prior history of depression: randomised controlled trial. The British Journal of Psychiatry, 201, 320-325. doi:10.1192/bjp.bp.111.104851. PubMed: 22878133.

6. Green, S. M., \& Bieling, P. J. (2012). Expanding the scope of mindfulnessbased cognitive therapy: Evidence for effectiveness in a heterogeneous psychiatric sample. Cognitive and Behavioral Practice, 19, 174-180. doi:10.1016/ j.cbpra.2011.02.006.

7. Kingston, T., Dooley, B., Bates, A., Lawlor, E., \& Malone, K. (2007). Mindfulness-based cognitive therapy for residual depressive symptoms. Psychology and Psychotherapy: Theory, Research and Practice, 80, 193-203. doi: 10.1348/147608306X116016. PubMed: 17535594.

8. Manicavasgar, V., Parker, G., \& Perich, T. (2011). Mindfulness-based cognitive therapy vs cognitive behaviour therapy as a treatment for non-melancholic depression. Journal of Affective Disorders, 130, 138 144. doi: 10.1016/j.jad.2010.09.027. PubMed: 21093925.

9. van Aalderen, J. R., Donders, A. R. T., Giommi, F., Spinhoven, P., Barendregt, H. P., \& Speckens, A. E. (2012). The efficacy of mindfulness-based cognitive therapy in recurrent depressed patients with and without a current depressive episode: A randomized controlled trial. Psychological Medicine, 42, 989-1001. doi: 10.1017/S0033291711002054. PubMed: 22017808.

10. Coelho, H. F., Canter, P. H., \& Ernst, E. (2007). Mindfulness-based cognitive therapy: Evaluating current evidence and informing future research. Journal of Consulting and Clinical Psychology, 75, 1000-1005. doi:10.1037/0022-006X. 75.6.1000. PubMed: 18085916.

11. Kuyken, W., Byford, S., Taylor, R. S., Watkins, E., Holden, E., White, K., Barrett, B., Byng, R., Evans, A., Mullan, E., \& Teasdale, J. D. (2008). Mindfulness-based cognitive therapy to prevent relapse in recurrent depression. Journal of Consulting and Clinical Psychology, 76, 966-978. doi:10.1037/ a0013786. PubMed: 19045965.

12. Laurenceau, J-P., Hayes, A. M., \& Feldman, G. C. (2007). Some methodological and statistical issues in the study of change processes in psychotherapy. Clinical Psychology Review, 27, 682-695. doi:10.1016/j.cpr. 2007.01.007. PubMed: 17328996.

13. Kazdin, A. E. (2007). Mediators and mechanisms of change in psychotherapy research. Annual Review of Clinical Psychology, 3, 1-27. doi:10.1146/ annurev.clinpsy.3.022806.091432. PubMed: 17716046.

14. Teasdale, J. D., Segal, Z. V., Williams, J. M. G., Ridgeway, V. A., Soulsby, J. M. \& Lau, M. A. (2000). Prevention of relapse/recurrence in major depression by mindfulness-based cognitive therapy. Journal of Consulting and Clinical Psychology, 68, 615-623. doi:10.1037/0022-006X.68.4.615. PubMed: 10965637.

15. Kuyken, W., Watkins, E., Holden, E., White, K., Taylor, R. S., Byford, S., Evans, A., Radford, S., Teasdale, J. D., \& Dalgleish, T. (2010). How does mindfulness-based cognitive therapy work? Behaviour Research and Therapy, 48, 1105-1112. doi:10.1016/j.brat.2010.08.003. PubMed: 20810101.

16. Shahar, B., Britton, W. B., Sbarra, D. A., Figueredo, A. J., \& Bootzin, R. R. (2010). Mechanisms of change in mindfulness-based cognitive therapy for depression: Preliminary evidence from a randomized controlled trial. International Journal of Cognitive Therapy, 3, 402-418. doi:10.1521/ijct.2010.3.4.402.

17. Geschwind, N., Peeters, F., Drukker, M., van Os, J., \& Wichers, M. (2011). Mindfulness training increases momentary positive emotions and reward experience in adults vulnerable to depression: A randomized controlled trial. Journal of Consulting and Clinical Psychology, 79, 618-628. doi:10.1037/ a0024595. PubMed: 21767001.

18. Teasdale, J. D. (2004). Mindfulness-based cognitive therapy. In J. Yield. Cognition, emotion and psychopathology: Theoretical, empirical and clinical directions (pp. 270-289). New York: Cambridge University Press.

19. McLeod, J. D., Turnbull, J. E., Kessler, R. C., \& Abelson, J. M. (1990). Sources of discrepancy in the comparison of a lay-administered diagnostic instrument with clinical diagnosis. Psychiatry Research, 31, 145-159. doi: 10.1016/0165-1781(90)90117-N. PubMed: 2326394. 
20. Hamilton, M. (1960). A rating scale for depression. Journal of Neurology, Neurosurgery \& Psychiatry, 23, 5662. doi:10.1136/jnnp.23.1.56.

21. Rush, A. J., Gullion, C. M., Basco, M. R., \& Jarrett, R. B. (1996). The Inventory of Depressive Symptomatology (IDS): Psychometric properties. Psychological Medicine, 26, 477-486. doi:10.1017/S0033291700035558. PubMed: 8733206.

22. Olden, M., Rosenfeld, B., Pessin, H., \& Breitbart, W. (2009). Measuring depression at the end of life: Is the Hamilton Depression Rating Scale a valid instrument? Assessment, 16, 43-54. PubMed: 18676960.

23. Trajković, G., Starčević, V., Latas, M., Leštarević, M., Ille, T., Bukumirić, Z., \& Marinković, J. (2011). Reliability of the Hamilton Rating Scale for Depression: A meta-analysis over a period of 49 years. Psychiatry Research, 189, 1-9. doi:10.1016/ j.psychres.2010.12.007. PubMed: 21276619.

24. Dekeyser, M., Raes, F., Leijssen, M., Leysen, S., \& Dewulf, D. (2008). Mindfulness skills and interpersonal behaviour. Personality and Individual Differences, 44, 1235-1245. doi:10.1016/j.paid.2007.11.018.

25. Baer, R. A., Smith, G. T., \& Allen, K. B. (2004). Assessment of Mindfulness by Self-Report: The Kentucky Inventory of Mindfulness Skills. Assessment, 11, 191-206. doi:10.1177/1073191104268029. PubMed: 15358875.

26. Baum, C., Kuyken, W., Bohus, M., Heidenreich, T., Michalak, J., \& Steil, R. (2010). The psychometric properties of the Kentucky Inventory of Mindfulness Skills in clinical populations. Assessment, 17, 220-229. doi: 10.1177/1073191109356525. PubMed: 20040728.

27. van Rijsoort, S., Emmelkamp, P., \& Vervaeke, G. (1999). The Penn State Worry Questionnaire and the Worry Domains Questionnaire: Structure, reliability and validity. Clinical Psychology \& Psychotherapy, 6, 297-307. doi:10.1002/ (SICI)1099-0879(199910)6:4.

28. Meyer, T. J., Miller, M. L., Metzger, R. L., \& Borkovec, T. D. (1990). Development and validation of the Penn State Worry Questionnaire. Behaviour Research and Therapy, 28, 487-495. doi:10.1016/00057967(90)90135-6. PubMed: 2076086.

29. Raes, F., Hermans, D., \& Eelen, P. (2003). Kort instrumenteel De Nederlandstalige versie van de Ruminative Response Scale (RRS-NL) en de Rumination on Sadness Scale (RSS-NL). Gedragstherapie, 36, 97-104.

30. Conway, M., Csank, P. A. R., Holm, S. L., \& Blake, C. K. (2000). On individual differences in rumination on sadness. Journal of Personality Assessment, 75, 404-425. doi: 10.1207/S15327752JPA7503_04. PubMed: 11117154.

31. Myin-Germeys, I., van Os, J., Schwartz, J. E., Stone, A. A., \& Delespaul, P. A. (2001). Emotional reactivity to daily life stress in psychosis. Archives of General Psychiatry, 58, 1137-1144. doi:10.1001/archpsyc.58.12.1137. PubMed: 11735842.

32. Wichers, M., Peeters, F., Geschwind, N., Jacobs, N., Simons, C. J., Derom, C., Thiery, E., Delespaul, P. H., \& van Os, J. (2010). Unveiling patterns of affective responses in daily life may improve outcome prediction in depression: A momentary assessment study. Journal of Affective Disorders, 124, 191-195. doi:10.1016/j. jad.2009.11.010. PubMed: 20004977.

33. Thombs, B. D., Bernstein, D. P., Lobbestael, J., \& Arntz, A. (2009). A validation study of the Dutch Childhood Trauma Questionnaire-Short Form: Factor structure, reliability, and known-groups validity. Child Abuse \& Neglect, 33, 518-523. doi:10.1016/j.chiabu.2009.03.001. PubMed: 19758699.

34. Bernstein, D. P., Ahluvalia, T., Pogge, D., \& Handelsman, L. (1997). Validity of the Childhood Trauma Questionnaire in an adolescent psychiatric population. Journal of the American Academy of Child and Adolescent Psychiatry, 36, 340-348. doi: 10.1097/00004583-199703000-00012. PubMed: 9055514.

35. Paykel, E. S. (1997). The interview for recent life events. Psychological Medicine, 27, 301-310. doi:10.1017/ S0033291796004424. PubMed: 9089823.

36. First, M. B., Spitzer, R. L., Gibbon, M., \& Williams, J. B. W. (2002). Structured Clinical Interview for DSM-IV-TR Axis I Disorders, Research Version, Patient Edition. (SCID-I/P). New York: Biometrics Research, New York State Psychiatric Institute.

37. Delespaul P. A. E. G. (1995). Assessing schizophrenia in daily life. The experience sampling method. Maastricht: Maastricht University Press.

38. Ma, S. H., \& Teasdale, J. D. (2004). Mindfulness-Based Cognitive Therapy for Depression: Replication and Exploration of Differential Relapse Prevention Effects. Journal of Consulting and Clinical Psychology, 72, 31 40. doi: 10.1037/0022-006X.72.1.31. PubMed: 14756612.

39. Goodman, L. A. (1960). On the exact variance of products. Journal of the American Statistical Association, 55, 708-713. doi:10.1080/01621459.1960.10483369.

40. MacKinnon, D. P., Fairchild, A. J., \& Fritz, M. S. (2007). Mediation Analysis. Annual Review of Psychology, 58, 593-614. doi:10.1146/annurev.psych. 58.110405.085542. PubMed: 16968208.

41. Sobel, M. E. (1982). Asymptotic confidence intervals for indirect effects in structural equation models. In S. Leinhardt. Sociological Methodology (pp. 290-312). Washington DC: American Sociological Association.

42. Ender, P. B. (2012). Sgmediation. Program to compute Sobel-Goodman mediation tests. Available: http:// www.ats.ucla.edu/stat/stata/ado/ analysis. Accessed 2013 August 2.

43. StataCorp (2012). Stata statistical software. Release 11: 2. TX: College Station: StataCorp LP. 
44. Wichers, M. C., Barge-Schaapveld, D. Q. C. M., Nicolson, N. A., Peeters, F., de Vries, M, Mengelers, R., \& van Os, J. (2009). Reduced stress-sensitivity or increased reward experience: The psychological mechanism of response to antidepressant medication. Neuropsychopharmacology, 34, 923-931. doi:10.1038/npp.2008.66. PubMed: 18496519.

45. Garland, E. L., Fredrickson, B., Kring, A. M., Johnson, D. P., Meyer, P. S., \& Penn, D. L. (2010). Upward spirals of positive emotions counter downward spirals of negativity: Insights from the broaden-and-build theory and affective neuroscience on the treatment of emotion dysfunctions and deficits in psychopathology. Clinical Psychology Review, 30, 849-864. doi:10.1016/j.cpr. 2010.03.002. PubMed: 20363063.

46. Segal, Z. V., Williams, J. M., Teasdale, J. D., \& Gemar, M. (1996). A cognitive science perspective on kindling and episode sensitization in recurrent affective disorder. Psychological Medicine, 26, 371-380. doi:10.1017/ S0033291700034760. PubMed: 8685293.

47. Wichers, M., Geschwind, N., van Os, J., \& Peeters, F. (2010). Scars in depression: Is a conceptual shift necessary to solve the puzzle? Psychological Medicine, 40, 359-365. doi:10.1017/S0033291709990420. PubMed: 20120516.

48. Post, R. M. (2007). Kindling and sensitization as models for affective episode recurrence, cyclicity, and tolerance phenomena. Neuroscience \& Biobehavioral Reviews, 31, 858-873. doi:10.1016/j. neubiorev.2007.04.003. PubMed: 17555817.

49. Stroud, C. B., Davila, J., Hammen, C., \& Vrshek-Schallhorn, S. (2011). Severe and nonsevere events in first onsets versus recurrences of depression: Evidence for stress sensitization. Journal of Abnormal Psychology, 120, 142-154. doi: 10.1037/a0021659. PubMed: 21171724.

50. Nanni, V., Uher, R., \& Danese, A. (2012). Childhood maltreatment predicts unfavorable course of illness and treatment outcome in depression: A meta-analysis. The American Journal of Psychiatry, 169, 141-151. doi:10.1176/appi.ajp. 2011.11020335. PubMed: 22420036.

51. Hetrick, S. E., Parker, A. G., Hickie, I. B., Purcell, R., Yung, A. R. \& McGorry, P. D. (2008). Early identification and intervention in depressive disorders: Towards a clinical staging model. Psychotherapy and Psychosomatics, 77, 263-270. doi: 10.1159/000140085. PubMed: 18560251.

52. McGorry, P., \& van Os, J. (2013). Redeeming diagnosis in psychiatry: timing versus specificity. Lancet, 381, 343-345. doi:10.1016/ S0140-6736(12)61268-9. PubMed: 23351805. 
How Does MBCT for Depression Work? 


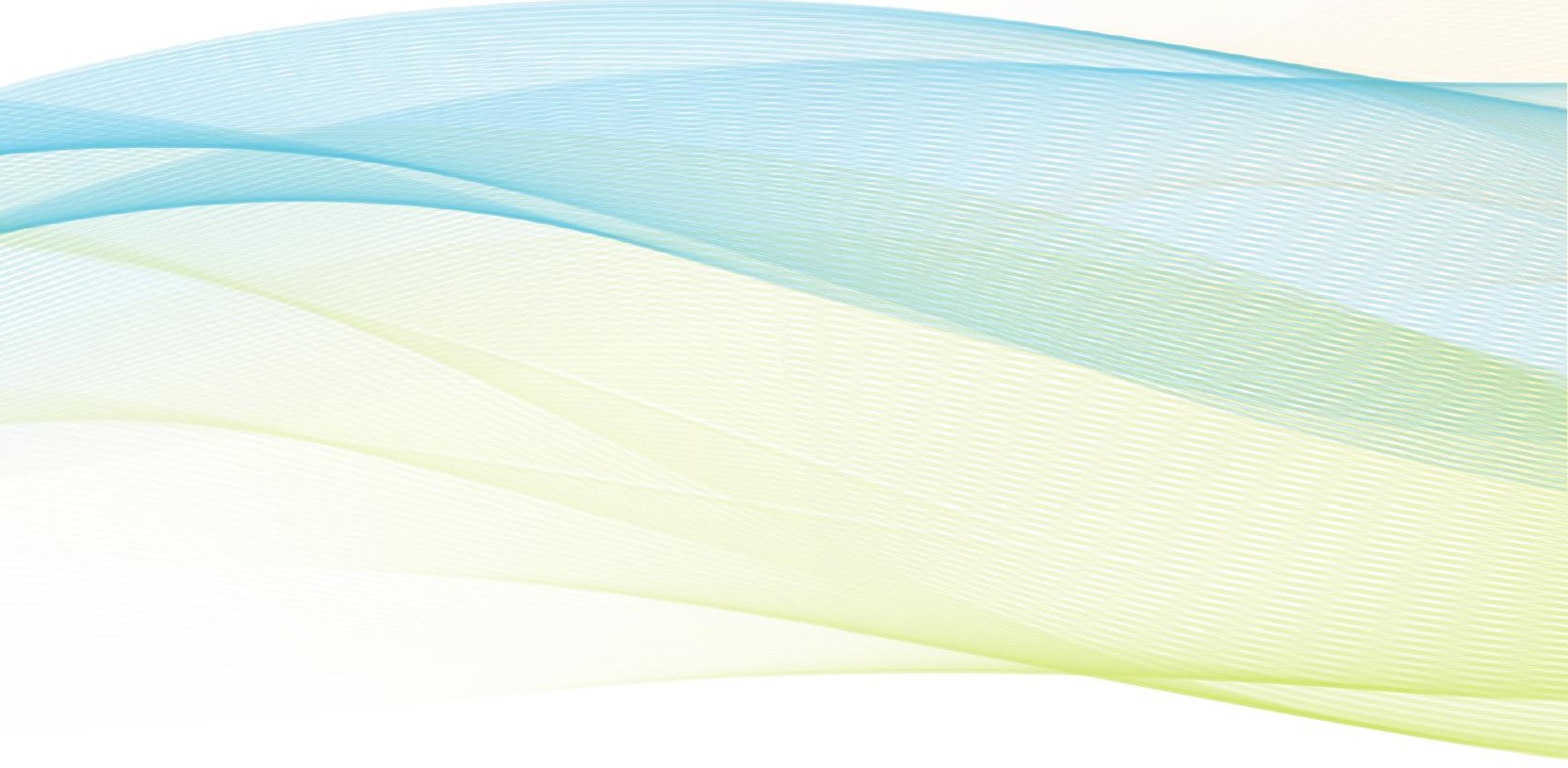


hoofdstuk

Algemene Discussie 
Deze thesis getiteld "Third Wave Behaviour Therapy; Process Measures and Contextual Interventions" heeft zich gericht op de functionele processen van de derde generatie gedragstherapieën. Er werd achtereenvolgens stilgestaan bij de assessment van deze processen, het faciliteren van deze processen in het dagelijks leven middels een contextuele interventie, en tenslotte kwamen de werkzame mechanismen van een specifieke behandelvorm binnen de derde generatie gedragstherapie aan bod.

\section{Assessment ACT-processen}

\section{Beschikbare Meetinstrumenten}

Het eerste deel van dit proefschrift heeft zich gericht op de assessment van de verschillende ACT-processen. In hoofdstuk twee wordt er ingezoomd op de beschikbare ACTmeetinstrumenten om deze processen in kaart te brengen. Zoals betoogd, zijn de reguliere klachtgerichte vragenlijsten weinig informatief als het gaat om het meten van ACTvaardigheden. De laatste systematische review hieromtrent dateert uit 2009 [1]; hier werden destijds in totaal 15 procesmaten geïdentificeerd voor het Nederlandse taalgebied waarvan de meesten echter niet voor ACT waren ontwikkeld. In 2011 verscheen er een ACT-measures package van Ciarrochi en Bilich [2] waarin 36 verschillende bruikbare instrumenten werden geïdentificeerd. En hoewel dit zeker bruikbare instrumenten waren voor ACT-onderzoek, waren ook hier de meeste instrumenten niet ontwikkeld in het ACT-veld hetgeen leidde tot een matige overeenkomst met de specifieke ACT-constructen. Dit gaf ons aanleiding tot het uitvoeren van een nieuw systematisch literatuur onderzoek, met extra aandacht voor de aansluiting tussen instrumenten en ACT-constructen. Uit deze review kwam naar voren dat per februari 2015 reeds 59 vragenlijsten beschikbaar waren om de verschillende ACTspecifieke processen in kaart te brengen - hierbij waren ook veel populatie-specifieke varianten van de Acceptance and Action Questionnaire te vinden - [3]. In figuur 1 staat een overzicht van de beschikbare ACT-instrumenten per component. Aangezien niet elke vragenlijst beschikbaar is voor het Nederlandstalig gebied of voldoende is onderzocht op psychometrische kwaliteit, is er per ACT-proces een suggestie gedaan voor het meest geschikte instrument (vetgedrukt).

Acceptatie: De Acceptance and Action Questionnaire (AAQ-II, [4]) is een zelfrapportagelijst die de mate van acceptatie en experientiele vermijding in kaart brengt. De psychometrische eigenschappen van de Nederlandse vertaling van AAQ-II zijn goed.

Defusie: De Cognitive Fusion Questionnaire (CFQ, [5]) is een zelfrapportagevragenlijst die de mate van fusie met gedachten in kaart brengt. De psychometrische kwaliteiten van de CFQ zijn uitstekend.

Zelf als Context: De Self as Context Scale (SACS, [6]) is een zelfrapportagevragenlijst die in kaart brengt in hoeverre iemand een basisgevoel van het zelf heeft dat verder gaat dan zijn

Noot: Een bewerkte versie van de Introductie en Algemene Discussie van dit proefschrift zal als artikel worden gepubliceerd in het tijdschrift De Psycholoog (Acceptance and Commitment Therapy: Achtergrond, Assessment \& Applicatie; T. Batink \& F. Peeters). 
zelfbeeld. Er is beperkte informatie beschikbaar aangaande de psychometrische kwaliteiten. Aandacht voor het Hier en Nu: De Five-Facet Mindfulness Questionnaire Short-Form (FFMQ$\mathrm{SF},[7]$ ) is een zelfrapportage vragenlijst die het vermogen meet om de aandacht te richten op het huidige moment. De psychometrische kwaliteit van de FFMQ-SF is ruim voldoende. Waarden: De Valued Living Questionnaire (VLQ, [8]) is een zelfrapportagevragenlijst die in kaart brengt welke levensgebieden belangrijk zijn voor iemand en in hoeverre deze persoon daadwerkelijk investeert in deze gebieden. De elementaire psychometrische kwaliteiten zijn voldoende gebleken.

Toegewijd Handelen: De Engaged Living Scale (ELS, [9]) is een zelfrapportagevragenlijst die zowel waarden als toegewijd handelen in kaart brengt. De psychometrische kwaliteiten van de ELS zijn goed.

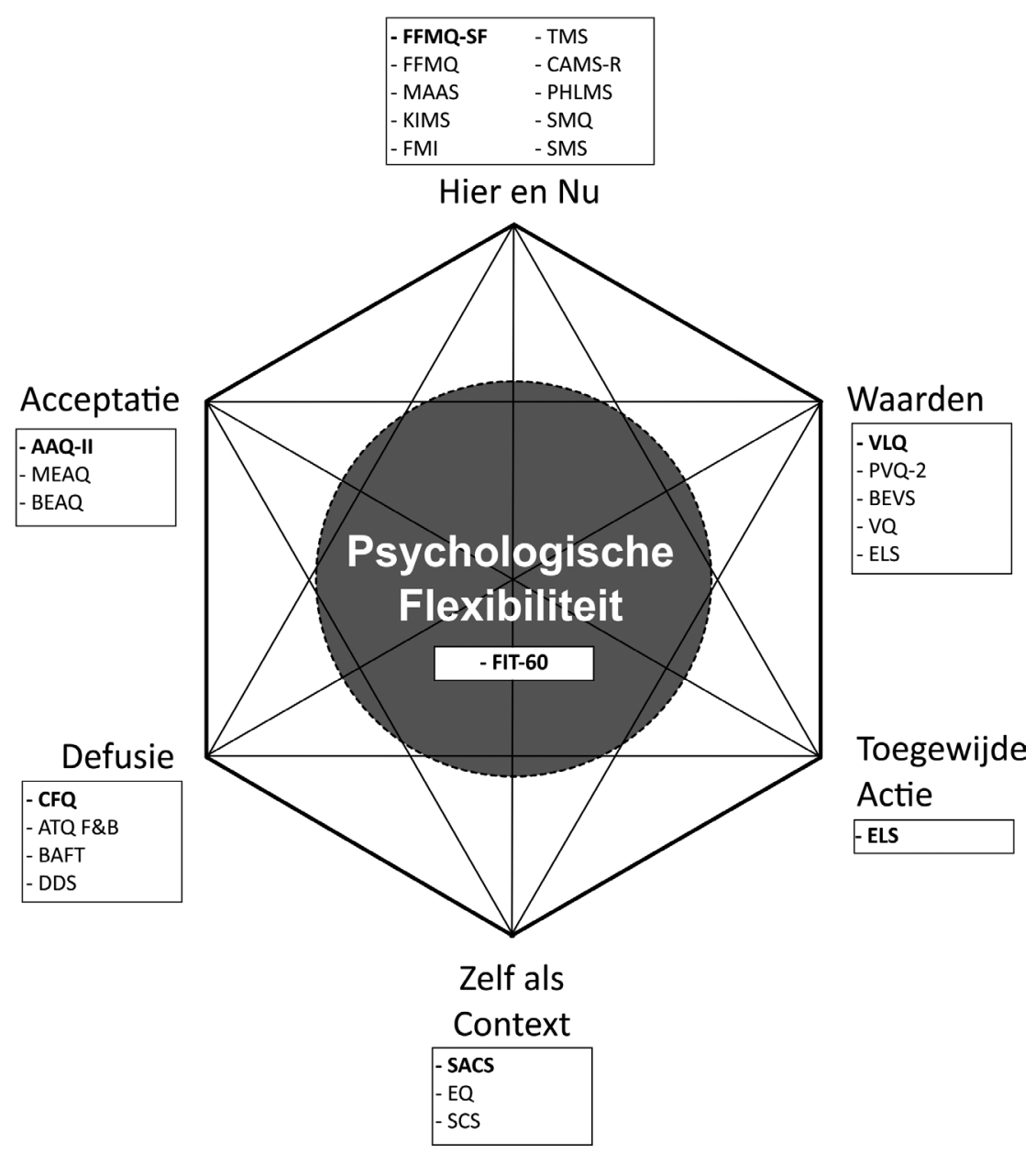

Figuur 1. Hexaflex, met per ACT-component beschikbare vragenlijsten. 
Psychologische Flexibiliteit: De Flexibiliteits Index Test (FIT-60, [10]); is een zelfrapportagevragenlijst die psychologische flexibiliteit (samenspel van de zes verschillende ACTprocessen) in kaart brengt. De psychometrische kwaliteiten van de FIT-60 zijn goed te noemen.

Bij bovenstaande selectie dient een kanttekening te worden geplaatst. Niet elke lijst is officieel vertaald naar het Nederlands en verder gevalideerd. Het gaat hier dus om een 'best clinical practice' lijst. Hoewel het waardevol is om een recent overzicht te hebben van de beschikbare vragenlijsten op dit moment, zal deze relatief snel outdated raken gezien de snelle ontwikkelingen in dit veld. Hierbij valt tevens op dat er na een eerste publicatie regelmatig geen vervolgonderzoek naar de psychometrische kwaliteiten van het instrument meer volgt. Een uitzondering hierop vormt de AAQ-II, die uitgebreid is onderzocht $[4,11]$ en is bewerkt voor meerdere specifieke problematieken waaronder body image [12], sociale angst [13], verslaving [14], hersenletsel [15] en werk [16] en die in meer dan 15 talen beschikbaar is. De AAQ-II heeft ook zijn weg gevonden buiten de ACT-onderzoeken en lijkt te worden gezien als een bruikbare maat om het transdiagnostische proces van experiëntiële vermijding in kaart te brengen $[17,18]$.

\section{Meten van Psychologische Flexibiliteit}

Het doel van ACT is het ontwikkelen van Psychologische Flexibiliteit: het vermogen flexibel om te gaan met de problemen die men tegenkomt, terwijl men blijft investeren in de dingen die er echt toe doen voor iemand [19, 20]. Deze psychologische flexibiliteit bestaat uit het samenspel van de zes verschillende ACT-processen; Acceptatie, Defusie, Zelf als Context, Aandacht voor het Hier en Nu, Waarden en Toegewijd Handelen. Het betreft hier dus een multidimensionaal concept. Er bleek echter nog geen instrument voorhanden te zijn die de zes verschillende processen tezamen in kaart kon brengen en daarmee uitspraken kon doen over de psychologische flexibiliteit. In het onderzoek wordt daarom de AAQ-II vaak gebruikt als indicatie [21]; echter deze is vooral gericht op de experiëntiële vermijding (unidimensiaal) en minder op de andere ACT-processen [4, 22, 23]. In hoofdstukken 3 en 4 wordt de ontwikkeling en psychometrisch onderzoek van een nieuw meetinstrument beschreven dat de zes ACT-processen en daarmee ook de psychologische flexibiliteit in kaart kan brengen; de Flexibiliteits Index Test (FIT-60).

De FIT-60 is een zelfrapportagelijst die de functionele ACT-processen in kaart brengt [10, 24]. De FIT-60 bestaat uit 60 items die op een zevenpunts Likertschaal worden gescoord (0 $=$ helemaal oneens, 6 = helemaal eens). De FIT-60 totaalscore weerspiegelt de psychologische flexibiliteit van een individu. Zes subschalen (acceptatie, defusie, zelf als context, aandacht voor het hier en nu, waarden en toegewijd handelen) brengen de specifieke processen uit de ACT-theorie in kaart. ledere subschaal bevat 10 items; de minimale score op een subschaal is 0 , de maximale score is 60 . Voor de totaalschaal is het minimum eveneens 0 en het maximum 360 (Flexibiliteits Index Score). Hoe hoger iemand scoort, hoe meer men deze ACT-vaardigheid beheerst. De items zijn gerandomiseerd, alsook gespiegeld. De scores kunnen worden vergeleken met vier normgroepen (algemeen, student, ambulant \& klinisch); en zijn visueel te maken in het flexibiliteitsprofiel (zie figuur 2a). Tevens is een ipsatieve 
vergelijking mogelijk (zie figuur 2b). De FIT-60 is ontwikkeld voor volwassenen (18-75 jaar) en vraagt 15 minuten afnametijd. De FIT-60 is gratis beschikbaar op de website www. hoeflexibelbenjij.nl, zowel als download (PDF) als in een online versie (geschikt voor tablet en pc), alsook in meerdere ROM-systemen (o.a. TelePsy, NetQ, Vital Health \& Reflectum). Er wordt tenslotte gewerkt aan een Engelse vertaling. Zie Appendix 1 voor de volledige vragenlijst en Appendix 2 voor een gebruikersinstructie van de FIT-60.
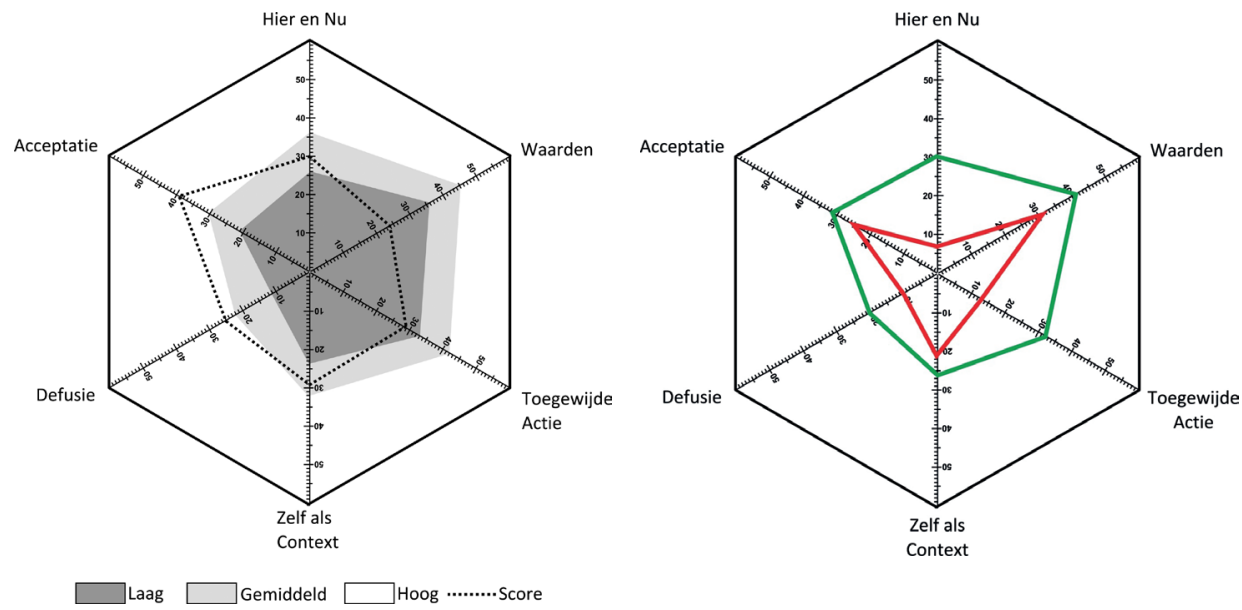

Figuur 2. Flexibiliteitsprofiel (Links Normatief, Rechts Ipsatief).

De psychometrische kwaliteiten van de FIT-60 zijn uitgebreid onderzocht in meerdere samples [24]. De interne betrouwbaarheid is als goed te classificeren voor de subschalen (uitgezonderd de subschaal "Zelf als Context") en de totaalschaal van de FIT-60 over de verschillende samples. De test-hertestbetrouwbaarheid van de subschalen en de totaalschaal zijn zelfs zeer goed te noemen. Tevens is de FIT-60 in staat gebleken verandering over tijd te meten en voor de ambulante normgroep is bepaald vanaf wanneer is sprake is van een klinisch betrouwbare verandering (Reliable Change Index, [25]). Daarnaast is de validiteit voor de verschillende subschalen alsook de totaalschaal van de FIT-60 onderzocht. Er is steun gevonden voor de constructvaliditeit van vijf van de zes subschalen (Acceptatie, Defusie, Aandacht voor het Hier en Nu, Waarden en Toegewijd Handelen) alsook voor de totaalschaal "Psychologische Flexibiliteit". Echter ook hier liet de subschaal "Zelf als Context" een matige constructvaliditeit zien. Tenslotte bleken demografische variabelen zeer beperkt van invloed te zijn op de uitkomsten van de FIT-60 [24].

De FIT-60 is tot op heden het enige meetinstrument in het Nederlands taalgebied dat zowel psychologische flexibiliteit, alsook de zes ACT-componenten in kaart brengt. Tevens beschikt de FIT-60 over vier normgroepen van substantiële grootte (iets wat veelal ontbreekt bij de eerder genoemde ACT-vragenlijsten). De FIT-60 is uitgebreid onderzocht en beschikt over 
goede psychometrische kwaliteiten; het is een betrouwbare en valide vragenlijst. De visuele weergave van de scores in het flexibiliteitsprofiel maakt de scores inzichtelijk en gemakkelijker te interpreteren. De FIT-60 is gratis beschikbaar en licentievrij te gebruiken. $\mathrm{Er}$ is actief samenwerking gezocht met ROM-aanbieders voor een integratie in hun systemen. De FIT-60 heeft zijn weg dus reeds gevonden in de klinische praktijk en in het wetenschappelijk onderzoek $[26,27,28]$.

Er dienen echter ook een aantal kanttekeningen te worden geplaatst. Het bleek niet mogelijk om middels factoranalyse de constructvaliditeit van de FIT-60 aan te tonen; de constructen waren hiervoor te weinig te onderscheiden. Dit sluit echter ook aan bij het ACT-model; de processen zijn niet alleen theoretisch maar ook in de empirie sterk verbonden [19]. De constructvaliditeit is daarom middels correlationeel onderzoek verder onderzocht.

Tevens bleek de betrouwbaarheid en validiteit van de "Zelf als Context"-schaal matig. Gezien dit ook het meest abstracte onderdeel van ACT is, is dit ook wel te begrijpen. Het feit dat er voor deze schaal nog maar één andere, ongepubliceerde, vragenlijst beschikbaar is illustreert het uitdagende karakter van het operationaliseren van dit thema.

Daarbij moet worden vermeld dat de definitie van het zelf in de FIT-60 geijkt is op de beschrijving uit het handboek uit 1999 [29]. In de herziene editie van het handboek [19] is deze verbreed; van contact maken met het observerende zelf (transcendente zelf) naar het leren innemen van een ander perspectief (zowel naar jezelf als naar anderen). Dit omvat o.a. transcendente zelf, maar ook zelfcompassie, alsook compassie naar anderen. Het domein zelf lijkt dus ook nog niet goed te zijn uitgekristalliseerd.

Ook kan een kanttekening worden geplaatst bij de klinische normgroep. Het betrof hier namelijk een vrij hoogopgeleide, hoog functionerende groep. Deze groep is dus niet zonder meer vergelijkbaar met een andere klinische patiënt populatie. Het is dan ook raadzaam om de gegevens van de normgroepen te bestuderen om te kunnen bepalen in hoeverre deze daadwerkelijk overeenkomen met de doelgroep waarvoor het instrument wordt gebruikt.

Tenslotte dient te worden opgemerkt dat er een mogelijkheid bestaat dat het ACT-hexaflex in de toekomst wordt teruggebracht naar een drie-componenten model [19, 30]. Dit zou enige aanpassing vereisen van de FIT-60; echter deze zou met name cosmetisch van aard zijn. De onderliggende processen zouden nog aanwezig zijn, maar worden samengevoegd.

Dit onderzoeksveld is constant in ontwikkeling. Medio 2016 verscheen er een artikel van Kelly Wilson (een van de drie ACT-founders) waarin de Multidimensional Psychological Flexibility Inventory wordt geïntroduceerd (MPFI, [31]): een ACT-vragenlijst met 60 items die zowel de zes functionele ACT-processen alsook de zes disfunctionele processen meet en daarmee ook uitspraken kan doen over de psychologische (in)flexibiliteit. Het instrument is echter nog niet beschikbaar voor het publiek. Het zou in de toekomst interessant zijn deze te kunnen vergelijken met de Flexibiliteits Index Test. 


\section{ACT-processen in het Dagelijks Leven}

\section{ACT in Daily Life Training: Ontwikkeling.}

De ACT-processen kunnen ook worden gezien als vaardigheden [32]. Naast het kunnen monitoren, willen we ze ook actief kunnen beïnvloeden in de patiënt tegenover ons. Echter we willen niet dat de toepassing van deze vaardigheden zich beperkt tot de therapieruimte maar ook generaliseert naar het dagelijks leven van de patiënt. Het tweede deel van dit proefschrift (hoofdstukken 5 en 6) richt zich dan ook op de ontwikkeling en onderzoek van een mHealth interventie die patiënten ondersteunt in het toepassen van ACT in het dagelijks leven: de ACT in Daily Life Training.

In hoofdstuk vijf werd het ACT in Daily Life Training project beschreven dat zich heeft gericht op het ontwikkelen van de ACT in Daily Life Training (ACT-DL), alsook het onderzoeken van de haalbaarheid (feasibility) en aanvaardbaarheid (acceptability) van deze interventie voor de deelnemers. Tenslotte is er in deze studie verkennend onderzoek gedaan naar de effectiviteit van deze interventie.

De ACT-DL is een aanvullende mHealth interventie (Mobile Health - Gebruik van mobiele technologie om gezondheid te bevorderen), die met een mobiel device (PsyMate) zowel ACT-training in het dagelijks leven aanbiedt, alsook monitoring in het dagelijks leven faciliteert met experience sampling [27]. Na het volgen van een reguliere ACT-therapie/ training, kunnen deelnemers de ACT-DL gebruiken om zich thuis verder te bekwamen in de verschillende ACT-vaardigheden. Het doel van deze interventie is om deelnemers te helpen ACT te integreren in hun dagelijks leven en daarmee de psychologisch flexibiliteit en kwaliteit van leven te bevorderen. De ACT-DL duurt vier weken, waarbij deelnemers drie dagen in de week actief aan het trainen zijn. De ACT-DL maakt gebruik van monitoring in het dagelijks leven om het bewustzijn van eigen mentale processen te vergroten [33]. Op tien willekeurige momenten op een dag wordt de deelnemer gevraagd een korte vragenlijst in te vullen over o.a zijn huidige mentale staat, activiteit en gezelschap. Tevens worden deelnemers in de ochtend gevraagd om een persoonlijke waarde te bepalen (bijvoorbeeld balans), waar zij die dag in willen gaan investeren. Deze investering wordt vervolgens gedurende de dag gemonitord (interval-contingent). Naast de monitoring wordt er ook ACT-training in het dagelijks leven aangeboden. De ACT-DL focust op vier kerncomponenten van ACT; Acceptatie, Defusie, Mindfulness en Toegewijd Handelen. Er zijn twee soorten oefeningen beschikbaar: algemene ACT-oefeningen die altijd toepasbaar zijn en ACTie-oefeningen die specifiek zijn ontwikkeld voor momenten waarop iemand onaangename gedachten, gevoelens of sensaties ervaart (event-contigent). In totaal zijn er 18 verschillende oefeningen beschikbaar. Het betreffen hier korte oefeningen die gemakkelijk in het dagelijks leven kunnen worden uitgevoerd. Deelnemers dienen minimaal drie ACT-oefeningen per dag uit te voeren (ochtend / middag / avond). Tenslotte worden er ook geïllustreerde ACT-metaforen gebruikt die dienen als reminder /cue voor de twee voornaamste ACT-concepten: Acceptatie en Defusie (waarmee de deelnemers reeds hebben kennis gemaakt in de reguliere training, voorafgaande aan de ACT-DL). Deze 
metaforen werden na 50\% van de monitormomenten aangeboden (signaal-contigent). De andere 50\% werd er een korte aandachtsoefening aangeboden.

De haalbaarheid en aanvaardbaarheid van deze nieuw ontwikkelde ACT-DL is onderzocht bij 49 deelnemers in een behandelcentrum in Epen waar een heterogene klinische populatie verblijft (o.a. stemmingsproblematiek, angststoornissen, verslaving en comorbide persoonlijkheidsproblematiek). De therapietrouw was ruim voldoende; meer dan driekwart van de deelnemers heeft de training volledig doorlopen waarmee de haalbaarheid van de interventie als meer dan voldoende kan worden beschouwd [34].

Uit semi-gestructureerde interviews met de deelnemers over hun ervaringen met de ACT-DL kwam naar voren dat de training hen stimuleerde tot het toepassen van ACT in hun dagelijks leven. Deelnemers oefenden meer dan een uur per week en voerden gemiddeld 10 oefeningen uit. Zowel de ACT-oefeningen als metaforen werden als waardevolle onderdelen van de training ervaren. De deelnemers zouden de ACT-DL dan ook aanbevelen bij anderen. Dit geeft een positieve indicatie van de aanvaardbaarheid van ACT-DL voor de deelnemers. Tevens is er aandacht geweest voor mogelijke verbeterpunten van de training. Hierbij kwam naar voren dat men graag meer verschillende oefeningen zou kunnen gebruiken. Ook werd er regelmatig de suggestie gedaan om de aandachtsoefeningen als audio-fragment aan te bieden (geleide-oefening). En hoewel de metaforen over het algemeen werden gewaardeerd, mocht wat betreft de deelnemers de frequentie van het aanbieden minder zijn. Eveneens werd duidelijk dat de interventie simpel in design en functie moet zijn (in lijn met Ahtinen [35]); het onderscheid tussen de algemene ACT-oefeningen en de ACTie-oefeningen was niet voor alle deelnemers helder.

Tenslotte heeft er nog verkennend onderzoek plaatsgevonden naar de effectiviteit van de ACT-DL. Hier kwam naar voren dat de ACT-DL op de korte termijn geen aanvullend effect liet zien bovenop het significante effect van de ACT-groepsinterventie zelf. Het is echter niet uit te sluiten dat het relatief subtiele aanvullende effect is gemaskeerd door het effect van de transitie van de klinische setting naar de thuisomgeving. Ook zou er sprake kunnen zijn van een plafond-effect direct na de ruime resultaten van de intensieve klinische behandeling. De effectiviteit van de interventie is alleen bepaald op de korte termijn, het is mogelijk dat de effecten pas op de langere termijn zichtbaar worden [36, 37]. Vervolgonderzoek zou rekening moeten houden met voldoende power om een relatief klein effect te kunnen detecteren (waarbij er wordt gewaakt voor grote contextuele veranderingen die de resultaten kunnen maskeren), waarbij het effect van de interventie niet alleen op korte maar ook op langere termijn in kaart wordt gebracht.

Het AiDLT-project heeft geresulteerd in de ontwikkeling van een mobiele add-on interventie, de ACT in Daily Life Training (ACT-DL). Dit is het eerste onderzoek dat experience sampling, welke bewustzijn in het dagelijks leven bevordert, combineert met Acceptance and Commitment Therapy, waarbij de ontwikkeling van ACT-vaardigheden in het dagelijks leven wordt bevorderd. Op basis van dit onderzoek kan worden geconcludeerd dat de combinatie van experience sampling en ACT niet alleen in theorie overeen lijkt te komen (ESM die de ACT kernpilaar awareness versterkt), maar ook in de praktijk goed blijkt te functioneren. Uit 
het huidige onderzoek komt naar voren dat deze interventie haalbaar en aanvaardbaar is voor een heterogene groep patiënten met substantiële psychopathologie. De generaliseerbaarheid van deze interventie lijkt dan ook hoog, wat suggereert dat de ACT-DL geschikt is voor een breed scala aan psychische problematieken. Tenslotte biedt dit onderzoek aanvullende ondersteuning voor de haalbaarheid van het aanbieden van een ACT-interventie via mHealth [38, 39, 40, 41].

Er zijn ook een aantal kanttekeningen te plaatsen bij bovenstaand onderzoek. Het ACT-model bestaat uit zes interacterende processen die elkaar versterken [19]. Door er twee achterwege te laten, wordt de synergetische werking van de componenten verzwakt en daarmee mogelijk de effectiviteit van de gehele interventie. Een ander aandachtspunt is de timing van de twee onderdelen (ACT-training en de aanvullende ACT-DL) waarbij er nu voor is gekozen om deelnemers eerst de ACT-training in de kliniek te laten doorlopen en vervolgens na ontslag in de thuissituatie te laten oefen met de ACT-DL (sequentieel). Het zou echter interessant zijn om dit te combineren, zodat de deelnemers direct na het bijwonen van een ACT-sessie in hun dagelijks leven kunnen gaan oefenen (parallel). Tevens moet er een kanttekening worden geplaatst bij het bepalen van de gebruikerservaringen van de deelnemers aangaande de ACT-DL; de data van de Experience Sampling zijn niet meegenomen en er is alleen gebruik gemaakt van gestructureerde interviews (met risico op recall bias). Hierop voortbordurend is het ook onfortuinlijk dat er geen gestructureerde logs beschikbaar waren om het gebruik van de ACT-DL te objectiveren.

De combinatie van monitoring enerzijds en het aanbieden van een interventie anderzijds is overigens niet nieuw; dit heeft vanuit het onderzoeksgebied van de ecologische monitoring zelfs al geleid tot specifieke acroniemen; vanuit de Experience Sampling Method is er ESM-i $[42,43]$ en vanuit de Ecological Momentry Assessment is er EMI [44]. Er zijn dan ook al meerdere studies verschenen die succesvol daily life monitoring combineerden met een interventie [45, 46]. De gerapporteerde effecten vallen tussen small en medium bij geestelijke gezondheid alsook psychologisch welzijn, waarbij de effecten groter zijn als er aanvullende hulp is van een professional.

Hoewel niet de focus van het huidige onderzoek, verdient het gebruikte medium om deze interventie aan te bieden nog even de aandacht. Het zowel kunnen aanbieden van frequente monitoring enerzijds alsook het aanbieden van een (complexe) interventie in het dagelijks leven anderzijds, vraagt om een veelzijdig, flexibel, maar vooral ook mobiel medium. Het zijn dan ook de ontwikkelingen op het vlak van mobiele technologie die het mogelijk hebben gemaakt om beide functies te verenigen in één medium; in het geval van dit onderzoek betrof het een PDA (PsyMate). Echter anno 2016 heeft 71\% van de volwassenen in Europa een smartphone [47]. De smartphone lijkt dan ook het ideale instrument voor monitoring en interventies in het dagelijks leven. Men heeft deze de gehele dag bij zich en de functionaliteiten van het apparaat zijn praktisch oneindig uit te breiden middels app's. Verderop in deze discussie zullen wij nog even teruggrijpen op de mogelijkheden die deze technologische ontwikkelingen ons bieden in de ondersteuning van onze patiënten. 


\section{ACT in Daily Life Training: Optimaliseren}

De resultaten van de feasibility study beschreven in hoofdstuk 5, gaven aanleiding tot het verder ontwikkelen van de ACT-DL. De aandachtspunten die naar voren kwamen uit dit onderzoek zijn meegenomen in de herziening van de interventie. Tevens is de ACT-DL uitgebreid naar alle ACT-processen en is er aandacht voor "Creatieve Hopeloosheid" als voorbereidende fase en "Psychologische Flexibiliteit" als integratie van alle ACT-processen. Daar waar er eerst sprake was van een sequentiële opzet (eerst algemene training en daarna training in het dagelijks leven), is er nu gekozen voor een synchrone opzet (algemene training en training in het dagelijks leven lopen parallel). Tenslotte is er de overstap gemaakt van de PsyMate als device (figuur 3a) naar de nieuw ontwikkelde PsyMate-app (figuur 3b). Dit resulteerde in een herziene versie van deze ACT in Daily Life Training die uitvoerig is beschreven in het concept-paper in hoofdstuk 6 (zowel de algemene training als de mHealth module; Steinhart et al., in voorbereiding [48]). Onderstaand volgt een beknopte beschrijving van deze herziene training.
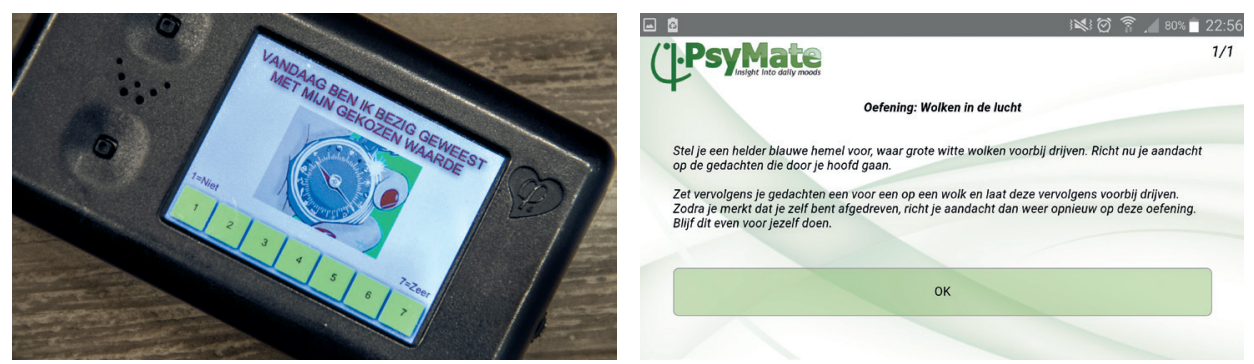

Figuur 3. Links: ACT-DL PsyMate-PDA. Rechts: ACT-DL PsyMate-App.

Bij de herziene ACT in Daily Life Training (ACT-DL) zijn de algemene ACT-therapie/training en de aanvullende $\mathrm{mHealth}$ interventie met elkaar geïntegreerd (daar waar het initieel alleen een aanvullende mHealth module betrof). Voor de algemene ACT-training is er een werkboek - inclusief CD met 12 geleide oefeningen - voor de cliënt ontwikkeld alsook een handleiding voor de therapeut. Daarnaast is de mHealth interventie aangepast op de algemene training, zodanig dat deze een optimale aansluiting heeft alsook een complementaire functie vervult. De duur van de interventie is flexibel, maar betreft doorgaans 8 weken. Per week zal een deelnemer na de ACT-bijeenkomst drie dagen actief bezig zijn met zelfmonitoring \& ACTtraining.

De herziene ACT-DL bestaat uit 8 flexibele modules waarin per module zowel de bijeenkomst staat uitgewerkt (psychoeducatie, oefeningen en metaforen) alsook de aanvullende mHealth training op is afgestemd. Het betreft de modules Creatieve Hopeloosheid, Acceptatie, Defusie, Zelf als Context, Hier en Nu, Waarden, Toegewijd Handelen en Psychologische Flexibiliteit. De modules kunnen flexibel worden ingezet. De begeleidende mHealth interventie zal de focus leggen op het aanbieden van de ACT-oefeningen en metaforen van 
de module waar de cliënt op dat moment aan werkt. Daarbij zullen de eerder behandelde modules ook beschikbaar blijven om mee te kunnen oefenen (cumulatieve opbouw). Daarnaast zullen er ongeacht de geactiveerde module eveneens aandachtsoefeningen beschikbaar zijn omdat dit als een belangrijke basisvaardigheid wordt gezien. Zodra de cliënt alle modules heeft doorlopen, heeft hij de beschikking over alle onderdelen en leert hij de verschillende ACT-vaardigheden flexibel in te zetten, afhankelijk van zijn interne en externe context. Dit maakt de interventie person-tailored en interactief. Een mogelijke volgende stap zou de automatische aanpassing van de oefeningen op basis van de zelfmonitoring zijn.

De herziene ACT-DL mHealth interventie is sterk uitgebreid; voor elke component zijn er 2 geillustreerde ACT-metaforen beschikbaar ${ }^{1}$ (16 in totaal); alsook meerdere ACT-oefeningen beschikbaar (34 in totaal). Er zijn nog steeds twee type oefeningen, echter in plaats van de cliënt hier zelf onderscheid in te laten maken wordt gevraagd of hij op dit moment last heeft van een ongewenste ervaring. Indien de cliënt "Ja" antwoordt, wordt hij doorgeleid naar hier specifiek voor ontwikkelde oefeningen. Indien "Nee" wordt geantwoord, wordt men doorgeleid naar de algemene oefeningen die altijd toepasbaar zijn. Deelnemers dienen minimaal 3 ACT-oefeningen per dag te doen (ochtend, middag, avond). Na de bijeenkomst met de module over Toegewijd Handelen, dienen de deelnemers drie waarden te selecteren waar ze vanaf die sessie aan gaan werken en die ze ook zullen monitoren. De monitoring in de mHealth interventie is eveneens aangepast; van 10 meetmomenten per dag naar 8 momenten per dag. Daarmee worden er tevens minder metaforen aangeboden; in plaats van vijf metaforen worden er nu vier aangeboden (50 \%). Bij de overige $50 \%$ van de meetmomenten wordt een cliënt uitgenodigd om een oefening te doen (maar wordt niet meer automatisch een oefening aangeboden). Zie figuur 4 voor een schematisch overzicht van de herziene ACT-DL.

De herziene versie van de ACT-DL wordt op dit moment gebruikt bij het SMARTSCAN-project aan de Universiteit Maastricht (5-sessie-variant, groepsformat, toegepast bij een populatie met subklinische depressieve klachten en/of subklinische psychose klachten) en bij het InterACT-project aan de KU Leuven (7-sessie-variant, individueel format, toegepast bij een ultra high risk en eerste psychose populatie). Het betreft in beide gevallen een RCT naar de effectiviteit van de gehele interventie. Zie figuur 5 voor een overzicht van de opzet van de verschillende varianten van de ACT-DL: AiDLT, SMARTSCAN \& InterACT.

\footnotetext{
${ }^{1}$ Deze metaforen komen ook allemaal aan bod in de begeleidende sessies met de therapeut.
} 


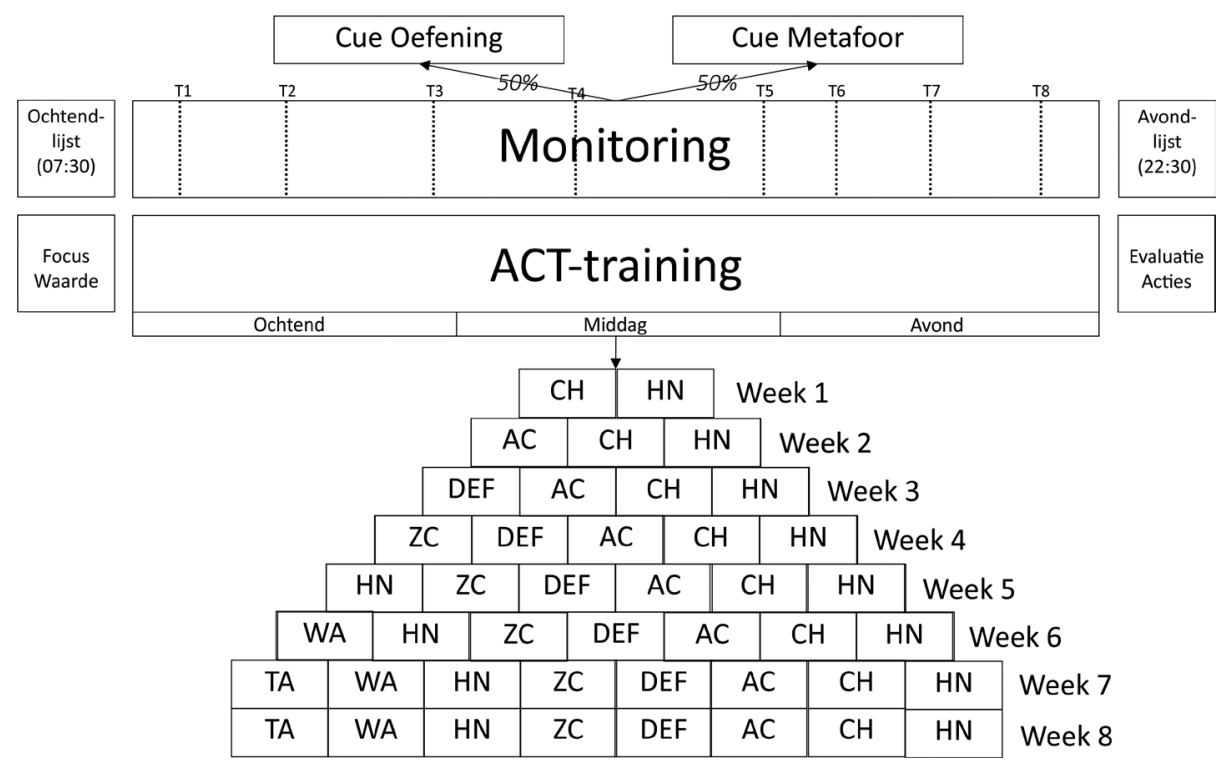

Figuur 4. Schematische weergave ACT-DL (mHealth training). Noot: $\mathrm{CH}$ - Creatieve Hopeloosheid, HN Hier en Nu, AC - Acceptatie, DEF - Defusie, ZC - Zelf als Context, WA - Waarden, TA - Toegewijde Actie.

\section{Werkzame processen derde generatie gedragstherapieën}

In het derde en laatste deel van dit proefschrift, meer specifiek hoofdstuk 7, werd er binnen het derde generatie gedragstherapeutisch kader een uitstap gemaakt van ACT naar Mindfulness Based Cognitive Therapy (MBCT). In een eerder onderzoek werd duidelijk dat MBCT een effectieve interventie is voor residuele depressie klachten bij een recidiverende depressie. De werkingsmechanismen van MBCT zijn echter nog verre van duidelijk. De werkzame mechanismen zijn ook informatief voor de mechanismen van andere loten aan de boom van de derde generatie gedragstherapie, en meer specifiek ACT gezien één van de ACT-processen (aandacht voor het hier en nu) duidelijke parallellen heeft met MBCT. MBCT wordt ook wel onder de acceptance-based therapieën geschaard.

Het effect van MBCT op residuele depressieve klachten bleek te worden gemedieerd door toename van mindfulness vaardigheden, afname van het toekomstgerichte piekeren (het op het verleden en heden gerichte rumineren bleek geen significante mediator te zijn) en door een toename van positief en afname van negatief affect. Dit is een gedeeltelijke replicatie van de resultaten van eerdere studies $[49,50,51]$. Positief en negatief affect bleken beide ook mediators van het effect van piekeren op reductie van depressieve klachten. Positief affect bleek een substantiële rol te spelen in het mechanisme; zowel als direct effect van de MBCT-interventie als indirect effect via de reductie van piekeren. Deze bevindingen passen goed binnen het theoretisch raamwerk van Garland en collega's [52, 53], het emotioneel systeem als een zichzelf instandhoudend systeem met wederkerige links tussen 
AiDLT

\begin{tabular}{l|l|}
\hline \multicolumn{1}{|c|}{$\begin{array}{c}\text { ACT-training (groep) } \\
\text { 6 weken }\end{array}$} & $\begin{array}{c}\text { mHealth-training - 4 weken } \\
\text { 18 oefeningen - 6 metaforen - 10 beeps p/d }\end{array}$ \\
\hline Fysieke bijeenkomsten & $\begin{array}{l}\text { mHealth training } \\
\text { Week 1: Acceptatie }\end{array}$ \\
Week 2: Defusie & Week 8: AC + DEF + HN \\
Week 3: Zelf als Context & Week 9: AC + DEF + HN \\
Week 4: Hier en Nu & Week 10: AC + DEF + HN \\
Week 5: Waerden &
\end{tabular}

Week 5: Waarden

Week 6: Toegewijde Actie

\section{SMARTSCAN}

\begin{tabular}{|c|}
\hline ACT-training (groep) \\
5 weken \\
\hline mHealth-training -6 weken \\
26 oefeningen - 16 metaforen - 8 beeps $p / d$ \\
\hline
\end{tabular}

Fysieke bijeenkomsten

Week 1: Creatieve Hopeloosheid

Week 2: Acceptatie

Week 3: Defusie \& Zelf als Context

Week 4: Waarden \& Toegewijde Actie

Week 5: Psychologische Flexibilietit

\section{mHealth training}

Week 1: $\mathrm{CH}+\mathrm{HN}$

Week 2: AC + HN

Week 3: DEF + HN

Week 4: WA + TA + HN

Week 5: AC + DEF + HN

Week 6: AC + DEF + HN

InterACT

\begin{tabular}{|c|c|}
\hline ACT-training (individueel) & \\
\hline $\begin{array}{l}\text { mHealth-training - } 7 \text { weken } \\
34 \text { oefeningen - } 14 \text { metaforen - } 8 \text { beeps } p / d\end{array}$ & \\
\hline $\begin{array}{l}\text { Fysieke bijeenkomsten } \\
\text { Week 1: Creatieve Hopeloosheid } \\
\text { Week 2: Acceptatie } \\
\text { Week 3: Defusie } \\
\text { Week 4: Zelf als Context \& Hier en Nu } \\
\text { Week 5: Waarden } \\
\text { Week 6: Toegewijde Actie } \\
\text { Week 7: Psychologische Flexibiliteit }\end{array}$ & $\begin{array}{l}\text { mHealth training } \\
\text { Week 1: } \mathrm{CH}+\mathrm{HN} \\
\text { Week 2: } \mathrm{AC}+\mathrm{CH}+\mathrm{HN} \\
\text { Week 3: } \mathrm{DEF}+\mathrm{AC}+\mathrm{CH}+\mathrm{HN} \\
\text { Week 4: } \mathrm{ZC}+\mathrm{DEF}+\mathrm{AC}+\mathrm{CH}+\mathrm{HN} \\
\text { Week 5: } \mathrm{WA}+\mathrm{ZC}+\mathrm{DEF}+\mathrm{AC}+\mathrm{CH}+\mathrm{HN} \\
\text { Week 6: TA + WA + ZC + DEF + } \mathrm{AC}+\mathrm{CH}+\mathrm{HN} \\
\text { Week 7: TA + WA + ZC + DEF + AC + CH+ HN }\end{array}$ \\
\hline
\end{tabular}

Figuur 5. Chronologie ontwikkeling ACT-DL (inclusief veranderingen opzet). Noot: $\mathrm{CH}$ - Creatieve Hopeloosheid, HN - Hier en Nu, AC - Acceptatie, DEF - Defusie, ZC - Zelf als Context, WA - Waarden, TA - Toegewijde Actie.

affectieve, cognitieve, gedragsmatige en fysieke mechanismes. Deze domeinen beïnvloeden elkaar voortdurend waarbij zowel opwaartse spiralen als neerwaartse spiralen kunnen ontstaan.

Daarnaast bleek dat het werkzame mechanisme van de interventie afhing van het aantal depressieve episodes dat iemand in het verleden heeft doorgemaakt. Daar waar bij twee of minder depressies eerder genoemde mechanisme van kracht is, bleek dat bij drie of meer eerdere depressies niet aan de orde te zijn; hier bleken alleen veranderingen in positief en negatief affect significante mediatoren te zijn. Hieruit kan niet worden geconcludeerd dat bij deze groep de veranderingen in cognitieve processen geen rol spelen in de klachtreductie, maar dat veranderingen in affectieve processen het meest cruciale element zijn in de MBCTgerelateerde verbetering. Daarbij lijkt het ook waarschijnlijk dat de verandering in het werkzame mechanisme niet zo'n duidelijk omslagpunt heeft, maar meer bezien dient te 
worden vanuit een continuüm; hoe meer episodes hoe meer de nadruk komt te liggen op de affectieve processen als mechanisme. Een mogelijke verklaring hiervoor is de sensitisering die optreedt na het doormaken van een depressieve episode. Men wordt hierdoor steeds kwetsbaarder voor het ontwikkelen van een volgende episode [54, 55, 56, 57].

Deze studie geeft inzicht in de cognitieve en affectieve factoren die het effect mediëren van de reductie van depressieve klachten door MBCT [58]. Naast replicatie van eerder onderzoek, heeft dit ook aanvullende informatie gegeven over de affectieve factoren en over de substantiële rol die deze lijkt te spelen. Tevens is het werkzame mechanisme voor twee subgroepen onderzocht waardoor de prominente rol van affect nog meer op de voorgrond kwam te staan. Affect werd gemeten in het dagelijks leven, op een ecologisch valide manier. Er zijn een aantal methodologische aandachtspunten. Alle variabelen zijn gemeten in hetzelfde tijdsbestek waardoor het onmogelijk is om een causale verklaring op te stellen. Daarnaast zijn de mediatie-analyses uitgevoerd met Sobel-Goodman analyses; hierbij kan maar één mediator per keer worden toegevoegd zonder rekening te houden met andere betrokken factoren. Voortschrijdend inzicht zou nu hebben geresulteerd tot de keuze voor Multilevel Structural Equation Modelling (SEM); deze techniek is meer geschikt voor complexe modellen waarmee meerdere mediatoren tegelijk kunnen worden onderzocht [59].

Het zou interessant zijn om te onderzoeken in hoeverre bovengenoemde mediatoren ook een rol spelen in het werkzame mechanisme van ACT. De mindfulness-vaardigheden zijn ook in ACT terug te vinden (mindfulness-component). De cognitieve processen zouden ook kunnen worden beïnvloed door defusie. Het proces aangaande het negatieve affect zou mogelijk ook kunnen worden beïnvloed door acceptatie en het proces aangaande positief affect door waarden. ACT beoogt het bevorderen van psychologische flexibiliteit en is theoretisch duidelijk over de zes onderliggende processen die hier aan bijdragen. In een component meta-analyse van Levin en collega's [60] werden positieve effectsizes gevonden voor Acceptatie, Defusie, Mindfulness en Waarden. Het "Zelf als Context" en "Toegewijd Handelen" behoeven dus nog verdere onderbouwing als werkzame processen die bijdragen aan de Psychologische Flexibiliteit. In een review van Ruiz [61] werd eveneens ondersteuning gevonden voor het feit dat ACT lijkt te werken op basis van (een gedeelte van) de voorgestelde ACT-processen. Recent onderzoek van Pots en collega's [62] laat zien dat het effect van ACT zowel wordt gemedieerd door mindfulness-processen als door psychologische flexibiliteit.

\section{Nieuwe wind in de GGZ - Toekomstige ontwikkelingen}

\section{Nieuwe behandelfocus}

De World Health Organisation definieert gezondheid als volgt: "Health is a state of complete physical, mental and social well-being and not merely the absence of disease or infirmity" (WHO, [63]). Dit lijkt een utopisch uitgangspunt te zijn, een gezondheidsideaal waardoor veel (goed functionerende) mensen zouden kunnen worden geclassificeerd als "ziek". Deze neiging tot pathologiseren is ook deels te wijten aan het gebruikte classificatiesysteem; de DSM-IV-TR [64] / DSM-5 [65] dat mensen middels labels classificeert als "ziek" of "gezond". Daarmee is 
het doel van de GGZ ook snel om mensen met labels, label-vrij te krijgen. De vraag is echter, of deze visie houdbaar is. Uit recent onderzoek blijkt dat in Europa op jaarbasis 38\% van de populatie last heeft van psychische klachten [66]. Kijkend naar Nederland is dit $24 \%$ van de populatie [67]. Het hebben van klachten is dus niet zo abnormaal/ziek als het classificatiesysteem doet vermoeden; het lijkt eerder een onderdeel te zijn van het menszijn. Huber en collega's [68] hebben onderzoek gedaan naar de houdbaarheid van de huidige definitie van gezondheid en komen op basis van hun bevindingen met een herziene defintie voor gezondheid: "Health as the ability to adapt and to self manage". In deze definitie ligt de nadruk dus niet op klachtenvrij zijn, maar op vaardigheden om zich aan te passen aan uitdagende omstandigheden en om het leven zelfstandig vorm te blijven geven. Recentelijk is er in Nederland een nieuwe beweging ontstaan die deze nieuwe definitie heeft opgenomen in hun visie op de GGZ; de Nieuwe GGZ [69]. Deze beweging pleit voor een nieuwe kijk op psychisch lijden en gezondheid; leren omgaan met klachten, eigen regie voeren over de behandeling en ontdekken dat ondanks de symptomen men bezig kan zijn met betekenisvolle doelen die voldoening geven.

De Positieve Psychologie is een nieuwe stroming in de psychologie die eveneens pleit voor een verschuiving van de aandacht voor het mechanisme van disfunctioneren (klachtreductie) naar mechanismes van optimaal functioneren (welbevinden); positieve gezondheid [70]. Dit welbevinden bestaat uit drie componenten: emotioneel welbevinden, psychologisch welbevinden (met de dimensies doelgerichtheid, persoonlijke groei, autonomie, omgevingsbeheersing, zelfacceptatie en positieve relaties) en sociaal welbevinden [71]. Keyes [72] heeft vervolgens onderzoek gedaan naar de samenhang van psychopathologie en welbevinden en kwam met het twee-continua-model; het zijn twee te onderscheiden maar gerelateerde factoren. Het is daarmee dus niet zo dat de afwezigheid van psychopathologie automatisch betekent dat mensen een hoog welbevinden ervaren. Klachtreductie leidt dus niet per definitie tot verhoging van welbevinden. Derhalve dient er in de GGZ dus ook aparte aandacht te zijn voor de bevordering van verschillende elementen van welbevinden.

Het lijkt er dus op dat er een nieuwe wind in de GGZ begint te waaien, waarbij er niet alleen meer aandacht is voor klachtreductie maar er ook aandacht is voor het ontwikkelen van (coping)vaardigheden en welbevinden. De derde generatie gedragstherapieën, en meer specifiek ACT, lijkt zeer goed aan te sluiten bij deze vernieuwde focus. De voorgestelde nieuwe definitie van gezondheid van Huber en collega's [68] toont duidelijke parallellen met de definitie van psychologische flexibiliteit: "Flexibel omgaan met de uitdagingen die men tegenkomt, terwijl men blijft investeren in de dingen die er echt toe doen". Ook de hierop geijkte visie van de Nieuwe GGZ aangaande psychische pijn en gezondheid komt opvallend veel overeen met datgeen wat men met een ACT-interventie probeert te bewerkstelligen; het ontwikkelen van persoonlijke veerkracht. En vanuit het perspectief van de Positieve Psychologie kan ACT worden gezien als een interventie die welbevinden faciliteert. Deze nieuwe wind in de GGZ lijkt dus heel goed samen te gaan met de nieuwe golf van de derde generatie gedragstherapie. 


\section{Modernisering behandelmethodiek}

De nieuwe wind in de GGZ betreft niet alleen een verschuiving in behandelfocus. Technologische ontwikkelingen maken het nu ook mogelijk om een ACT-behandeling op verschillende manieren aan te bieden die complementair kunnen werken. Uiteraard blijven de reguliere face to face contacten met de therapeut een belangrijk onderdeel van de behandeling. Deze kunnen in levende lijve plaatsvinden of plaatsvinden middels een videochat (denk aan Skype \& FaceTime) als vervoersproblemen of het ontbreken van een geschikte therapie-ruimte een obstakel zijn. Uit onderzoek is echter gebleken dat maar $20 \%$ van wat er in de sessies wordt besproken ook daadwerkelijk wordt onthouden [73]. Een ondersteunende eHealth-module zou dan kunnen worden aangeboden in het kader van psychoeducatie (waarbij naast tekst ook gebruik kan worden gemaakt van multimedia), alsook kunnen fungeren als aanvullend behandelprogramma waar oefeningen te vinden zijn om de verschillende vaardigheden verder eigen te maken. Aangezien ACT een flexibele behandelmethodiek is, dient deze eHealth-module ook flexibel te zijn en te kunnen worden aangepast (men kan in principe vanuit elk proces starten). Tezamen met TelePsy (ROMprovider \& eHealth-provider) is er een dergelijk flexibele module ontwikkeld, waarbij de therapeut voor iedere cliënt persoonlijk de module kan samenstellen op basis van een breed pallet aan ACT-oefeningen, metaforen en psychoeducatie [74]. Om de vaardigheden vervolgens actief te oefenen in het dagelijks leven, zou er gebruik kunnen worden gemaakt van een aanvullende mHealth interventie, zoals de ACT in Daily Life Training, waarbij men verschillende oefeningen die speciaal zijn ontwikkeld voor de dagelijkse praktijk ter beschikking zou kunnen stellen. Deze zouden kunnen worden aangeboden met een smartphone en in de toekomst mogelijk via de nieuwe generatie wearables (vb. Smartwatch). Hiermee kan er een totaalbehandeling worden aangeboden, waarbij technologie wordt ingezet om de reguliere behandeling te ondersteunen en aan te vullen. Men spreekt dan van blended-care.

\section{Monitoring functionele processen}

In de huidige GGZ is Routine Outcome Monitoring (ROM) verplicht. Echter de instrumenten die Stichting Benchmark GGZ verplicht stelt en meeneemt als outcome maat, hebben veelal een klachtgerichte focus (SBG, [75]). Tot op heden zijn er geen maten in opgenomen die succesvol de beoogde functionele processen in kaart kunnen brengen die de focus zijn van de derdegeneratie gedragstherapie. De FIT-60 is specifiek met dit doel ontwikkeld en zou een goede aanvulling kunnen zijn binnen het ROM-systeem. Daarom wordt deze dan ook actief aangeboden aan de ROM-providers in Nederland. Het afnemen van een vragenlijst betreft echter per definitie een momentopname. Tevens zijn we afhankelijk van zelfrapportage, welke kwetsbaar is voor recall-bias. Het zou daarom waardevol zijn om naast deze vragenlijsten de ACT-processen ook op een meer ecologische manier in kaart te kunnen brengen en de processen over de tijd te kunnen volgen. Toekomstig onderzoek zou zich kunnen richten op het operationaliseren van de ACT-processen in het ESM-paradigma en elk ACT-proces te kunnen vertalen naar een aantal ESM-items. De eerste stappen zijn hiervoor reeds gezet $[76,77]$, echter tot op heden is er nog geen volledige operationalisatie ontwikkeld van psychologische flexibiliteit waarin alle zes de ACT-processen zijn meegenomen. 
De ontwikkeling van een samengestelde derdegeneratie gedragstherapeutische interventie (face to face, eHealth \& mHealth), alsook aanvullend effectiviteitsonderzoek naar deze interventie - waarbij er primair wordt gekeken naar welbevinden en secundair naar klachtreductie - zou een interessante focus zijn voor toekomstig onderzoek. Een aanbeveling hierbij is de mHealth interventie te combineren met monitoring in het dagelijks leven en op basis van de invoer van de patiënt de aangeboden ACT-oefeningen aan te passen (personal tailored intervention). Tenslotte zouden de ACT-processen naast de reguliere zelfrapportagevragenlijsten (vb FIT-60) ook op een ecologische manier kunnen worden gemonitord. Dit geeft tevens de mogelijkheid de werkzame mechanismen van ACT nader te bestuderen. 


\section{Literatuur}

1. Jacobs, N., Beckers, J., \& Raes, F. (2009). Evaluatie van ACT in de praktijk: geschikte procesmaten. Psychopraxis, 1, 152-156.

2. Ciarrochi, J., \& Blich, L. (2011). Acceptance and Commitment Therapy. Measures Package: Process measures of potential relevance to ACT. Unpublished manuscript, School of Psychology, University of Wollongong, Wollongong, Australia.

3. Batink, T., Jansen, G., \& Peeters, F. P. M. L. (2015). Nieuwe generatie gedragstherapie, nieuwe generatie meetinstrumenten. Een overzicht van beschikbare meetinstrumenten. Tijdschrift voor Psychiatrie, 57, 739748.

4. Bond F. W., Hayes, S. C., Baer, R. A., Carpenter, K. C., Guenole, N., Orcutt, H. K., Waltz, T., \& Zettle, R. D. (2011). Preliminary psychometric properties of the Acceptance and Action Questionnaire - II: A revised measure of psychological flexibility and acceptance. Behavior Therapy, 42, 676-88.

5. Gillanders, D. T., Bolderston, H., Bond, F. W., Dempster, M., Flaxman, P. E., Campbell, L., Kerr, S., Tansey, L., Noel, P., Ferenbach, C., Masley, S., Roach, L., Lloyd, J., May, L., Clarke, S., \& Remington, B. (2014). The development and initial validation of The Cognitive Fusion Questionnaire. Behavior Therapy, 45, 83-101.

6. Gird, S. R., Zettle, R. D., Webster, B. K., Hardage-Bundy, A. (2012, July). Developing a Quantitative Measure of Self-as-Context: Preliminary Findings. In R. D. Zettle (Chair), Sizing up Selfing: Efforts to Assess Self-asContext. Symposium conducted at the ACBS World Conference $\mathrm{X}$, Washington.

7. Bohlmeijer, E. T., Ten Klooster, P. M., Fledderus, M., Veehof, M. M., \& Baer, R. (2012). Psychometric properties of the Five Facet Mindfulness Questionnaire in depressed adults and development of a short form. Assessment, 18, 308-320.

8. Wilson, K. G., \& Murrell, A. R. (2004). Values work in acceptance and commitment therapy: Setting a course for behavioral treatment. In S. C. Hayes, V. M. Follette \& M. M. Linehan (Eds.), Mindfulness and acceptance: Expanding the cognitivebehavioral tradition (pp. 120-151). New York: Guilford Press.

9. Trompetter, H. R., ten Klooster, P. M., Schreurs, K. M. G., Fledderus, M., Westerhof, G. J., \& Bohlmeijer, E. T. (2013). Measuring values and committed action with the Engaged Living Scale (ELS): Psychometric evaluation in a nonclinical and chronic pain sample. Psychological Assessment, 25, 1235-1246.

10. Batink, T., Jansen, G. \& De Mey, H. R. A. (2012). De Flexibiliteits Index Test (FIT-60): Een beknopte beschrijving. GZ-Psychologie, 5, 18-21.

11. Fledderus, M., Oude Voshaar, M. A., Ten Klooster, P. M., \& Bohlmeijer, E. T. (2012). Further evaluation of the psychometric properties of the Acceptance and Action Questionnaire-II. Psychological Assessment, 24(4), 925-936.

12. Sandoz, E. K., Wilson, K. G., Merwin, R. M., \& Kellum, K. K. (2013). Assessment of body image flexibility: The Body Image-Acceptance and Action Questionnaire. Journal of Contextual Behavioral Science, 2, 39-48.

13. MacKenzie, M. B. \& Kocovski, N. L. (2010). Self-reported acceptance of social anxiety symptoms: Development and validation of the Social Anxiety - Acceptance and Action Questionnaire. International Journal of Behavioral Consultation and Therapy, 6, 214-232.

14. Luoma, J. B., Drake, C., Hayes, S. C., \& Kohlenberg, B. (2011). Substance Abuse and Psychological Flexibility: The Development of a New Measure. Addiction Research and Theory, 19, 3-13.

15. Sylvester, M. (2011). Acceptance and commitment therapy for improving adaptive functioning in persons with a history of pediatric acquired brain injury (Doctoral dissertation). Retrieved from ProQuest Dissertations \& Theses (Publication Number 3472789)

16. Bond, F. W., Lloyd, J., \& Guenole, N. (2013). The work-related acceptance and action questionnaire (WAAQ): Initial psychometric findings and their implications for measuring psychological flexibility in specific contexts. Journal of Occupational and Organizational Psychology, 86, 331-347.

17. Spinhoven. P., Drost, J., de Rooij, M., van Hemert, A. M., \& Penninx, B. W. (2014). A longitudinal study of experiential avoidance in emotional disorders. Behavior Therapy, 45(6), 840-850.

18. Ellis, T. E., \& Rufino, K. A. (2016). Change in Experiential Avoidance is Associated with Reduced Suicidal Ideation over the Course of Psychiatric Hospitalization. Archives of Suicide Research, 20(3), 426-437.

19. Hayes, S. C, Strosahl, K. D., \& Wilson, K. G. (2012). Acceptance and commitment therapy: The process and practice of mindful change (2nd edition). New York: The Guilford Press.

20. Jansen, G., \& Batink, T. (2014). Time to ACT! Het basisboek voor professionals. Zaltbommel: Uitgeverij Thema.

21. A-Tjak, J. G., Davis, M. L., Morina, N., Powers, M. B., Smits, J. A., \& Emmelkamp, P. M. (2015). A meta-analysis of the efficacy of acceptance and commitment therapy for clinically relevant mental and physical health problems. Psychotherapy and Psychosomatics, 84, 30-36.

22. Gámez, W., Chmielewski, M., Kotov, R., Ruggero, C., \& Watson, D. (2011). Development of a measure of experiential avoidance: the Multidimensional Experiential Avoidance Questionnaire. Psychological Assessment, 23(3), 692-713.

23. Wolgast, M. (2014). What does the Acceptance and Action Questionnaire (AAQ-II) really measure? Behavior Therapy, 45(6), 831-839. 
24. Batink, T., \& Delespaul, P. (2015). Meten van psychologische flexibiliteit - De Flexibiliteits Index Test (FIT60). Tijdschrift voor Gedragstherapie en Cognitieve Therapie, 4, 310-332.

25. Jacobson, N. S., Dobson, K. S., Truax, P. A., Addis, M. E., Koerner, K., Gollan, J. K., Gortner, E. \& Prince, S. E. (1996). A component analysis of cognitive-behavioral treatment for depression. Journal of Consulting and Clinical Psychology, 64, 295-304.

26. Bol, Y., Ysermans, R. \& Batink, T. (2014, October). Psychological flexibility in patients with multiple sclerosis : does the FIT-60 fit? Poster session presented at the ACBS training institute, Brussels (Belgium).

27. Batink, T., Bakker, J., Vaessen, T., Kasanova, Z., Collip, D., van Os, J., Wichers, M., Germeys, I., \& Peeters. F. (2016). Acceptance and Commitment Therapy in Daily Life Training: A Feasibility Study of an mHealth Intervention. JMIR Mhealth Uhealth, 4(3), e103.

28. Essen van, H., \& Mol, A. (2016). Acceptance and Commitment Therapy for autism spectrum disorders: a qualitative study of a group therapy. Manuscript in preparation.

29. Hayes, S. C., Strosahl, K. D., \& Wilson, K. G. (1999). Acceptance and Commitment Therapy: An experiential approach to behavior change. New York: Guilford Press.

30. Harris, R. (2009). ACT Made Simple: An Easy-To-Read Primer on Acceptance and Commitment Therapy. Oakland: New Harbinger.

31. Rolffs, J. L., Rogge, R. D., \& Wilson, K. G. (2016). Disentangling Components of Flexibility via the Hexaflex Model: Development and Validation of the Multidimensional Psychological Flexibility Inventory (MPFI). Assessment. Advance online publication. doi: 10.1177/1073191116645905

32. A-Tjak, J. (Ed.). (2015). Acceptance \& Commitment Therapy: Theorie en praktijk (Tweede, herziene druk). Houten: Bohn Stafleu van Loghum.

33. Barta, W. D., Tennen, H., \& Litt, M. D. (2012). Measurement reactivity in diary research. In M.R. Mehl \& T.S. Connor (Eds.), Handbook of Research Methods for Studying Daily Life (pp. 108-123). New York: Guilford Press.

34. Stoner, S. A., Arenella, P. B., \& Hendershot, C. S. (2015). Randomized controlled trial of a mobile phone intervention for improving adherence to naltrexone for alcohol use disorders. PLoS One, 10(4), e0124613.

35. Ahtinen, A., Mattila, E., Välkkynen, P., Kaipainen, K., Vanhala, T., Ermes, M, Sairanen, E., Myllymäki, T., \& Lappalainen, R. (2013). Mobile mental wellness training for stress management: feasibility and design implications based on a one-month field study. JMIR Mhealth Uhealth, 1(2), e11.

36. Ruiz, F. J. (2010). A review of acceptance and commitment therapy (ACT) empirical evidence: Correlational, experimental psychopathology, component and outcome studies. International Journal of Psychology and Psychological Therapy, 10(1), 125-162.

37. Lappalainen, P., Granlund, A., Siltanen, S., Ahonen, S., Vitikainen, M., Tolvanen, A, \& Lappalainen, R. (2014). ACT Internet-based vs face-to-face? A randomized controlled trial of two ways to deliver acceptance and commitment therapy for depressive symptoms: an 18-month follow-up. Behaviour Research and Therapy, 61, 43-54.

38. Cheng, C., Brown, R. C., Cohen, L. L., Venugopalan, J., Stokes, T. H., \& Wang, M. D. (2013). iACT: an interactive $\mathrm{mHealth}$ monitoring system to enhance psychotherapy for adolescents with sickle cell disease. Conf Proc IEEE Eng Med Biol Soc, 2013, 2279-2282. doi:10.1109/EMBC.2013.6609992

39. Ly, K. H., Dahl, J., Carlbring, P., \& Andersson, G. (2012). Development and initial evaluation of a smartphone application based on acceptance and commitment therapy. SpringerPlus, 1,11.

40. Ly, K. H., Asplund, K., \& Andersson, G. (2014). Stress management for middle managers via an acceptance and commitment-based smartphone application: A randomized controlled trial. Internet Interventions, 1(3), 95-101.

41. Bricker, J. B., Mull, K. E., Kientz, J. A., Vilardaga, R., Mercer, L. D., Akioka, K. J., \& Heffner, J. L. (2014). Randomized, controlled pilot trial of a smartphone app for smoking cessation using acceptance and commitment therapy. Drug and Alcohol Dependence, 143, 87-94.

42. Kramer, I., Simons, C. J., Hartmann, J. A., Menne-Lothmann, C., Viechtbauer, W., Peeters, F., Schruers, K., van Bemmel, A. L., Myin-Germeys, I., Delespaul, P., van Os, J., \& Wichers, M. (2014). A therapeutic application of the experience sampling method in the treatment of depression: a randomized controlled trial. World Psychiatry, 13(1), 68-77.

43. Simons, C. J., Hartmann, J. A., Kramer, I., Menne-Lothmann, C., Höhn, P., van Bemmel, A. L., Myin-Germeys, I., Delespaul, P., van Os, J., \& Wichers, M. (2015). Effects of momentary self-monitoring on empowerment in a randomized controlled trial in patients with depression. European Psychiatry, 30, 900-906.

44. Heron, K. E., \& Smyth, J. M. (2010). Ecological momentary interventions: incorporating mobile technology into psychosocial and health behaviour treatments. British Journal of Health Psychology, 15, 1-39.

45. Myin-Germeys, I., Klippel, A., Steinhart, H., \& Reininghaus, U. (2016). Ecological momentary interventions in psychiatry. Current Opinion in Psychiatry, 29(4), 258-263.

46. Versluis, A., Verkuil, B., Spinhoven, P., van der Ploeg, M. M., \& Brosschot, J. F. (2016). Changing Mental Health and Positive Psychological Well-Being Using Ecological Momentary Interventions: A Systematic Review and Meta-analysis. Journal of Medical Internet Research, 18(6), e152. 
47. Pew Research Center (2016). Smartphone Ownership and Internet Usage Continues to Climb in Emerging Economies. Retrieved from http://www.pewglobal.org/files/2016/02/ pew_research_center_global_ technology_report_final_february_22_2016.pdf [accessed 2016-11-23]

48. Steinhart, H., Vaessen., T, Batink., T. \& Myin-Germeys, I. (2017). ACT in Daily Life - A momentary Intervention Approach. Manuscript in preparation.

49. van Aalderen, J. R., Donders, A. R. T., Giommi, F., Spinhoven, P., Barendregt, H. P., \& Speckens, A. E. (2012). The efficacy of mindfulness-based cognitive therapy in recurrent depressed patients with and without a current depressive episode: A randomized controlled trial. Psychological Medicine, 42, 989-1001.

50. Kuyken, W., Watkins, E., Holden, E., White, K., Taylor, R. S., Byford, S., Evans, A., Radford, S., Teasdale, J. D., \& Dalgeish, T. (2010). How does mindfulness-based cognitive therapy work? Behaviour Research and Therapy, $48,1105-1112$.

51. Shahar, B., Britton, W. B., Sbarra, D. A., Figueredo, A. J., \& Bootzin, R. R. (2010). Mechanisms of change in mindfulness-based cognitive therapy for depression: Preliminary evidence from a randomized controlled trial. International Journal of Cognitive Therapy, 3, 402-418.

52. Garland, E. L., Fredrickson, B., Kring, A. M., Johnson, D. P., Meyer, P. S., \& Penn, D. L. (2010). Upward spirals of positive emotions counter downward spirals of negativity: Insights from the broaden-and-build theory and affective neuroscience on the treatment of emotion dysfunctions and deficits in psychopathology. Clinical Psychology Review, 30, 849-864.

53. Garland, E. L., Geschwind, N., Peeters, F., \& Wichers, M. (2015). Mindfulness training promotes upward spirals of positive affect and cognition: multilevel and autoregressive latent trajectory modeling analyses. Frontiers in Psychology, 6, 15.

54. Segal, Z. V., Williams, J. M., Teasdale, J. D., \& Gemar, M. (1996). A cognitive science perspective on kindling and episode sensitization in recurrent affective disorder. Psychological Medicine, 26, 371-380.

55. Wichers, M., Geschwind, N., van Os, J., Peeters, F. (2010). Scars in depression: Is a conceptual shift necessary to solve the puzzle? Psychological Medicine, 40, 359-365.

56. Post, R. M. (2007). Kindling and sensitization as models for affective episode recurrence, cyclicity, and tolerance phenomena. Neuroscience and Biobehavioral Reviews, 31, 858-873.

57. Stroud, C. B., Davila, J., Hammen, C., \& Vrshek-Schallhorn, S. (2011). Severe and nonsevere events in first onsets versus recurrences of depression: Evidence for stress sensitization. Journal of Abnormal Psychology, $120,142-154$.

58. Batink, T., Peeters, F., Geschwind, N., van Os, J., \& Wichers, M. (2013). How Does MBCT for Depression Work? Studying Cognitive and Affective Mediation Pathways. PLOS ONE 8(8), e72778.

59. Preacher, K. J., Zyphur, M. J., \& Zhang, Z. (2010). A general multilevel SEM framework for assessing multilevel mediation. Psychological Methods, 15, 209-233.

60. Levin, M. E., Hildebrandt, M. J., Lillis, J., \& Hayes, S. C. (2012). The impact of treatment components suggested by the psychological flexibility model: a meta-analysis of laboratory-based component studies. Behavior Therapy, 43(4), 741-56.

61. Ruiz, F. J. (2012). Acceptance and Commitment Therapy versus Traditional Cognitive Behavioral Therapy: A Systematic Review and Meta-analysis of Current Empirical Evidence. International Journal of Psychology and Psychological Therapy, 12(2), 333-357.

62. Pots, W. T., Trompetter, H. R., Schreurs, K. M., \& Bohlmeijer, E. T. (2016). How and for whom does webbased acceptance and commitment therapy work? Mediation and moderation analyses of web-based ACT for depressive symptoms. BMC Psychiatry, 16, 158.

63. Preamble to the Constitution of the World Health Organization as adopted by the International Health Conference, New York, 19-22 June, 1946; signed on 22 July 1946 by the representatives of 61 States (Official Records of the World Health Organization, no. 2, p. 100) and entered into force on 7 April 1948.

64. American Psychiatric Association. (2000). Diagnostic and statistical manual of mental disorders (4th ed., text rev.). Washington, DC: Author.

65. American Psychiatric Association. (2013). Diagnostic and statistical manual of mental disorders (5th ed.). Washington, DC: Author.

66. Wittchen, H. U., Jacobi, F., Rehm, J., Gustavsson, A., Svensson, M., Jönsson, B., Olesen, J., Allgulander, C., Alonso, J., Faravelli, C., Fratiglioni, L., Jennum, P., Lieb, R.,Maercker, A., van Os, J., Preisig, M., SalvadorCarulla, L., Simon, R., \& Steinhausen, H. C. (2011). The size and burden of mental disorders and other disorders of the brain in Europe 2010. European Neuropsychopharmacology, 21(9), 655-679.

67. Delespaul, P., Milo, M., Schalken, F., Boevink, W., \& van Os, J. (2016). Goede GGZ! Nieuwe concepten, aangepaste taal en betere organisatie. Diagnosis uitgevers; Leusden.

68. Huber, M., Knottnerus, J. A., Green, L., van der Horst, H., Jadad, A. R., Kromhout, D., Leonard, B., Lorig, K., Loureiro, M. I., van der Meer, J. W., Schnabel, P., Smith, R., van Weel, C., \& Smid, H. (2011). How should we define health? BMJ, 343, d4163.

69. Van Os, J., Delespaul, P., Boevink, W., Milo, M., \& Schalken, F. (2015). Pamflet De Nieuwe GGZ. Retrieved from http://www.denieuweggz.nl/ondertekenaars/ [accessed 2016-11-23] 
70. Seligman, M. E. P. \& Csikszentmihalyi, M. (2000). Positive Psychology. An Introduction. American Psychologist, 55(1), 5-14.

71. Bohlmeijer, E., Bolier, L., Westerhof, G., \& Walburg, J. (2013). Handboek Positieve Psychologie: Theorie Onderzoek - Toepassingen. Uitgeverij Boom: Amsterdam.

72. Keyes, C. L. (2005). Mental illness and/or mental health? Investigating axioms of the complete state model of health. Journal of Consulting and Clinical Psychology 73(3), 539-548.

73. Kessels R. P. (2003). Patients' memory for medical information. Journal of the Royal Society of Medicine, 96(5), 219-222.

74. Batink, T., \& TelePsy (2015). TelePsy Platform - Oefeningen. Retrieved from https://www.telepsy.nl/ introductieact [accessed 2016-11-23]

75. Stichting Benchmark GGZ (2016). SBG Minimale Dataset 20160701. Retrieved from https://www.sbggz.nl/ Documenten [accessed 2016-11-23]

76. Vilardaga, R., Hayes, S. C., Atkins, D. C., Bresee, C., \& Kambiz, A. (2013). Comparing experiential acceptance and cognitive reappraisal as predictors of functional outcome in individuals with serious mental-illness. Behaviour Research and Therapy, 51(8), 425-433.

77. Kashdan, T. B., Goodman, F. R., Machell, K. A., Kleiman, E. M., Monfort, S. S., Ciarrochi, J., \& Nezlek, J. B. (2014). A contextual approach to experiential avoidance and social anxiety: Evidence from an experimental interaction and daily interactions of people with social anxiety disorder. Emotion, 14, 769-781. 


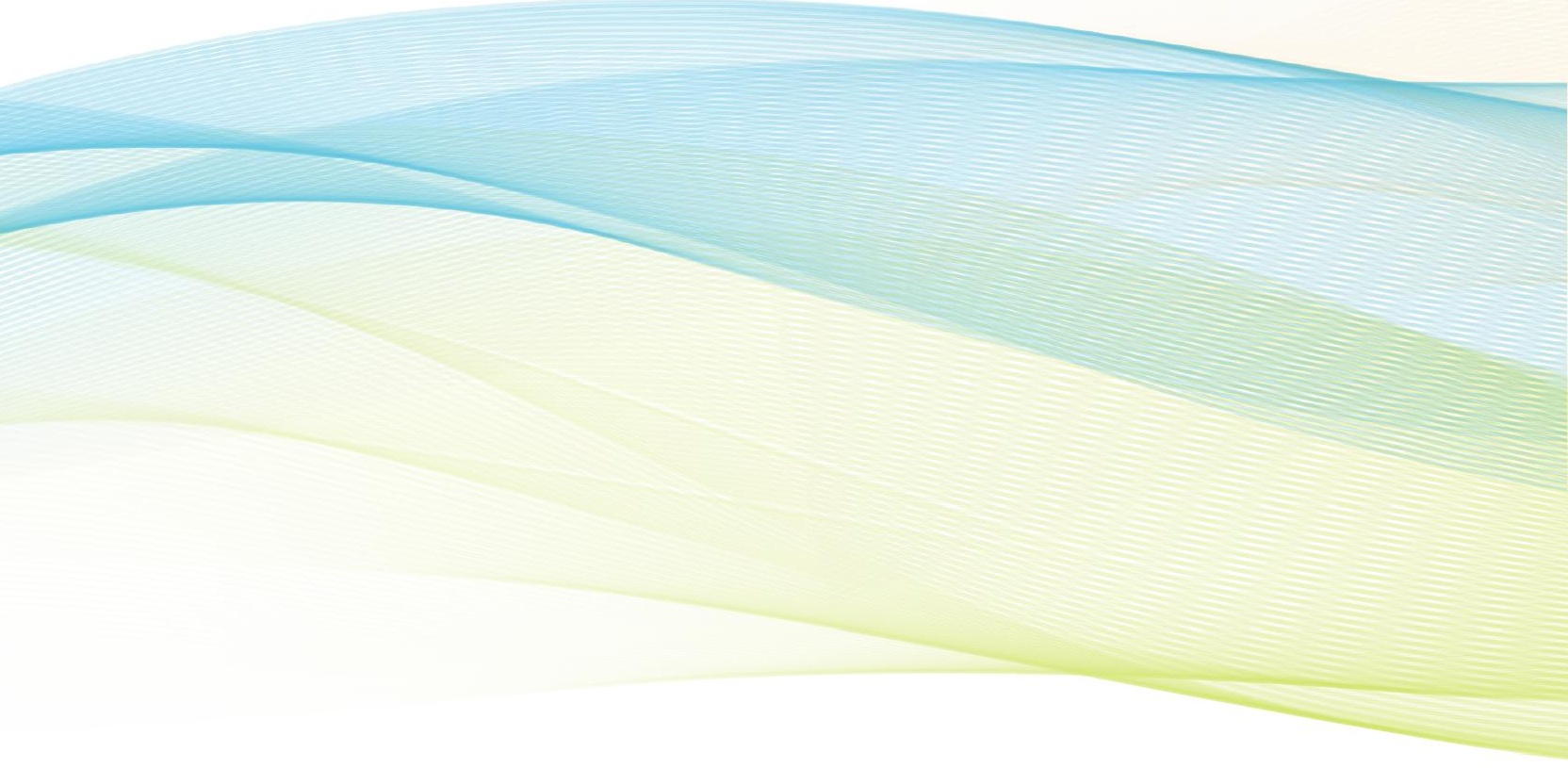




\section{Epiloog}

Valorisatie

Samenvatting

Summary

Dankwoord

Curriculum Vitae

Publicaties 


\section{Valorisatie}

\section{Relevantie}

Naast de wetenschappelijke relevante van dit proefschrift, zal er tenslotte worden stilgestaan bij de maatschappelijke relevantie van deze thesis. Het behandelparadigma in de huidige GGZ is klachtgericht en curatief van aard. Er worden DSM-classificaties vastgesteld welke vervolgens focus zijn van klachtreducerende interventies (met de cognitieve gedragstherapie als meest dominante behandelvorm). Dit proefschrift hoopt bij te dragen aan een verschuiving van deze nauwe focus, naar een GGZ waar niet alleen aandacht is voor klachten en klachtreductie, maar ook ruimte is voor het ontwikkelen van vaardigheden om om te gaan met psychische obstakels en het zich richten op betekenisverlening en welbevinden; kortom aandacht voor de gehele mens. De derdegeneratie gedragstherapie, en in het bijzonder Acceptance and Commitment Therapy kan bijdragen aan deze verschuiving in het behandelparadigma in de GGZ. Dit proefschrift heeft gepoogd bij te dragen aan de inzetbaarheid van deze therapievorm door praktische handvatten te leveren om ACT toe te passen in de praktijk. Het nieuw ontwikkelde meetinstrument, de Flexibiliteits Index Test (FIT-60) draagt deze verschuiving van focus uit. Deze is namelijk niet gericht op het in kaart brengen van klachten maar van functionele processen / vaardigheden waarbij er zowel aandacht is voor omgang met psychische obstakels alsook vaardigheden om weer te gaan investeren in voor die persoon belangrijke dingen. Impliciet zit hier ook een normaliserende boodschap in aangaande deze psychische obstakels; iedereen komt deze tegen en ze zijn nu eenmaal een onderdeel van het menselijk leven.

De informatie in dit proefschrift is niet alleen relevant voor academici maar ook voor de klinische praktijk. Te beginnen met een overzicht van vrij beschikbare vragenlijsten die kunnen worden ingezet om de verschillende ACT-processen in kaart te brengen. Vervolgens komt de ontwikkeling van de FIT-60 aan bod; een zelfrapportage vragenlijst die zes verschillende ACT-processen in kaart kan brengen en die eveneens vrij beschikbaar is. Tenslotte komt de ACT in Daily Life Training (ACT-DL) aan bod die een aanvullende interventie betreft die direct toepasbaar is in de klinische praktijk. Het betreft allemaal tools die direct kunnen worden ingezet in de klinische praktijk. Dit proefschrift is grotendeels in het Nederlands geschreven. Dit in de hoop de toegankelijkheid van deze kennis te vergroten, zodat deze niet alleen binnen de academische wereld blijft maar ook zijn weg vindt in de klinische praktijk (waar Engelstalige literatuur vaak als drempel wordt ervaren).

\section{Innovatie}

De ontwikkeling van een meetinstrument dat zich richt op de relevante processen binnen de derdegeneratie gedragstherapieën is op zich niet vernieuwend. Het feit dat het ontwikkelde meetinstrument niet één proces, maar alle zes de verschillende ACT-processen in kaart brengt en daarmee op een multidimensionale manier de psychologische flexibiliteit van een persoon in kaart kan brengen, kan wellicht wel worden aangemerkt als innovatief. Bij de ontwikkeling van de FIT-60 is er gebruik gemaakt van een open-source survey platform (LimeSurvey). Het huidige onderzoek heeft tevens geillustreerd dat dit een zeer geschikt 
platform is om een uitgebreid, grootschalig vragenlijstonderzoek mee uit te voeren, waarmee ook de kosten van dergelijk onderzoek in de toekomst kunnen worden gereduceerd (veel meer geautomatiseerd en geen licentiekosten). Ditzelfde platform werd ook gebruikt om de FIT-60 online beschikbaar te stellen en automatische terugkoppeling te verwezenlijken.

De combinatie van experience sampling enerzijds en een actieve ACT-interventie in het dagelijks leven anderzijds tot de ACT in Daily Life training zou ook als innovatief kunnen worden gekenmerkt. Deze combinatie is namelijk nog niet eerder in gepubliceerd onderzoek naar voren gekomen. Het gebruikte device, de PsyMate, met achterliggende software en flexibele database (4D) is tevens vernieuwend te noemen. In plaats van een statisch instrument te ontwikkelen, is er een flexibel platform ontwikkeld dat gemakkelijk kan worden aangepast naargelang de focus van het onderzoek. Het vervolgtraject van de ACT-DL zal verder plaatsvinden middels de PsyMate-app (Android \& iOS) zodat er gebruik kan worden gemaakt van smartphones. De PsyMate-app is echter geen statische app, maar een dynamische app die zijn informatie inlaadt vanuit deze zelfde flexibele database.

\section{Disseminatie}

Getracht is om de kennis uit dit proefschrift zo breed mogelijk beschikbaar te maken. De drie publicaties over de Nederlandstalige Flexibiliteits Index Test (FIT-60) zijn alle drie verschenen in drie Nederlandstalige tijdschriften (specifiek voor het klinische publiek) en online beschikbaar gesteld. Er is ruchtbaarheid gegeven aan deze publicaties op de website van de nationale ACT-vereniging, alsook via een drietal populair wetenschappelijke publicaties (Kenniscentrum Psychologie, VVP-nieuws \& Psychopraktijk). Tevens is op de website van de internationale ACT-vereniging een Engelse samenvatting beschikbaar gesteld van de systematische literatuurreview. De andere twee gepubliceerde papers zijn gepubliceerd in open-acces journals. Hierdoor zijn deze publicaties voor iedereen toegankelijk (niet alleen voor medewerkers aan universiteiten, met abonnementen op de verschillende journals). Tenslotte zijn de bevindingen uit deze thesis op meerdere nationale (o.a. VGCt \& NVVP) en internationale congressen gepresenteerd (o.a. ACBS Worldconferences).

De Flexibiliteits Index Test (FIT-60) zelf is vrij beschikbaar gesteld, onder de Creative Commons licentie (CC-BY-NC-SA Versie 3.0). Er is een platform opgericht (www. hoeflexibelbenjij.nl) waar deze vragenlijst gratis te downloaden is als PDF, inclusief Excelscoreformulier alsook gebruikershandleiding. Tevens is de FIT-60 daar online in te vullen en krijgt men daar direct de scoring te zien. De FIT-60 is reeds meer dan 8000 keer gedownload, 18.000 keer online ingevuld en de website heeft vanaf oprichting 1.000.000 hits verkregen (status augustus 2017). Er is door een testuitgever aangeboden om de FIT-60 onder licentie uit te brengen, echter met de restrictie dat deze uit het publieke domein zou worden gehaald. Er is daarom afgezien van het aanbod. Ook wordt de FIT-60 reeds actief gebruikt in wetenschappelijk onderzoek (zie algemene discussie). Tenslotte is er actief contact gezocht met de ROM-aanbieders in Nederland om de FIT-60 te integreren in de systemen. TelePsy, NetQ, VitalHealth \& Reflectum hebben de FIT-60 reeds in hun systeem opgenomen en andere aanbieders zijn op dit moment bezig met de implementatie. 
De FIT-60 is ook gepubliceerd in Time to ACT! het basisboek voor professionals. Tenslotte is de FIT-60 opgenomen als appendix in dit proefschrift, inclusief een uitgebreide gebruikersinstructie. Er wordt momenteel gewerkt aan een Engelse vertaling van de FIT-60, zodat deze ook internationaal inzetbaar wordt.

De ACT in Daily Life Training is op dit moment nog in ontwikkeling. Er lopen twee vervolgonderzoeken aan de universiteit Maastricht (SMARTSCAN-project) en de KU-Leuven (InterACT-project). Er is een gratis versie van de ACT in Daily Life beschikbaar gesteld, zodat mensen een indruk kunnen krijgen van de interventie (zie Appendix I). Het concept-paper in hoofdstuk 6 biedt een uitgebreide beschrijving van de opzet van de interventie, zodat deze ook zou kunnen worden gebruikt door andere onderzoeksgroepen. Hoewel het werkboek en de handleiding niet publiekelijk beschikbaar zijn, zijn via de website www. actinactie.nl wel verschillende oefeningen en metaforen hieruit gratis beschikbaar gesteld voor de klinische praktijk (o.a. ACT in het dagelijks leven, een oefening die die basisstappen van de ACT in Daily Life Training doorloopt). Zodra de onderzoeken zijn afgerond zullen het werkboek, de trainershandleiding en de mHealth interventie ook beschikbaar worden gemaakt voor het bredere publiek. De ACT-DL is zo ontwikkeld, dat deze kan worden ingezet in de Generalistische Basis GGZ (product middel), alsook in de Specialistische GGZ.

Een bewerkte versie van de Introductie en Algemene Discussie van dit proefschrift is als artikel aangeboden aan het Nederlandstalige tijdschrift De Psycholoog met het doel ook deze informatie zo breed mogelijk beschikbaar te stellen. Tenslotte zal dit proefschrift ook als gratis eBook verschijnen. 


\section{Samenvatting}

De derde generatie gedragstherapie is een nieuwe stroming binnen de gedragstherapeutische school, die zich richt op acceptance en mindfulness-based strategieën om patiënten om te leren gaan met hun psychische klachten. Dit proefschrift heeft zich gericht op de processen binnen de derdegeneratie gedragstherapie, met specifieke aandacht voor Acceptance and Commitment Therapy (ACT). In het eerste deel van dit proefschrift werd er aandacht besteed aan verschillende meetinstrumenten die de verschillende ACT-processen in kaart kunnen brengen en is de ontwikkeling beschreven van een meetinstrument dat deze verschillende processen tegelijk in kaart kan brengen en waarmee de psychologische flexibiliteit van een cliënt wordt gemeten: de Flexibiliteits Index Test (FIT-60). Het tweede gedeelte van het proefschrift was gericht op de ontwikkeling van een mHealth interventie die deze ACT-processen in de dagelijkse praktijk van de cliënt kan faciliteren, en bevat een beschrijving van de haalbaarheid en aanvaardbaarheid van deze interventie: de ACT in Daily Life Training (ACT-DL). Tenslotte is in het laatste deel van het proefschrift aandacht geweest voor het werkzame mechanisme van een gelieerde derdegeneratie gedragstherapie: Mindfulness.

Hoofdstuk 2 betrof een systematische literatuur review van de beschikbare ACTmeetinstrumenten. Uit deze review kwam naar voren dat er per februari 2015 reeds 59 verschillende meetinstrumenten beschikbaar waren om de verschillende ACT-processen in kaart te brengen. Voor het Nederlands taalgebied werd de AAQ-2 (acceptatie), CFQ-13 (defusie), SACS (zelf als context), FFMQ-SQ (hier en nu), VLQ-2 (waarden), ELS (toegewijd handelen) en FIT-60 (psychologische flexibiliteit) als 'best clinical practise' instrumenten aangeraden welke beschikbaar zijn in het Nederland en beschikken over goede psychometrische kwaliteiten.

In hoofdstuk 3 werd de ontwikkeling van de Flexibiliteit Index Test (FIT-60), alsook initieel onderzoek naar de psychometrische kwaliteiten van dit instrument beschreven. De FIT-60 is een zelfrapportagevragenlijst bestaande uit 60 items, die op een 7-punts likert-schaal dienen te worden gescoord ( 0 = helemaal oneens, $6=$ helemaal eens). De FIT-60 totaalscore weerspiegelt de psychologische flexibiliteit van een individu. Zes subschalen (acceptatie, defusie, zelf als context, aandacht voor het hier en nu, waarden en toegewijd handelen) brengen de specifieke processen uit de ACT-theorie in kaart. De scores zijn grafisch weer te geven in het flexibiliteitsprofiel. Er zijn tenslotte twee normgroepen beschikbaar; algemene populatie en studenten. De initiële psychometrische kwaliteiten van de FIT-60 zijn bemoedigend: de interne betrouwbaarheid is acceptabel tot goed en de eerste resultaten met betrekking tot de validiteit zijn bemoedigend te noemen.

Hoofdstuk 4 betrof uitgebreid vervolgonderzoek naar de psychometrische kwaliteiten van de FIT-60, welke bestond uit drie deelonderzoeken. De FIT-60 werd onderzocht bij drie verschillende populaties te weten ACT-therapeuten, ambulante en klinische patiënten. De FIT-60 bleek bij alle drie de samples over een goede betrouwbaarheid te beschikken, 
de interne betrouwbaarheid voor de schalen bleek redelijk tot goed met uitzondering van de subschaal 'Zelf als context'. De test-hertest betrouwbaarheid voor de verschillende schalen was zeer goed. Daarnaast bleek de FIT-60 ook in staat om verandering over tijd te meten. Tevens is er ondersteuning gevonden voor een goede constructvaliditeit van de verschillende subschalen, met ook hier als uitzondering de schaal 'Zelf als context'. Het effect van de demografische variabelen op de score van de FIT-60 bleek beperkt te zijn. Naast aanvullende informatie aangaande de psychometrische kwaliteiten van de FIT-60 heeft dit onderzoek ook normgegevens opgeleverd voor een ambulante en klinische populatie.

In hoofdstuk 5 werd de ontwikkeling van de ACT in Daily Life Training (ACT-DL) beschreven, alsook de resultaten van het onderzoek naar de haalbaarheid en aanvaardbaarheid van deze interventie beschreven. De ACT-DL is een aanvullende mHealth interventie ${ }^{1}$, die middels een mobiel device (PsyMate) zowel ACT-training in het dagelijks leven aanbiedt, als monitoring in het dagelijks leven faciliteert middels experience sampling. De ACT-DL focust op vier kerncomponenten van ACT: Acceptatie, Defusie, Mindfulness en Toegewijd Handelen en duurt vier weken. Het doel van deze interventie is om deelnemers te helpen ACT te integreren in hun dagelijks leven en daarmee psychologische flexibiliteit en kwaliteit van leven te bevorderen. Dit is het eerste onderzoek waarin experience sampling, dat bewustzijn in het dagelijks leven bevordert, is gecombineerd met ACT, met als doel het toepassen van ACT-vaardigheden in het dagelijks leven te bevorderen. Uit het onderzoek kwam naar voren dat deze interventie haalbaar en aanvaardbaar is voor een heterogene groep patiënten met substantiële psychopathologie.

Hoofdstuk 6 betrof een conceptueel paper betreffende de herziene versie van de ACT in Daily Life training op basis van de aandachtspunten die naar voren kwamen bij het feasibilityonderzoek. Bij de herziene ACT in Daily Life Training (ACT-DL) zijn de algemene ACT-therapie/ training en de aanvullende mHealth interventie met elkaar geïntegreerd (daar waar het initieel alleen een aanvullende mHealth module betrof). De duur van deze interventie is flexibel, maar betreft doorgaans 8 weken. De herziene ACT-DL bestaat uit 8 flexibele modules waarbij per module de bijeenkomst staat uitgewerkt in een trainershandleiding en werkboek (psychoeducatie, oefeningen en metaforen). De aanvullende mHealth training is vervolgens afgestemd op de gevolgde bijeenkomst. Het betreft de modules Creatieve Hopeloosheid, Acceptatie, Defusie, Zelf als Context, Hier en Nu, Waarden, Toegewijd Handelen en Psychologische Flexibiliteit. De modules kunnen flexibel worden ingezet. De begeleidende mHealth-interventie zal de focus leggen op het aanbieden van de ACT-oefeningen en metaforen van de module waar de cliënt op dat moment aan werkt. De eerder behandelde modules blijven echter ook beschikbaar om mee te oefenen (cumulatieve opbouw). Zodra de cliënt alle modules heeft doorlopen, heeft deze de beschikking over alle onderdelen en leert hij de verschillende ACT-vaardigheden flexibel in te zetten, afhankelijk van de interne en externe context. Dit maakt de interventie person-tailored en interactief.

\footnotetext{
${ }^{1}$ Reguliere ACT-therapie / training voorafgaand aan deze interventie is vereist.
} 
Tenslotte richtte hoofdstuk 7 zich op de werkzame mechanismen van MBCT, een andere therapie binnen de stroom van de derdegeneratie gedragstherapie. Het effect van MBCT op residuele depressieve klachten bleek te worden gemedieerd door toename van mindfulness vaardigheden, afname van piekeren (rumineren bleek geen significante mediator te zijn) en toename in positief affect en afname in negatief affect. Positief en negatief affect bleken beiden ook mediators van het effect van piekeren op reductie van depressieve klachten (afname van piekeren zorgde voor toename in positief en afname in negatief affect). Positief affect bleek een substantiële rol te spelen in het mechanisme, zowel als direct effect van de MBCT-interventie als indirect effect via de reductie van piekeren. Daarnaast bleek dat het werkzame mechanisme van de interventie afhing van het aantal depressieve episodes dat iemand in het verleden heeft gehad. Daar waar bij twee of minder depressies eerder genoemde mechanisme van kracht is, is dat bij drie of meer depressies niet aan de orde. Hier bleken alleen positief (toename) en negatief affect (afname) significante mediatoren. Hieruit kan niet worden geconcludeerd dat bij deze groep de veranderingen in cognitieve processen geen rol spelen in de klachtreductie, maar dat affectieve processen het meest cruciale element zijn in de MBCT-gerelateerde verbetering. 


\section{Summary}

Third generation behavioural therapy is a new trend within the behavioural therapy field, which is directed towards acceptance and mindfulness-based strategies in order to teach patients how to deal with their psychological symptoms. This thesis has focussed on the processes within third generation behavioural therapy, with specific attention given to Acceptance and Commitment Therapy (ACT). In the first section of this thesis, attention is paid to various assessment measures which can chart the various ACT-processes, and includes a description of the development of an instrument which can map these processes together, whereby the psychological flexibility of the client can be measured: the Flexibility Index Test (FIT-60). The second section of the thesis concerns the development of an mHealth intervention that can facilitate these ACT-processes in the clients' daily practice, as well as a description of the feasibility and acceptability of this intervention: the ACT in Daily Life Training (ACT-DL). Finally, in the last section of the thesis attention is given to the working mechanism of a related third generation behavioural therapy: Mindfulness.

Chapter 2 concerns a systematic literature review of the available ACT-measures. This review revealed that as of February 2015 there were already 59 different assessment measures available to describe the various ACT-processes. For Dutch-language areas the AAQ2(acceptance), CFQ-13 (defusion), SACS (self-as-context), FFMQ-SQ (here-and-now), VLQ-2 (values), ELS (committed action) and FIT-60 (psychological flexibility) are recommended as 'best clinical practise' instruments.

In Chapter 3 the development of the Flexibility Index Test (FIT-60) is described, as well as initial research into the psychometric properties of this measure. The FIT-60 is a self-report questionnaire consisting of 60 items, which should be scored on a 7-point Likert-scale $(0=$ completely disagree, 6 = completely agree). The FIT-60 total score reflects the psychological flexibility of an individual. Six sub-scales (acceptance, defusion, self-as-context, attention to the present moment, values and committed action) chart the specific processes within ACTtheory. The scores can be shown graphically in the flexibility-profile. Finally, two norm-groups are available: general population and students. The initial psychometric properties of the FIT-60 are encouraging, the internal reliability is acceptable to good and the first results regarding the validity can be said to be encouraging.

Chapter 4 concerns extensive follow-up research on the psychometric properties of the FIT-60, which consists of three sub-studies. The FIT-60 was studied in three different populations, namely ACT-therapists, outpatients and inpatients. The FIT-60 appeared to show good reliability with all three samples, the internal reliability for the scales seeming to be reasonable to good, with the exception of the sub-scale 'self as context'. The test-retest reliability for the various groups was very good. In addition the FIT-60 also appeared to be able to measure change over time. At the same time support was found for a good construct validity for the various sub-scales, again with the exception of the scale 'self-as-context'. The effect of the demographic variables on the results of the FIT-60 appears to be limited. Apart 
from the additional information concerning the psychometric properties of the FIT-60 this research also produced normative data for inpatient and outpatient populations.

In Chapter $\mathbf{5}$ the development of ACT in Daily Life Training (ACT-DL) is described, as well as the results of research into the feasibility and acceptability of this intervention. ACT-DL is an additional mHealth intervention ${ }^{2}$, that by making use of a mobile device (PsyMate) offers both ACT-training for daily life as well as facilitating monitoring in daily life by using experience sampling. ACT-DL focusses on four core components of ACT: Acceptance, Defusion, Mindfulness and Committed Action, and lasts four weeks. The goal of this invention is to help participants incorporate ACT into their daily lives, and thereby to promote their psychological flexibility and quality of life. This is the first study wherein experience sampling, that promotes consciousness in daily life, is combined with ACT, with the goal of promoting the application of ACT-skills in daily life. The study demonstrated that this intervention is feasible and acceptable for a heterogenous group of patients with substantial psychopathology.

Chapter 6 concerns a conceptual paper covering the revised version of the ACT in Daily Life Training, based on the points raised by the feasibility study. In the revised ACT in Daily Life Training (ACT-DL) the general ACT-therapy/training and the additional mHealth intervention are integrated with each other (whereas the initial version only concerned an additional mHealth module). The duration of this intervention is flexible, but usually lasts 8 weeks. The revised ACT-DL consists of 8 flexible modules where for each module the session is detailed in a trainers manual and workbook (psycho-education, exercises and metaphors). The additional mHealth training is matched to the session that was followed. It concerns the modules Creative Hopelessness, Acceptance, Defusion, Self-as-Context, Here-and-Now, Values, Committed Action and Psychological Flexibility. The modules can be deployed flexibly. The accompanying mHealth intervention shall focus on offering the ACT-exercises and metaphors of the module that the client is working on at that particular moment. The modules dealt with earlier still remain available for practice (cumulative building). As soon as the client has gone through all the modules they have all components at their disposal and learns to apply the different ACT skills flexibly, depending on the internal and external context. This makes the intervention personalised and interactive.

Finally, Chapter 7 concerns itself with the working mechanism of MBCT, another therapy in the field of third generation behavioural therapy. The effect of MBCT on residual depressive symptoms was found to have been mediated by increasing mindfulness skills, decrease in worrying (rumination was found to be no significant mediator) and increase in positive affect and decrease in negative affect. Positive and negative affect both mediated the effect of worrying on reduction of depressive symptoms (decrease in worrying caused an increase in positive and decrease in negative affect). Positive affect was found to have a

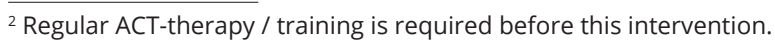


substantial role in the mechanism, not only as a direct effect of the MBCT intervention but as indirect effect via the reduction in worrying. In addition it was also found that the working mechanism of the intervention depended on the number of depressive episodes that someone had had in the past. Whereas with two or fewer depressions the previously mentioned mechanism does operate, that is not the case with three or more depressions. Here it was found that only positive (increase) and negative affect (decrease) were significant mediators. From this it cannot be concluded that for this group the alteration in cognitive processes plays no role in complaint reduction, but that affective processes are the most crucial element in the MBCT-related improvements. 


\section{Dankwoord}

De derde generatie gedragstherapie heeft veel aandacht voor de invloed van de context waarin de gebeurtenissen zich ontvouwen. Ik zou dan ook graag willen afronden met het stilstaan bij de context die het tot stand komen van dit proefschrift heeft mogelijk gemaakt; in het bijzonder alle mensen die hieraan hebben bijgedragen.

Te beginnen met mijn promotors: professor Frenk Peeters, professor Jim van Os en professor Marieke Wichers, welke alle drie een belangrijke rol hebben gespeeld in mijn promotietraject. Jim, dank voor de kans om dit parttime promotietraject aan te mogen gaan, alsook de carte blanche wat betreft de focus van het promotieonderzoek. Tijdens het promotietraject was je een belangrijke facilitator, alsook positief bekrachtigend aanwezig. Marieke, dank voor de intensieve begeleiding in de beginfase van mijn promotietraject. Je hebt mij door mijn eerste paper heen geloodst en daarmee mij als clinicus wegwijs gemaakt in onderzoeksland. Frenk, jij was vanaf het begin betrokken en bent een steeds belangrijkere rol gaan spelen gedurende mijn promotietraject. Je bent bij nagenoeg alle papers betrokken geweest en hebt daarin toegezien op mijn verdere ontwikkeling als onderzoeker. Je had begrip voor mijn dubbele baan, gaf mij ruimte als dat nodig was en kon mij ook stimuleren op de juiste momenten. Je hebt mij geholpen om dit promotietraject tot een goed einde te brengen, waarvoor dank!

Bij de start van mijn promotietraject heb ik de luxe gehad te mogen voortborduren op de MBCT-onderzoekslijn van Nicole Geschwind. Nicole, dank voor de kans met zo'n mooie dataset te mogen werken. Tevens wil ik Hubert de Mey en Gijs Jansen bedanken voor onze samenwerking in de ontwikkeling van de Flexibiliteits Index Test (FIT-60). Wat begon als een leuk onderzoeksproject naast mijn baan als clinicus, heeft zich ontpopt tot een belangrijk onderdeel van mijn promotieonderzoek! Ook wil ik professor Inez Meyin-Germeys bedanken. Zij heeft het ACT-onderzoek geïntroduceerd in de vakgroep en heeft daarmee een basis geschapen voor mij om hiermee aan de slag te kunnen gaan.

Klinisch onderzoek is niet mogelijk zonder de medewerking van de proefpersonen en cliënten. Ik wil jullie bij deze dan ook allemaal hartelijke danken voor jullie cruciale bijdrage! Daarbij wil ik ook even stilstaan bij de verschillende instellingen die bereid zijn geweest mee te werken aan het onderzoek naar de psychometrische kwaliteiten van de FIT-60: Radboud Universiteit Nijmegen, Psychologie Magazine en PsyQ Maastricht, Heerlen, Eindhoven en Tilburg. Mijn dank gaat in het bijzonder uit naar U-center. Daar is mij de tijd en ruimte geboden om onderzoek uit te voeren en is deelgenomen aan een tweetal onderzoeken. Tevens zijn mij daar alle mogelijkheden geboden om mij verder te ontwikkelen als clinicus. Onderzoek doe je niet alleen, maar in een team. Als parttime promovendus is dit team van nog groter belang. Naast mijn promotoren ben ik ook dank verschuldigd aan mijn collega's van de vakgroep. Ik wil Rufa, Jindra en Thomas nog even apart vermelden voor de ondersteuning bij de ACT in Daily Life Training. En Wolfgang, dank voor alle waardevolle adviezen op het vlak van statistische analyses. Truda, Debora en Wendy, dank voor het in 
goede banen leiden van de verschillende onderzoeken! Ook wil ik Ron bedanken voor alle support op het ICT-vlak, alsook de lunchgesprekken over onze gedeelde interesses.

De ACT-community heeft een open-source traditie; er is veel materiaal vrij beschikbaar gesteld. Zo zijn de eerder ontwikkelde ACT-vragenlijsten van grote invloed geweest op de ontwikkeling van de FIT-60. Hierbij is tevens gebruik gemaakt van het open-source platform LimeSurvey. Het vrij beschikbare ACT-materiaal is ook een hoeksteen geweest bij de ontwikkeling van het ACT-protocol van de ACT in Daily Life Training. Ik ben iedereen die heeft bijgedragen aan het vrij beschikbaar stellen van dit open-source materiaal zeer dankbaar en probeer dit goede voorbeeld te volgen.

Ik ben ook dank verschuldigd aan verschillende mensen die redactioneel hebben bijgedragen aan het proefschrift. Graeme, dank voor je input aangaande de Engelse teksten. En Joke, dank voor je zorgvuldige eindredactie van het gehele proefschrift! Wendy, dank voor geslaagde cover en de lay-out van dit proefschrift. Tevens wil ik PsyMate BV, TelePsy en U-center bedanken voor de sponsoring van de publicatie van dit proefschrift.

Naast mijn werkzaamheden als parttime onderzoeker, ben ik in deze periode ook parttime werkzaam geweest als psycholoog bij het U-center. Ik ben al mijn collega's daar ook dankbaar voor hun steun tijdens deze drukke periode (en zeker mijn collega's van Team 1 in de afrondende fase). Dit geldt ook voor mijn collega's van de GZ-opleiding, specifiek voor de delegatie Zuid-Limburg (Emily, Inge, Iris \& Jeroen).

Ook wil ik nog even stilstaan bij mijn twee paranimfen Rufa en Truda. Rufa, ik heb je leren kennen toen je werkzaam was als onderzoeksassistent aan de Universiteit Maastricht. Vervolgens kwam ik je tegen als collega bij de RIAGG, nu als psycholoog. En ik zat goed en wel twee jaar bij U-center, en jawel hoor, daar kwam jij ook weer als collega-psycholoog om de hoek kijken ;-). Je hebt een belangrijke rol gespeeld bij het ACT in Daily Life Onderzoek bij het U-center, in de briefings alsook het coördineren tijdens mijn afwezigheid. Daarnaast ben je een heel fijn mens, waarmee ik goed kan geinen en het ook over de meer serieuze dingen kan hebben. Truda, jij bent mijn rots in de branding geweest op de afdeling op de Univeristiteit. Als parttimer ben je afhankelijk van de mensen om je heen als het gaat om het uitvoerende gedeelte van het onderzoek. Toen ik met 500 ingevulde papieren vragenlijsten kwam aanzetten en vroeg hoe ik ze in het systeem moest zetten, nam jij ze uit mijn handen en zei: "Aah, ik vind nog wel een gaatje om ze in te voeren". Ook het programmeren en inladen van de PsyMate's voor het ACT in Daily Life onderzoek nam je alsof het een vanzelfsprekendheid was op je. Maar naast deze praktische support, was er ook altijd tijd voor een praatje; je was benieuwd hoe het nu ging en met tijden zelfs wat bezorgd ("Tim, je ziet wat wit, moet je niet wat rustiger aan doen?'). In alle drukte, chaos en veranderingen ben je een vertrouwd punt voor mij geweest om even te kunnen landen. Rufa en Truda, ik ben blij dat jullie mij bijstaan bij de verdediging van dit proefschrift. 
Tenslotte heb ik veel steun gehad van de dierbaren om mij heen. Pa en Ma, dank voor jullie steun en vertrouwen! Mijn interesse in de psychologie is geboren vanuit jullie betrokkenheid met de mensen om jullie heen. Mam, in 2008 kreeg ik van jou als collega psycholoog de DSM-IV, met daarin een persoonlijk voorwoord waarin je schrijft dat het belangrijk is de mens achter het label te blijven zien. Dit proefschrift, is in zekere zin een pleidooi voor deze boodschap. Pa, meerdere illustraties van jouw hand zijn in het ACT-onderzoek gebruikt en daarmee ook in verschillende hoofdstukken van dit proefschrift terecht gekomen. Het is fijn een tweede thuisbasis te hebben bij jou, om even stoom af te blazen met een goede bak koffie. En Sam en Anna, ik ben trots jullie broer te zijn en te zien hoe jullie je eigen waardevolle weg bewandelen. Lieve Opa, je was altijd zo trots op de dingen die ik deed, wat jammer dat je deze mijlpaal niet kunt meemaken... Bas, Janyk, Moh en Niels; jullie vriendschap heb ik hard nodig gehad in deze drukke periode; een goede uitlaatklep in fotografie (\#isdateenpolitiebusje), squashen (\#jammervandeklok), wielrennen (\#zethemop30) en van tijd tot tijd een goed gesprek, alsook ruimte voor slap geouwehoer met een goed speciaal-bier! Lisa, ook jou wil ik hier bedanken voor je steun tijdens dit traject. En lieve Inge, dankjewel voor je liefde en je steun, alsook je hulp om naast al dat gewerk ook nog te genieten van het leven.

Het schrijven van het dankwoord is een bijzonder moment. De afronding van het proefschrift, de terugblik op het proces en iedereen die eraan heeft bijgedragen dit mogelijk te maken (als ik iemand ben vergeten, sorry!). Ik heb dit moment gebruikt om deze reflectie over mijn dankbaarheid te verbreden, voor welke dingen ik nog meer dankbaar ben. Ik zou dan ook willen afronden met de vraag aan de lezer om eens stil te staan bij de dingen waar uzelf dankbaar voor bent in uw eigen leven? 


\section{Curriculum Vitae}

Tim Batink is 2 januari 1987 geboren te Sittard. Na het behalen van zijn Atheneum-diploma aan het Trevianum in Sittard-Geleen in 2006 is hij psychologie gaan studeren aan de Radboud Universiteit in Nijmegen. In 2010 heeft hij zijn Master in de klinische psychologie succesvol afgerond (met judicium Summa Cum Laude). Zijn masterscriptie betrof de toepassing van Acceptance and Commitment Therapy bij Fibromyalgie.

Daarna heeft hij een jaar gewerkt als psycholoog bij Lavori, dependance van de RIAGG Maastricht. In 2011 is hij een parttime promotieonderzoek gestart aan Maastricht University, School for Mental Health and Neuroscience, Devision II: Mental Health; bij professor dr. Jim van Os, professor dr. Frenk Peeters, en professor dr. Marieke Wichers. De focus van dit promotieonderzoek betrof de derde generatie gedragstherapie, meer specifiek het meten van de verschillende ACT-processen (o.a. ontwikkeling van de FIT-60) alsook het optimaliseren van deze processen in het dagelijks leven (ontwikkeling van de ACT in Daily Life Training). In 2014 verscheen Time to ACT! het basisboek van professionals van zijn hand (2014), op basis waarvan in 2017 een gratis eHealth-module is verschenen bij ZorgIQ. Tevens heeft hij in samenwerking met TelePsy een uitgebreide eHealth module op basis van ACT ontwikkeld (2016).

Daarnaast is Tim in 2011 parttime als psycholoog gaan werken bij U-center. Hij heeft in deze periode de opleiding tot Cognitief Gedragstherapeut VGCt doorlopen, alsook de postacademische opleiding tot GZ-psycholoog afgerond. Hij heeft zich verder gespecialiseerd in Acceptance and Commitment Therapy middels het volgen van verschillende ACTworkshops en -trainingen in Europa, de USA en Australië bij de grondleggers van ACT (Steven Hayes, Kelly Wilson \& Kirk Strosahl).

Sinds 2012 verzorgt Tim workshops, opleidingen en supervisie via zijn bedrijf ACT in Actie en heeft hij reeds meer dan 250 professionals opgeleid in ACT. Ook is hij als docent werkzaam bij de RINO Zuid. Hij is in 2014 aangetreden als algemeen bestuurslid van Nederlandse ACT-vereniging (ACBS BeNe) en is tevens voorzitter van ACTing with technology SIG, onderdeel van de internationale ACT-vereniging (ACBS). In 2015 was hij co-organisator Nederlandstalig ACT-congres Den Bosch: Leven met Waarden.

Tim zal als Assistant Professor aan de Open Universiteit, vakgroep Levenslooppsychologie zijn ACT-onderzoek continueren. Tevens zal hij als wetenschappelijk onderzoeker verbonden blijven aan Maastricht University, School for Mental Health and Neuroscience (SMARTSCANproject) en is hij eveneens als research affiliate verbonden aan de KU-Leuven, Center for Contextual Psychiatry (InterACT-project). Tenslotte is hij als co-promotor betrokken bij het promotieonderzoek van Guna Schwanen (Maastricht University). 


\section{Publicaties}

\section{Wetenschappelijk}

Batink, T. \& De Mey, H. R. A. (2011). De Nederlandstalige Cognitive Fusion Questionnaire (CFQ13). Retrieved from http://contextualpsychology.org/cognitive_fusion_questionnaire_ dutch_translation.

Batink, T., Jansen, G. \& H. R. A. De Mey (2012). Flexibiliteits Index Test (FIT-60). Retrieved from http://www.hoeflexibelbenjij.nl/page2.html.

Batink, T., Jansen, G. \& De Mey, H. R. A. (2012). De Flexibiliteits Index Test (FIT-60): Een beknopte rapportage. GZ-Psychologie, 5, 18-21.

Batink, T., Peeters, F., Geschwind, N., van Os, J., \& Wichers, M. (2013). How Does MBCT for Depression Work? Studying Cognitive and Affective Mediation Pathways. PLoS ONE 8(8):e72778. doi:10.1371/journal.pone.0072778.

Jansen, G. \& Batink, T. (2014). Time to ACT! Het basisboek voor professionals (derde druk). Zaltbommel, Thema.

Batink, T., Jansen, G., \& Peeters, F. (2015). Nieuwe generatie gedragstherapie, nieuwe generatie meetinstrumenten. Tijdschrift voor Psychiatrie, 57, 739-748.

Batink, T., \& Delespaul, P. (2015). Meten van Psychologische Flexibiliteit: De Flexibiliteits Index Test (FIT-60). Tijdschrift voor Gedragstherapie, 4, 310-332.

Batink, T., Bakker, J., Vaessen, T., Kasanova, Z., Collip, D., van Os, J., Wichers, M., Germeys, I., \& Peeters, F. (2016). Acceptance and Commitment Therapy in Daily Life Training: A Feasibility Study of an mHealth intervention. JMIR mHealth uHealth, 4(3): e103. DOI: 10.2196/ mhealth.5437

Steinhart, H., Vaessen, T., Batink, T., \& Meyin-Germeys, I. (submitted). ACT in Daily Life: A Momentary Intervention Approach.

Batink, T. \& Peeters, F. (submitted). Acceptance and Commitment Therapy: Achtergrond, Assessment \& Applicatie. 


\section{Populair wetenschappelijk}

Batink, T. (2011). ACT effectief bij chronische pijn. FES-Magazine, 133, 14-15.

Batink, T. (2011). De Fibrometer: Meten is weten. FES-Magazine, 135, 5.

Jansen, G. \& Batink, T. (2012). Introductie van de Flexibiliteits Index Test (FIT-60). Kenniscentrum Psychologie.

Batink, T. (2013). De FIT-60: Nieuwe generatie therapie, nieuwe generatie psychodiagnostiek. Psychopraktijk, 2, 39.

Batink, T. (2013). Functionele diagnostiek: De Flexibiliteits Index Test (FIT-60). WP Nieuws.

Batink, T. (2015, april). ACT challenges in our local community - Interview with Prof. Steven Hayes. https://www.youtube.com/watch?v=FckwA1EuWXs\&t=10s

Batink, T. (2015, mei). ACT en Positieve Psychologie - Interview Tim Batink. https://www. youtube.com/watch?v=dWb0DxunZ2Q \&t=184s 


\section{Presentaties}

Batink, T. (2011). MBCT werkt, maar hoe werkt het eigenlijk? In N. Geschwind (Chair) Symposium MindMaastricht, Maastricht.

Batink, T. (2012). Mindfulness Based Cognitive Therapy \& Mechanisms of

Change. In J. Ormel (Chair), Symposium presented at the EPA-EU-GEI Conference, Maastricht.

Batink, T. (2012). PsyMate: An instrument for ecological, momentary assessment of behavior and its context. (Posterpresentation at ACBS World Conference X, Washington D.C).

Batink, T., Jansen, G., \& De Mey, H. (2013). Introductie nieuwe contextueel-gedragstherapeutische vragenlijst: De Flexibiliteits Index Test (FIT-60). (Posterpresentation at the NVvP Voorjaarscongres 2013, Maastricht).

Batink, T., Wichers, M., Peeters, F., Geschwind, \& N., van Os, J. (2013). Mindfulness Based Cognitive Therapy \& Werkzame Mechanismen. In M. Wichers (Chair), Symposium presented at the NVvP Voorjaarscongres 2013, Maastricht.

Batink, T., Peeters, F., Geschwind, N., van Os, J., \& Wichers, M. (2013). Using ESM to examine the mechanism of change of Mindfulness Based Cognitive Therapy. (Posterpresentation at the $3^{\text {rd }}$ conference of the Society of Ambulatory Assessment, Amsterdam).

Batink, T., Jansen, G., \& De Mey, H. (2013). Development of the Flexibility Index Test (FIT-60). (Posterpresentation at the ACBS World Conference XI, Sydney).

Batink, T., Collip, D., \& Wichers, M. (2013). Mobile technology fostering ACT-practice in daily Life. In C. Horan (Chair), Symposium presented at the ACBS World Conference XI, Sydney.

Ciarrochi, J., Walser, R., Batink, T., Picosszi, S., Pistorello, J., \&Hayes, L. (2013). ACTing with Technology: How technology can be used to transform the accessibility and effectiveness of ACT practice and research. In C. Horan (Chair), Panel at the ACBS World Conference XI, Sydney.

Batink, T., Wichers, M., Myin-Germeys, I., \& van Os, J (2014). Mobile technology fostering ACTpractice in daily life. In J. Pistorello (Chair), Symposium presented at the ACBS World Conference XII, Minneapolis.

Batink, T., Bakker, J., Collip, D., Wichers, M., \& Myin-Germeys, I. (2014). Mobile Technology Fostering Acceptance and Commitment Therapy in Daily Life. (Posterpresentation at the EABCT Congress 2014, The Hague).

Batink, T. (2014). Time to ACT! NOLOC Loopbaancongres 2014: Veerkracht en Vuur, Den Bosch. 
Batink, T. (2015). ACT en Authenticiteit. Dag van de Trainer 2015: Authenticiteit, Bussum.

Batink, T. (2015). Voorzitter Symposium "Wetenschappelijke aspecten van ACT", ACBS BeNe Lustrumcongres: Leven en Werken met Waarden, Den Bosch.

Batink, T. (2016). Van Klacht naar Veerkracht - Acceptance and Commitment Therapy (ACT). Goede GGZ, herstel van de menselijke maat, Utrecht.

Batink, T. (2016). Uitzicht door Inzicht. Een verdiepingsessie gebaseerd op Acceptance and Commitment Therapy. NOLOC Loopbaancongres 2016: Inzicht geeft uitzicht, Apeldoorn.

Batink, T. (2016). Acceptance and Commit Therapy (ACT) bij NAH: Van Klacht naar Veerkracht. Congres Neuropsychotherapie, Driebergen.

Batink, T. (2017). Acceptance and Commitment Therapy bij kanker - Waardenvol Leven \& Levenseinde. Sterkte met je tumor, symposium psychosociale oncologie, Maastricht. 
Tim Batink, Gijs Jansen \& Hubert de Mey.

Met dank aan: David Rinsampessy, Jos Egger \& Monique Samsen.

Copyright 2015 @ T. Batink, G. Jansen \& H.R.A. De Mey.

Sommige rechten voorbehouden

Op dit werk is de Creative Commons licentie CC-BY-NC-SA Versie 3.0 van toepassing

Men mag dit werk kopiëren, verspreiden, doorgeven, of afgeleide werken van maken, mits de naam van de oorspronkelijke auteurs wordt vermeld. Tevens mag het werk niet voor commerciële doeleinden worden gebruikt. Indien de gebruiker het werk bewerkt, kan het daaruit ontstane werk uitsluitend krachtens dezelfde licentie als de onderhavige licentie of een gelijksoortige licentie worden verspreid. Onder geen beding worden de intellectuele eigendomsrechten en de morele rechten van de auteurs in het gedrang gebracht. 


\section{appendix 1}

Flexibiliteits Index Test (FIT-60) 


\section{Introductie}

De FIT is een instrument waarmee in kaart kan worden gebracht hoe flexibel $u$ in het leven staat. Deze flexibiliteit bepaalt hoe u omgaat met vervelende gedachten, gevoelens en (lichamelijke) ervaringen. Hoe flexibeler iemand is, hoe makkelijker deze om kan gaan met de vervelende ervaringen die hij/zij op haar pad tegenkomt. De hier gemeten flexibiliteit, wordt gedefinieerd door de aanwezigheid van de zes kerncomponenten van Acceptance and Commitment Therapie; Acceptatie, Defusie, Zelf als Context, Hier en Nu, Waarden, en Toegewijde Actie. De FIT geeft zowel een totaalscore (Flexibiliteits Index Score), als een score per subschaal. Deze subschaalscores zijn tevens visueel weer te geven in het corresponderende ACT-hexaflex op het resultatenblad.

De FIT is goed te gebruiken als instrument waarmee de richting van een ACT-therapie kan worden bepaald, welke componenten extra aandacht vereisen. Tevens is het instrument goed inzetbaar om de vorderingen van een ACT-therapie/training te monitoren. Tenslotte is dit instrument ook bruikbaar bij Mindfulness trainingen, welke zich beperken tot de linker vier componenten van het ACT-hexaflex.

\section{Instructie voor het invullen}

De FIT bestaat uit 60 stellingen. Lees elke stelling aandachtig door, en geef daarna aan in hoeverre deze stelling van toepassing is op $u$. Denk niet te lang na, maar geef uw eerste mening. Hoe hoger het cijfer dat $u$ geeft, hoe meer deze stelling van toepassing is op $u$ (6=helemaal eens). Hoe lager het cijfer dat u geeft, hoe minder deze stelling van toepassing is op $u(0=$ helemaal oneens). Er zijn geen goede of foute antwoorden. Wilt $u$ alstublieft geen vragen overslaan.

Om uw antwoordkeuze aan te geven, kunt u het corresponderende cijfer omcirkelen.

Voorbeeld:

Vraag: Ik doe mijn best om geen negatieve dingen te hoeven ervaren. 01 (2)3456

Indien u een verkeerd antwoord heeft omcirkeld, kunt u dit corrigeren door een streep te zetten door het gegeven antwoord. Vervolgens omcirkeld $u$ alsnog het correcte antwoord.

Voorbeeld:

Vraag: Ik doe mijn best om geen negatieve dingen te hoeven ervaren. 01 1/2) 3 4(5) 6

Succes met het invullen van deze lijst!

Contact: info@hoeflexibelbenjij.nl

Informatie: www.hoeflexibelbenjij.nl 
Naam: Geslacht: M / V Leeftijd:

Burg. staat: Opleiding: Datum afname:

In welke mate zijn onderstaande stellingen van toepassing op u? Omcirkel het meest passende antwoord. Sla alstublieft geen stellingen over.

\begin{tabular}{|c|c|c|c|c|c|c|c|c|}
\hline & & 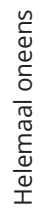 & & & & & & 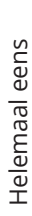 \\
\hline 1 & Zorgen staan mijn succes in de weg. & 0 & 1 & 2 & 3 & 4 & 5 & 6 \\
\hline 2 & Ik voel me vaak beperkt door alles wat ik van mezelf moet. & 0 & 1 & 2 & 3 & 4 & 5 & 6 \\
\hline 3 & $\begin{array}{l}\text { Ik kan negatieve gedachten over mijzelf hebben en tegelijkertijd weten } \\
\text { dat ik oké ben. }\end{array}$ & 0 & 1 & 2 & 3 & 4 & 5 & 6 \\
\hline 4 & Als ik iets wil doen, dan ga ik er voor. & 0 & 1 & 2 & 3 & 4 & 5 & 6 \\
\hline 5 & $\begin{array}{l}\text { Ik ben goed in staat om lange termijn doelen op te delen in korte } \\
\text { termijn mogelijkheden. }\end{array}$ & 0 & 1 & 2 & 3 & 4 & 5 & 6 \\
\hline 6 & Mijn leven is goed in balans. & 0 & 1 & 2 & 3 & 4 & 5 & 6 \\
\hline 7 & Ik vind het moeilijk om doelgericht bezig te blijven. & 0 & 1 & 2 & 3 & 4 & 5 & 6 \\
\hline 8 & Ik heb voldoende vrienden. & 0 & 1 & 2 & 3 & 4 & 5 & 6 \\
\hline 9 & Mijn gedachten bezorgen mij ongemak of emotionele pijn. & 0 & 1 & 2 & 3 & 4 & 5 & 6 \\
\hline 10 & Het is OK als ik me iets onaangenaams herinner. & 0 & 1 & 2 & 3 & 4 & 5 & 6 \\
\hline 11 & Ik maak regelmatig concrete plannen voor de toekomst. & 0 & 1 & 2 & 3 & 4 & 5 & 6 \\
\hline 12 & $\begin{array}{l}\text { Als iets me niet lukt dan zet ik door, en probeer ik het op een andere } \\
\text { manier aan te pakken. }\end{array}$ & 0 & 1 & 2 & 3 & 4 & 5 & 6 \\
\hline 13 & Ik ga graag naar mijn werk. & 0 & 1 & 2 & 3 & 4 & 5 & 6 \\
\hline 14 & Ik ben bereid om mijn angst volledig toe te laten. & 0 & 1 & 2 & 3 & 4 & 5 & 6 \\
\hline 15 & $\begin{array}{l}\text { Ik vind het moeilijk om mijn aandacht te houden bij wat er in het hier } \\
\text { en nu gebeurt. }\end{array}$ & 0 & 1 & 2 & 3 & 4 & 5 & 6 \\
\hline 16 & Ik ben snel afgeleid. & 0 & 1 & 2 & 3 & 4 & 5 & 6 \\
\hline 17 & Ik vind van mezelf dat ik altijd aardig moet zijn. & 0 & 1 & 2 & 3 & 4 & 5 & 6 \\
\hline 18 & $\begin{array}{l}\text { Het is moeilijk voor me om de woorden te vinden die mijn gedachten } \\
\text { beschrijven. }\end{array}$ & 0 & 1 & 2 & 3 & 4 & 5 & 6 \\
\hline 19 & Ik besef dat mijn zelfbeeld niet zoveel over mij als persoon zegt. & 0 & 1 & 2 & 3 & 4 & 5 & 6 \\
\hline 20 & Ik observeer mijn gevoelens zonder dat ik me erin verlies. & 0 & 1 & 2 & 3 & 4 & 5 & 6 \\
\hline 21 & Als ik thuis ben voel ik me op mijn gemak. & 0 & 1 & 2 & 3 & 4 & 5 & 6 \\
\hline 22 & Ik doe mijn best om geen negatieve dingen te hoeven ervaren. & 0 & 1 & 2 & 3 & 4 & 5 & 6 \\
\hline 23 & Ik heb last van een negatief zelfbeeld. & 0 & 1 & 2 & 3 & 4 & 5 & 6 \\
\hline 24 & Als ik iets niet goed doe, dan reken ik dat mezelf aan. & 0 & 1 & 2 & 3 & 4 & 5 & 6 \\
\hline 25 & Ik besef dat ik de dingen die ik doe, zelf heb gekozen. & 0 & 1 & 2 & 3 & 4 & 5 & 6 \\
\hline
\end{tabular}


In welke mate zijn onderstaande stellingen van toepassing op u? Omcirkel het meest passende antwoord. Sla alstublieft geen stellingen over.

\begin{tabular}{|c|c|c|c|c|c|c|c|c|}
\hline & & 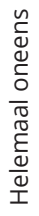 & & & & & & 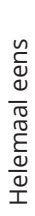 \\
\hline 26 & $\begin{array}{l}\text { Als ik pijnlijke gevoelens toelaat, dan ben ik bang dat ze niet meer } \\
\text { verdwijnen. }\end{array}$ & 0 & 1 & 2 & 3 & 4 & 5 & 6 \\
\hline 27 & Er zijn een aantal dingen die ik doe, die ik belangrijk vind. & 0 & 1 & 2 & 3 & 4 & 5 & 6 \\
\hline 28 & Ik heb last van het gevoel dat ik door de bomen het bos niet meer zie. & 0 & 1 & 2 & 3 & 4 & 5 & 6 \\
\hline 29 & Ik heb de neiging mijn pijn erger te maken met mijn gedachten. & 0 & 1 & 2 & 3 & 4 & 5 & 6 \\
\hline 30 & $\begin{array}{l}\text { Ik vind het makkelijk om mijn gedachten van een andere kant te } \\
\text { bekijken. }\end{array}$ & 0 & 1 & 2 & 3 & 4 & 5 & 6 \\
\hline 31 & $\begin{array}{l}\text { Mijn pijnlijke ervaringen en herinneringen maken het me moeilijk om } \\
\text { een waardevol leven te leiden. }\end{array}$ & 0 & 1 & 2 & 3 & 4 & 5 & 6 \\
\hline 32 & $\begin{array}{l}\text { Als iemand een vervelende opmerking maakt, kan ik daar nog lang last } \\
\text { van hebben. }\end{array}$ & 0 & 1 & 2 & 3 & 4 & 5 & 6 \\
\hline 33 & Ik hoef dingen niet altijd goed te doen van mezelf. & 0 & 1 & 2 & 3 & 4 & 5 & 6 \\
\hline 34 & Mijn werk en / of studie speelt een belangrijke rol in mijn leven. & 0 & 1 & 2 & 3 & 4 & 5 & 6 \\
\hline 35 & Gedachten die bij me opkomen moet ik onder controle houden. & 0 & 1 & 2 & 3 & 4 & 5 & 6 \\
\hline 36 & Ik kan goed beschrijven wat ik voel. & 0 & 1 & 2 & 3 & 4 & 5 & 6 \\
\hline 37 & Ik vind mijn leven waardevol. & 0 & 1 & 2 & 3 & 4 & 5 & 6 \\
\hline 38 & $\begin{array}{l}\text { Ik geloof dat sommige van mijn gedachten abnormaal of slecht zijn en } \\
\text { dat ik niet zo zou moeten denken. }\end{array}$ & 0 & 1 & 2 & 3 & 4 & 5 & 6 \\
\hline 39 & Sommige woorden kunnen mij heel hard raken. & 0 & 1 & 2 & 3 & 4 & 5 & 6 \\
\hline 40 & Ik ben onderweg om mijn doelen en dromen te bereiken. & 0 & 1 & 2 & 3 & 4 & 5 & 6 \\
\hline 41 & Ik besteed regelmatig tijd aan mijn hobby's. & 0 & 1 & 2 & 3 & 4 & 5 & 6 \\
\hline 42 & $\begin{array}{l}\text { Ik heb de neiging erg sterk te reageren op mijn eigen negatieve } \\
\text { gedachten. }\end{array}$ & 0 & 1 & 2 & 3 & 4 & 5 & 6 \\
\hline 43 & Ik keur mezelf af als ik rare gedachten heb. & 0 & 1 & 2 & 3 & 4 & 5 & 6 \\
\hline 44 & $\begin{array}{l}\text { Ik kan makkelijk mijn overtuigingen en meningen onder woorden } \\
\text { brengen. }\end{array}$ & 0 & 1 & 2 & 3 & 4 & 5 & 6 \\
\hline 45 & $\begin{array}{l}\text { Emoties (zoals boosheid, verdriet) veroorzaken problemen in mijn } \\
\text { leven. }\end{array}$ & 0 & 1 & 2 & 3 & 4 & 5 & 6 \\
\hline 46 & Ik sta los van mijn omgeving & & & & & & & \\
\hline 47 & Ik doe meerdere dingen die ik belangrijk vind. & 0 & 1 & 2 & 3 & 4 & 5 & 6 \\
\hline 48 & Ik vind het leuk om nieuwe uitdagingen aan te gaan. & 0 & 1 & 2 & 3 & 4 & 5 & 6 \\
\hline 49 & $\begin{array}{l}\text { Ik kan goed beschrijven wat ik ervaar met mijn zintuigen, zoals wat ik } \\
\text { hoor, zie en ruik. }\end{array}$ & 0 & 1 & 2 & 3 & 4 & 5 & 6 \\
\hline 50 & Ik vind steun bij de mensen in mijn omgeving. & 0 & 1 & 2 & 3 & 4 & 5 & 6 \\
\hline 51 & De gedachten die ik over mijzelf heb, bepalen niet wie ik ben. & 0 & 1 & 2 & 3 & 4 & 5 & 6 \\
\hline 52 & Ik schrik soms van de gedachten die ik heb. & 0 & 1 & 2 & 3 & 4 & 5 & 6 \\
\hline
\end{tabular}


In welke mate zijn onderstaande stellingen van toepassing op u? Omcirkel het meest passende antwoord. Sla alstublieft geen stellingen over.

\begin{tabular}{|c|c|c|c|c|c|c|c|c|}
\hline & & 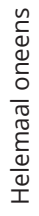 & & & & & & 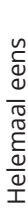 \\
\hline 53 & Ik ben bang voor mijn gevoelens. & 0 & 1 & 2 & 3 & 4 & 5 & 6 \\
\hline 54 & $\begin{array}{l}\text { Mijn gedachten en gevoelens staan de manier waarop ik wil leven niet } \\
\text { in de weg. }\end{array}$ & 0 & 1 & 2 & 3 & 4 & 5 & 6 \\
\hline 55 & Ik vind familie en / of vrienden belangrijk. & 0 & 1 & 2 & 3 & 4 & 5 & 6 \\
\hline 56 & $\begin{array}{l}\text { Wanneer ik mezelf vergelijk met andere mensen, lijkt het dat de } \\
\text { meesten onder hen hun leven beter in de hand hebben dan ik. }\end{array}$ & 0 & 1 & 2 & 3 & 4 & 5 & 6 \\
\hline 57 & $\begin{array}{l}\text { Het is erg moeilijk om verontrustende gedachten los te laten, zelfs } \\
\text { wanneer ik weet dat los laten mij zou helpen. }\end{array}$ & 0 & 1 & 2 & 3 & 4 & 5 & 6 \\
\hline 58 & Van sommige gedachten raak ik van streek. & 0 & 1 & 2 & 3 & 4 & 5 & 6 \\
\hline 59 & Ik ben erop uit om nieuwe dingen te doen. & 0 & 1 & 2 & 3 & 4 & 5 & 6 \\
\hline 60 & $\begin{array}{l}\text { Ik denk dat mijn emoties soms slecht of ongepast zijn en dat ik ze niet } \\
\text { zou moeten voelen. }\end{array}$ & 0 & 1 & 2 & 3 & 4 & 5 & 6 \\
\hline
\end{tabular}

Heeft u alle stellingen ingevuld? Hartelijk dank voor het invullen van deze lijst! 
Scoreblad Flexibiliteits Index Test (FIT-60)

Naam: Geslacht: M / V Datum:

\section{Scoringsmethode}

Neem de scores van de ingevulde FIT-60 over in de eerste regel Org. Score (originele score) van elke subschaal. De scores in de grijze vlakken dienen gespiegeld te worden (6-0, 5-1, 4-2, 3-3, 2-4, 1-5, 0-6). Noteer de gespiegelde scores in de ondergelegen regel Aang. Score (aangepaste score). Neem vervolgens ook de niet gespiegelde items over in deze regel. Tel hierna de scores uit de onderste regel van elke subschaal op tot een subschaal-totaal en tel tenslotte deze subtotalen op tot een eindtotaal; de Flexibiliteits Index Score.

Subschaal Acceptatie

\begin{tabular}{|c|c|c|c|c|c|c|c|c|c|c|c|}
\hline Vraag & 1 & 10 & 14 & 22 & 26 & 31 & 35 & 45 & 53 & 54 & Totaal \\
\hline Org. Score & & & & & & & & & & & \\
\hline Aang. Score & & & & & & & & & & & \\
\hline
\end{tabular}

Subschaal Defusie

\begin{tabular}{|c|c|c|c|c|c|c|c|c|c|c|c|}
\hline Vraag & 9 & 28 & 29 & 30 & 32 & 39 & 42 & 52 & 57 & 58 & Totaal \\
\hline Org. Score & & & & & & & & & & & \\
\hline Aang. Score & & & & & & & & & & & $\ldots .$. \\
\hline
\end{tabular}

Subschaal Zelf

\begin{tabular}{|c|c|c|c|c|c|c|c|c|c|c|c|}
\hline Vraag & 2 & 3 & 17 & 19 & 23 & 24 & 33 & 46 & 51 & 56 & Totaal \\
\hline Org. Score & & & & & & & & & & & \\
\hline Aang. Score & & & & & & & & & & & ....... \\
\hline
\end{tabular}

Subschaal Hier en Nu

\begin{tabular}{|c|c|c|c|c|c|c|c|c|c|c|c|}
\hline Vraag & 15 & 16 & 18 & 20 & 36 & 38 & 43 & 44 & 49 & 60 & Totaal \\
\hline Org. Score & & & & & & & & & & & \\
\hline Aang. Score & & & & & & & & & & & \\
\hline
\end{tabular}

Subschaal Waarden

\begin{tabular}{|c|c|c|c|c|c|c|c|c|c|c|c|}
\hline Vraag & 6 & 8 & 21 & 25 & 27 & 34 & 37 & 41 & 50 & 55 & Totaal \\
\hline Org. Score & & & & & & & & & & & \\
\hline Aang. Score & & & & & & & & & & & ............ \\
\hline
\end{tabular}

Subschaal Toegewijd Handelen

\begin{tabular}{|c|c|c|c|c|c|c|c|c|c|c|c|}
\hline Vraag & 4 & 5 & 7 & 11 & 12 & 13 & 40 & 47 & 48 & 59 & Totaal \\
\hline Org. Score & & & & & & & & & & & \\
\hline Aang. Score & & & & & & & & & & & ..... \\
\hline
\end{tabular}


Totaalscore FIT:

\begin{tabular}{|l|l|l|}
\hline FIT-Subschaal & Score & \\
\hline Acceptatie & $/ 60$ & \\
\hline Defusie & $/ 60$ & \\
\hline Zelf als context & $/ 60$ & \\
\hline Hier en Nu & $/ 60$ & \\
\hline Waarden & $/ 60$ & \\
\hline Toegewijd Handelen & $-/ 60$ & \\
\hline Totaal & $-/ 360$ & = Flexibiliteits Index Score \\
\hline
\end{tabular}

Zie referentiegroepen $1 \mathrm{t} / \mathrm{m} 4$ om de scores te kunnen vergelijken met de meest gelijkende populatie. 


\section{Resultatenblad Flexibiliteits Index Test (Algemeen)}

Vul hier de schaalscores \& totaalscore in.

\begin{tabular}{|c|c|c|c|c|}
\hline & Score & Lager dan Gem. & Gemiddeld & Hoger dan Gem. \\
\hline \multicolumn{5}{|l|}{ Acceptatie } \\
\hline \multicolumn{5}{|l|}{ Defusie } \\
\hline \multicolumn{5}{|l|}{ Zelf als Context } \\
\hline \multicolumn{5}{|l|}{ Hier en Nu } \\
\hline \multicolumn{5}{|l|}{ Waarden } \\
\hline \multicolumn{5}{|l|}{ Toegewijde Actie } \\
\hline Flexibiliteits Index & & & & \\
\hline
\end{tabular}

Vul in onderstaande hexaflex de subschaalscores op de assen in en verbind de punten met elkaar. Dit is het persoonlijke flexibiliteitsprofiel.

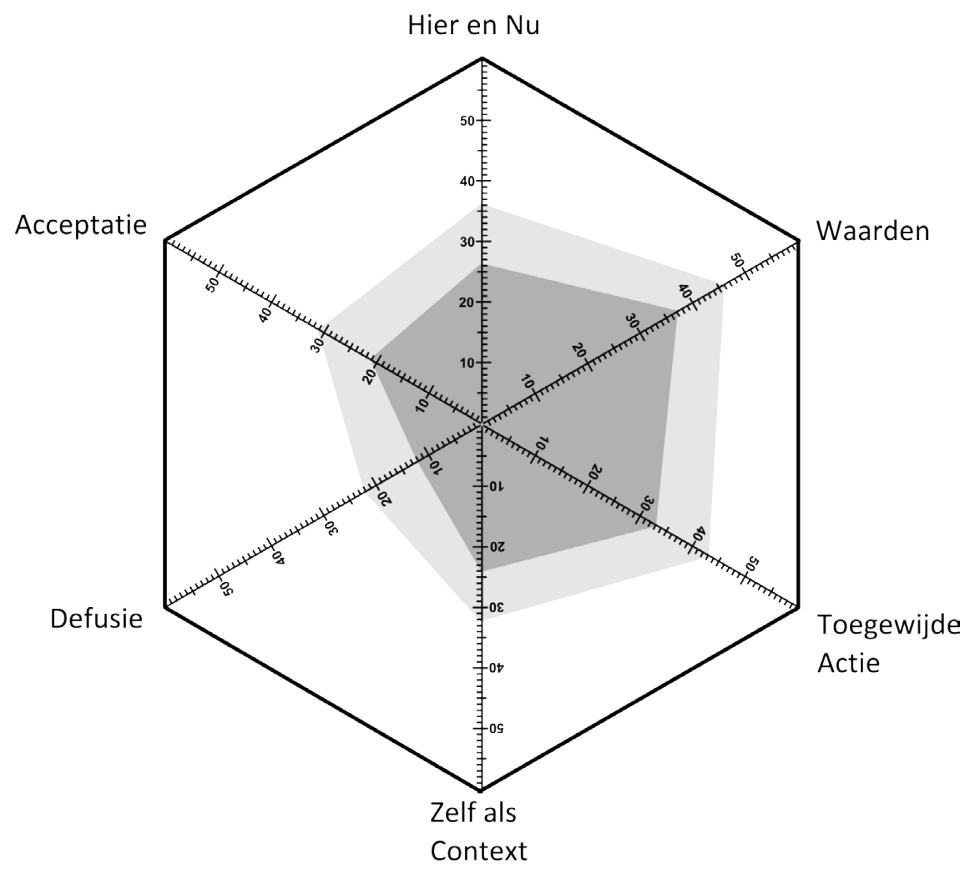

$\square$ Laag $\square$ Gemiddeld $\square$ Hoog 


\section{Resultatenblad Flexibiliteits Index Test (Student)}

Vul hier de schaalscores \& totaalscore in.

\begin{tabular}{lcccc}
\hline & \multicolumn{1}{c}{ Score } & Lager dan Gem. & Gemiddeld & Hoger dan Gem. \\
\hline Acceptatie & & & $\bigcirc$ & $\bigcirc$ \\
Defusie & - & & $\bigcirc$ \\
Zelf als Context & - & & $\bigcirc$ & $\bigcirc$ \\
Hier en Nu & - & & $\bigcirc$ & $\bigcirc$ \\
Waarden & - & & $\bigcirc$ & $\bigcirc$ \\
Toegewijde Actie & - & & $\bigcirc$ & $\bigcirc$ \\
Flexibiliteits Index & & & $\bigcirc$ & $\bigcirc$ \\
\hline
\end{tabular}

Vul in onderstaande hexaflex de subschaalscores op de assen in en verbind de punten met elkaar. Dit is het persoonlijke flexibiliteitsprofiel.

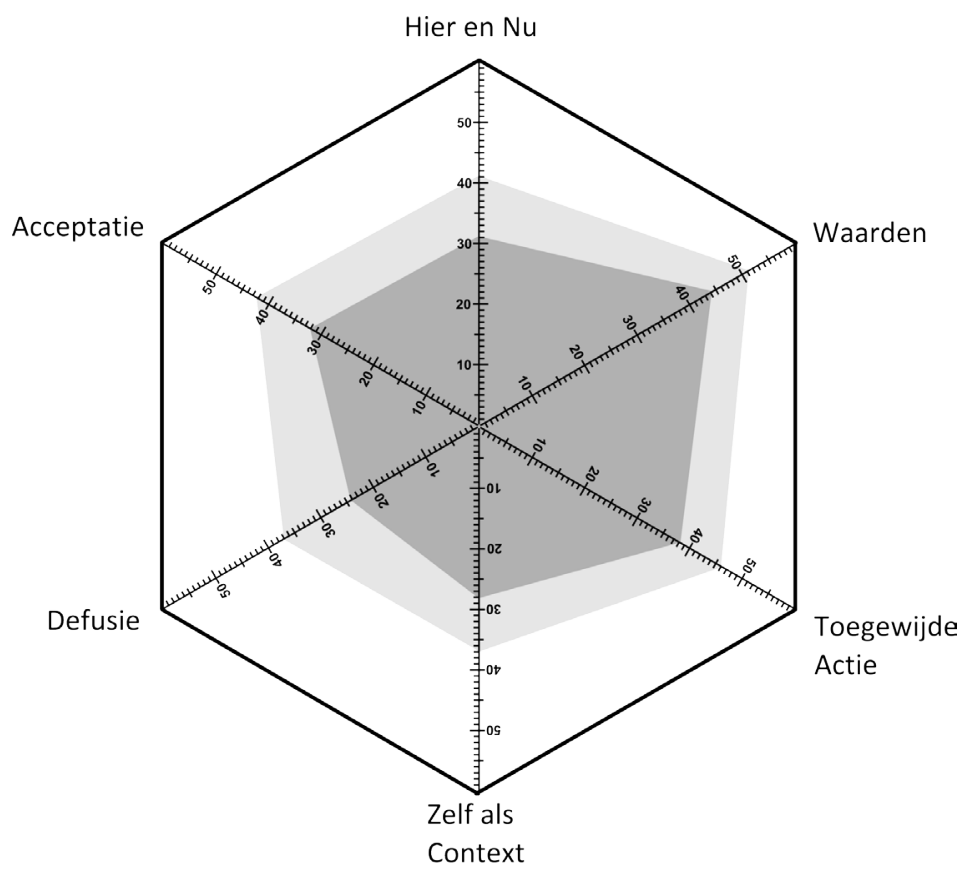

$\square$ Laag $\square$ Gemiddeld $\square$ Hoog 
Resultatenblad Flexibiliteits Index Test (Patiënt - Ambulant)

Vul hier de schaalscores \& totaalscore in.

\begin{tabular}{lcccc}
\hline Acceptatie & \multicolumn{1}{c}{ Score } & Lager dan Gem. & Gemiddeld & Hoger dan Gem. \\
Defusie & - & & $\bigcirc$ & $\bigcirc$ \\
Zelf als Context & - & & $\bigcirc$ & $\bigcirc$ \\
Hier en Nu & - & & $\bigcirc$ & $\bigcirc$ \\
Waarden & - & & $\bigcirc$ & $\bigcirc$ \\
Toegewijde Actie & - & & $\bigcirc$ & $\bigcirc$ \\
Flexibiliteits Index & - & & $\bigcirc$ & $\bigcirc$ \\
\hline
\end{tabular}

Vul in onderstaande hexaflex de subschaalscores op de assen in en verbind de punten met elkaar. Dit is het persoonlijke flexibiliteitsprofiel.

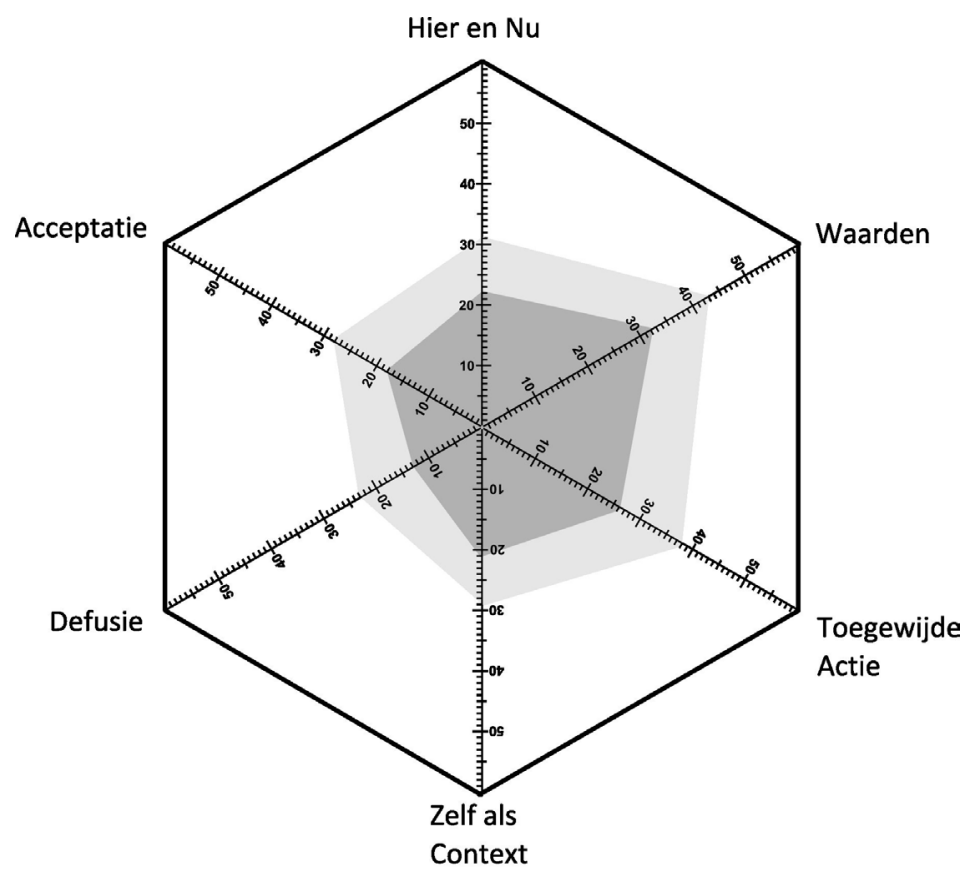

$\square$ Laag $\square$ Gemiddeld $\square$ Hoog 


\section{Resultatenblad Flexibiliteits Index Test (Patiënt - Klinisch)}

Vul hier de schaalscores \& totaalscore in.

\begin{tabular}{|c|c|c|c|c|}
\hline \multirow{2}{*}{ Acceptatie } & Score & Lager dan Gem. & Gemiddeld & Hoger dan Gem. \\
\hline & & & & \\
\hline Defusie & & & & \\
\hline Zelf als Context & & & & \\
\hline Hier en $\mathrm{Nu}$ & & & & \\
\hline Waarden & & & & \\
\hline Toegewijde Actie & & & & \\
\hline Flexibiliteits Index & & & & \\
\hline
\end{tabular}

Vul in onderstaande hexaflex de subschaalscores op de assen in en verbind de punten met elkaar. Dit is het persoonlijke flexibiliteitsprofiel.

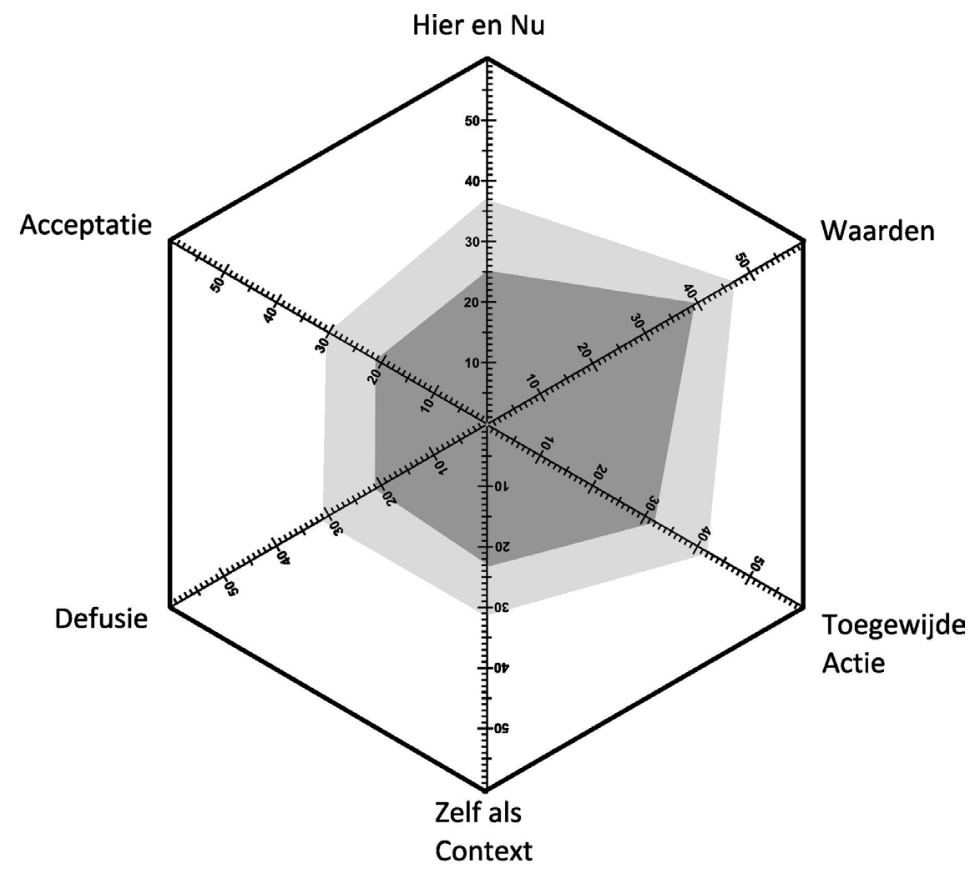

$\square$ Laag $\square$ Gemiddeld $\square$ Hoog 


\section{Resultatenblad Flexibiliteits Index Test (Individueel)}

Vul hier de schaalscores \& totaalscore in.

Score meetmoment $1 \quad$ Score meetmoment $2 \quad$ Score meetmoment 3

Acceptatie

Defusie

Zelf als Context

Hier en $\mathrm{Nu}$

Waarden

Toegewijde Actie

Flexibiliteits Index

Vul in onderstaande hexaflex de subschaalscores in en verbind de punten met elkaar zodat er een vlak ontstaat (zie voorbeeld rechts onderaan de pagina). Dit is het persoonlijke flexibiliteitsprofiel.

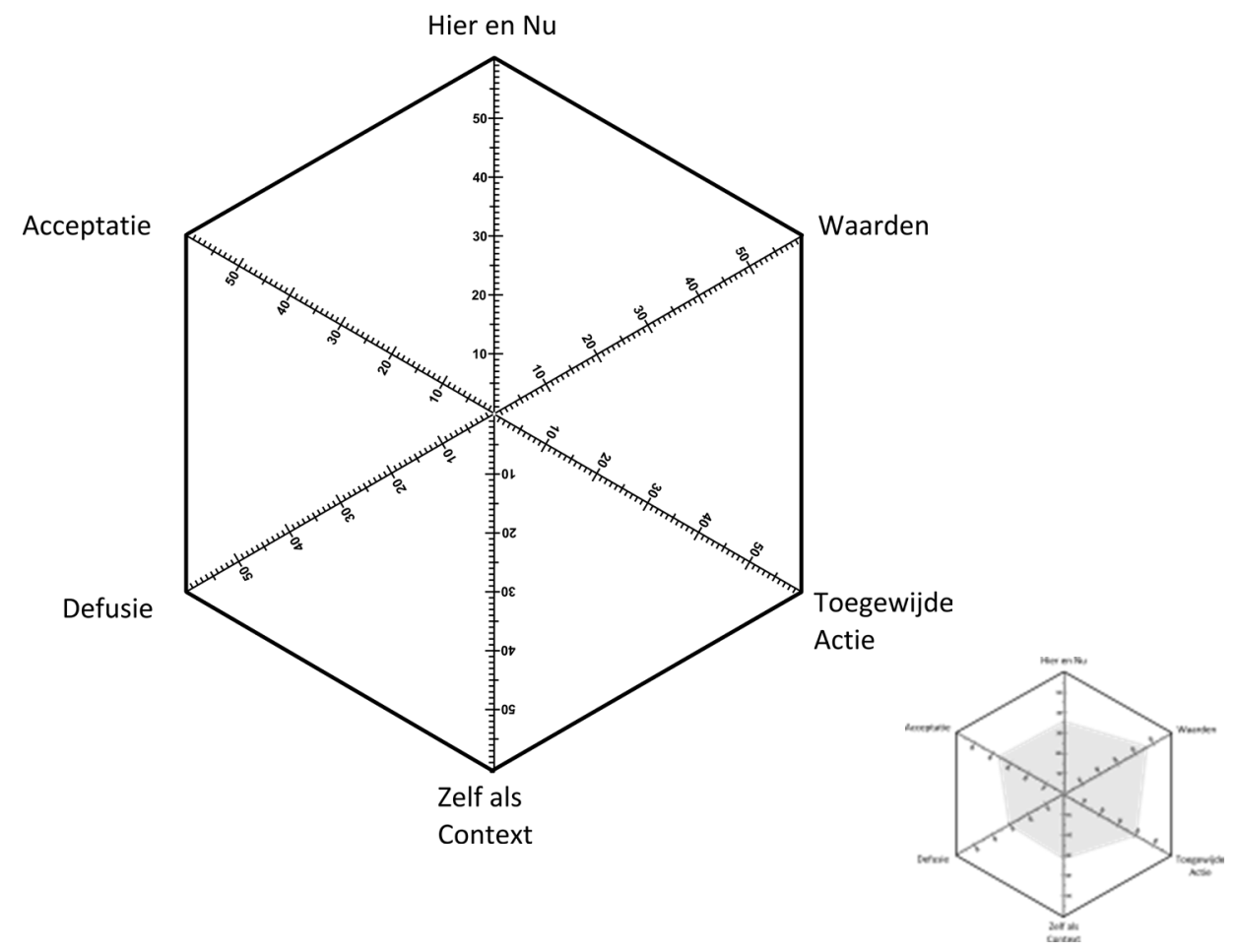




\section{Aanvullende informatie Referentiegroepen}

Referentiegroep 1: Algemeen

Gemiddelde score \& spreiding van score.

\begin{tabular}{lllllll}
\hline Acceptatie & Defusie & $\begin{array}{l}\text { Zelf als } \\
\text { Context }\end{array}$ & Hier en Nu & Waarden & $\begin{array}{l}\text { Toegewijd } \\
\text { Handelen }\end{array}$ & $\begin{array}{l}\text { Flexibiliteits } \\
\text { Index Score }\end{array}$ \\
\hline $26,3(10,4)$ & $18,2(9,6)$ & $28,0(7,9)$ & $31,3(9,7)$ & $41,3(7,8)$ & $37,8(9,5)$ & $182,8(41,9)$ \\
\hline
\end{tabular}

Normtabel Referentiegroep 1: Algemene populatie

\begin{tabular}{lccc}
\hline & Lager dan gemiddeld & Gemiddeld & Hoger dan gemiddeld \\
\hline Acceptatie & $0-21$ & $22-31$ & $32-60$ \\
Defusie & $0-12$ & $13-22$ & $23-60$ \\
Zelf als context & $0-24$ & $25-32$ & $33-60$ \\
Hier en Nu & $0-26$ & $27-36$ & $37-60$ \\
Waarden & $0-37$ & $38-46$ & $47-60$ \\
Toegewijd Handelen & $0-33$ & $34-43$ & $44-60$ \\
Flexibiliteits Index & $0-161$ & $162-201$ & $202-360$ \\
\hline
\end{tabular}

\section{Demografische informatie algemene populatie $(\mathrm{N}=1087)$}

Leeftijd: $\quad$ Gemiddeld 42,73 jaar (SD 10,66), minimum 19 \& maximum 76 jaar.

Geslacht: $\quad$ Man 10,1 \% - Vrouw 89,9\%.

Opleiding: $\quad$ 25\% Universitair; 56 \% HBO/VWO/HAVO; 18 \% MBO/MAVO; 1\% LBO.

Locatie: Heel Nederland via de online training "Leer Loslaten" Psychologie Magazine.

Tijdsbestek: Februari 2011 - Januari 2012. 
Referentiegroep 2: Student

Gemiddelde score \& spreiding van score.

\begin{tabular}{lllllll}
\hline Acceptatie & Defusie & $\begin{array}{l}\text { Zelf als } \\
\text { Context }\end{array}$ & Hier en Nu & Waarden & $\begin{array}{l}\text { Toegewijd } \\
\text { Handelen }\end{array}$ & $\begin{array}{l}\text { Flexibiliteits } \\
\text { Index Score }\end{array}$ \\
\hline $36,3(9,6)$ & $30,4(11,4)$ & $32,0(8,2)$ & $35,8(9,2)$ & $46,7(6,9)$ & $41,3(8,0)$ & $222,6(43,1)$ \\
\hline
\end{tabular}

Normtabel Referentiegroep 2: Student

\begin{tabular}{lccc}
\hline & Lager dan gemiddeld & Gemiddeld & Hoger dan gemiddeld \\
\hline Acceptatie & $0-32$ & $33-42$ & $43-60$ \\
Defusie & $0-24$ & $25-37$ & $38-60$ \\
Zelf als context & $0-28$ & $29-37$ & $38-60$ \\
Hier en Nu & $0-31$ & $32-41$ & $42-60$ \\
Waarden & $0-44$ & $45-51$ & $52-60$ \\
Toegewijd Handelen & $0-38$ & $39-46$ & $47-60$ \\
Flexibiliteits Index & $0-201$ & $202-249$ & $250-360$ \\
\hline
\end{tabular}

\section{Demografische informatie student populatie ( $N=529)$}

Leeftijd: $\quad$ Gemiddeld 20,8 jaar (SD 3,07), minimum 17 \& maximum 46 jaar.

Geslacht: $\quad$ Man 14,0 \% - Vrouw 86,0\%.

Opleiding: $\quad 100 \%$ Universitair.

Locatie: $\quad$ Radboud Universiteit, studenten Psychologie \& Pedagogische Wetenschap.

Tijdsbestek: Mei 2010 - Mei 2011. 
Referentiegroep 3: Patiënt - Ambulant

Gemiddelde score \& spreiding van score.

\begin{tabular}{lllllll}
\hline Acceptatie & Defusie & $\begin{array}{l}\text { Zelf als } \\
\text { Context }\end{array}$ & Hier en Nu & Waarden & $\begin{array}{l}\text { Toegewijd } \\
\text { Handelen }\end{array}$ & $\begin{array}{l}\text { Flexibiliteits } \\
\text { Index Score }\end{array}$ \\
\hline $23,4(10,4)$ & $18,9(10,5)$ & $25,0(7,3)$ & $27,1(9,6)$ & $37,0(9,1)$ & $31,7(11,1)$ & $163,2(43,8)$ \\
\hline
\end{tabular}

Normtabel Referentiegroep 3: Patiënt (Ambulant)

\begin{tabular}{lccc}
\hline & Lager dan gemiddeld & Gemiddeld & Hoger dan gemiddeld \\
\hline Acceptatie & $0-18$ & $19-28$ & $29-60$ \\
Defusie & $0-13$ & $14-23$ & $24-60$ \\
Zelf als context & $0-21$ & $22-29$ & $30-60$ \\
Hier en Nu & $0-22$ & $23-31$ & $32-60$ \\
Waarden & $0-32$ & $33-43$ & $44-60$ \\
Toegewijd Handelen & $0-26$ & $27-38$ & $39-60$ \\
Flexibiliteits Index & $0-141$ & $142-183$ & $184-360$ \\
\hline
\end{tabular}

\section{Demografische informatie patiënt - ambulant $(\mathrm{N}=674)$}

Leeftijd: $\quad$ Gemiddeld 35,0 jaar (SD 11,4), minimum 15 \& maximum 73 jaar.

Geslacht: $\quad$ Man $43,5 \%$ - Vrouw $56,5 \%$.

Opleiding: $\quad$ 5,8\% Universitair; 26,7\% HBO/NWO/HAVO; 35,5\% MBO/MAVO; 32\% LBO.

Locatie: $\quad$ PsyQ Maastricht, Heerlen, Eindhoven \& Tilburg.

Tijdsbestek: Januari 2013 - December 2013. 
Referentiegroep 4: Patiënt - Klinisch

Gemiddelde score \& spreiding van score.

\begin{tabular}{lllllll}
\hline Acceptatie & Defusie & $\begin{array}{l}\text { Zelf als } \\
\text { Context }\end{array}$ & Hier en Nu & Waarden & $\begin{array}{l}\text { Toegewijd } \\
\text { Handelen }\end{array}$ & $\begin{array}{l}\text { Flexibiliteits } \\
\text { Index Score }\end{array}$ \\
\hline $26,3(8,9)$ & $27,6(10,2)$ & $27,7(8,0)$ & $31,6(10,3)$ & $43,1(7,1)$ & $37,6(8,8)$ & $186,2(40,8)$ \\
\hline
\end{tabular}

Normtabel Referentiegroep 4: Patiënt (Klinisch)

\begin{tabular}{llll}
\hline & Lager dan gemiddeld & Gemiddeld & Hoger dan gemiddeld \\
\hline Acceptatie & $0-21$ & $22-30$ & $31-60$ \\
Defusie & $0-21$ & $22-31$ & $32-60$ \\
Zelf als context & $0-23$ & $24-31$ & $32-60$ \\
Hier en Nu & $0-25$ & $26-37$ & $38-60$ \\
Waarden & $0-39$ & $40-47$ & $48-60$ \\
Toegewijd Handelen & $0-32$ & $33-42$ & $43-60$ \\
Flexibiliteits Index & $0-161$ & $162-200$ & $201-360$ \\
\hline
\end{tabular}

\section{Demografische informatie patiënt - klinisch $(\mathrm{N}=\mathbf{4 1 4})$}

Leeftijd: $\quad$ Gemiddeld 45,43 jaar (SD 12,55), minimum 21 \& maximum 71 jaar.

Geslacht: $\quad$ Man 51,0\% - Vrouw 49,0\%.

Opleiding: 26,6\% Universitair; 29,5\% HBO/VWO/HAVO; 31,6\% MBO/MAVO; 12,3\% LBO.

Locatie: $\quad$ Breedspectrum kliniek U-center (Epen).

Tijdsbestek: November 2012 - April 2014. 
Flexibiliteits Index Test (FIT-60) 
Auteurs: T. Batink, G. Jansen \& H.R.A. De Mey. 
Handleiding Flexibiliteits Index Test (FIT-60) 


\section{Introductie}

De Flexibiliteits Index Test (FIT-60) is een zelfrapportage-vragenlijst die bestaat uit 60 stellingen (10 per subschaal), met elk een 7-punts Likertantwoordschaal $(0=$ helemaal oneens, tot 6 = helemaal eens). Als uitslag krijgt men zowel een totaalscore van psychologische flexibiliteit (de Flexibiliteits Index Score) als een score voor elk van de zes subschalen (acceptatie, defusie, zelf, hier en nu, waarden, toegewijd handelen). De focus van de FIT-60 ligt niet op het meten van klachten, maar op het registeren van de aanwezigheid van functioneel gedrag, gebaseerd op de theoretische principes van ACT. De FIT-60 is goed te gebruiken als instrument waarmee de richting van een ACT-therapie kan worden bepaald, en welke componenten extra aandacht vereisen. Tevens is het instrument goed inzetbaar om de vorderingen van een ACT-therapie/training te monitoren. Het instrument is ook bruikbaar bij mindfulness-trainingen, die zich beperken tot de vier linker componenten van het ACT-hexaflex. De FIT-60 lijkt ook buiten de derde generatie gedragstherapie van meerwaarde te zijn, aangezien ze ook kan worden gebruikt als een maat voor coping (afleiding, vermijding, piekeren) en als een maat voor kwaliteit van leven (waarden en toegewijd handelen). Ten slotte is de FIT-60 bruikbaar voor wetenschappelijk onderzoek. De FIT-60 is een vrij verkrijgbare vragenlijst (Batink, Jansen \& De Mey, 2012a).

De volledige FIT-60 bestaat uit de volgende onderdelen:

- De FIT-60-vragenlijst.

- Het scoreblad.

- Vijf resultatenbladen (Algemeen, Student, Ambulant, Klinisch \& Individueel).

- Aanvullende informatie referentiegroepen.

\section{Afname}

De FIT-60 is een zelfrapportage-vragenlijst die aan de cliënt kan worden meegegeven om op eigen gelegenheid in te vullen (paper \& pencil test). De FIT-60 is ontwikkeld voor volwassenen (18-75 jaar). De FIT is zowel geschikt voor gezonde populaties als voor ambulante en klinische populaties. De instructies voor het invullen staan op de vragenlijst. Het kan echter raadzaam zijn deze expliciet onder de aandacht te brengen van de cliënt.

"De FIT bestaat uit 60 stellingen. Lees elke stelling aandachtig door, en geef daarna aan in hoeverre deze stelling van toepassing is op u. Denk niet te lang na, maar geef uw eerste mening. Hoe hoger het cijfer dat u geeft, hoe meer deze stelling van toepassing is op u (6 = helemaal eens). Hoe lager het cijfer dat u geeft, hoe minder deze stelling van toepassing is op u ( 0 = helemaal oneens). Er zijn geen goede of foute antwoorden. Wilt u alstublieft geen vragen overslaan." 
Het invullen van de FIT zal ongeveer 15 minuten in beslag nemen. Het is ook mogelijk de FIT-60 met een computer of tablet af te nemen, via de website www.hoeflexibelbenjij.nl (directe automatische scoring). Op deze website is tevens de PDF-versie van de FIT-60 gratis te downloaden.

\section{Scoring}

Gezien de complexe scoring (randomisering \& omkering van items) wordt bij de FITvragenlijst standaard een scoreblad geleverd. Dit scoreblad maakt het mogelijk de FIT handmatig te scoren. Het scoren van de FIT zal ongeveer 10 à 15 minuten in beslag nemen. Er is ook een zelfscorend Excelformulier beschikbaar via de website. Met het gebruik van dit Excelformulier wordt de scoretijd gereduceerd tot 5 minuten. Er wordt zowel een totaalscore berekend die een indicatie geeft van de psychologische flexibiliteit (de Flexibiliteits Index Score), als de zes subschaalscores (één per ACT-component).

Het gebruik van het Excelformulier spreekt voor zich. We zullen ons dan ook beperken tot de uitleg van de handscoring door middel van het bijgeleverde scoreblad. Als eerste stap dienen de scores van de FIT-60 te worden overgezet naar het scoreblad. Noteer voor elke ACT-subschaal de scores op de bijbehorende items in de bovenste regel (Org. Score). De scores van de items in de grijze vlakken dienen vervolgens gespiegeld te worden (6-0, 5-1, 4-2, 3-3, 2-4, 1-5, 0-6). Noteer de gespiegelde scores in de ondergelegen regel (Angp. Score). Neem vervolgens ook de niet-gespiegelde items over in deze tweede regel. Tel hierna de scores uit de onderste regel van elke subschaal op tot het subschaal-totaal. Tel ten slotte deze zes subschaaltotalen op tot een eindtotaal: de Flexibiliteits Index Score (psychologische flexibiliteit). De minimale score per ACT-component is 0 , de maximale score is 60 . De minimale Flexibiliteits Index Score is 0 , de maximale score is 360 . Hoe hoger de score, hoe meer iemand deze ACT-vaardigheid in huis heeft.

\section{Interpretatie}

De interpretatie van de scores op de FIT-60 kan op twee manieren. Je kunt de score vergelijken met een referentiegroep om de hoogte van de score te bepalen, of je kunt de score vergelijken met een eerdere meting van de cliënt in kwestie, om zo de persoonlijke ontwikkeling in kaart te brengen. We zullen beide strategieën apart bespreken.

\section{Methode 1: vergelijken met referentiegroep.}

Er zijn vier referentiegroepen beschikbaar voor de FIT-60: algemeen, student, ambulante patiënten en klinische patiënten. Op basis van behandelcontext en demografische eigenschappen (o.a. leeftijd, opleiding) kun je bepalen welke referentiegroep je gaat gebruiken om de scores van de cliënt mee te vergelijken (normatieve vergelijking). De demografische gegevens van de referentiegroepen zijn te vinden aan het eind van de FIT-60, bij de aanvullende informatie. Als je moeite hebt met het bepalen van de geschikte referentiegroep, is het raadzaam de algemene referentiegroep te nemen om mee te vergelijken. Dit is de grootste groep met de meeste diversiteit. Na het vaststellen van de best matchende referentiegroep kun je het bijbehorende resultatenblad invullen. Neem de 
resultaten van het scoreblad over in de scoresectie van het resultatenblad, vul vervolgens de subschaalscores in op de bijbehorende assen van het ACT-hexaflex en verbindt de scores op de zes assen met een lijn tot een figuur: het flexibiliteitsprofiel. In het ACT-hexaflex staat de categorisering van de scores voor de referentiegroep weergegeven met behulp van kleurvlakken; donkergrijs = lager dan gemiddeld (0-30\%), grijs = gemiddeld $(30-70 \%)$, wit = hoger dan gemiddeld (70-100\%). Door per ACT-component te kijken in welk kleurvlak de cliënt heeft gescoord, kan men bepalen hoe hoog de score is ten opzichte van de referentiegroep. De categorisering van de score kan ten slotte ook nog worden aangegeven in de scoresectie van het resultatenblad.

Figuur 1 is een voorbeeld van een flexibiliteitsprofiel in het ACT-hexaflex van de algemene populatie (normatieve vergelijking). De zwarte stippellijn die de scores van een cliënt op de zes assen verbindt, is het flexibiliteitsprofiel. In dit figuur is te zien dat er op acceptatie en defusie hoger dan gemiddeld wordt gescoord, op het zelf en hier en nu gemiddeld, en op waarden en handelen wordt lager dan gemiddeld gescoord.
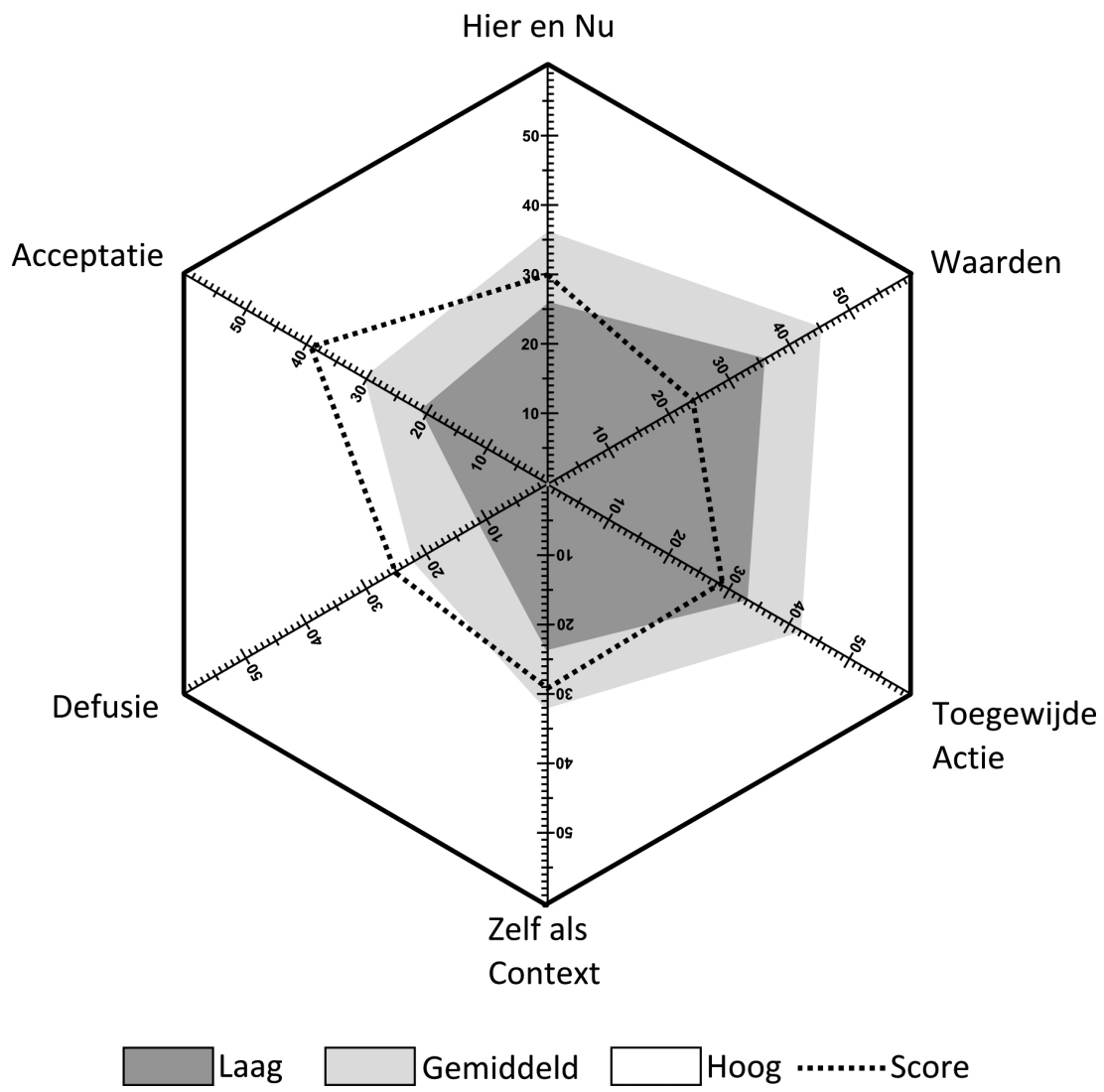

Figuur 1. Normatief flexibiliteitsprofiel. 
Flexibiliteits Index Score; psychologische flexibiliteit.

Wat ten slotte nog overblijft, is de categorisering van de Flexibiliteits Index Score. Het is niet direct uit het flexibiliteitsprofiel af te lezen hoe hoog deze totaalscore is (betreft het oppervlakte). Deze Flexibiliteits Index Score dient te worden opgezocht in het blad met aanvullende informatie over de referentiegroepen. Hier staan de scorecategorieën in een overzichtstabel weergegeven. Bepaal in welke categorie de Flexibiliteits Index Score valt (lager dan gemiddeld, gemiddeld, hoger dan gemiddeld) en vul deze in op het resultatenblad. Indien deze score lager dan gemiddeld is, geeft dit aan dat de persoon waarschijnlijk weinig handvatten heeft om te kunnen omgaan met vervelende ervaringen in het leven. Bij een gemiddelde score is er ruimte voor ontwikkeling. Het is dan raadzaam te kijken welke specifieke ACT-componenten lager dan gemiddeld scoren om zo doelgericht te investeren in het aanleren van specifieke vaardigheden. Bij een score hoger dan gemiddeld bezit de cliënt een aantal functionele vaardigheden waarmee hij kan omgaan met de problemen die hij tegenkomt in het leven. Het kan waardevol zijn te kijken naar het laagst scorende ACTcomponent, en om hier samen met de cliënt aandacht aan te besteden. Het kan echter ook zo zijn dat deze cliënt geen verdere begeleiding nodig heeft.

Methode 2: vergelijken met eerdere meting.

Het is ook mogelijk de scores niet te vergelijken met anderen, maar de cliënt zelf als referentiekader te nemen (ipsatieve vergelijking). Het vergelijken met de eigen scores heeft als voordeel dat je de persoonlijke ontwikkeling van een individu in kaart kunt brengen. Je kunt op meerdere momenten het profiel bepalen (tip: gebruik verschillende kleuren voor verschillende meetmomenten), en zien in welke richting iemand zich ontwikkelt (en welke ACT-componenten mogelijk achterblijven en derhalve meer aandacht nodig hebben). Het nadeel van deze strategie is dat je niet weet of de behaalde scores hoog of laag zijn; je ziet alleen op welke schalen de cliënt lager scoort ten opzichte van de andere schalen. Het is belangrijk te realiseren, dat een score van 30/60 niet per se gemiddeld hoeft te zijn. Voor de ene subschaal is dat lager dan gemiddeld, voor een andere schaal kan dat juist weer hoger dan gemiddeld zijn. Een gemiddelde score op elk ACT-component leidt dus niet automatisch tot een gelijke zeshoek (zoals ook te zien is bij de referentiegroepen). Deze tweede methodiek is dus niet zo geschikt om de hoogte van de scores zelf te bepalen; deze kijkt puur naar de ontwikkeling die de cliënt tijdens de therapie doormaakt.

Figuur 2 is een voorbeeld van twee flexibiliteitsprofielen die zijn ingevuld in een ACT-hexaflex (ipsatieve vergelijking). Met rood is het profiel vóór aanvang van de behandeling aangegeven, en met groen is het profiel na afronding van de behandeling weergegeven. Je ziet in één oogopslag dat deze cliënt op alle vlakken vooruit is gegaan. 


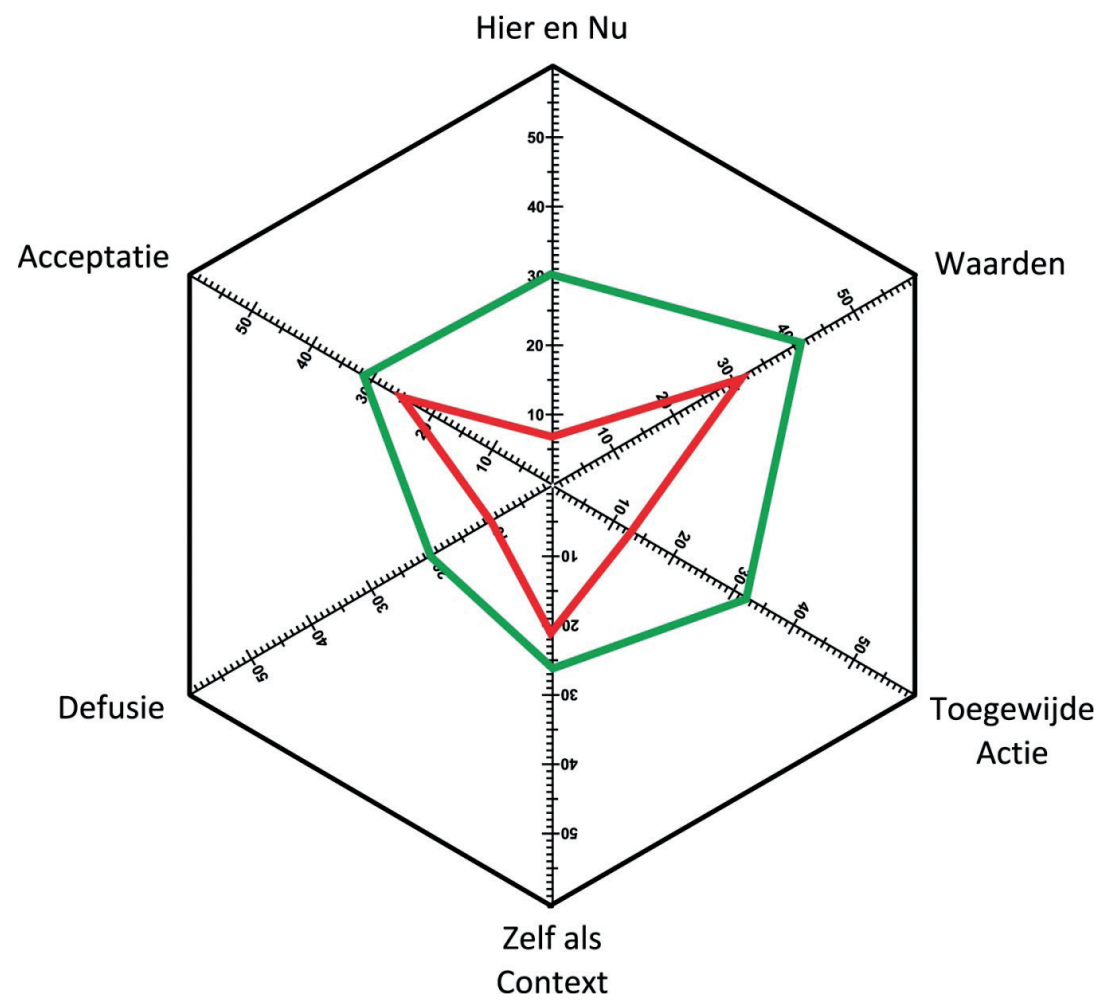

Figuur 2. Ipsatief flexibiliteitsprofiel.

Het is ook mogelijk om de interpretatiemethodes 1 en 2 te combineren, door de verschillende metingen met een kleur aan te geven in het resultatenblad van de overeenkomende referentiegroep. Hierdoor kun je zowel de hoogte van de score bepalen, als de ontwikkeling monitoren.

\section{Psychometrische kwaliteiten}

De FIT-60 werd onderzocht op de psychometrische kwaliteiten bij vier verschillende populaties: algemene bevolking, studenten, ambulante patiënten en klinische patiënten in de GGZ. De FIT-60 bleek bij alle vier de populaties over een goede betrouwbaarheid te beschikken; de interne betrouwbaarheid voor de schalen was redelijk tot goed met uitzondering van de subschaal Zelf als Context. De test-hertest betrouwbaarheid voor de verschillende schalen was zeer goed. Daarnaast bleek de FIT-60 ook in staat te zijn om verandering over tijd te meten. Tevens is er ondersteuning gevonden voor een goede constructvaliditeit van de verschillende schalen, met ook hier als uitzondering de Zelf als Context schaal. Hoewel de Zelf als Context schaal onderpresteert, blijft deze nog acceptabel en dus bruikbaar. Er kan geconcludeerd worden dat de FIT-60 beschikt over goede psychometrische kwaliteiten. Het is een betrouwbaar en valide meetinstrument dat goed 
kan worden gebruikt om psychologische flexibiliteit en de zes onderliggende kernprocessen in kaart te brengen binnen het domein van de Acceptance and Commitment Therapy (Batink, Jansen \& De Mey, 2012b; Batink \& Delespaul, 2015).

\section{Literatuur}

Batink, T., Jansen, G. \& De Mey, H.R.A. (2012a). Flexibiliteits Index Test (FIT-60). Batink, T., Jansen, G. \& De Mey, H.R.A. (2012b). De Flexibiliteits Index Test (FIT-60): Een beknopte beschrijving. GZ-Psychologie, 5, 18-21.

Batink, T. \& Delespaul., P. (2015). Meten van Psychologische Flexibiliteit; De FIT-60. Tijdschrift voor Gedragstherapie, 4, 310-332.

Voor vragen / opmerkingen kunt u mailen naar info@hoeflexibelbenjij.nl. 


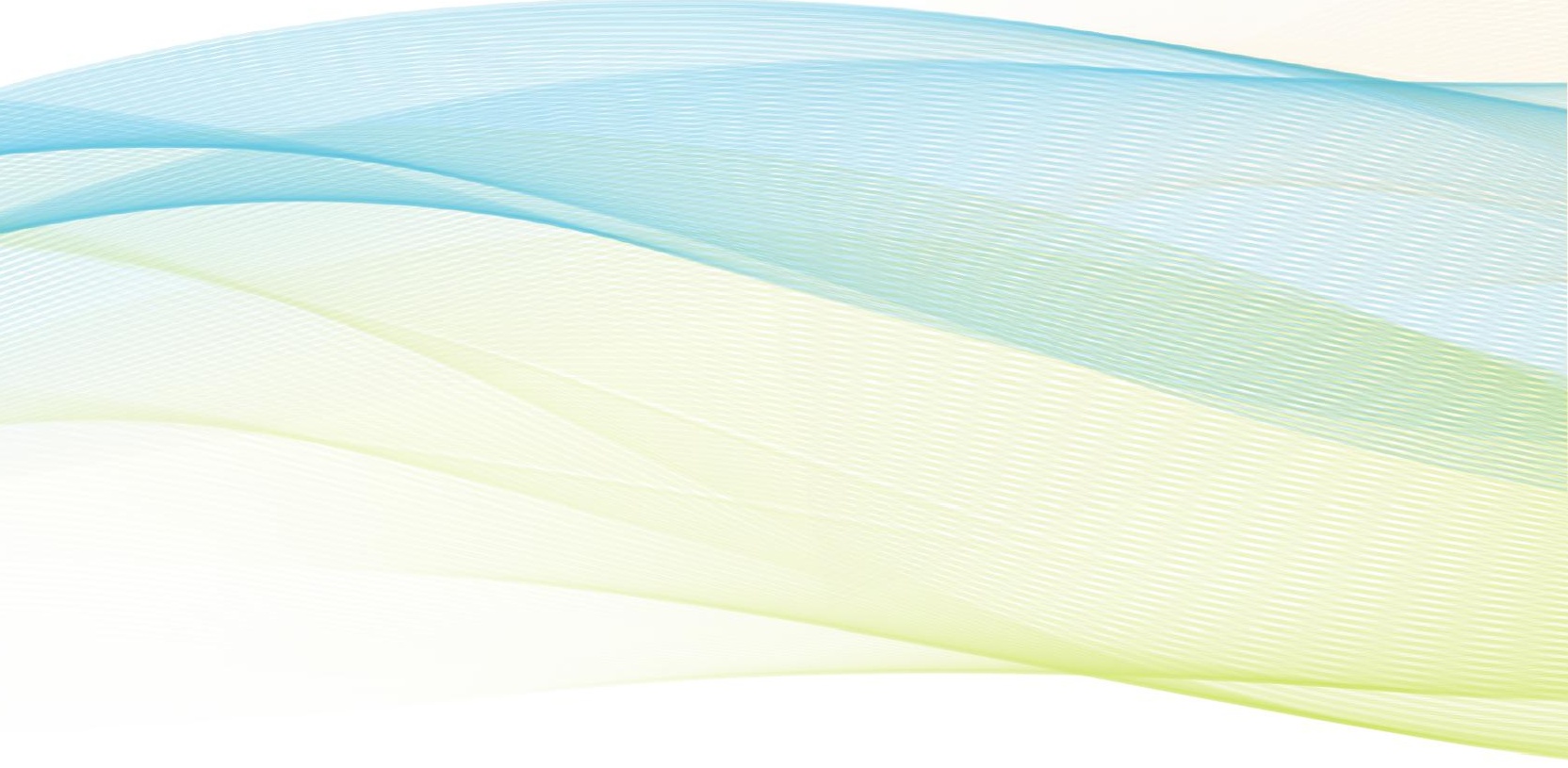


appendix

ACT-materiaal 
De ACT-community is een open-source community. Dit betekent dat het ontwikkelde materiaal zo veel mogelijk beschikbaar wordt gesteld. Hoewel de ontwikkelde behandelprotocollen voor het onderzoek op dit moment nog niet vrij kunnen worden gegeven; volgt onderstaand een overzicht van zelf ontwikkeld materiaal dat wel vrij te gebruiken is (en ook in de protocollen wordt gebruikt). Middels QR-codes zijn de links naar de verschillende bronnen aangegeven.

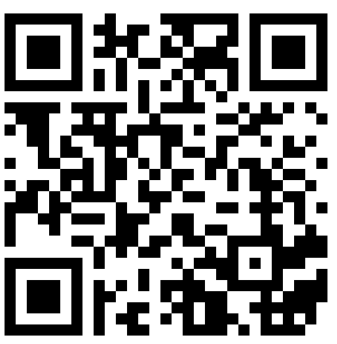

Video: Wat is ACT?

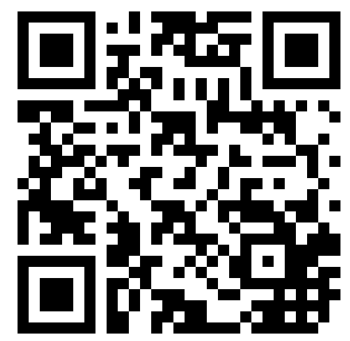

Website: ACT-oefeningen \& metaforen ontwikkeld door ACT in Actie

(50 downloads).

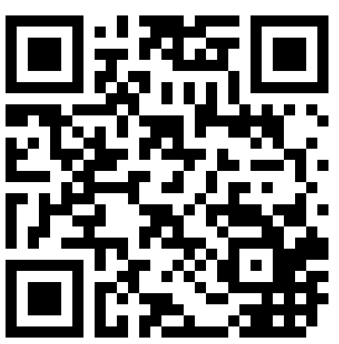

Website: Online ACTvragenlijsten (AAQ-II, CFQ-13, FFMQ-SF, VLQ, ELS, FIT-60).

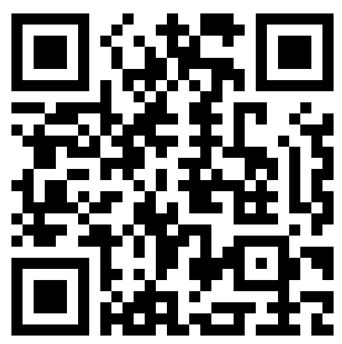

Video: ACT \& Positieve Psychologie.

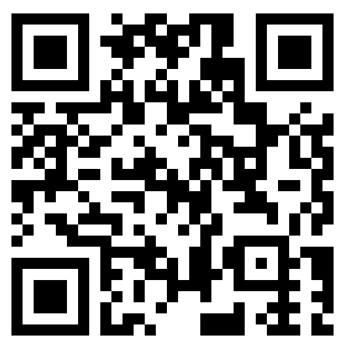

Website: ACT-oefeningen \& metaforen behorende bij Time to ACT!

(50 downloads).

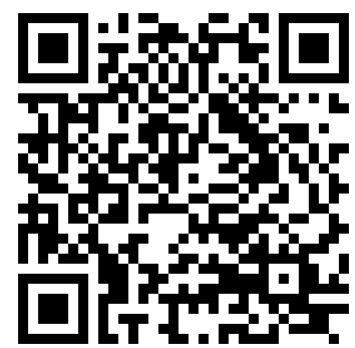

Website: Flexibiliteits Index Test (FIT-60) -Online-versie.

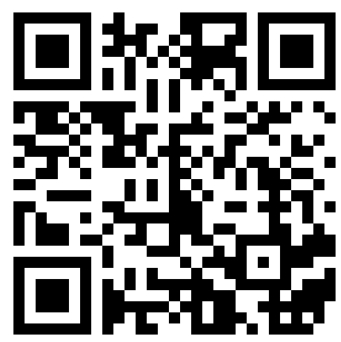

Video: ACT \& Local Challenges (with Prof. Steven Hayes.

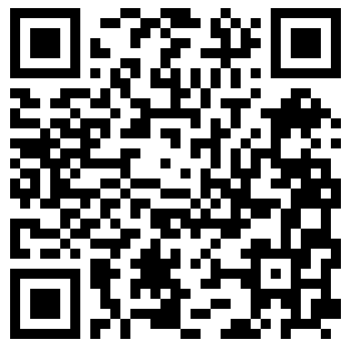

Website: ACT-illustraties bijhorende bij Time to ACT (50 downloads).

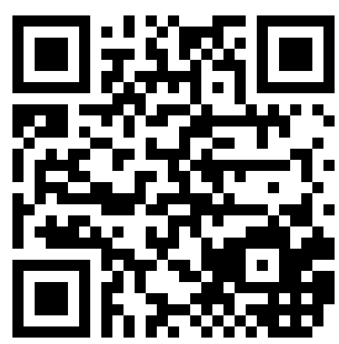

Website: Flexibiliteits Index Test (FIT-60) - PDF \& Excel. 


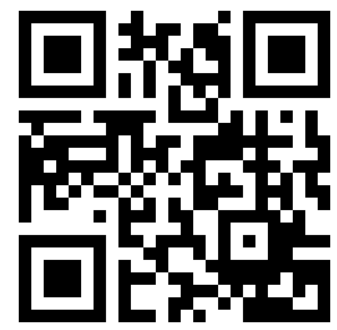

Website: Demo ACT in

Daily Life Training

(PsyMate).

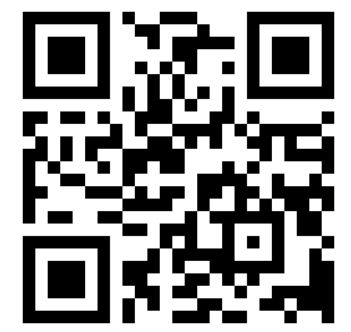

Website: Demo eHealthmodule ACT (TelePsy).

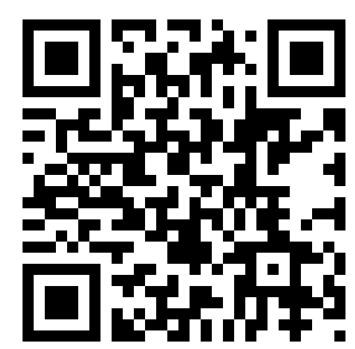

Website: eHealth-module

Time to ACT! (ZorgIQ). 



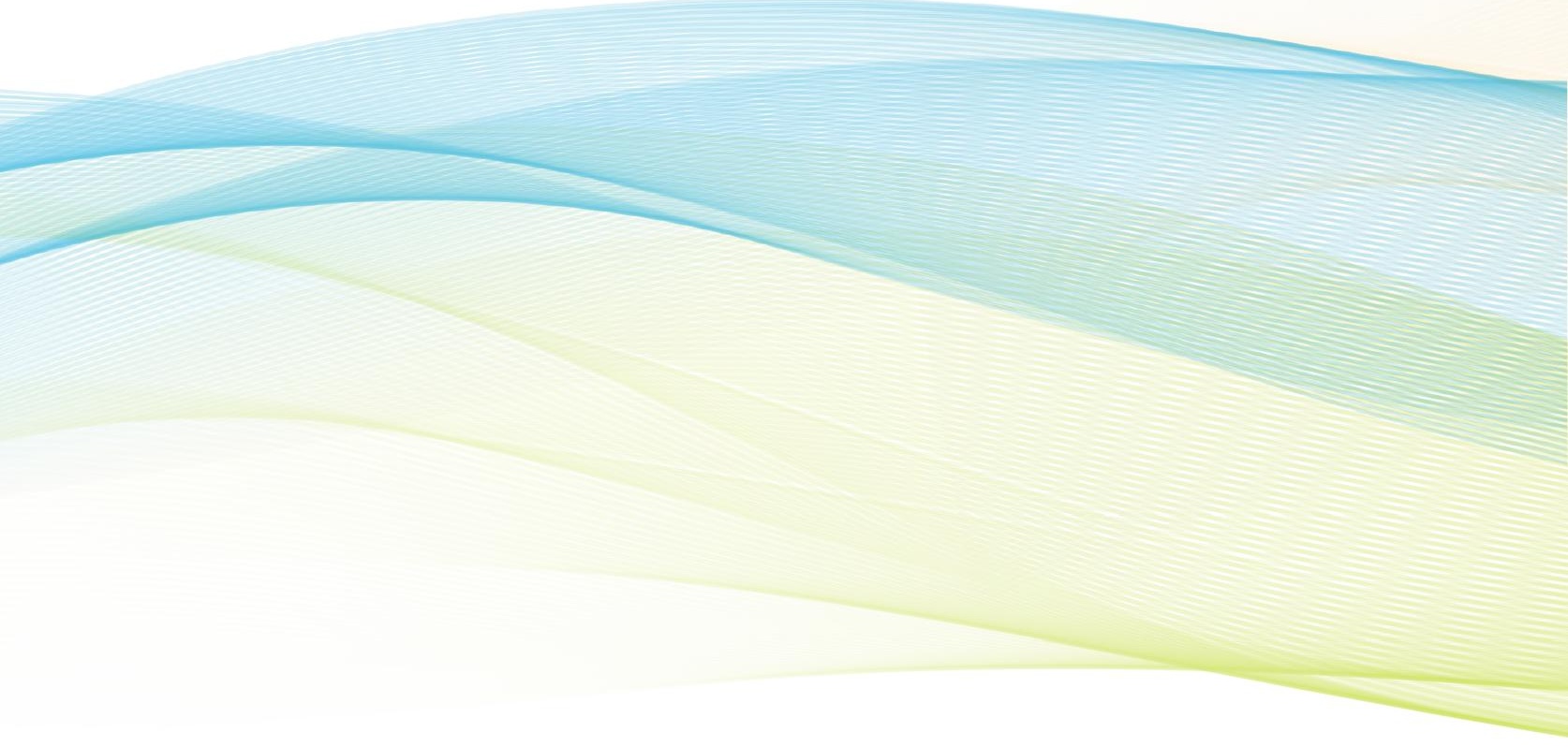

